\title{
Highly Potent and Selective Butyrylcholinesterase Inhibitors for Cognitive
}

\section{Improvement and Neuroprotection}

Qi Li ${ }^{\text {a,c }}$, Ying Chen ${ }^{\mathrm{d}}$, Shuaishuai Xing ${ }^{\mathrm{a}}$, Qinghong Liao ${ }^{\mathrm{d}}$, Baichen Xiong ${ }^{\text {a }}$, Yuanyuan Wang ${ }^{\text {a }}$, Weixuan Lu ${ }^{\text {a }}$, Siyu He ${ }^{\text {e }}$, Feng Feng ${ }^{\text {d,f }}$, Wenyuan Liu ${ }^{\text {a, * }}$, Yao Chen ${ }^{\text {b, * }}$, Haopeng $\operatorname{Sun}^{\mathrm{a}, *}$

a School of Pharmacy, China Pharmaceutical University, Nanjing, 211198, People's Republic of China

${ }^{b}$ School of Pharmacy, Nanjing University of Chinese Medicine, Nanjing, 210023, People's Republic of China

${ }^{c}$ School of Basic Medicine, Qingdao University, Qingdao, 266071, People’s Republic of China

${ }^{d}$ Department of Natural Medicinal Chemistry, China Pharmaceutical University, Nanjing, 211198, People's Republic of China

e State Key Laboratory of Natural Medicines, Jiangsu Key Laboratory of Carcinogenesis and Intervention, School of Basic Medicine and Clinical Pharmacy, China Pharmaceutical University, Nanjing 210009, People's Republic of China

${ }^{f}$ Jiangsu Food and Pharmaceutical Science College, No.4 Meicheng Road, Huai'an, 223003, People's Republic of China 
Table of contents:

1. Figure S1. Molecular dynamic (MD) simulation result of the lead compound S061001.

2. Figure S2. (A) Inhibitory rates (IR) on eeAChE under concentration of $10 \mu \mathrm{M}$. (B) IR of partial compounds on eqBuChE under concentration of $10 \mu \mathrm{M}$.

3. Figure S3. Molecular docking modes of compounds S06-1002 (A), S06-1011 (B) and S06-1014 (C).

4. Figure S4. Molecular dynamic simulation results of compounds S06-1002 (A), S06-1011 (B), S06-1014 (C) in 100 ns.

5. Table S1. Chromatographic and mass spectrometric identification information for the prototype of compound S06-1011 and its possible metabolites.

6. Figure S5. Mean plasma concentration-time curves of compound S06-1011 (p.o. and i.v. respectively).

7. Figure S6. PAMPA-BBB penetration study of compounds S06-1011, S06-1015 and S06-1031.

8. Figure S7. The ROS reduction abilities of S06-1001, S06-1011, S06-1015 and S061031.

9. Figure S8. Protocol followed for the in vivo experiments.

10. Compound characterization. 
1. Figure S1. Molecular dynamic (MD) simulation result of the lead compound S061001 (PDB code: 5k5e). (A) Last frame of MD simulation. The ligand S06-1001 is shown in blue and the important residues of the receptor are shown in green. Hydrophobic interactions are shown in pink and hydrogen bond is shown in green (dotted lines). (B) Residue contribution for the receptor-ligand combination.
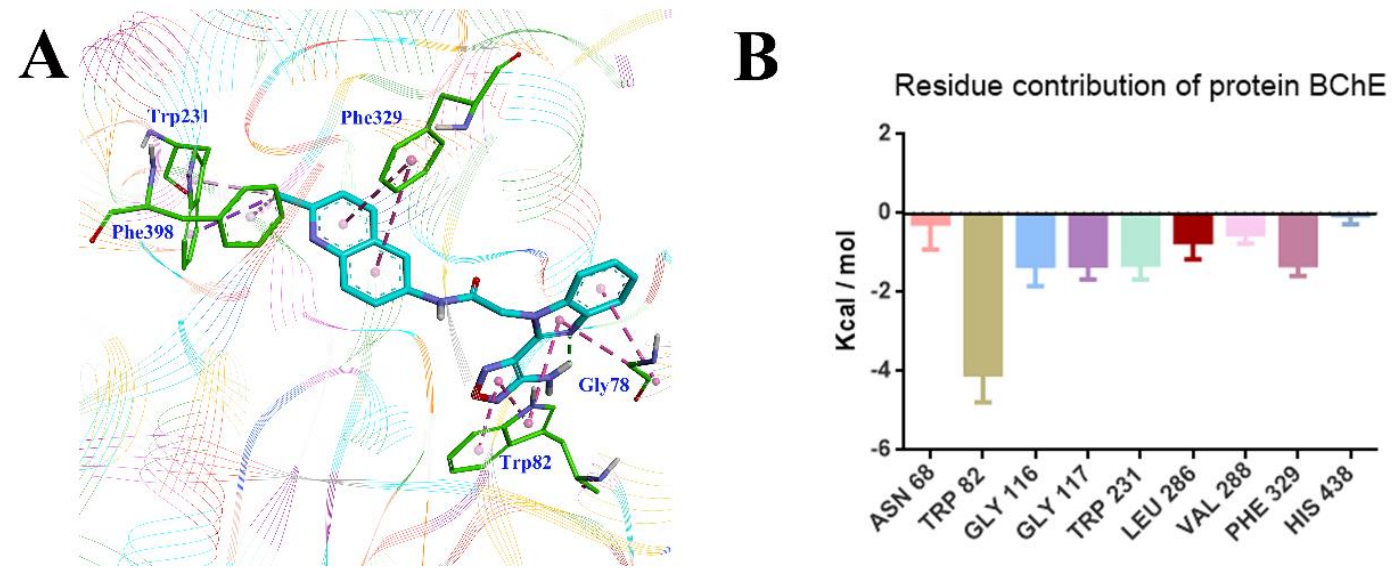
2. Figure S2. (A) Inhibitory rates (IR) on eeAChE under concentration of $10 \mu \mathrm{M}$. All compounds exhibited less than $50.0 \%$ IR on eeAChE. (B) IR of partial compounds on $e q \mathrm{BuChE}$ under concentration of $10 \mu \mathrm{M}$.

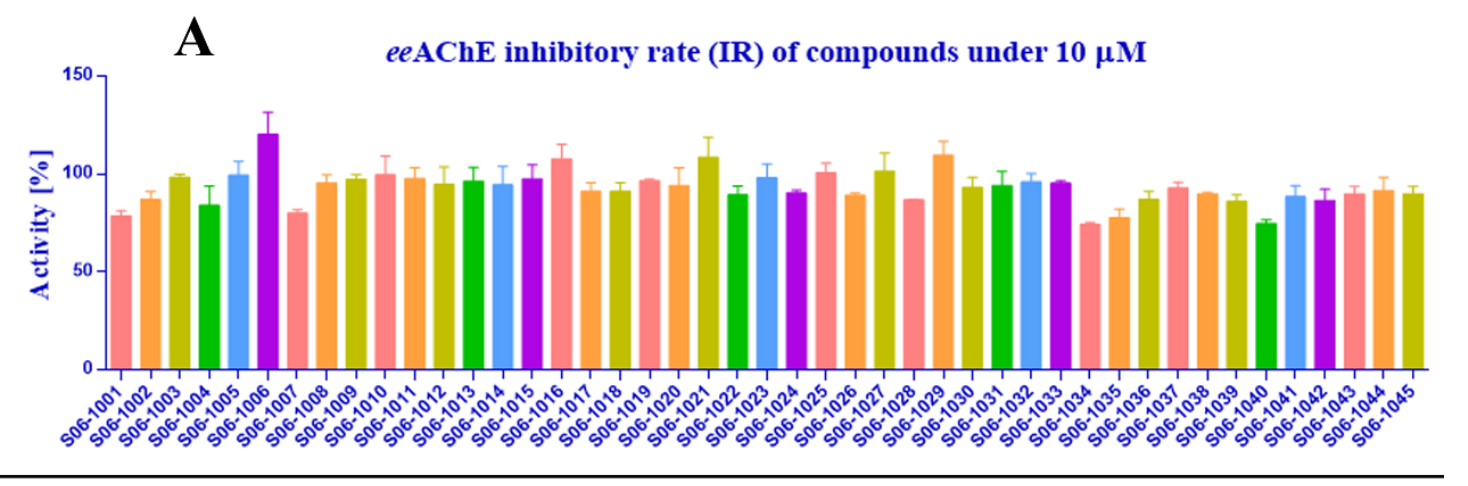

B eqBuChE inhibitory rate (IR) of compounds under $10 \mu \mathrm{M}$

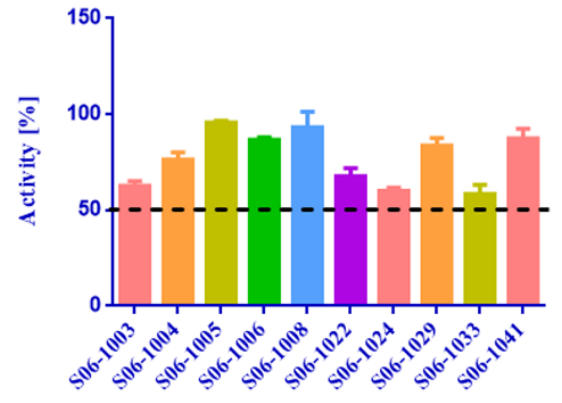


3. Figure S3. Molecular docking modes of compounds S06-1002 (A), S06-1011 (B) and S06-1014 (C) (PDB code: 5k5e). Compounds are shown in green, only important residues are presented in blue. Hydrophobic interactions are shown in pink and hydrogen bonds are presented in green (dotted lines). $\pi$-anion interactions are exhibited in yellow and amide- $\pi$ interactions are in blue (dotted lines).

A

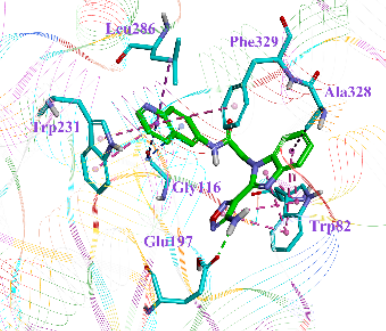

B

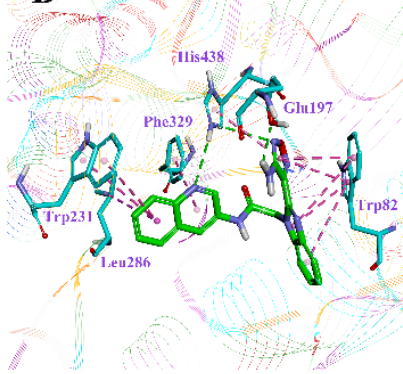

C

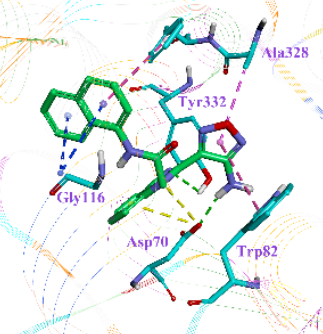


4. Figure S4. Molecular dynamic simulation results of compounds S06-1002 (A),

S06-1011 (B), S06-1014 (C) in 100 ns. Total binding free energy and its components are shown on the left and residue contributions for receptor-ligand combination are on the right. The main interaction mode between all three compounds and the target is van de Waals force. The main contributing residues of three ligands are mostly hydrophobic amino acids especially $\operatorname{Trp} 82$.

A

Binding Energy Difference of S06-1002 (Complex)
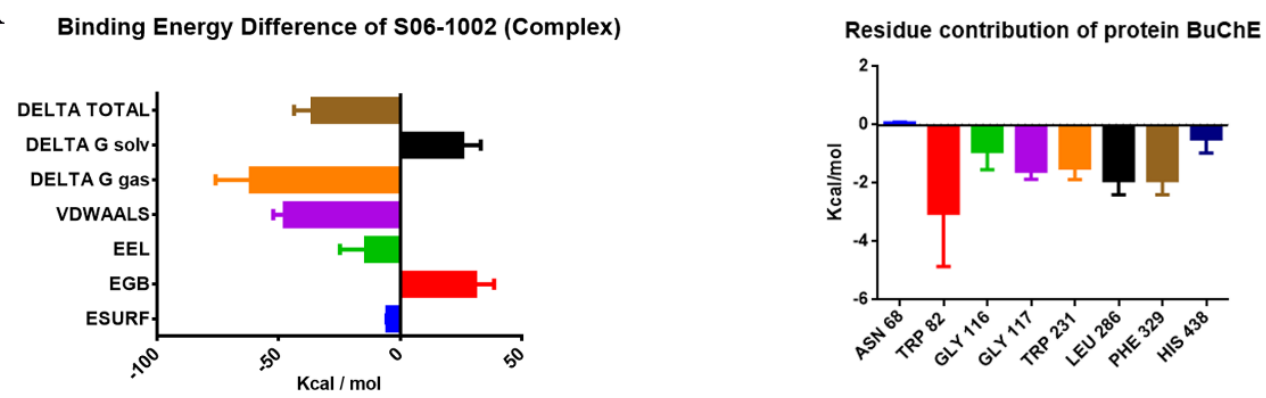

B

Binding energy differences of S06-1011 (Complex)

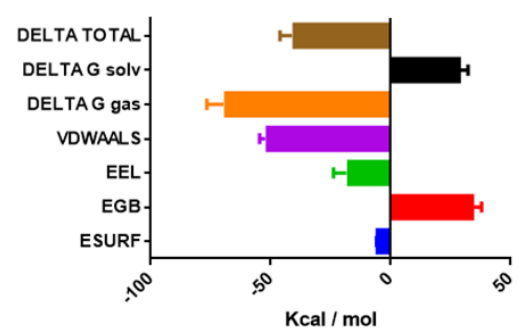

Residue contribution of protein BuChE

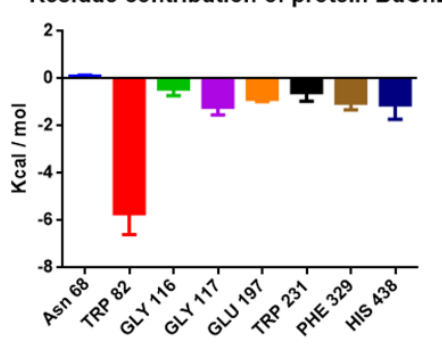

Binding energy differences of S06-1014 (Complex)

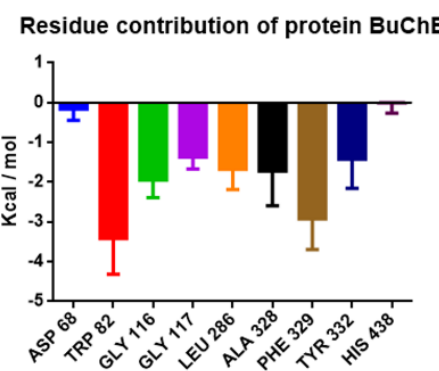


5. Table S1. Chromatographic and mass spectrometric identification information for the prototype of compound S06-1011 and its possible metabolites.

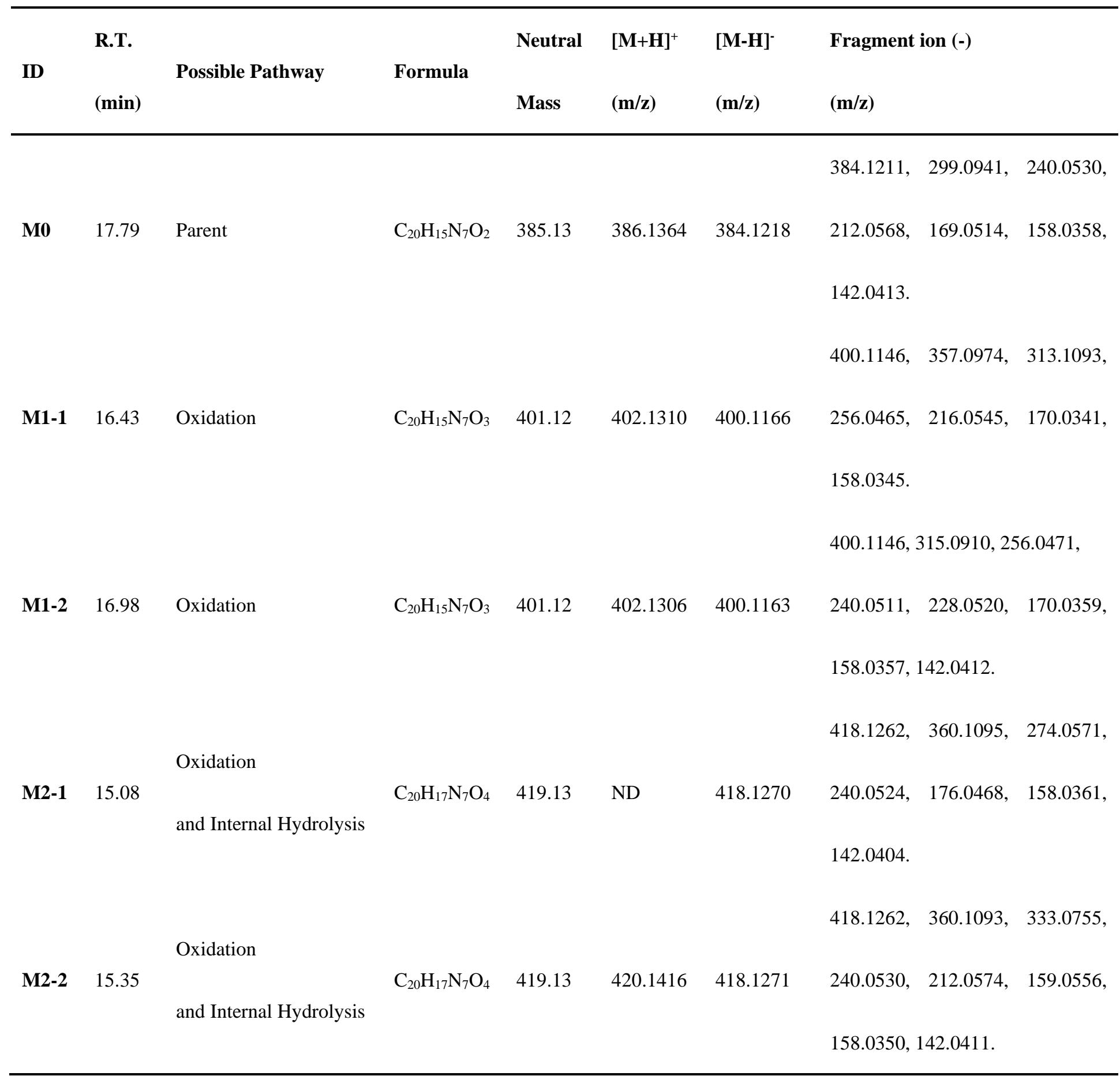

ND, not detected under positive ion mode. 
6. Figure S5. Mean plasma concentration-time curves of compound S06-1011 (p.o. and i.v. respectively). Studies were carried out in male Sprague-Dawley rats dosing at $10 \mathrm{mg} / \mathrm{kg}$ (p.o. and i.v.) in PEG400 with sampling time up to 24h. All data are the mean $\pm \mathrm{SD}$ of eight independent determinations for plasma.
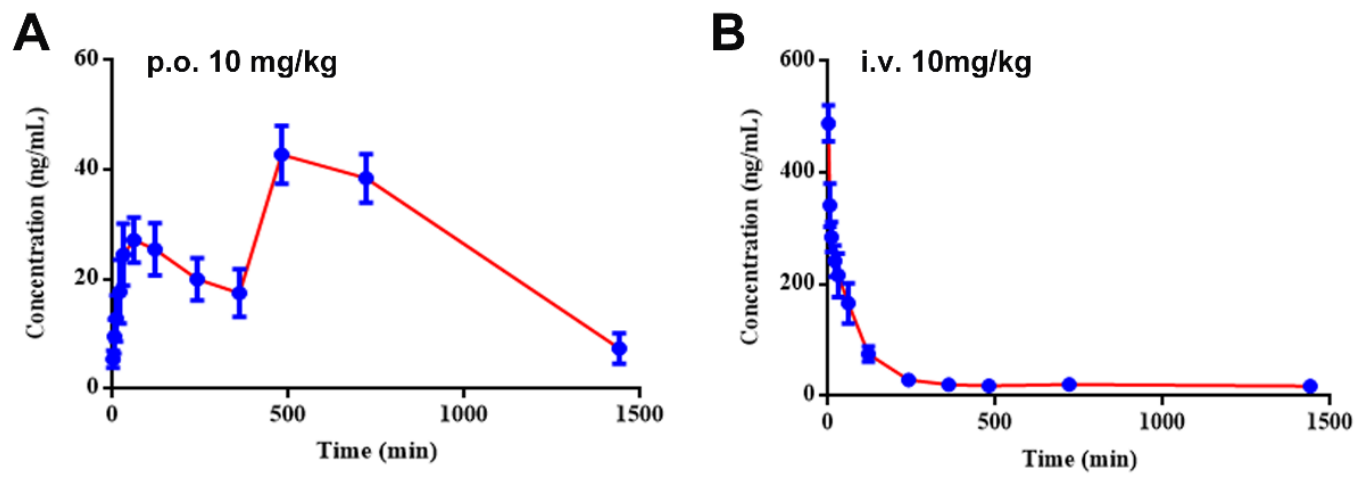
7. Figure S6. PAMPA-BBB penetration study of compounds S06-1011, S06-1015 and S06-1031. (A) Result of PAMPA-BBB assay for 9 commercial drugs used in the experimental procedure validation and compounds S06-1011, S06-1015 and S06-1031. ${ }^{a}$ Bibl. values are reported data from the reference. ${ }^{b}$ All tests were obtained from three independent experiments. ${ }^{c}$ 'CNS +' (high BBB permeation): $P_{e}\left(\times 10^{-6} \mathrm{~cm} / \mathrm{s}\right)>6.37$; 'CNS +/-' (uncertain BBB permeation): $P_{e}\left(\times 10^{-6} \mathrm{~cm} / \mathrm{s}\right)$ from 3.14 to 6.37 ; 'CNS -' (low BBB permeation): $P_{e}\left(\times 10^{-6} \mathrm{~cm} / \mathrm{s}\right)<3.14$. (B) Linear correlation presenting experimental versus bibliographic data of commercial drugs. $P_{e}(\exp )=.1.6156 P_{e}$ (bibl.) $-0.0916\left(\mathrm{R}^{2}=0.9347\right)$.

A

\begin{tabular}{|c|c|c|c|}
\hline \multirow{2}{*}{ Commercial drug } & \multicolumn{2}{|c|}{$P e \times 10^{6} \mathrm{~cm} / \mathrm{s}$} & \multirow{2}{*}{ BBB penetration } \\
\hline & Bibl. value & Exp. value ${ }^{\circ}$ & \\
\hline Clonidine & 5.3 & 8.80 & CNS + \\
\hline Adenosterone & 5.1 & 6.05 & $\mathrm{CNS}+/=$ \\
\hline Chlorpromazine & 6.5 & 12.4 & CNS + \\
\hline Piroxicam & 2.5 & 1.69 & CNS - \\
\hline Dopamine & 0.15 & 3.30 & CNS - \\
\hline Verapamil & 13.2 & 20.06 & CNS + \\
\hline Progesterone & 9.3 & 15.53 & $\mathrm{CNS}+$ \\
\hline Hydrocortisone & 1.9 & 1.24 & CNS - \\
\hline$\beta$-Estradiol & 12 & 20.51 & CNS + \\
\hline
\end{tabular}

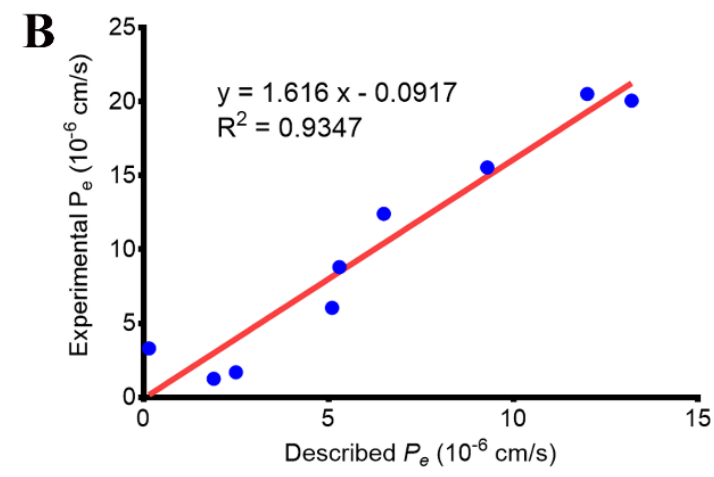


8. Figure S7. The ROS reduction abilities of S06-1001, S06-1011, S06-1015 and S06-1031. The green fluorescence intensity (GFI) represents the amount of intracellular ROS production. The BV2 cells were pre-incubated with $5 \mu \mathrm{M}$ of the test compounds for $1 \mathrm{~h}$ and subsequently co-incubated with LPS $(2.5 \mu \mathrm{g} / \mathrm{mL})$ for additional $24 \mathrm{~h}$. The GFI was quantified by the software ImageJ. The data are expressed as mean $\pm \mathrm{SD}$ of three independent experiments $\left({ }^{\# \# \#} \mathrm{p}<0.0001\right.$ vs. control group; ${ }^{* * * *} \mathrm{p}<0.0001$ vs. model group).

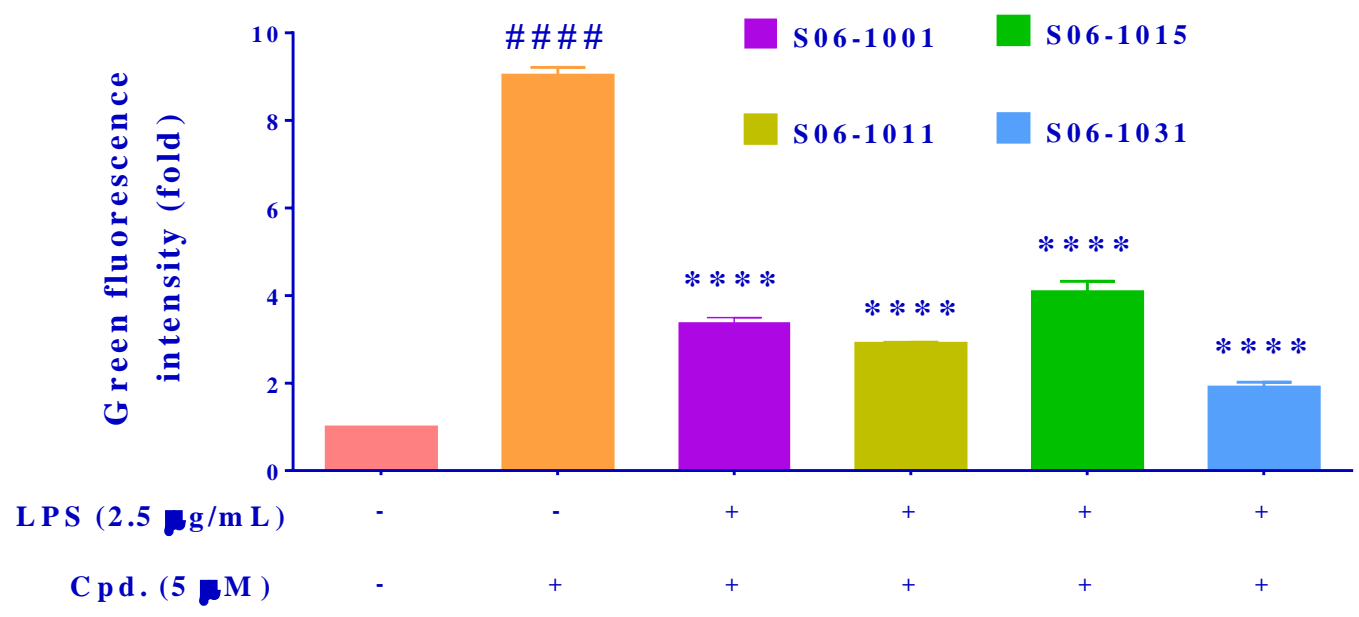


9. Figure S8. Protocol followed for the in vivo experiments. Abbreviations: ip., intraperitoneal injection; po., orally administration; icv., intracerebroventricular injection.

A

\begin{tabular}{|l|l|l|l|l|l|l|l|l|l|}
\hline 1 & 2 & 3 & 4 & 5 & 6 & 7 & 8 & 9 & 10 \\
\hline
\end{tabular}

Scopolamine ip.

Compounds po.

Morris water maze test

$\begin{array}{llllllllll}1 & 1 & 1 & 1 & 1 & 1 & 1 & 1 & 1 & 1 \\ 1 & 1 & 1 & 1 & 1 & 1 & 1 & 1 & 1 & 1\end{array}$

B

\begin{tabular}{|l|l|l|l|l|l|l|l|l|l|l|l|l|l|l|}
\hline 1 & 2 & 3 & 4 & 5 & 6 & 7 & 8 & 9 & 10 & 11 & 12 & 13 & 14 & 15 \\
\hline
\end{tabular}

Saline or $A \beta$ peptide icv

Compounds po

Morris water maze

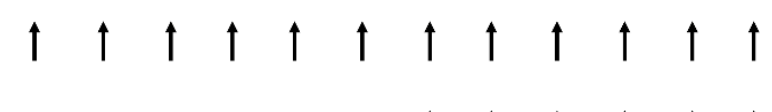

Y maze

Y maze 


\section{Compound characterization.}

HPLC of compound $\mathbf{S 0 6 - 1 0 0 2}\left(t_{R}=3.85 \mathrm{~min}\right)$.

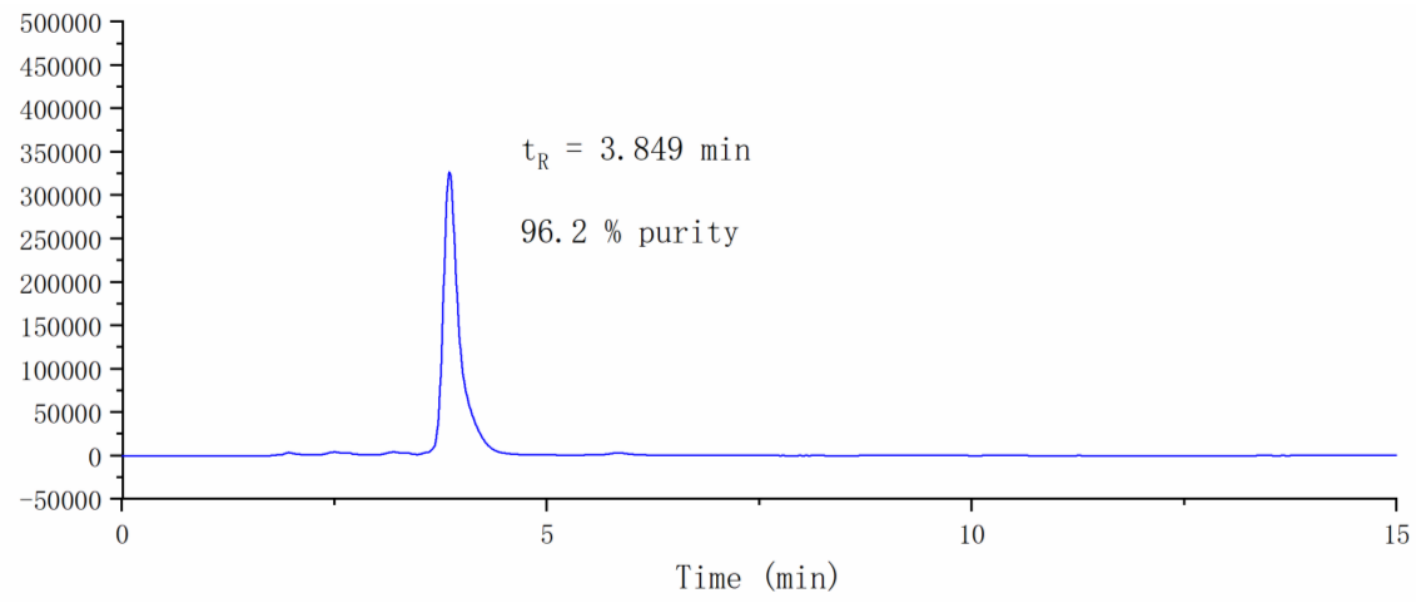

${ }^{1} \mathrm{H}$ NMR of compound S06-1002.

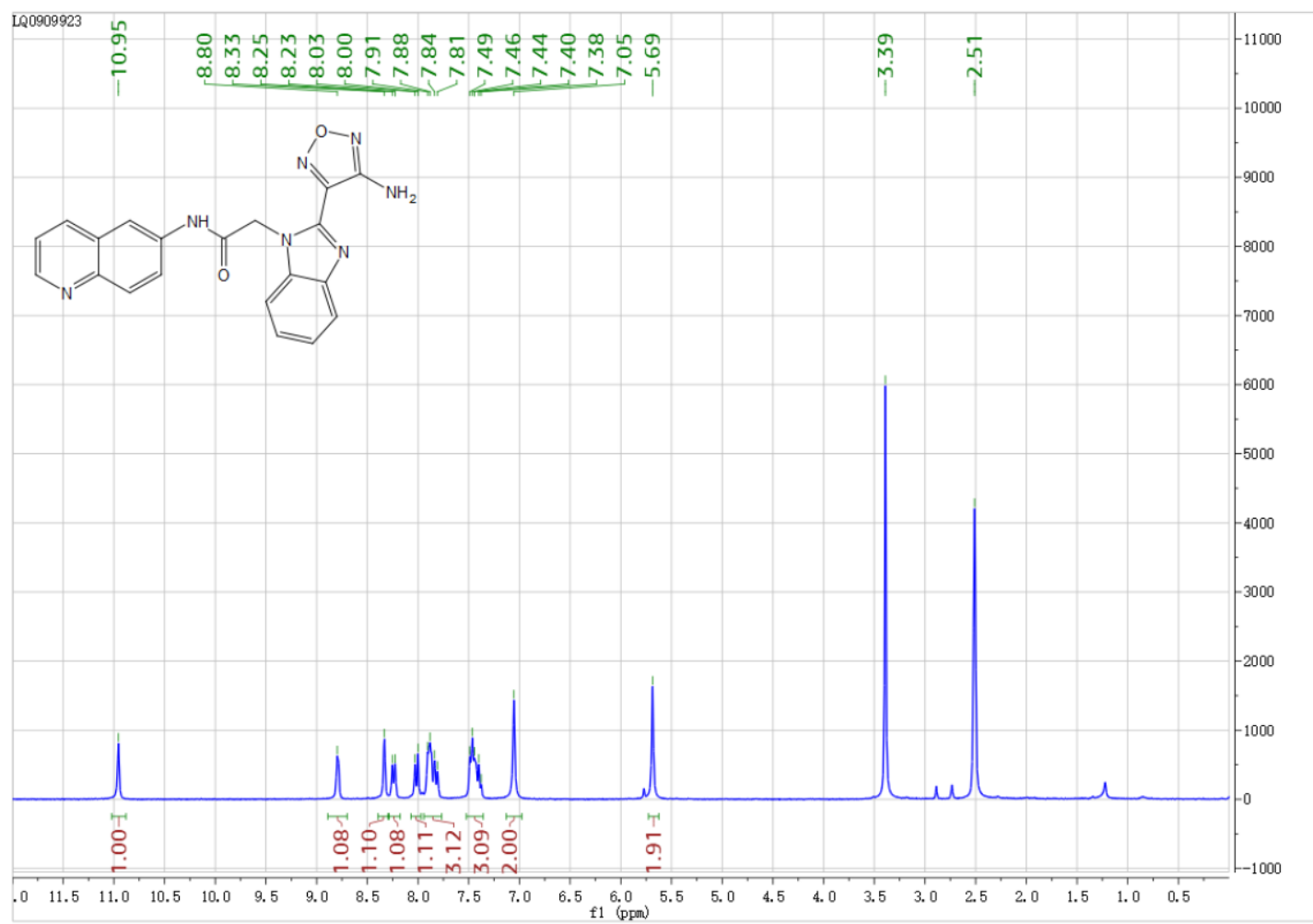

${ }^{13} \mathrm{C}$ NMR of compound S06-1002. 


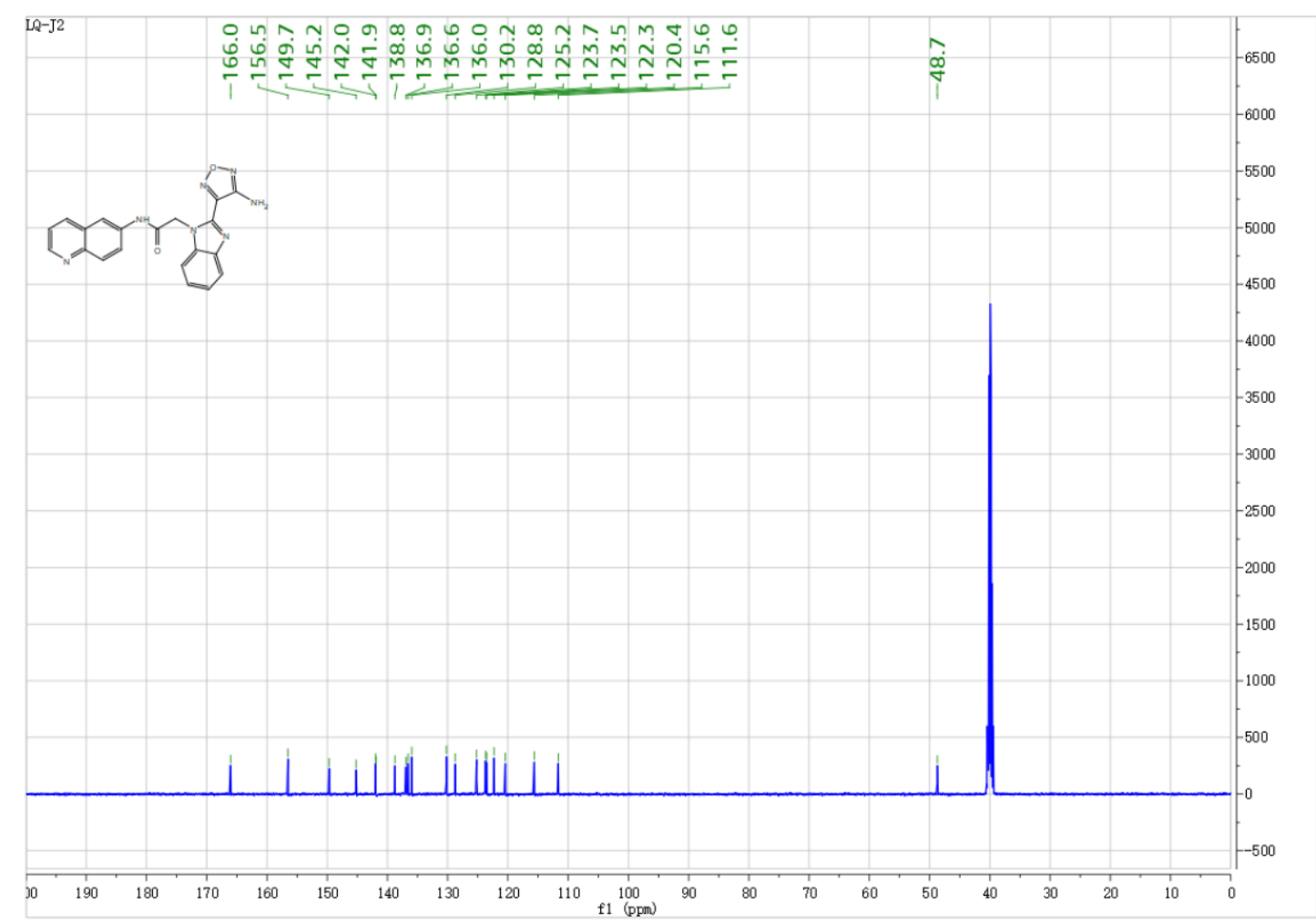

HRMS of compound S06-1002.

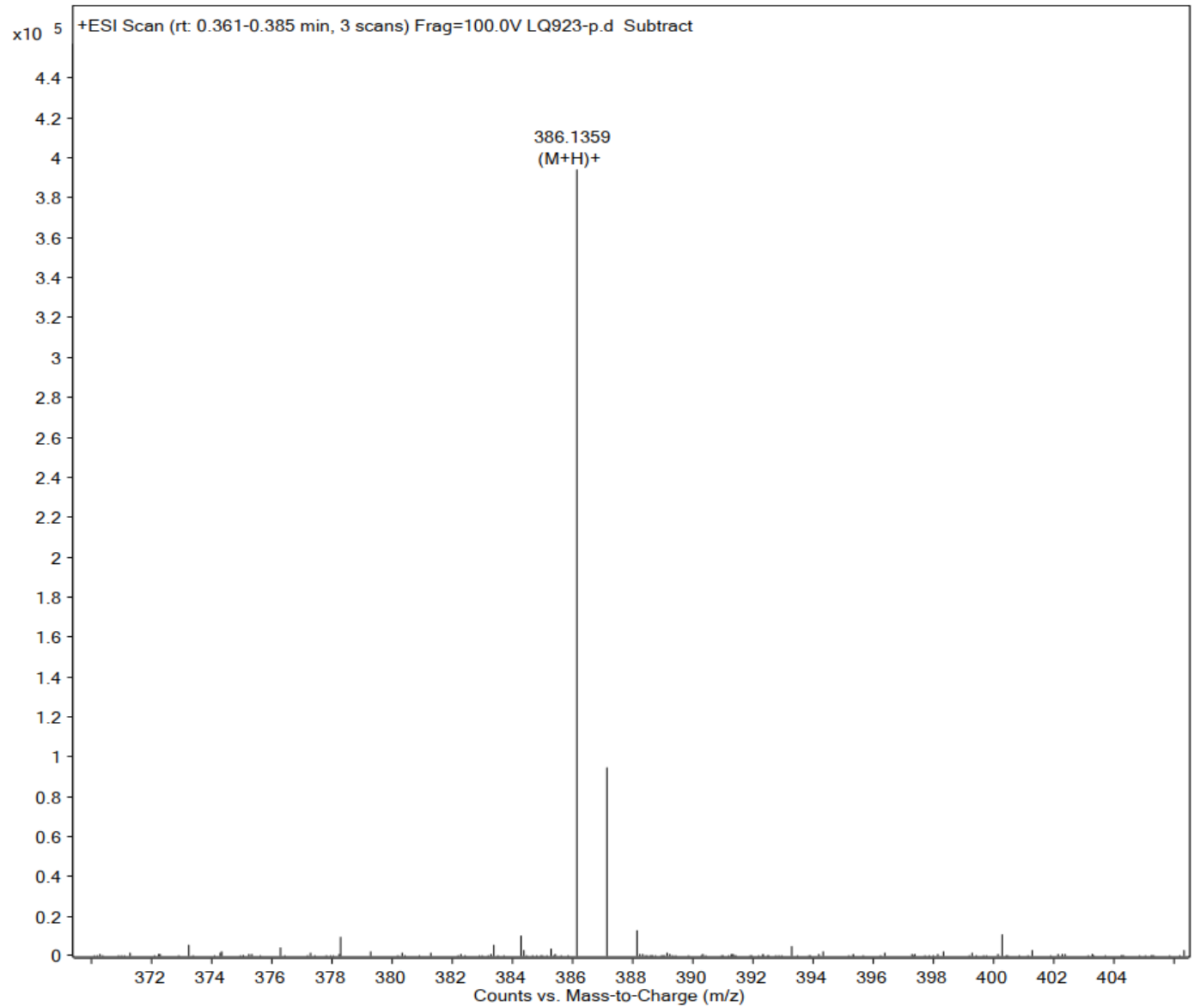


HPLC of compound S06-1003 $\left(t_{R}=6.94 \mathrm{~min}\right)$.

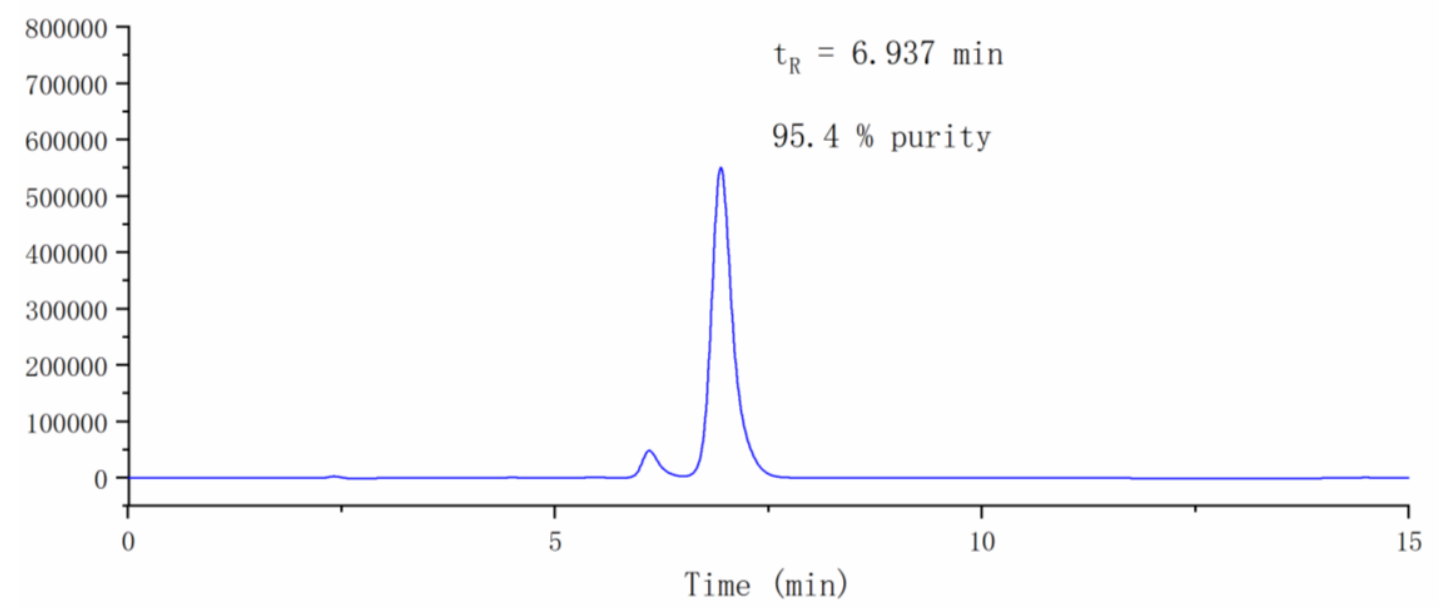

${ }^{1} \mathrm{H}$ NMR of compound S06-1003.

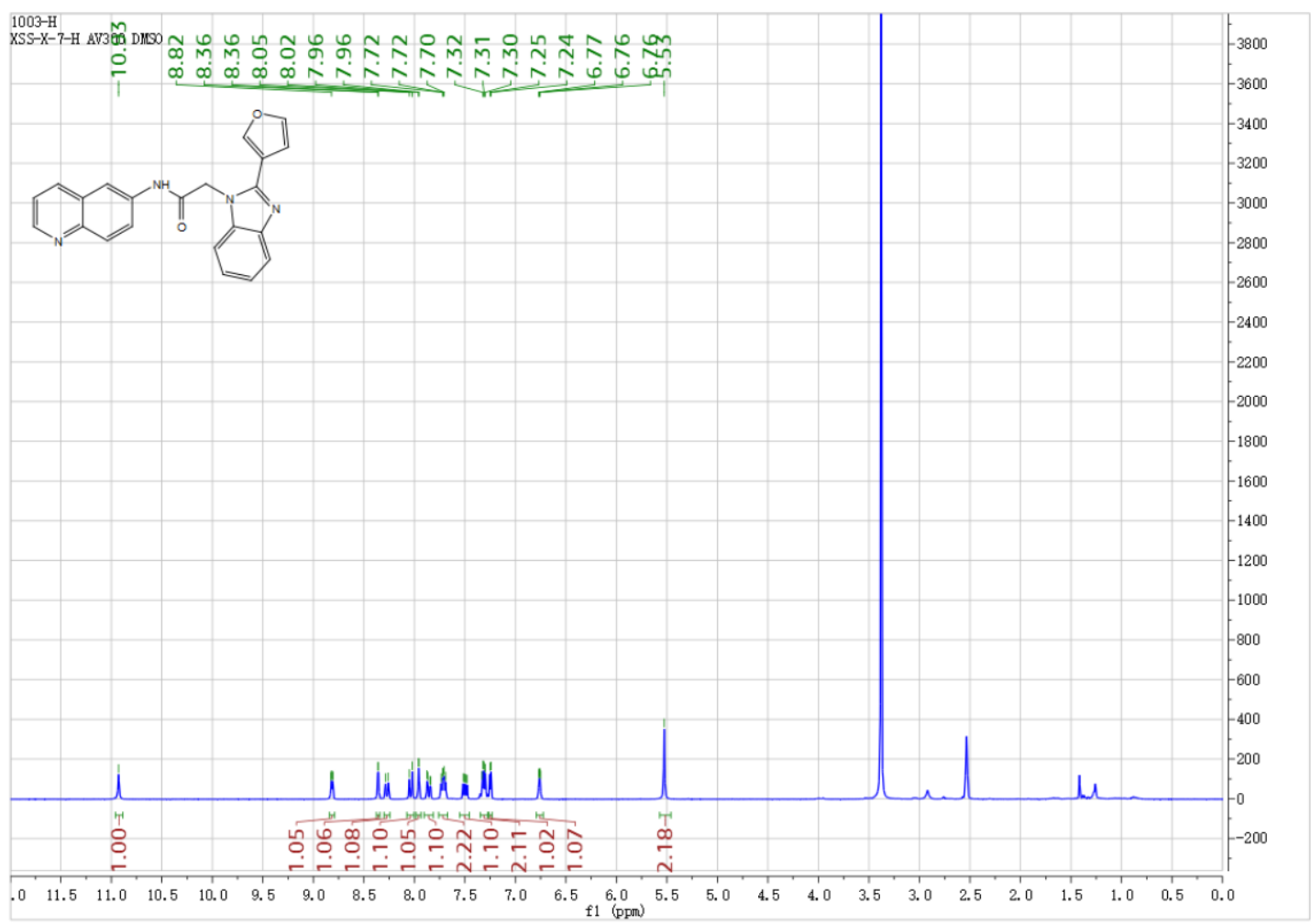

${ }^{13} \mathrm{C}$ NMR of compound S06-1003. 


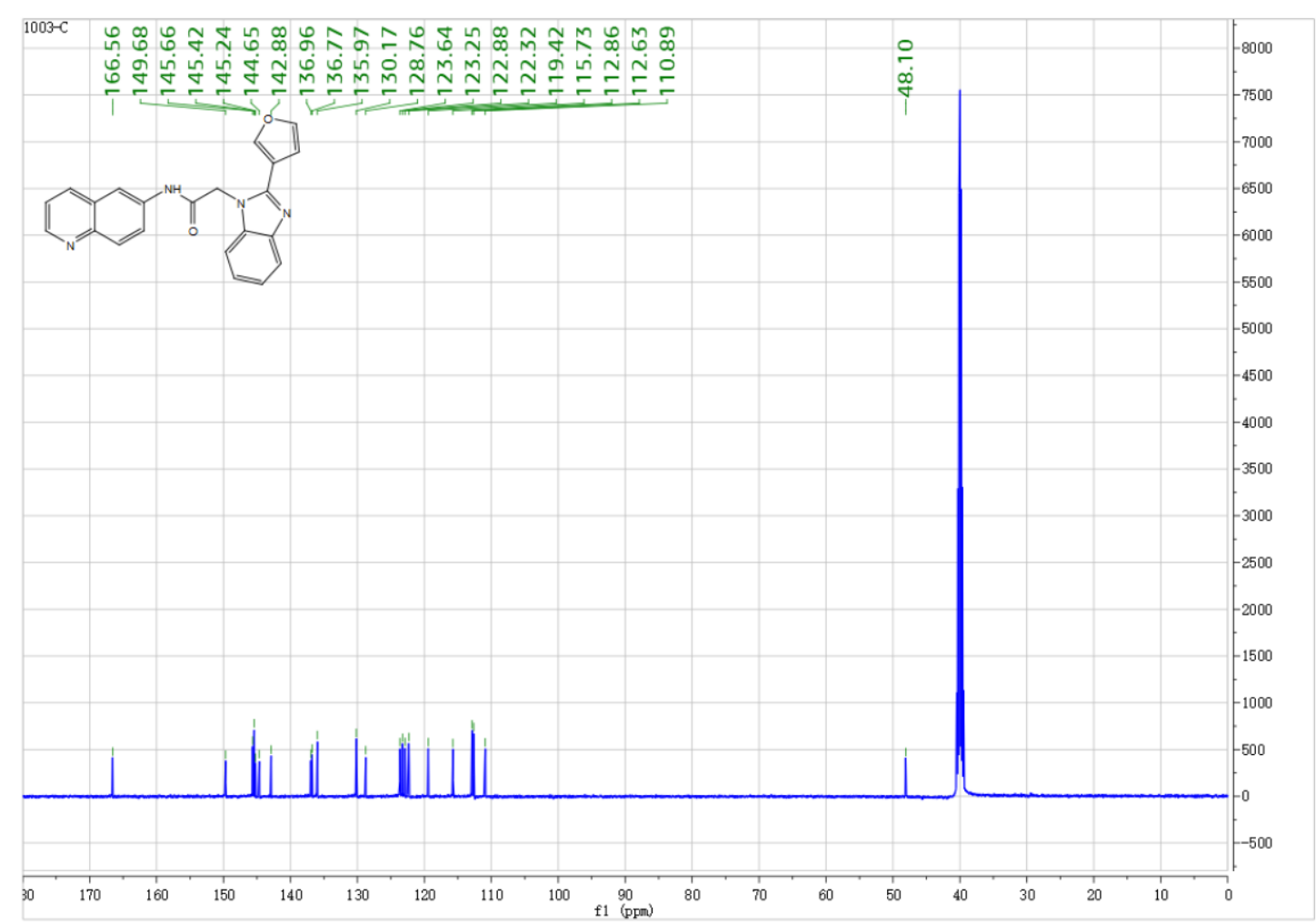

HRMS of compound S06-1003.

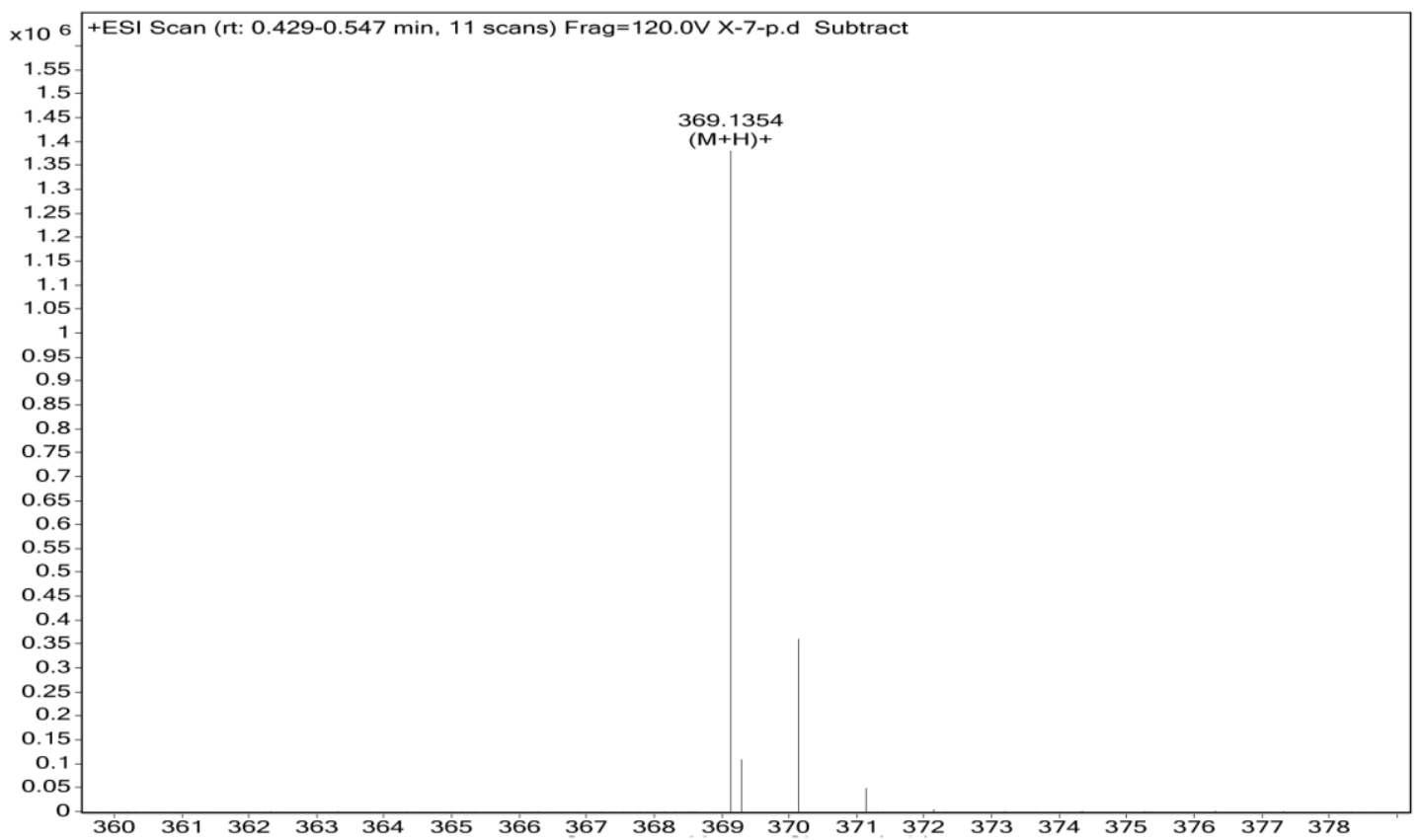


HPLC of compound S06-1004 $\left(t_{R}=6.00 \mathrm{~min}\right)$.

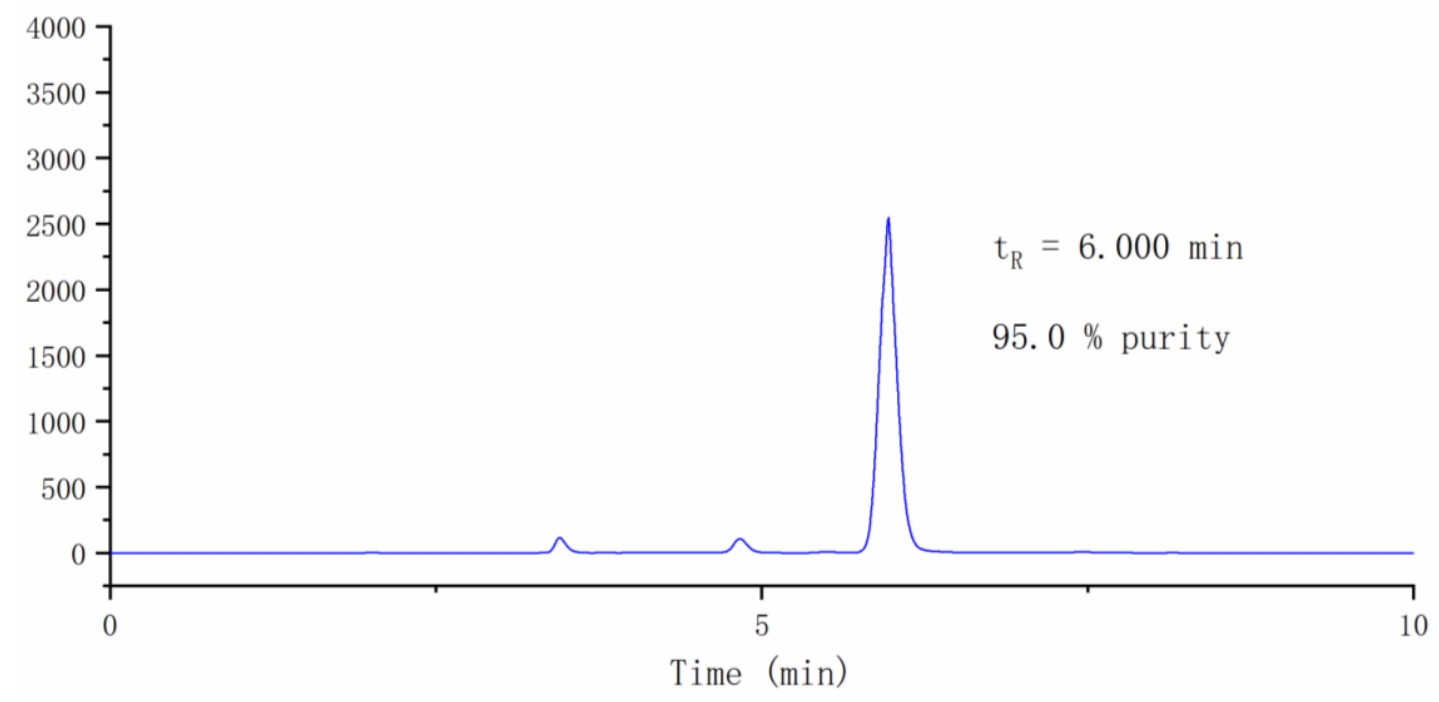

${ }^{1} \mathrm{H}$ NMR of compound S06-1004.

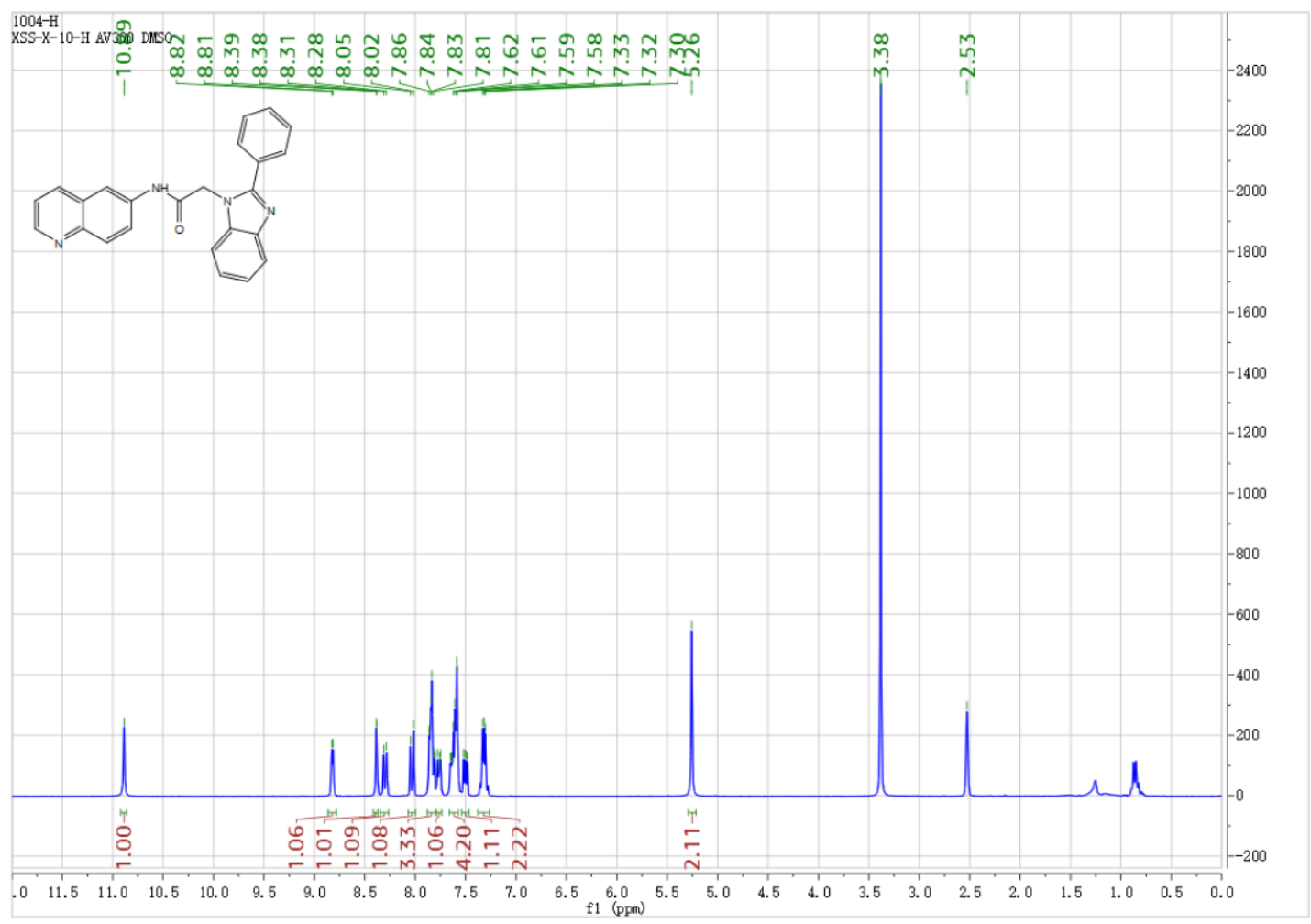

${ }^{13} \mathrm{C}$ NMR of compound S06-1004. 


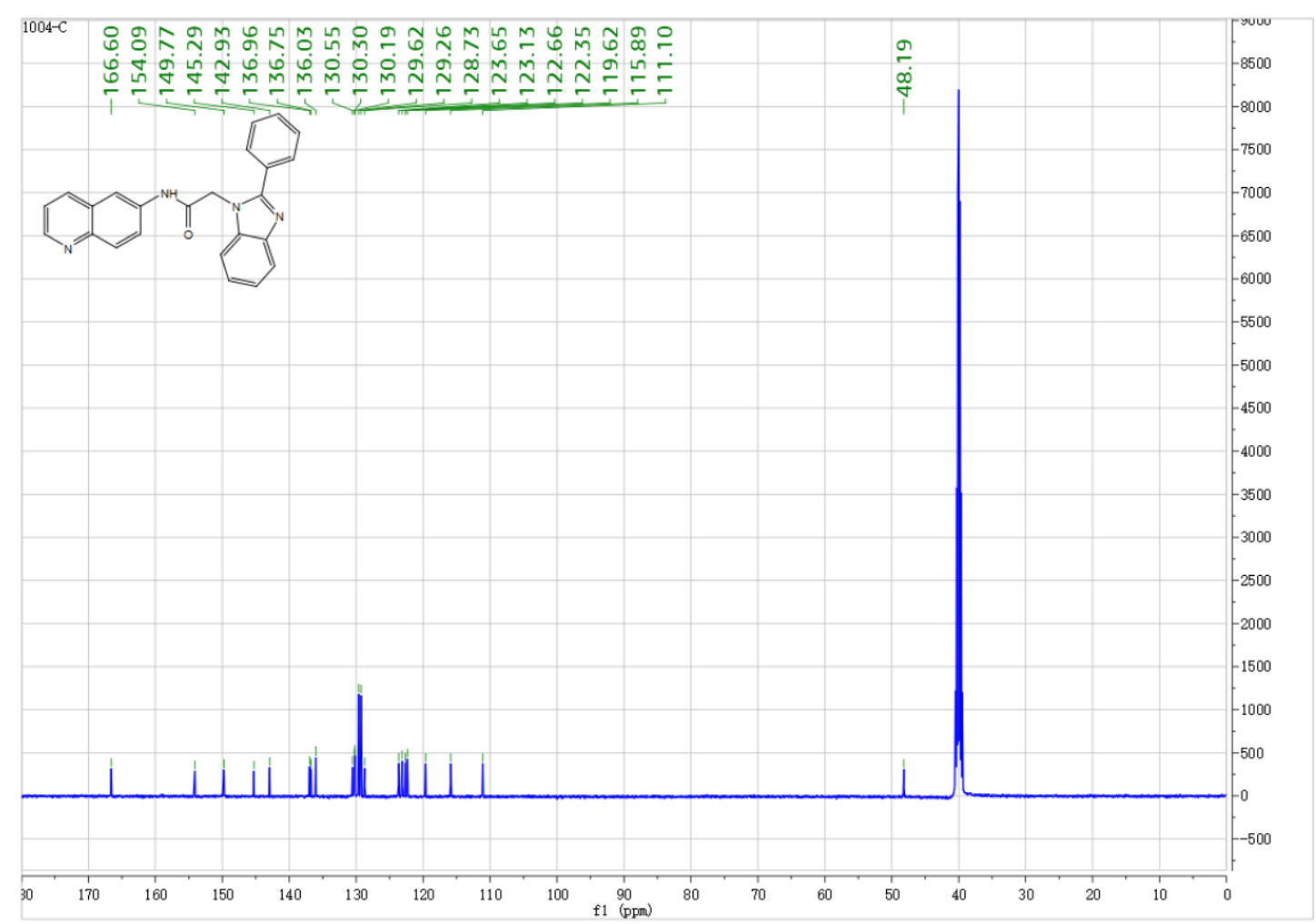

HRMS of compound S06-1004.

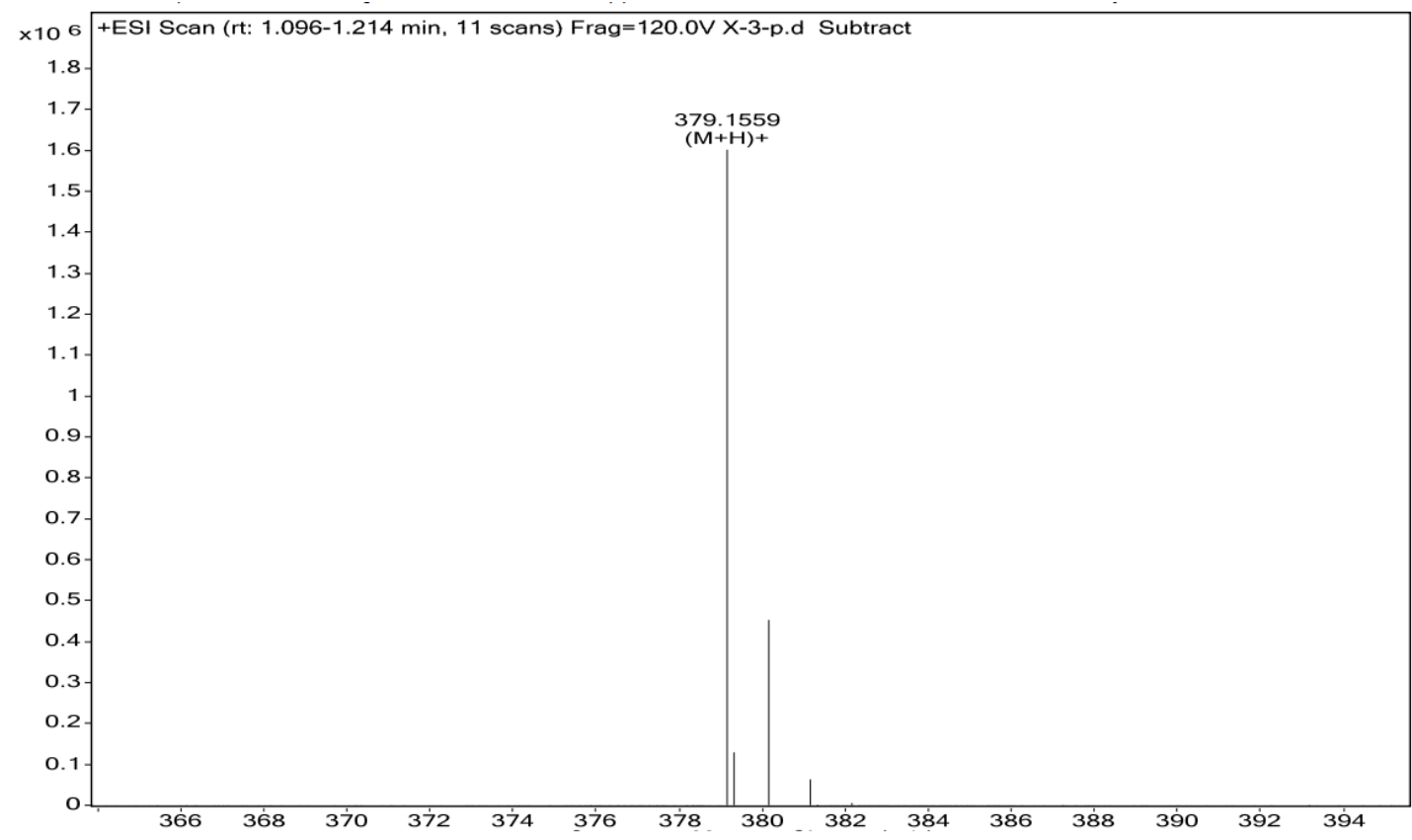


HPLC of compound S06-1005 $\left(t_{R}=5.67 \mathrm{~min}\right)$.

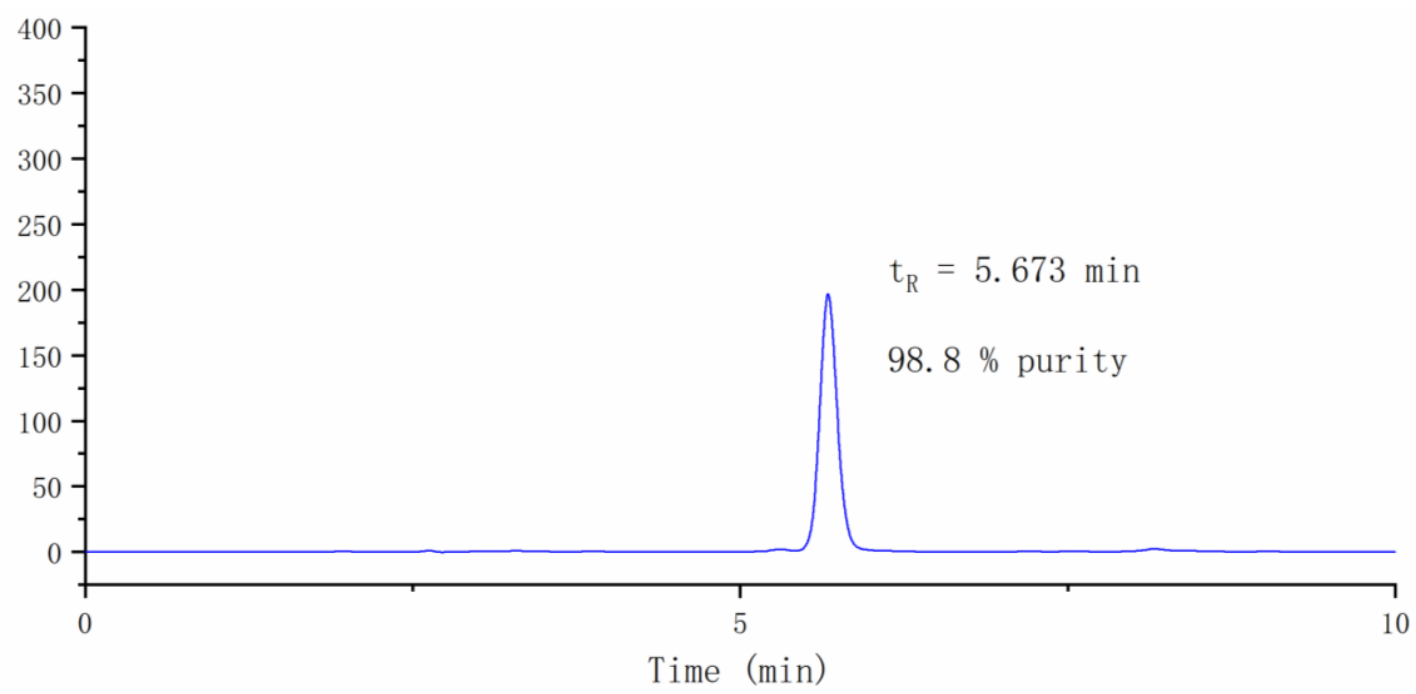

${ }^{1} \mathrm{H}$ NMR of compound S06-1005.

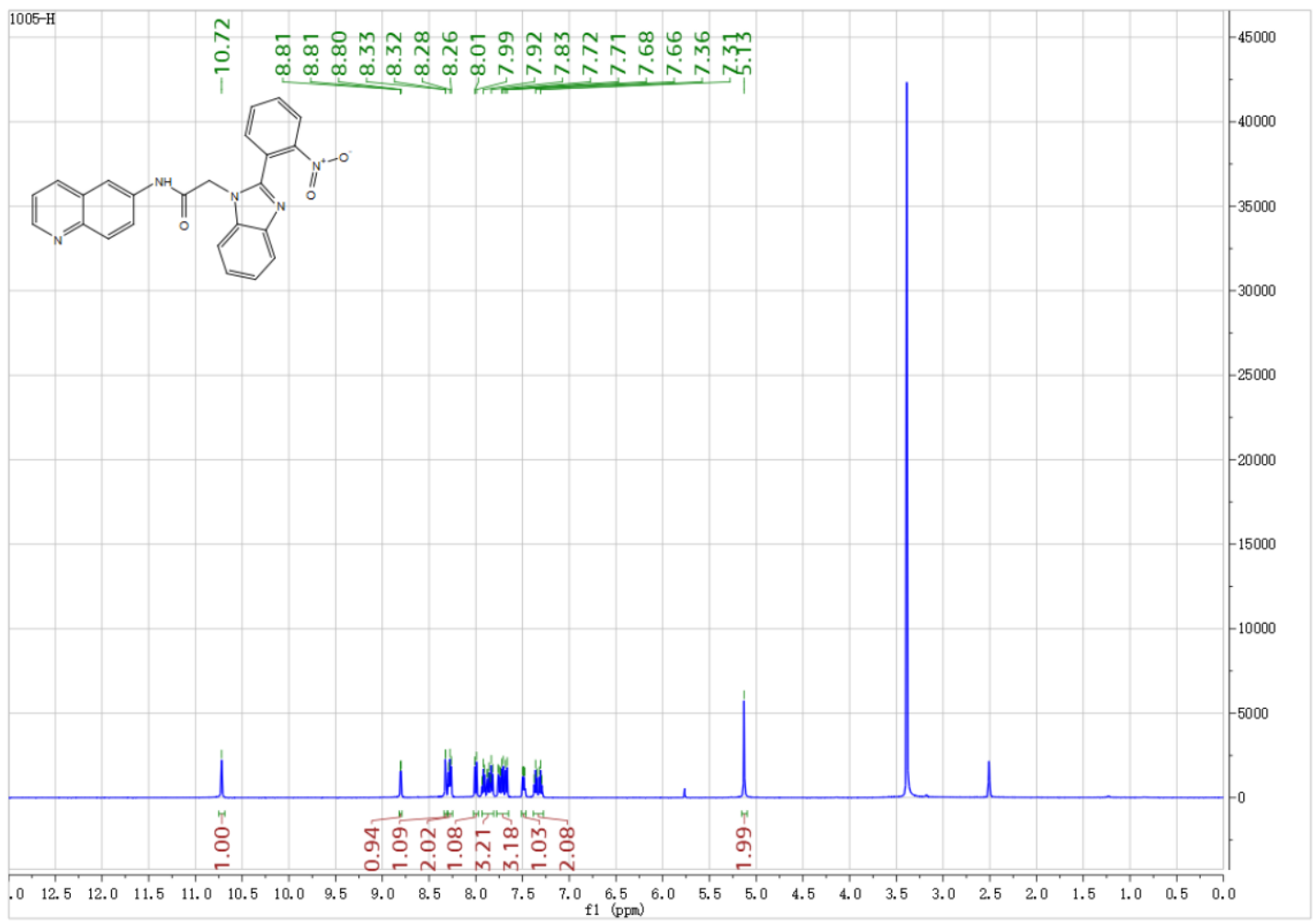

${ }^{13} \mathrm{C}$ NMR of compound S06-1005. 


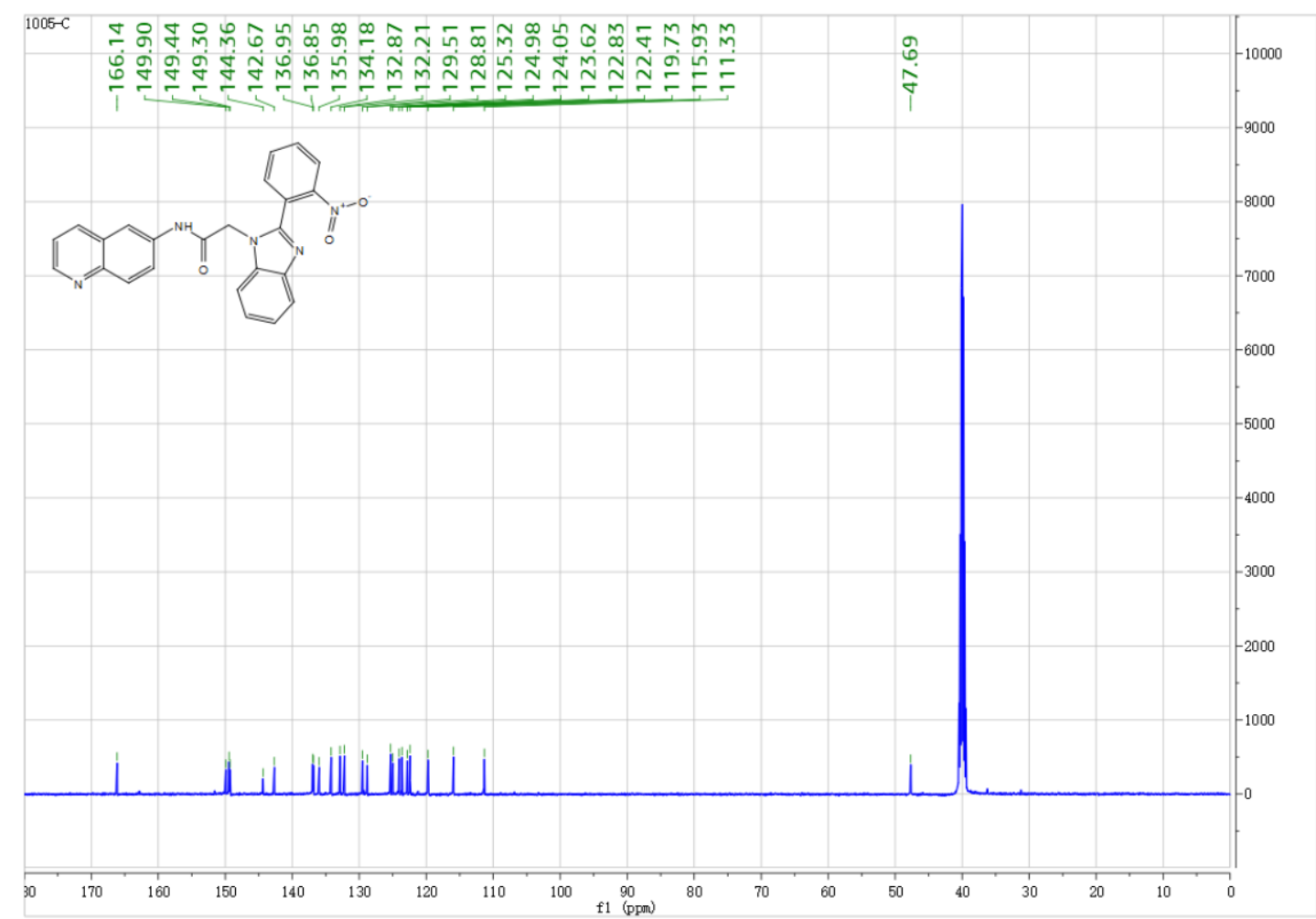

HRMS of compound S06-1005.

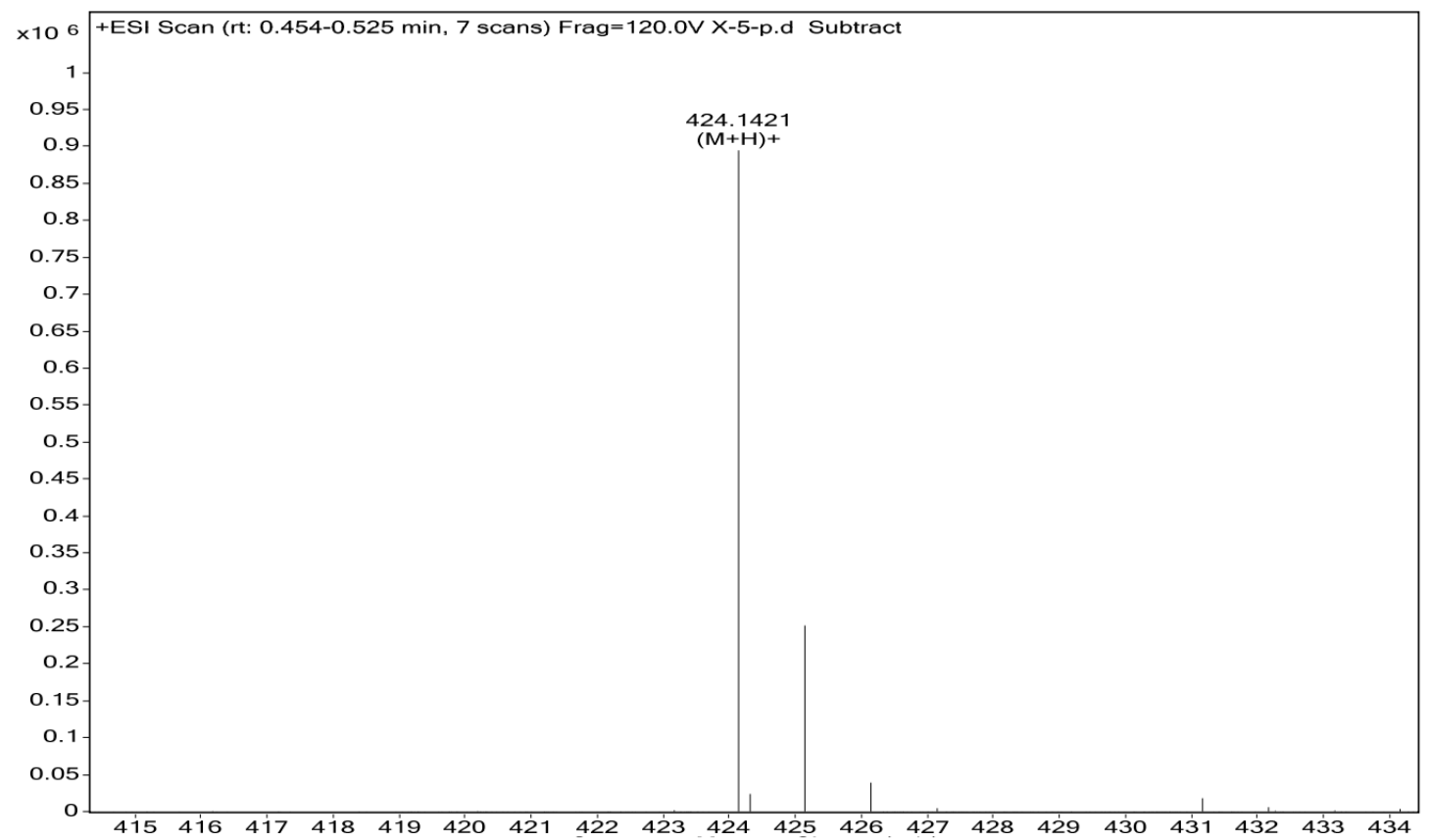


HPLC of compound S06-1006 $\left(t_{R}=5.67 \mathrm{~min}\right)$.

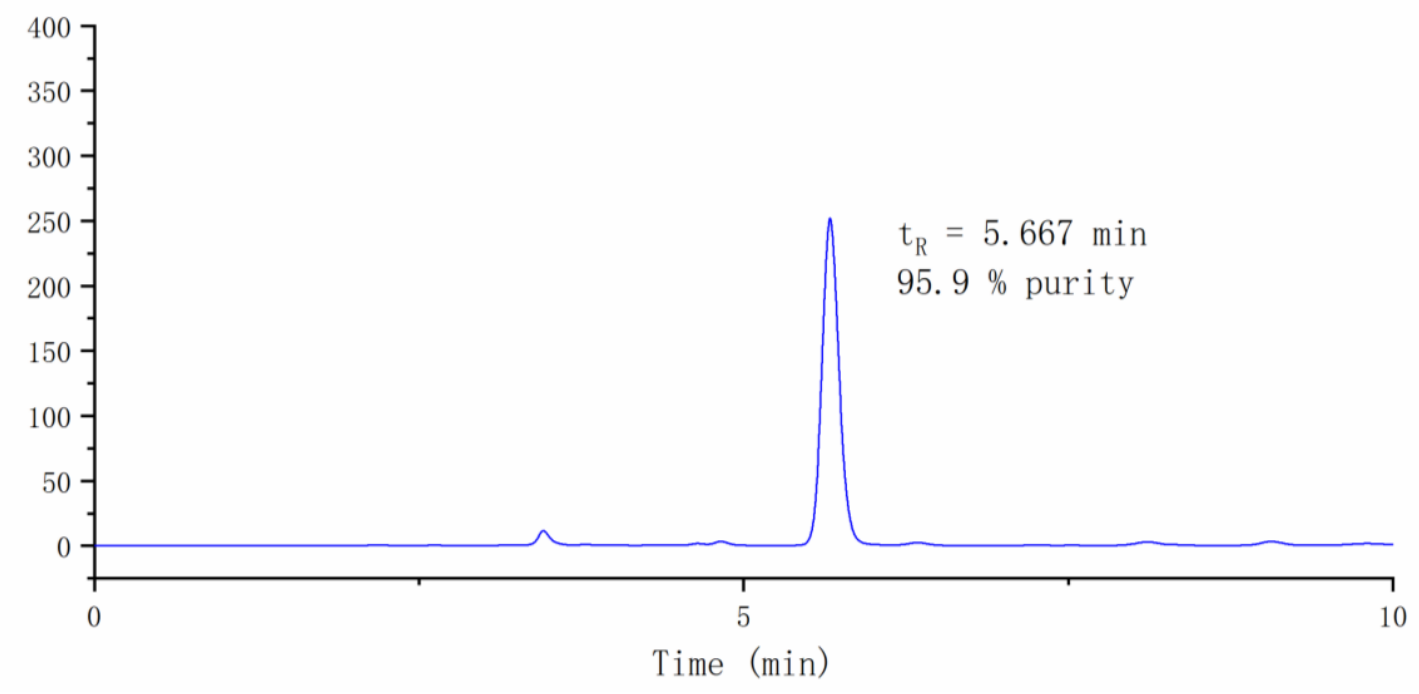

${ }^{1} \mathrm{H}$ NMR of compound S06-1006.

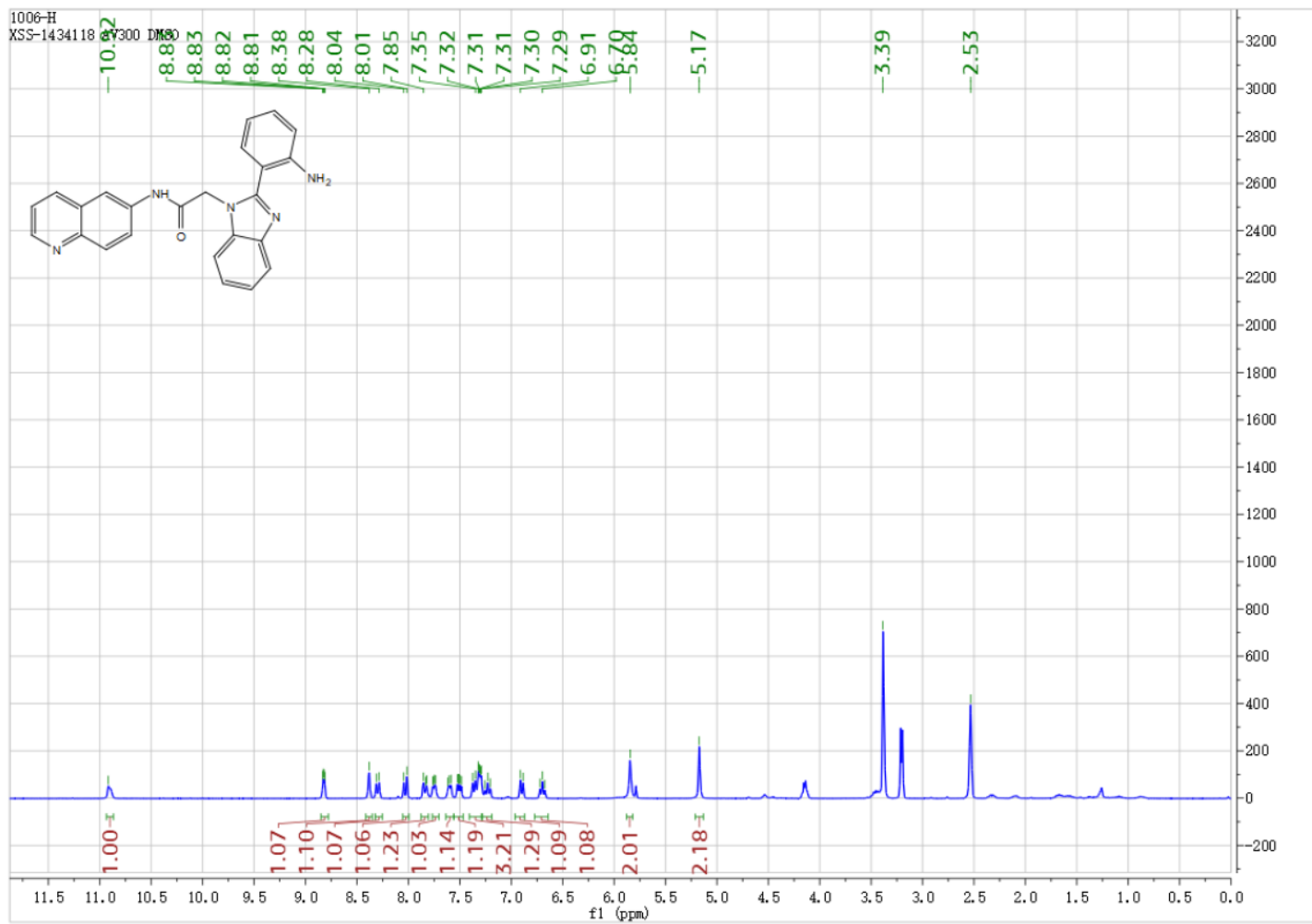

${ }^{13} \mathrm{C}$ NMR of compound S06-1006. 


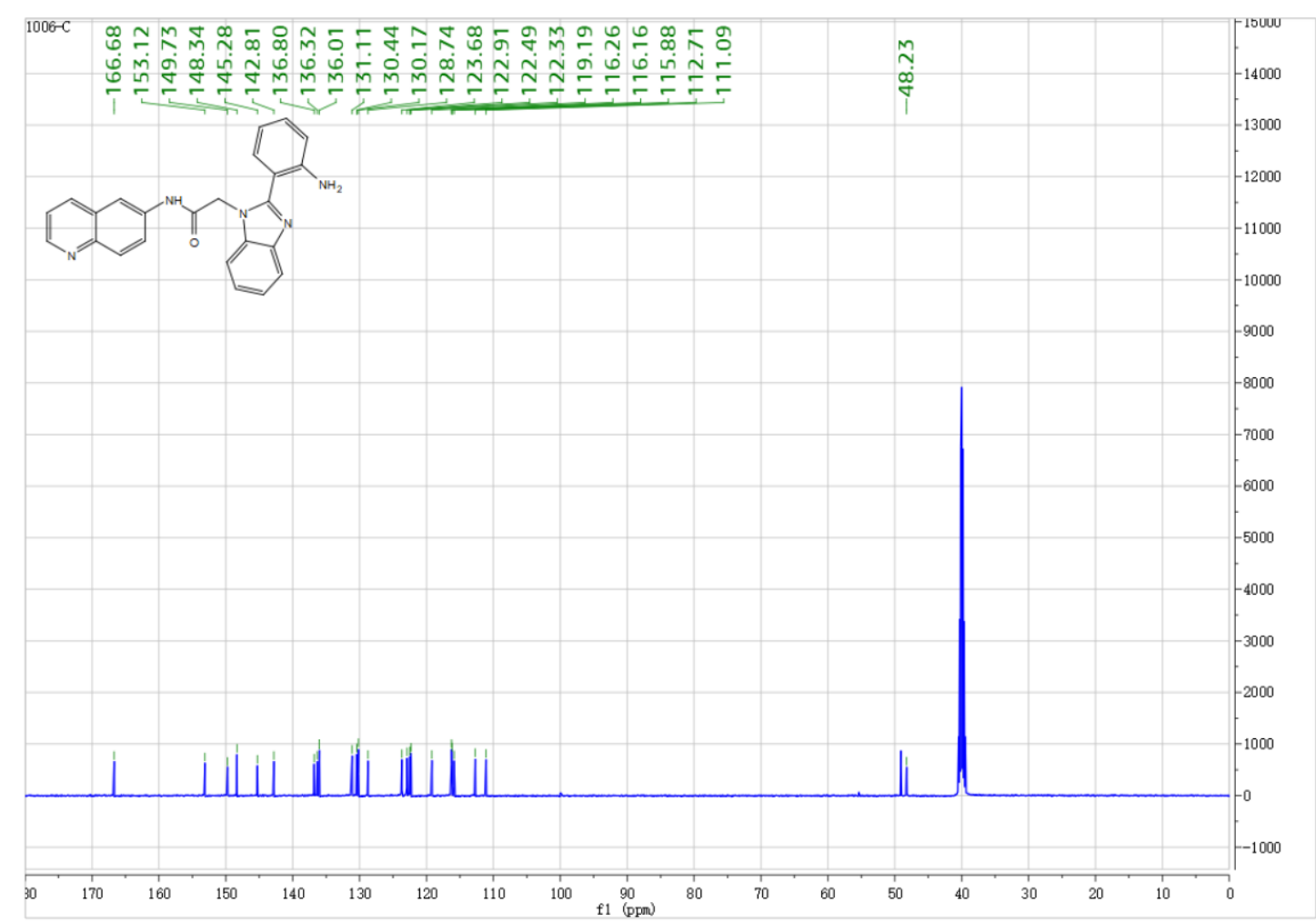

HRMS of compound S06-1006.

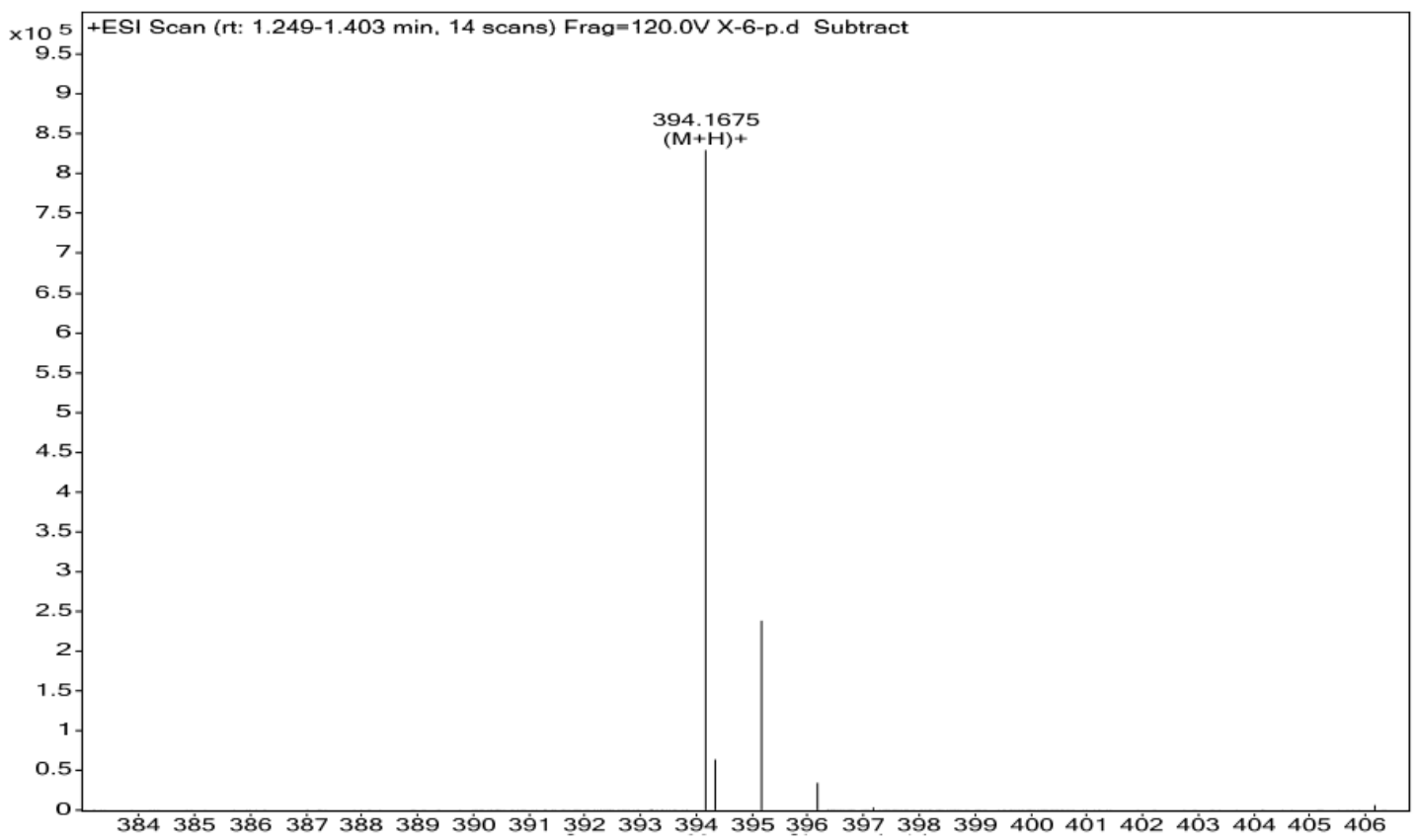


HPLC of compound S06-1007 $\left(t_{R}=5.51 \mathrm{~min}\right)$.

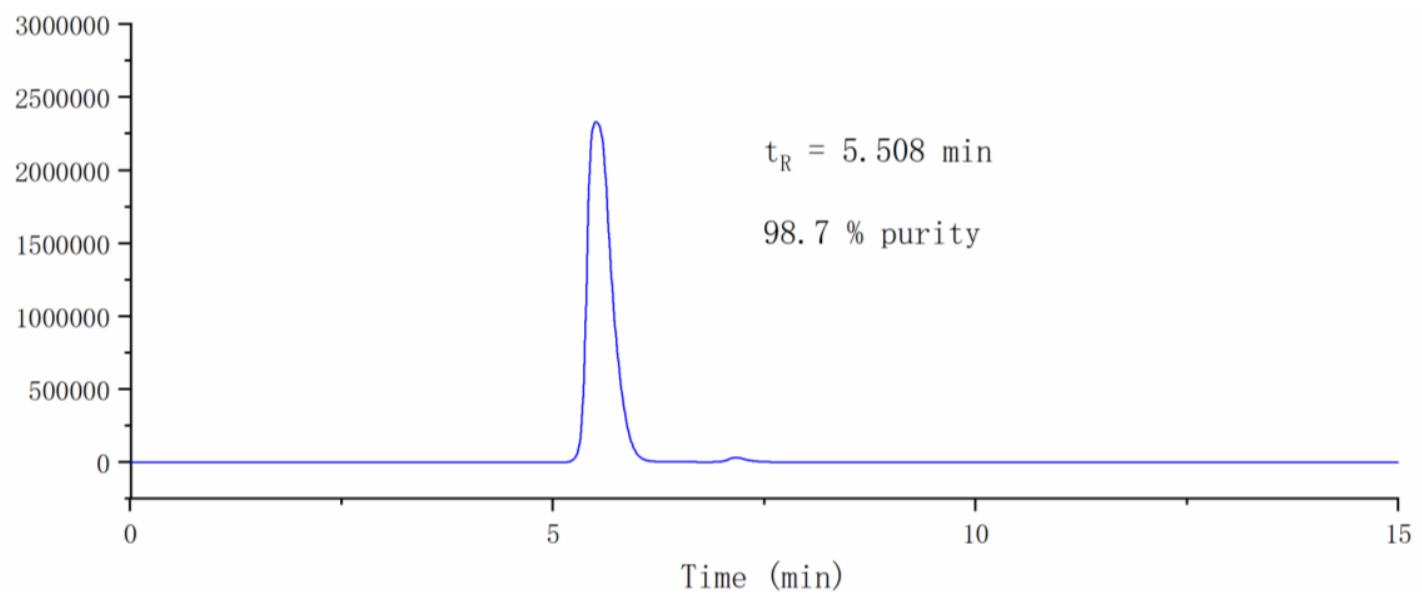

${ }^{1} \mathrm{H}$ NMR of compound S06-1007.

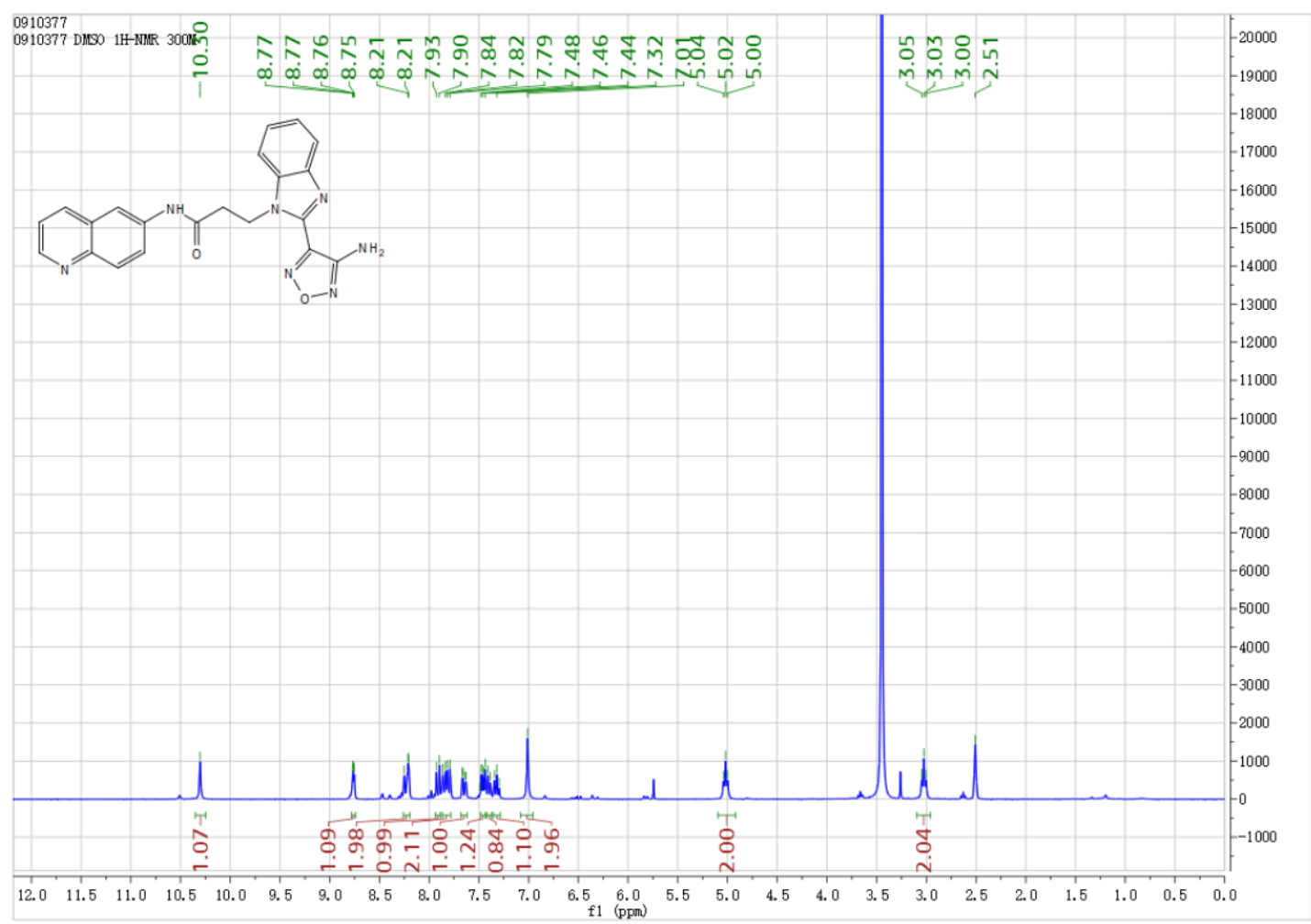

${ }^{13} \mathrm{C}$ NMR of compound S06-1007. 


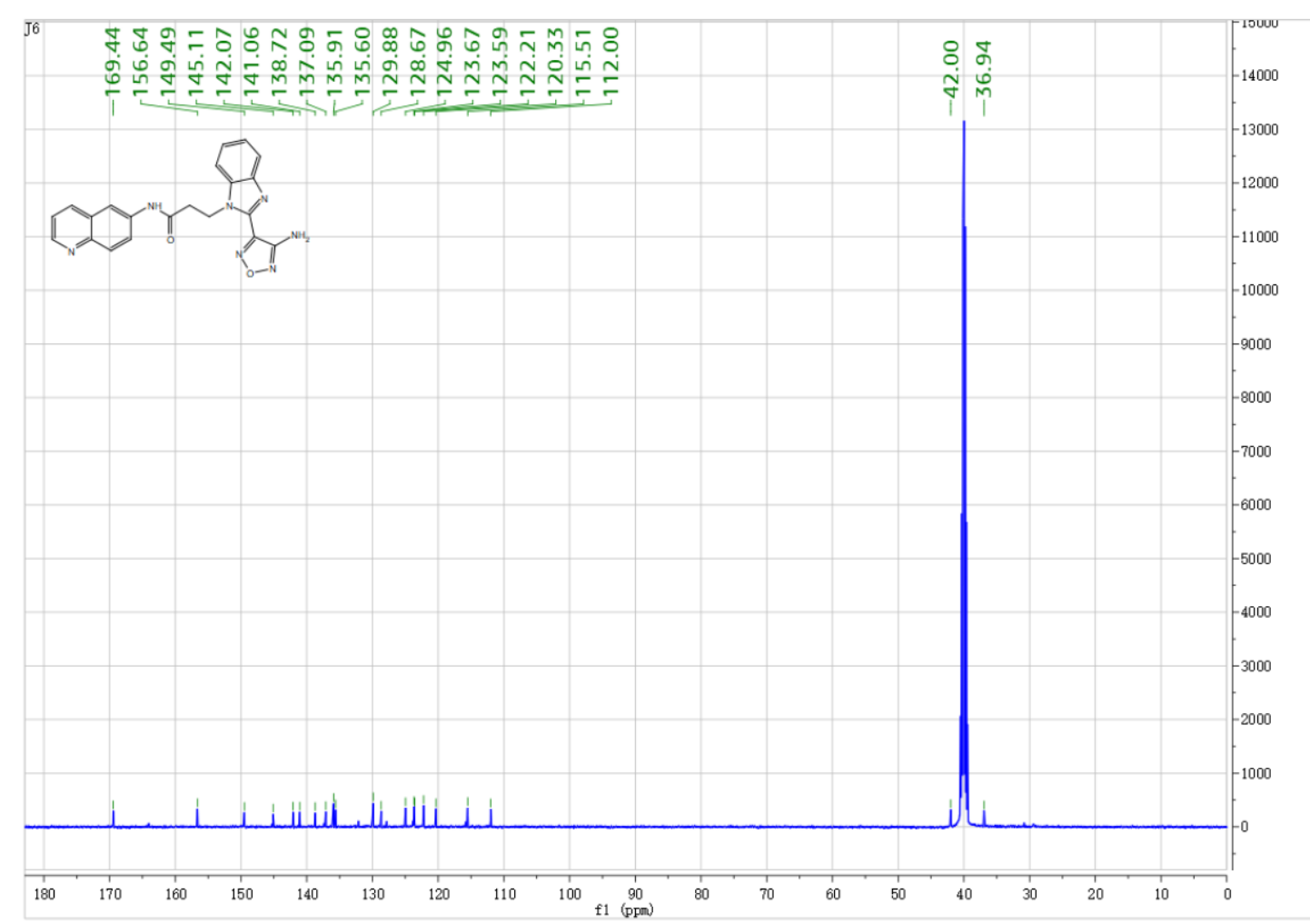

HRMS of compound S06-1007.

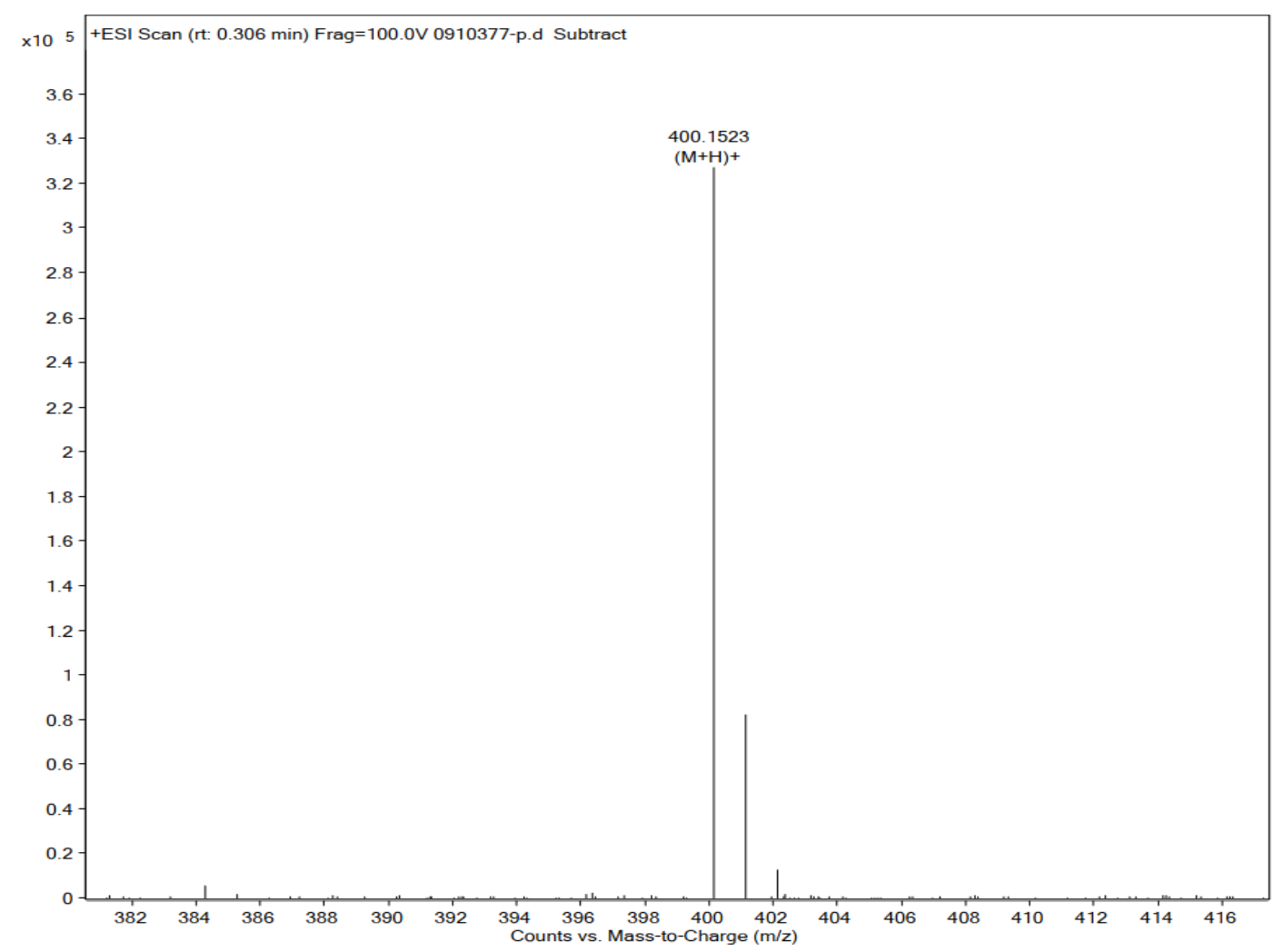


HPLC of compound S06-1008 $\left(t_{R}=6.80 \mathrm{~min}\right)$.

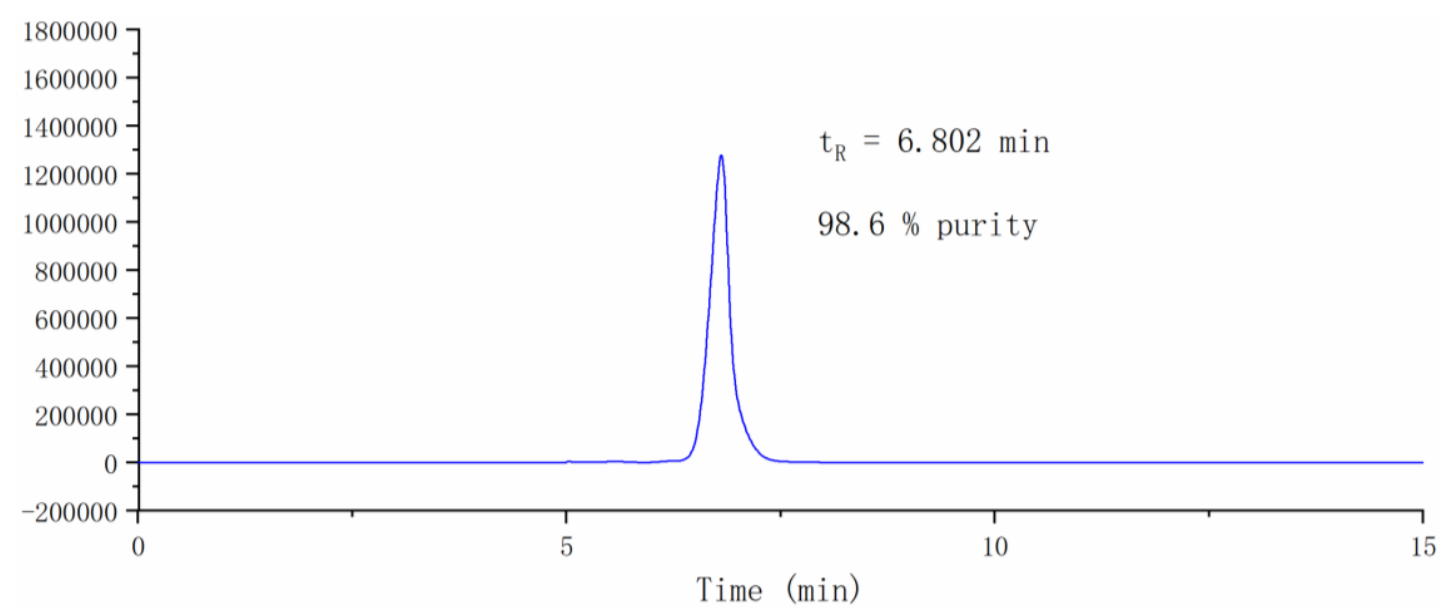

${ }^{1} \mathrm{H}$ NMR of compound S06-1008.

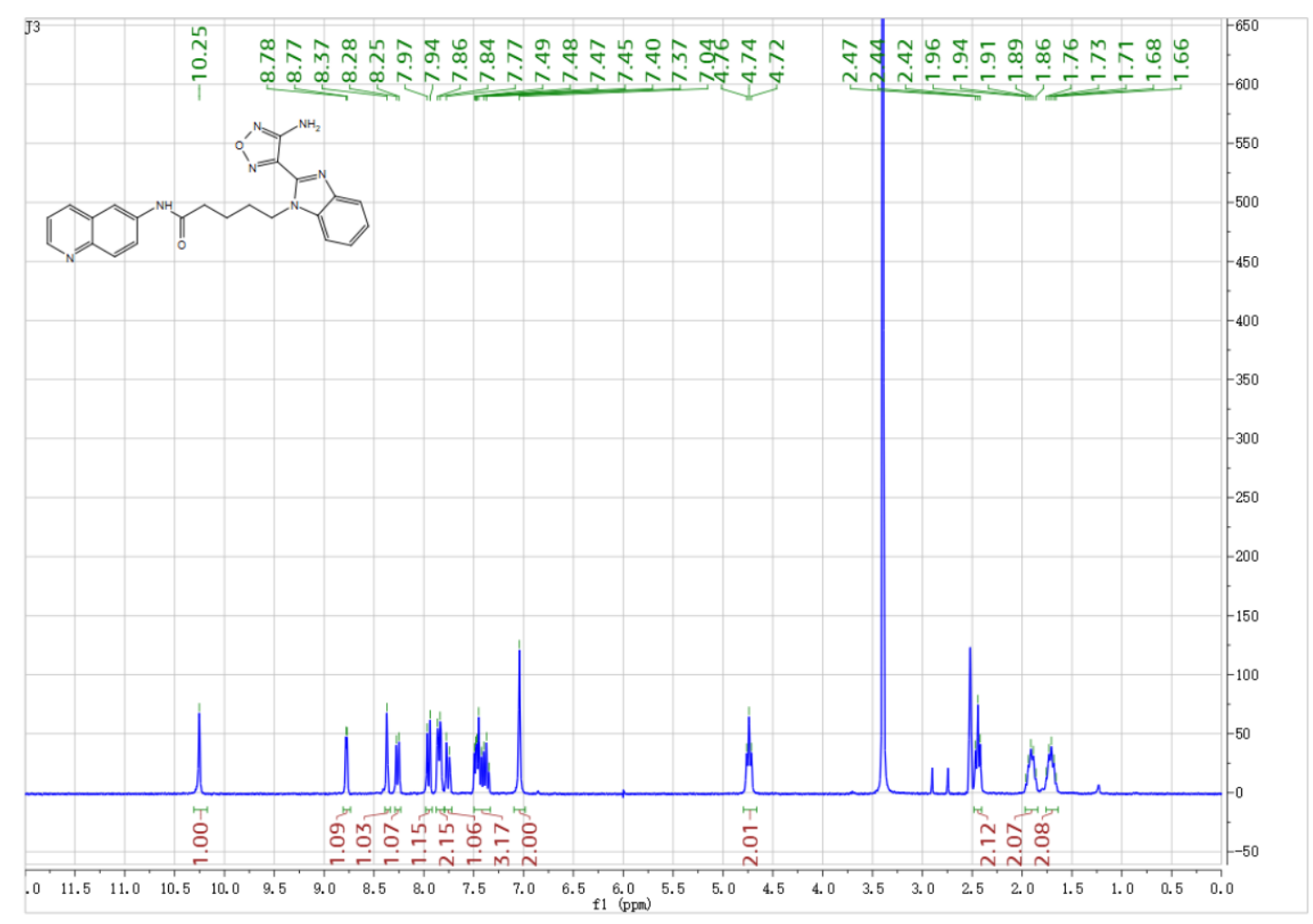

${ }^{13} \mathrm{C}$ NMR of compound S06-1008. 


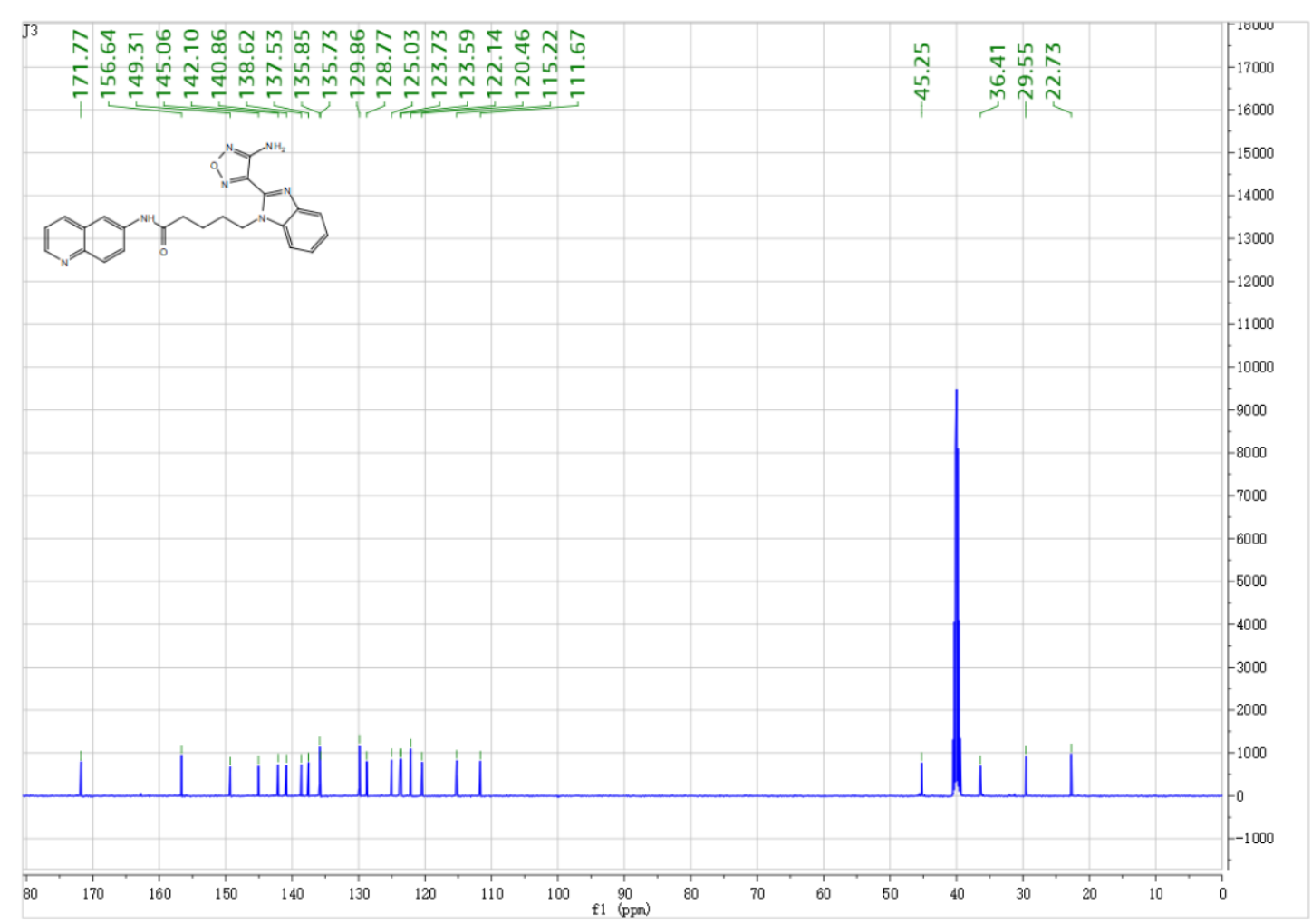

HRMS of compound S06-1008.

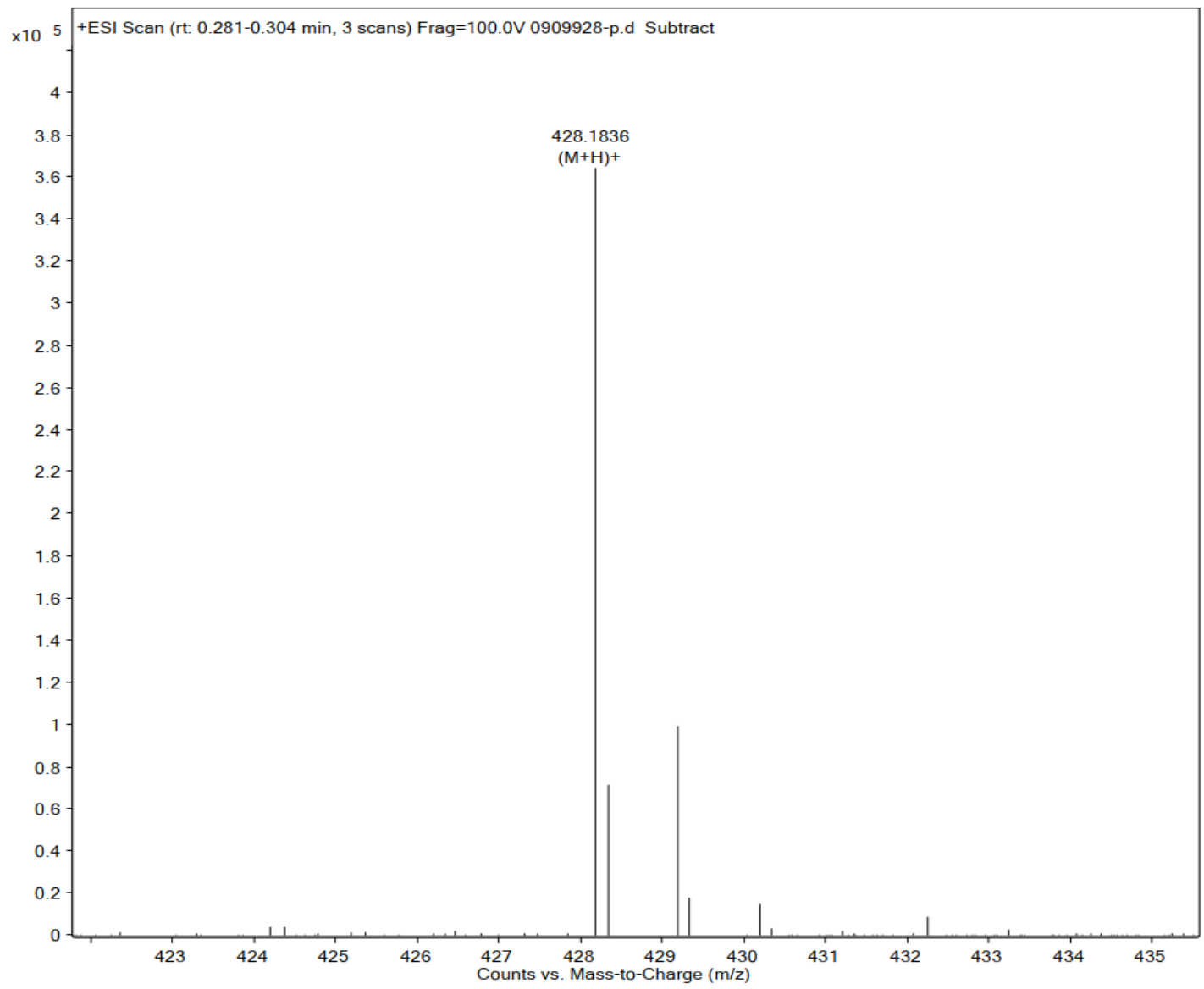


HPLC of compound S06-1009 $\left(t_{R}=4.09 \mathrm{~min}\right)$.

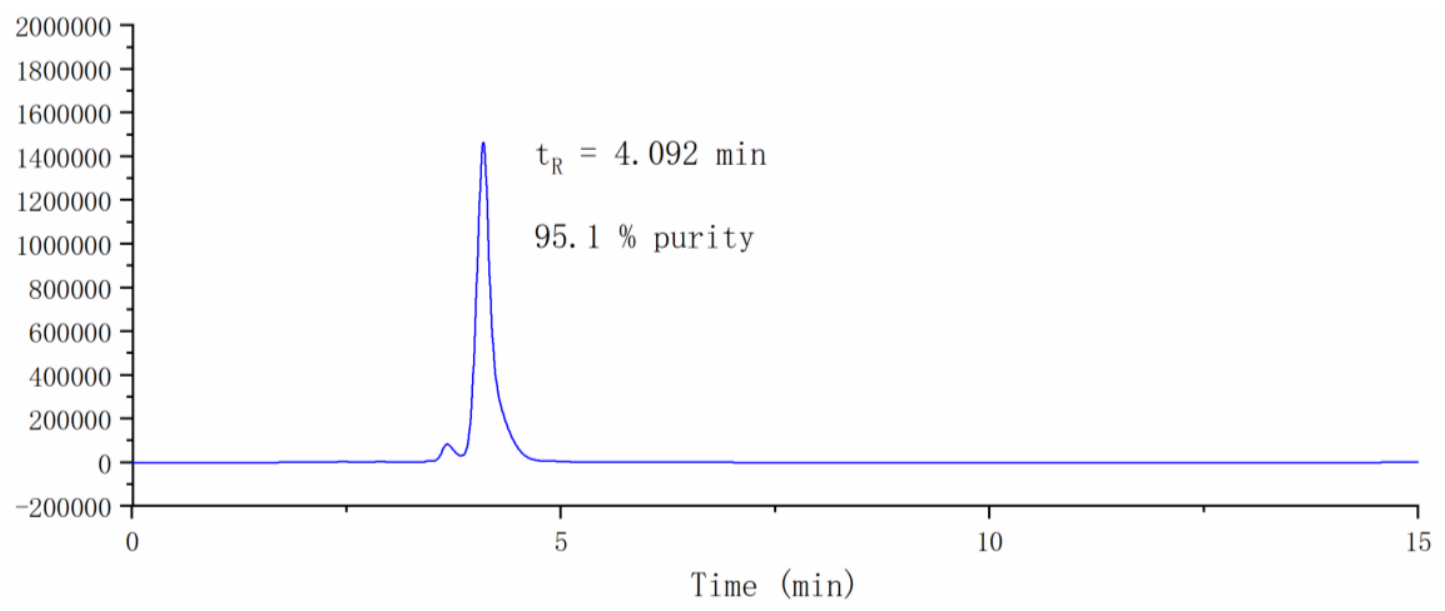

${ }^{1} \mathrm{H}$ NMR of compound S06-1009.

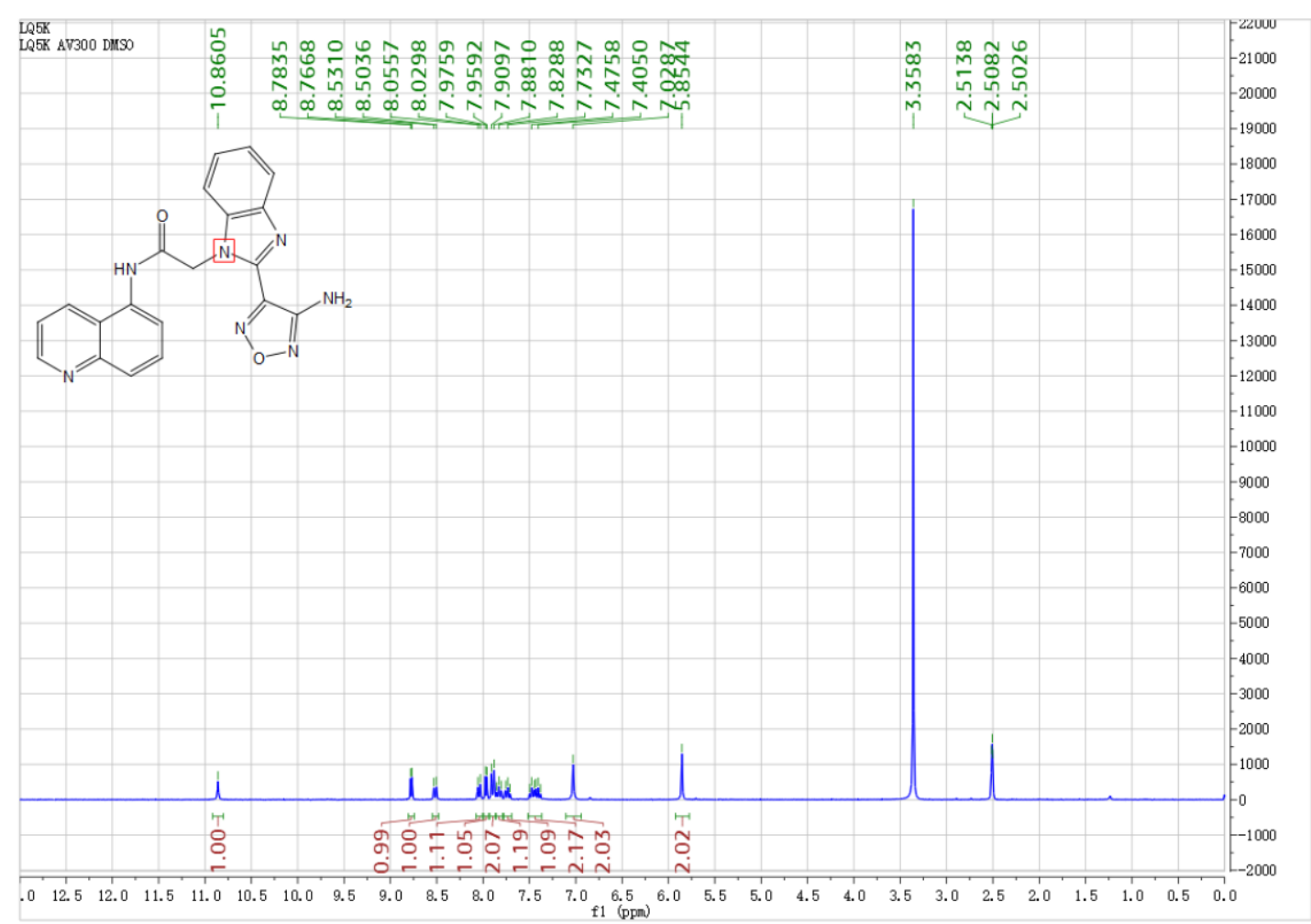

${ }^{13} \mathrm{C}$ NMR of compound S06-1009. 


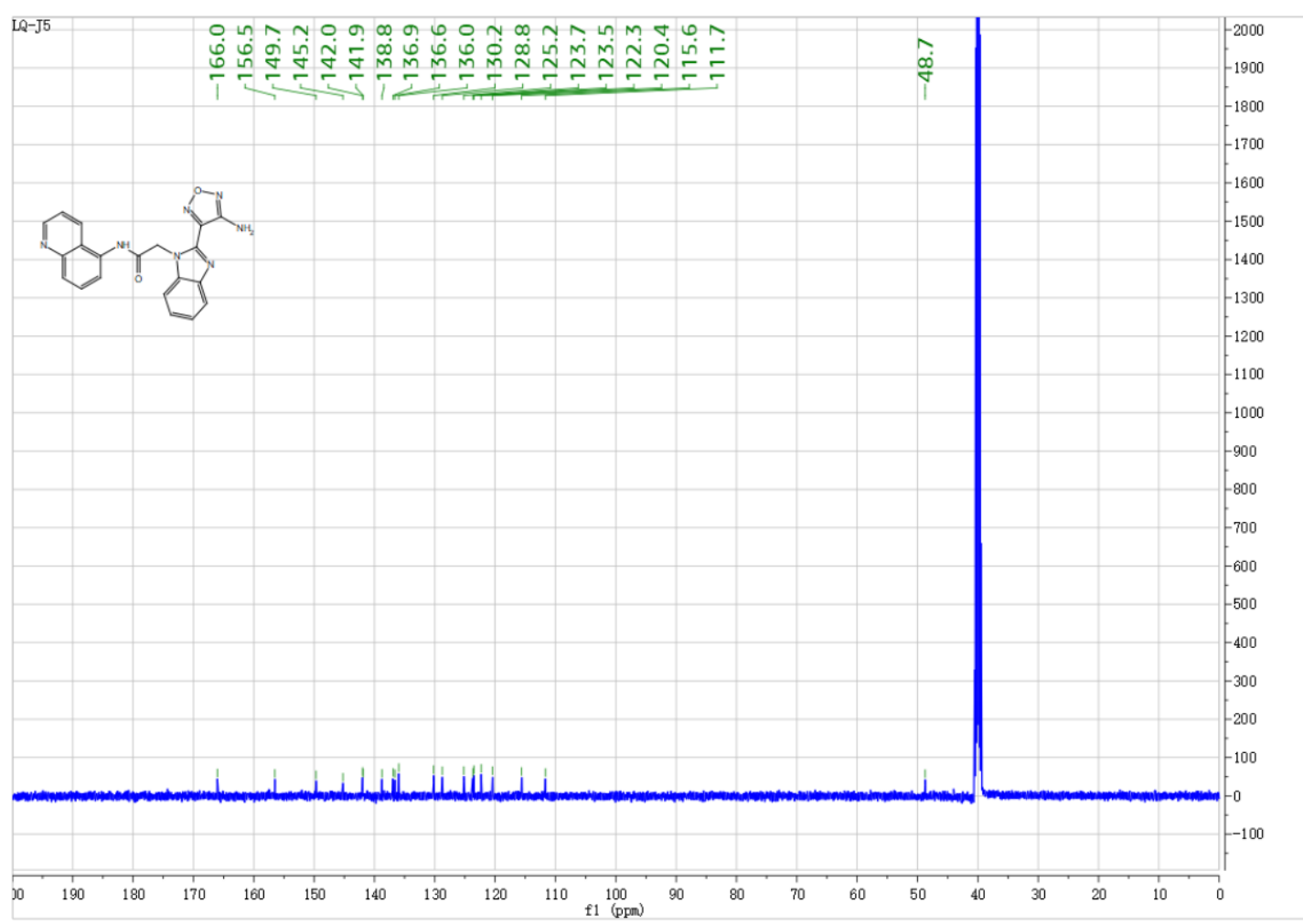

HRMS of compound S06-1009.

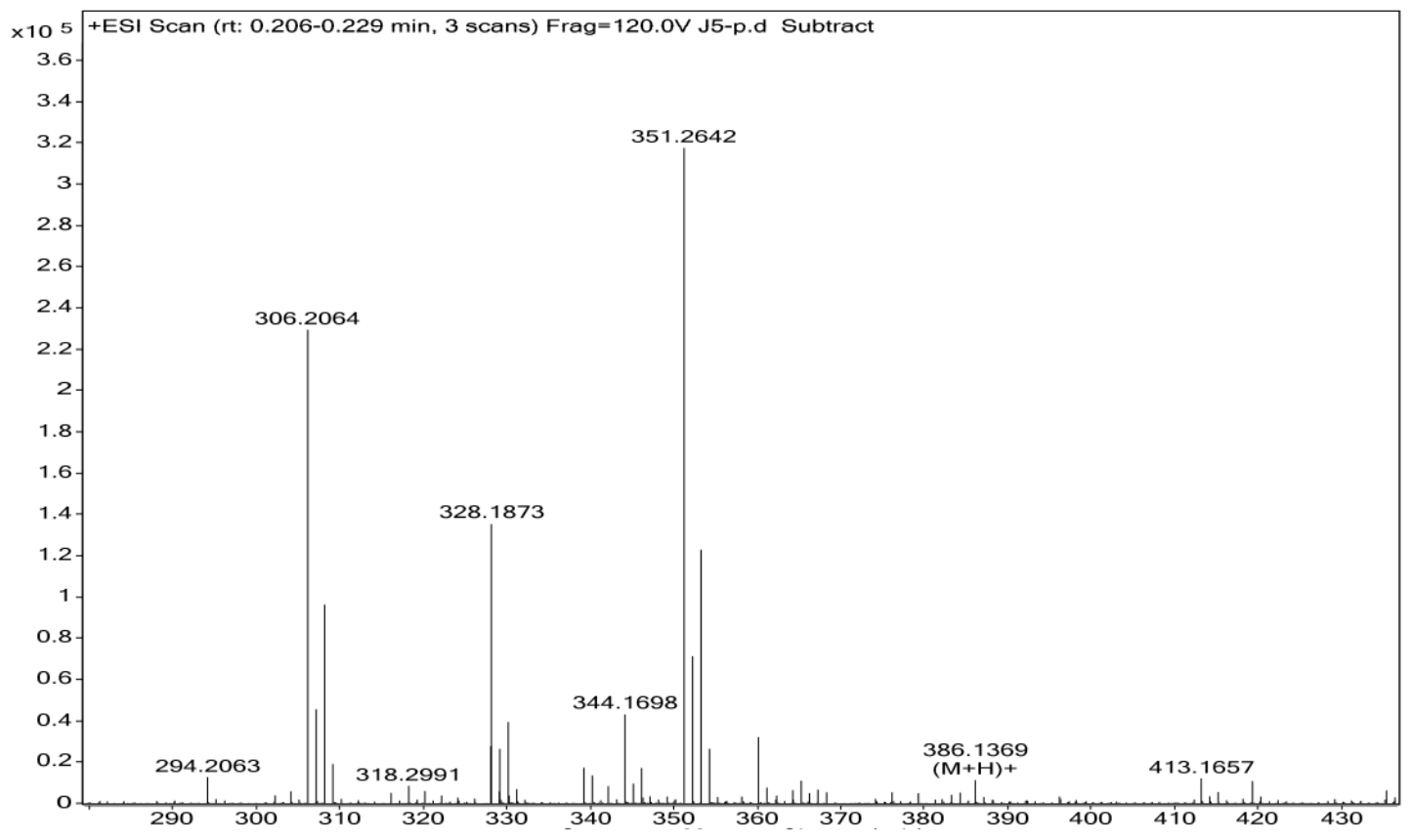


HPLC of compound S06-1010 $\left(t_{R}=6.03 \mathrm{~min}\right)$.

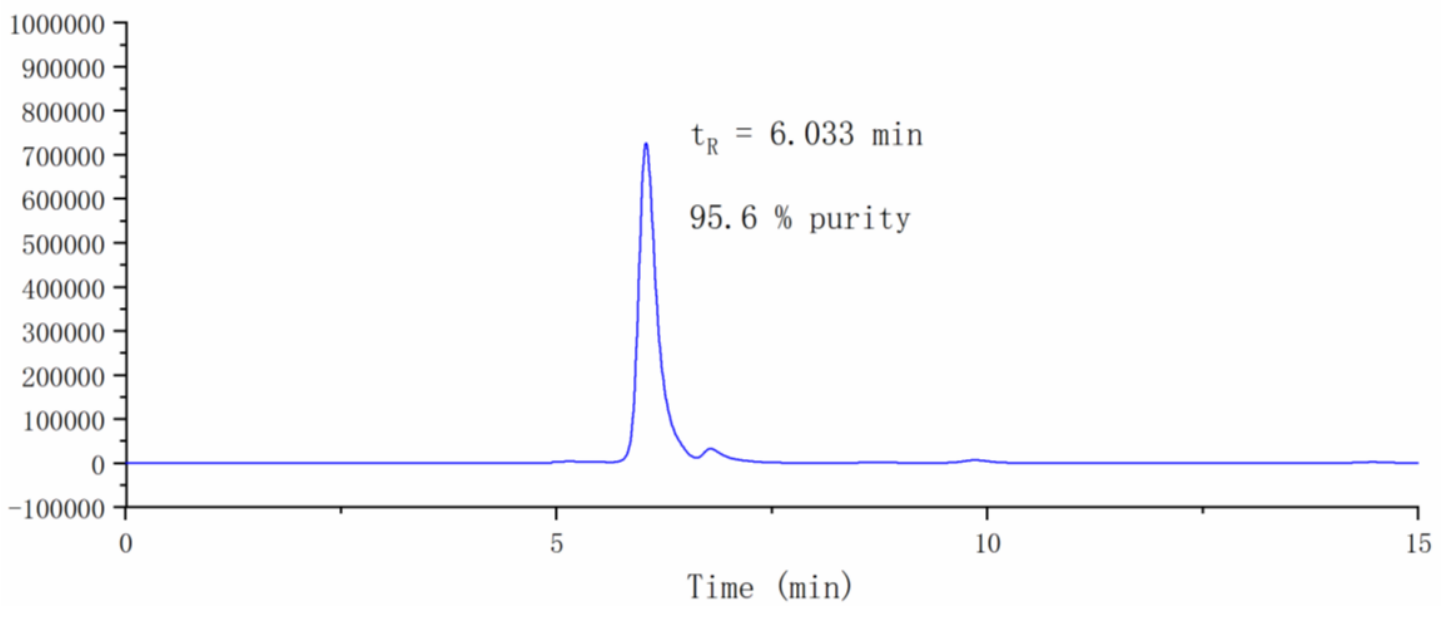

${ }^{1} \mathrm{H}$ NMR of compound S06-1010.

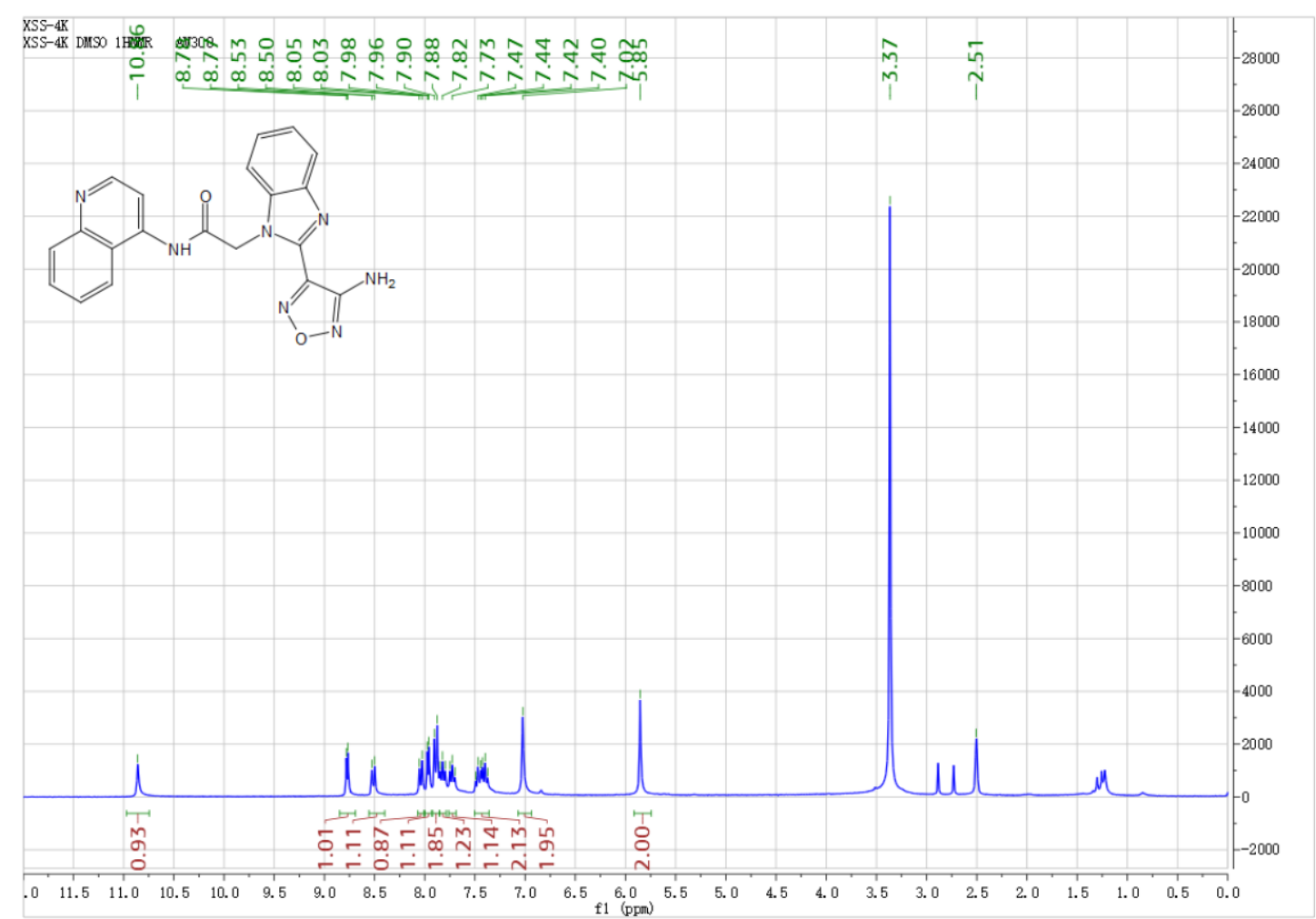

${ }^{13} \mathrm{C}$ NMR of compound S06-1010. 


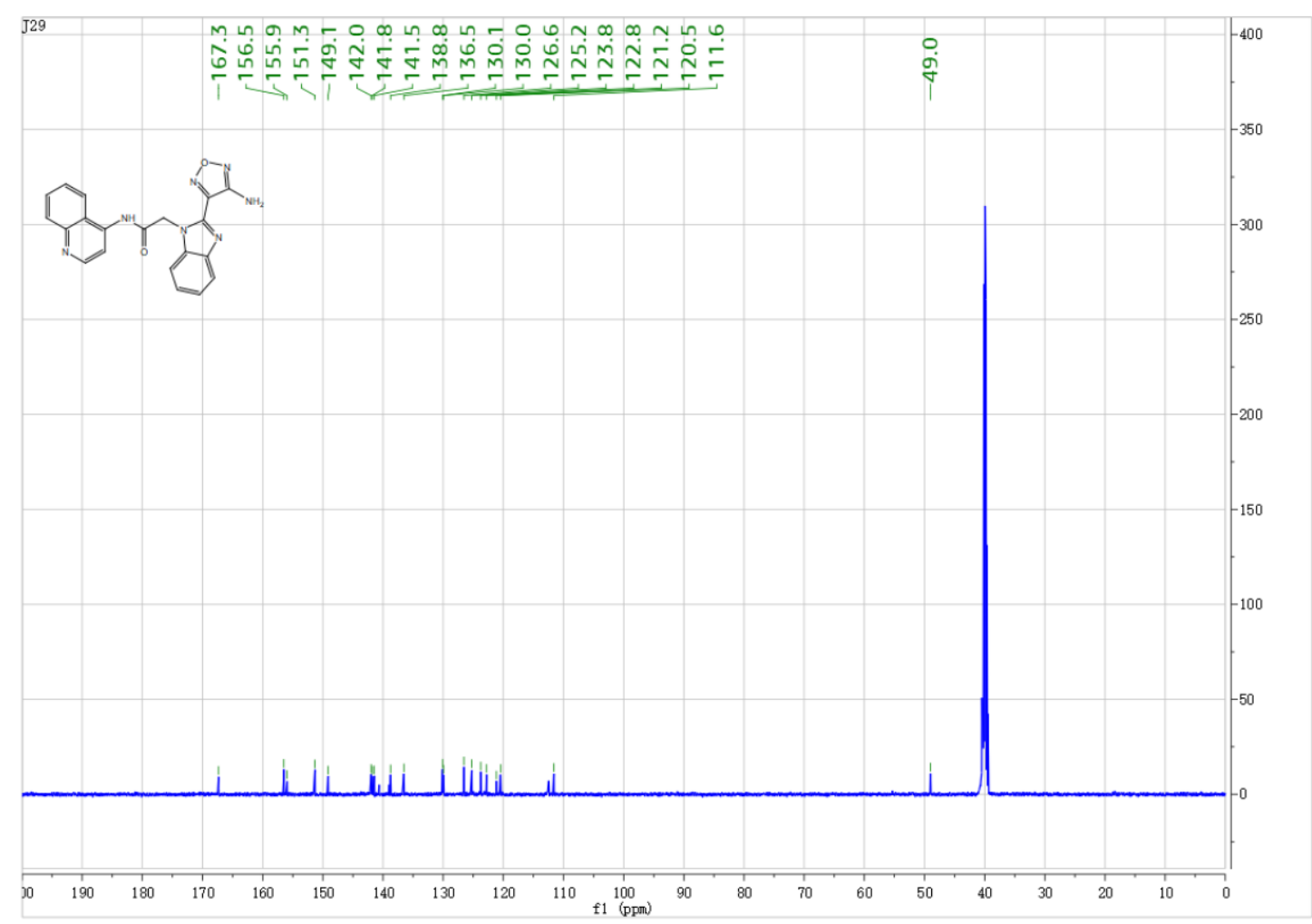

HRMS of compound S06-1010.

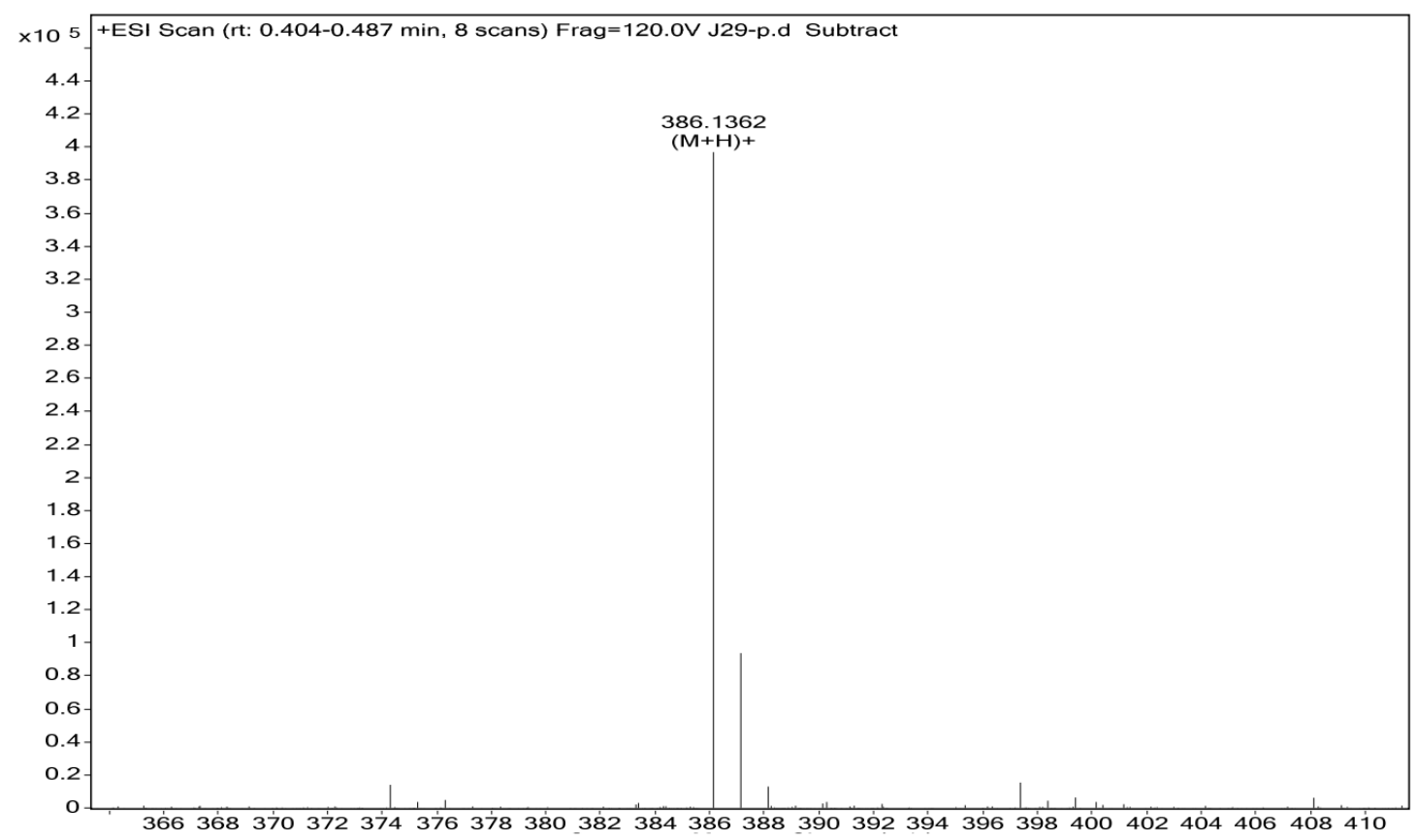


HPLC of compound S06-1011 $\left(t_{R}=2.84 \mathrm{~min}\right)$.

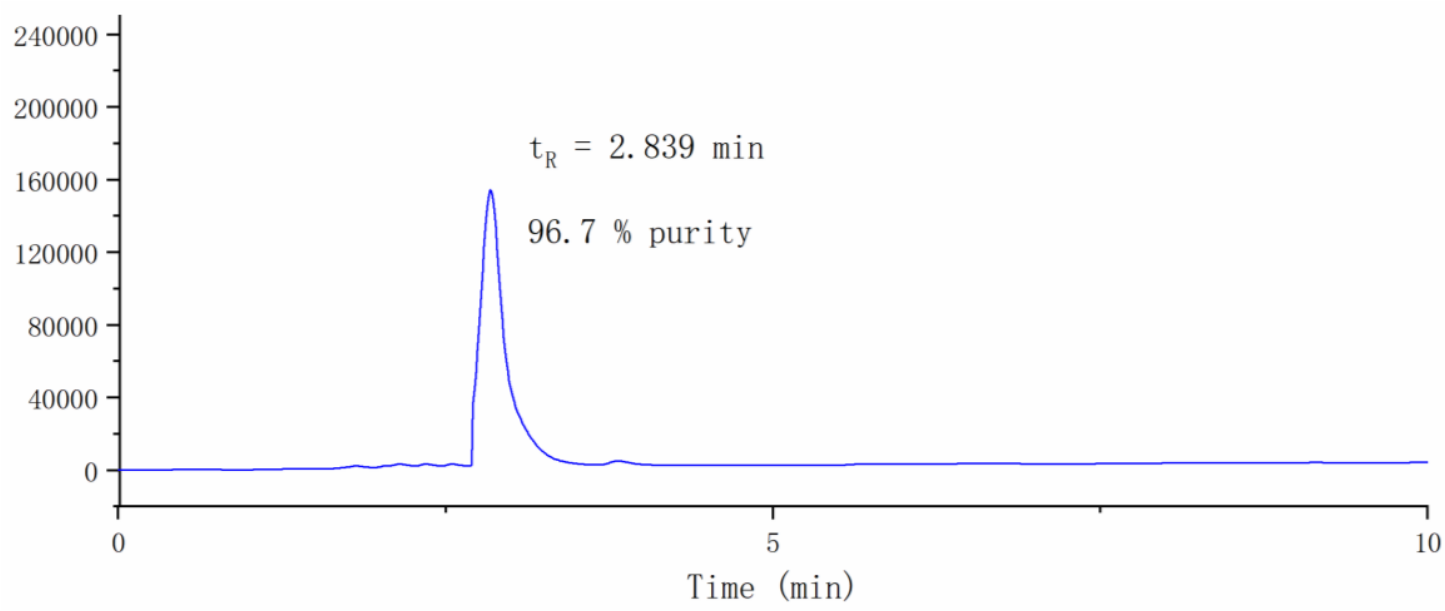

${ }^{1} \mathrm{H}$ NMR of compound S06-1011.

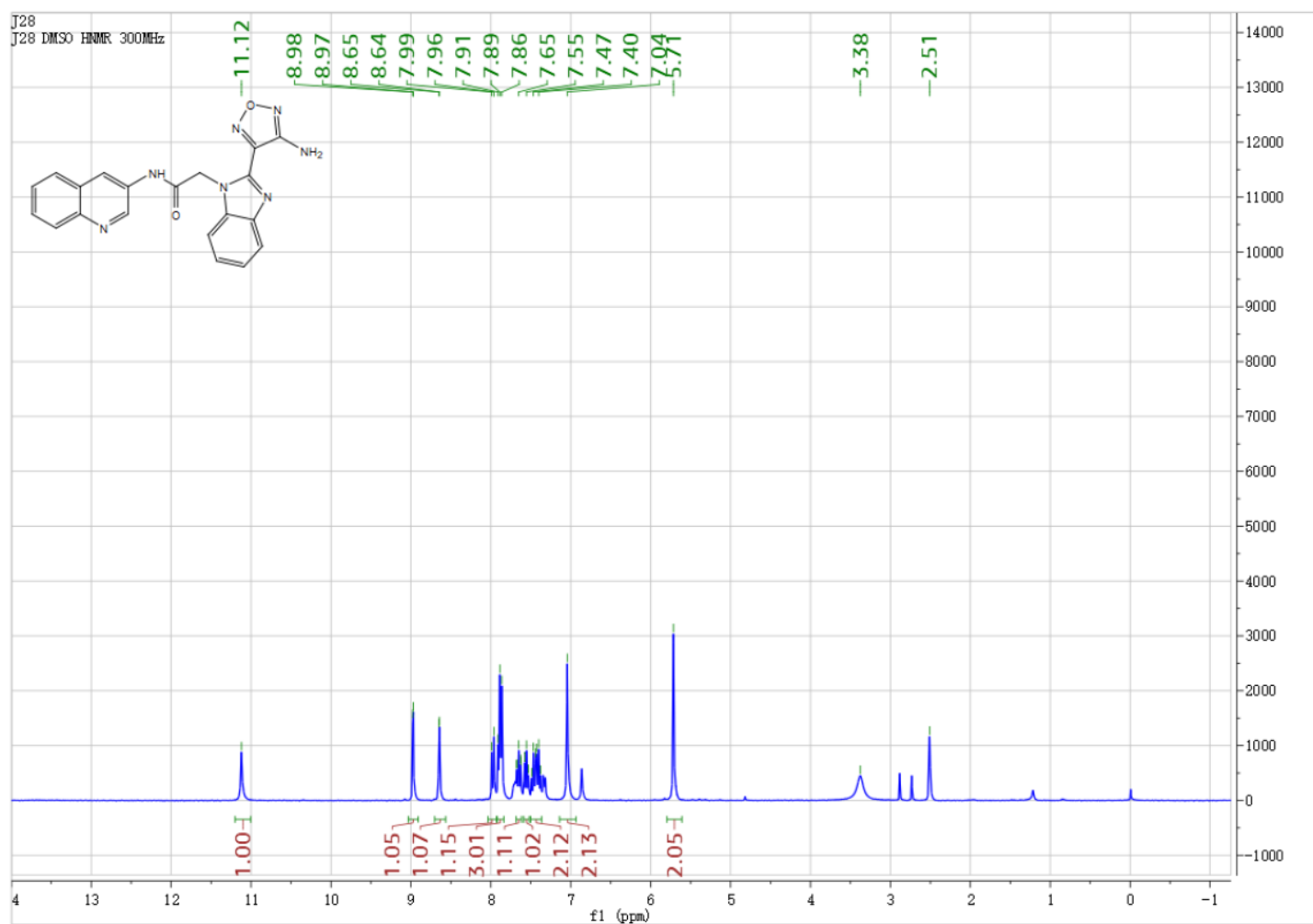

${ }^{13} \mathrm{C}$ NMR of compound S06-1011. 


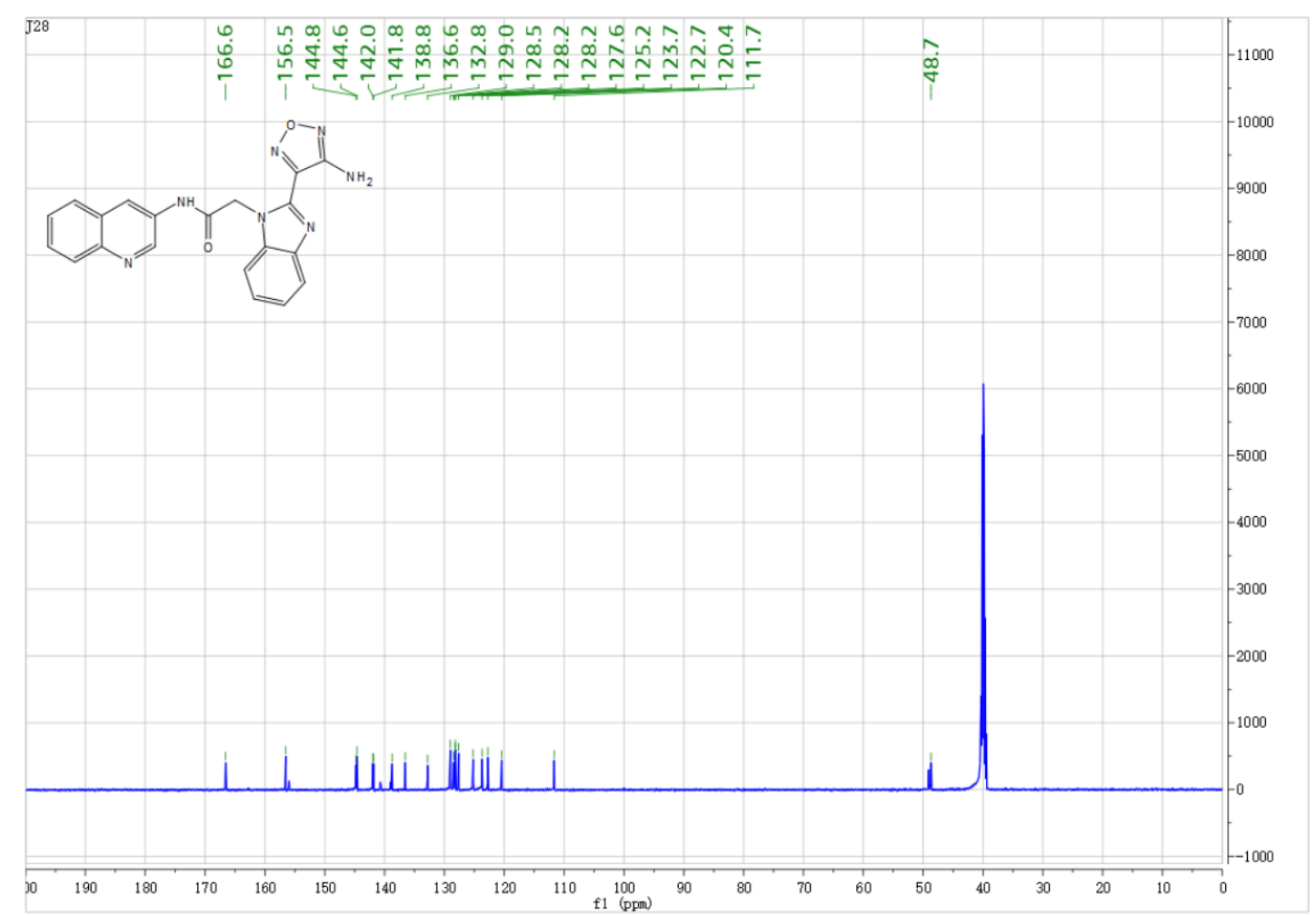

HRMS of compound S06-1011.

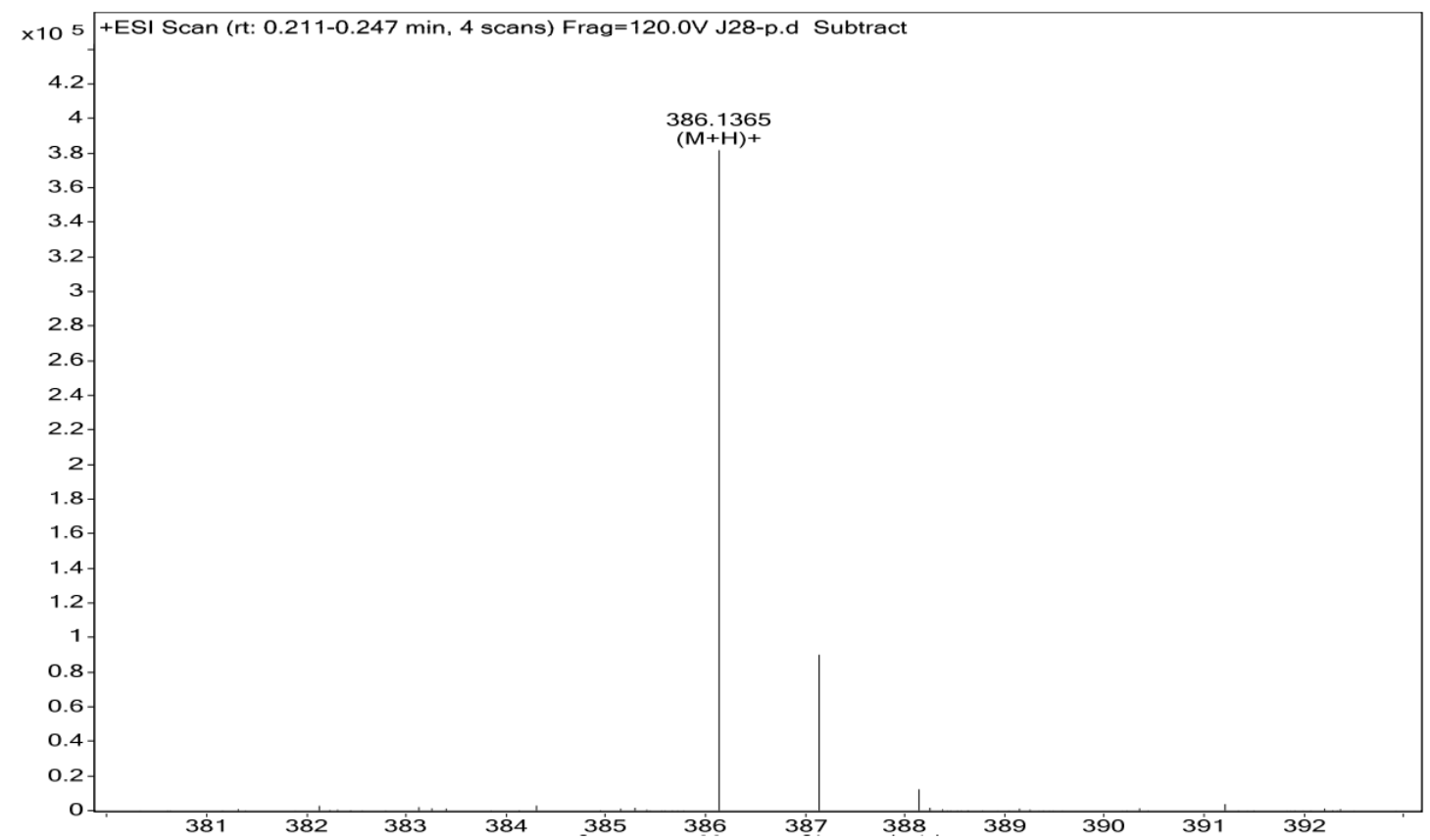


HPLC of compound S06-1012 $\left(\mathrm{t}_{\mathrm{R}}=19.84 \mathrm{~min}\right)$.

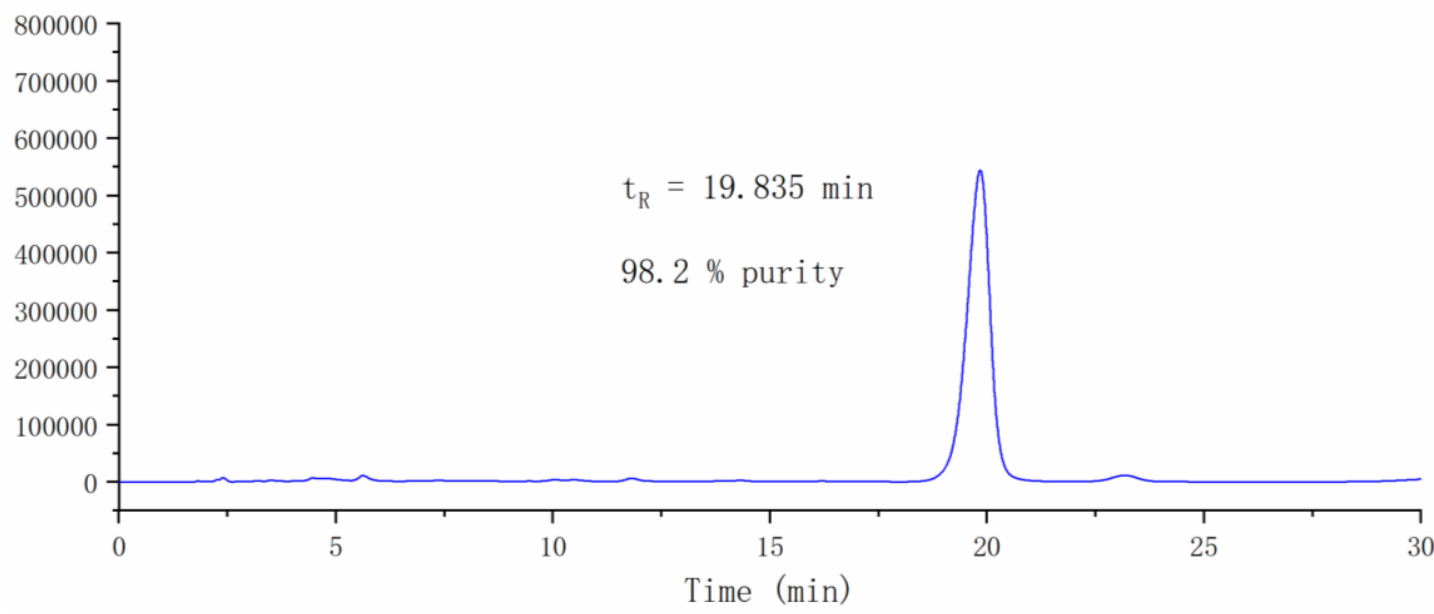

${ }^{1} \mathrm{H}$ NMR of compound S06-1012.

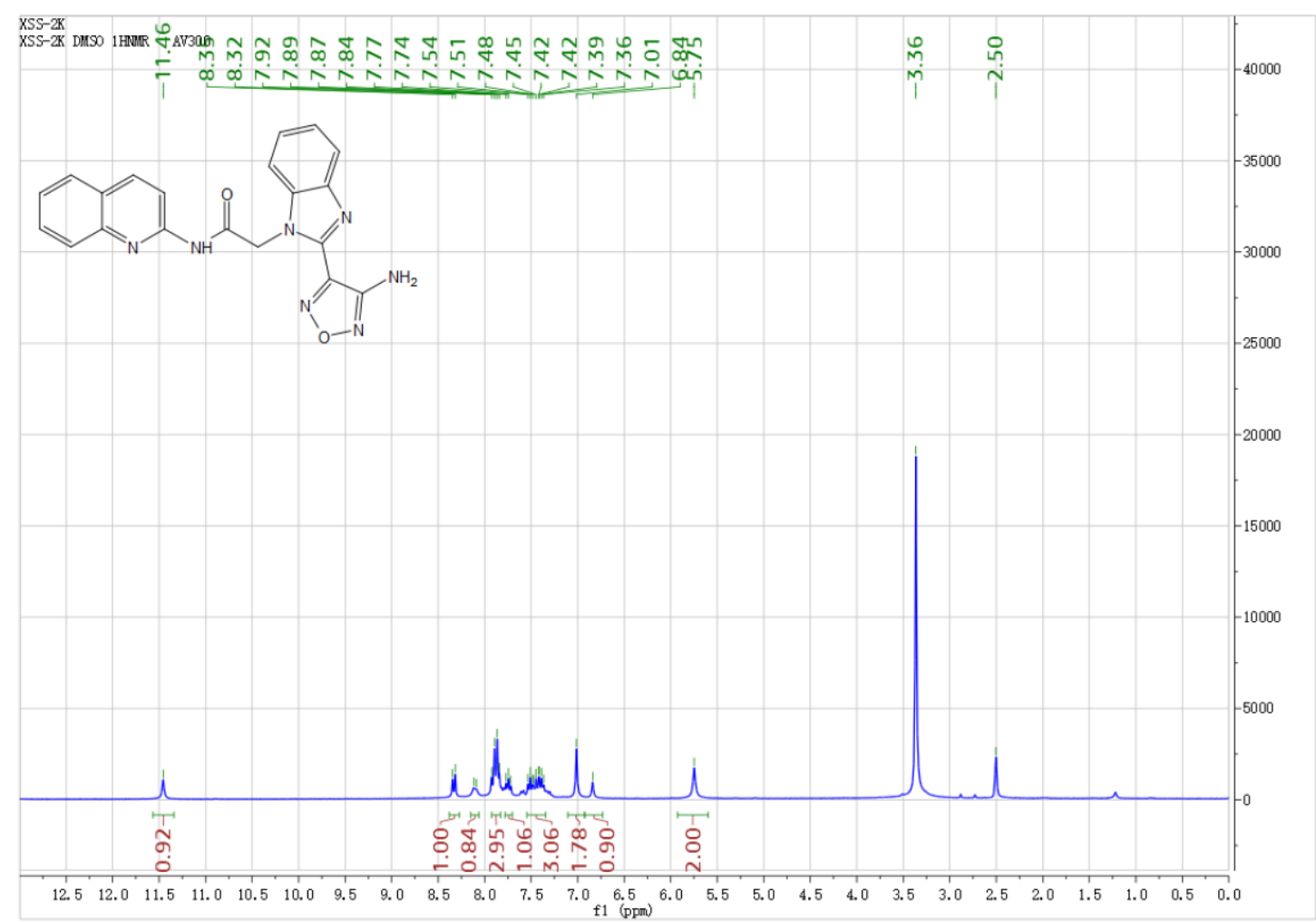

${ }^{13} \mathrm{C}$ NMR of compound S06-1012. 


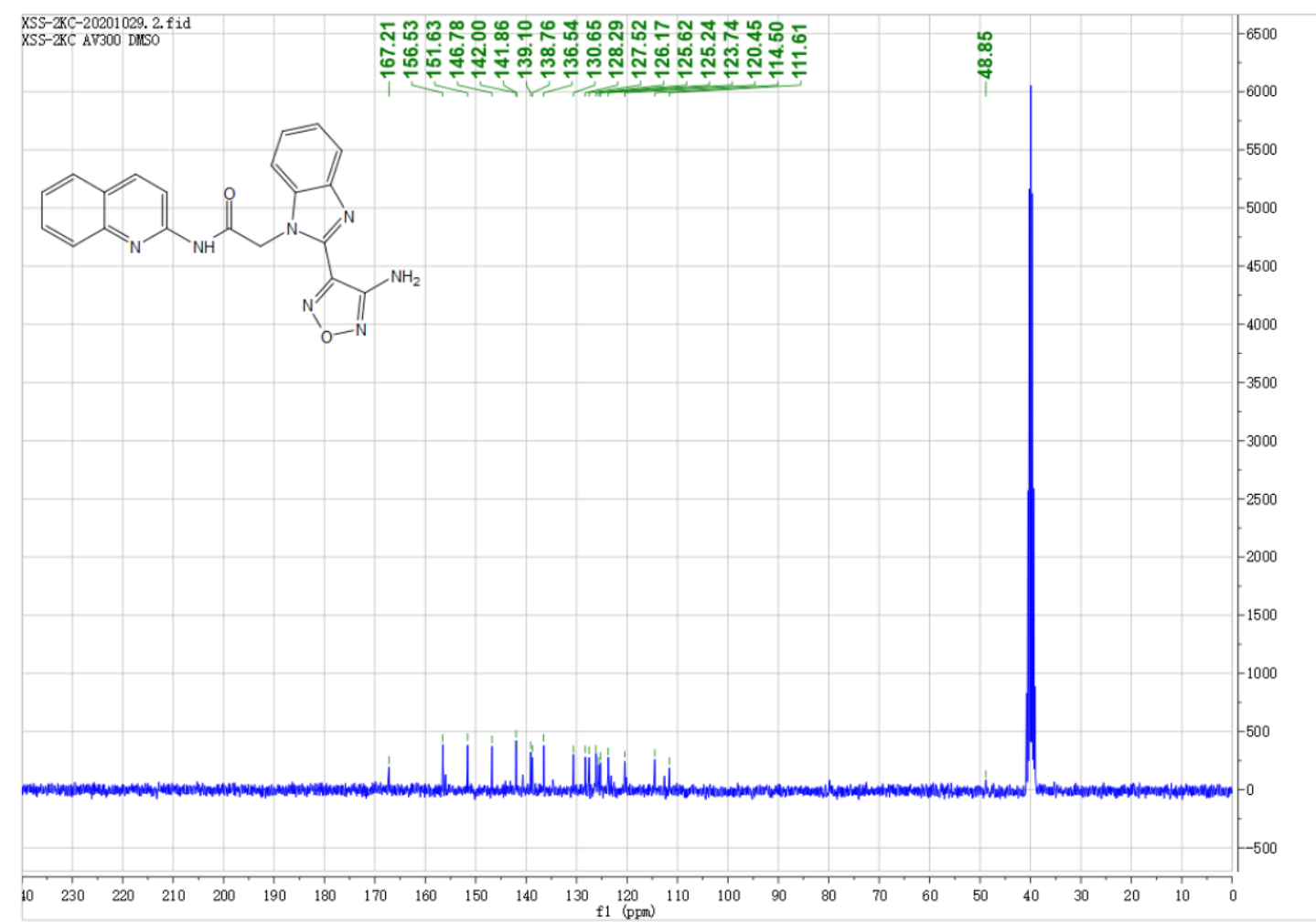

HRMS of compound S06-1012.

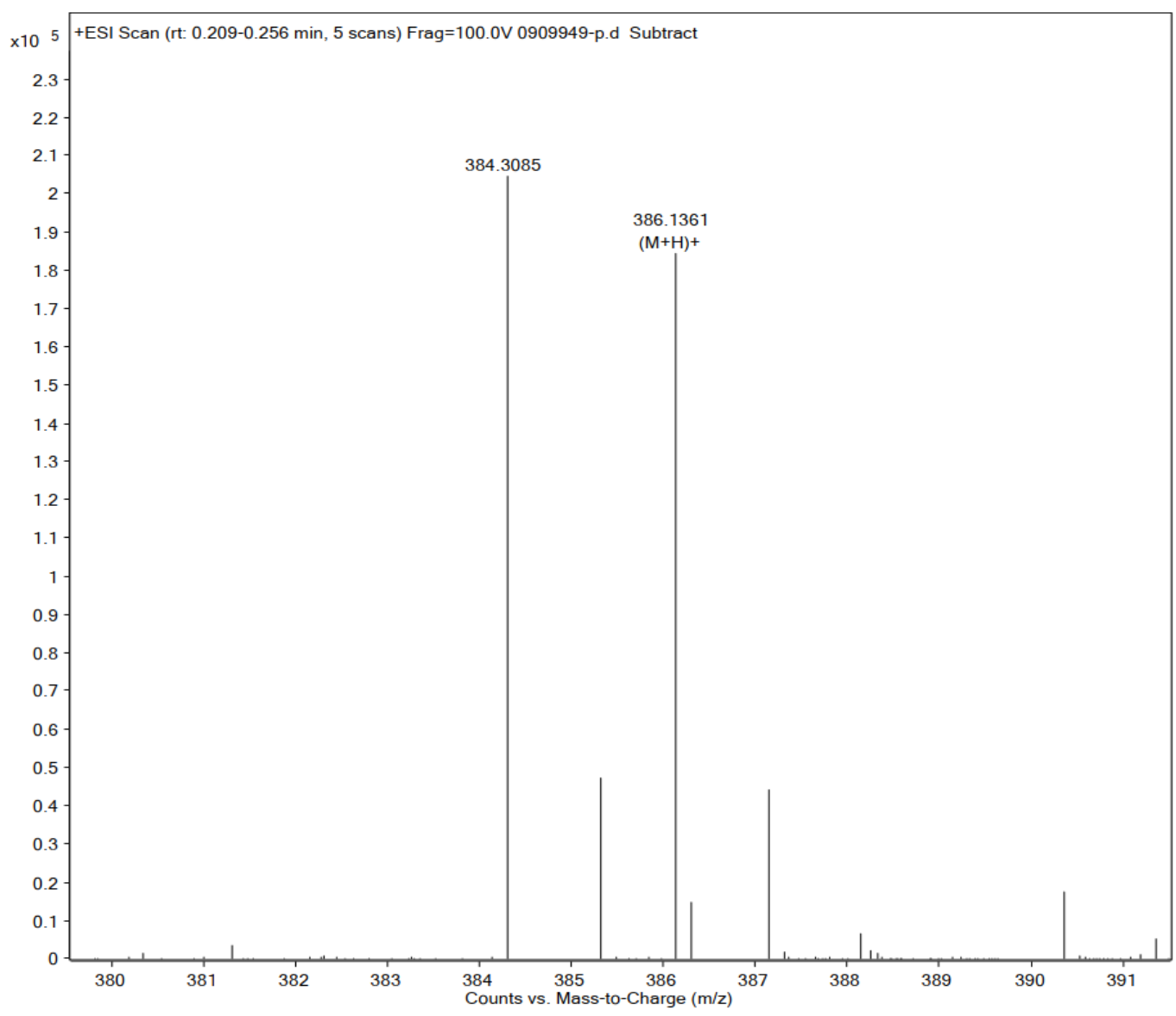


HPLC of compound S06-1013 $\left(t_{R}=5.46 \mathrm{~min}\right)$.

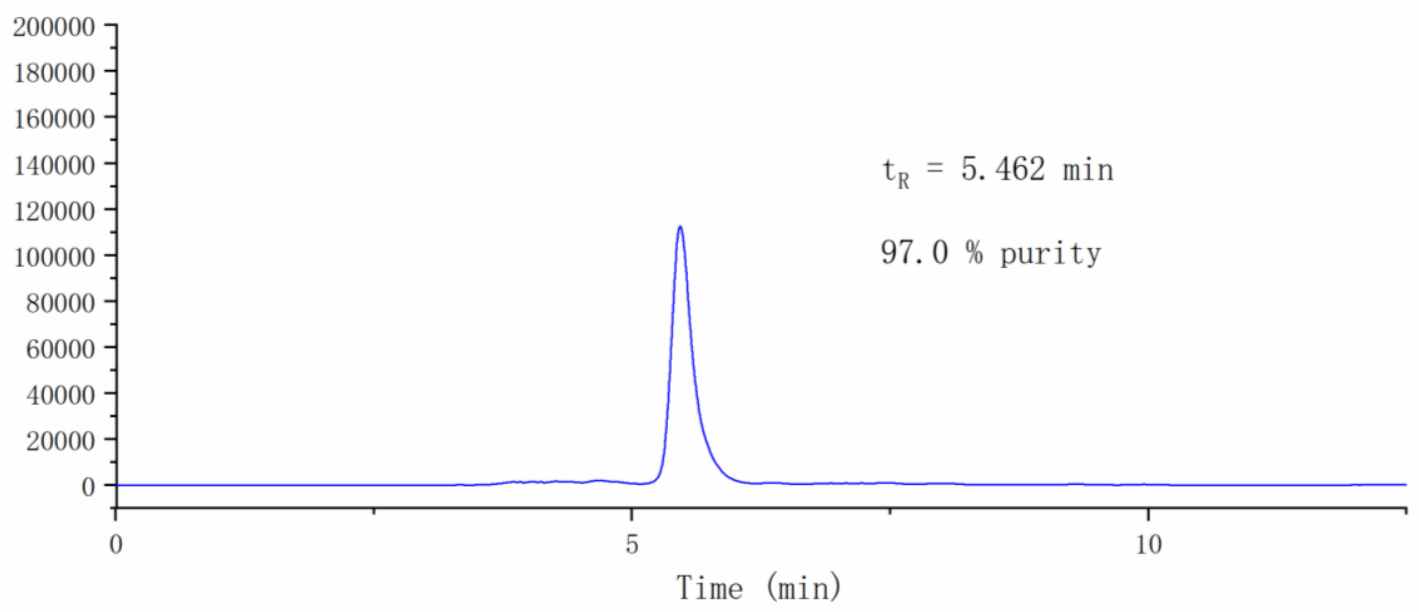

${ }^{1} \mathrm{H}$ NMR of compound S06-1013.

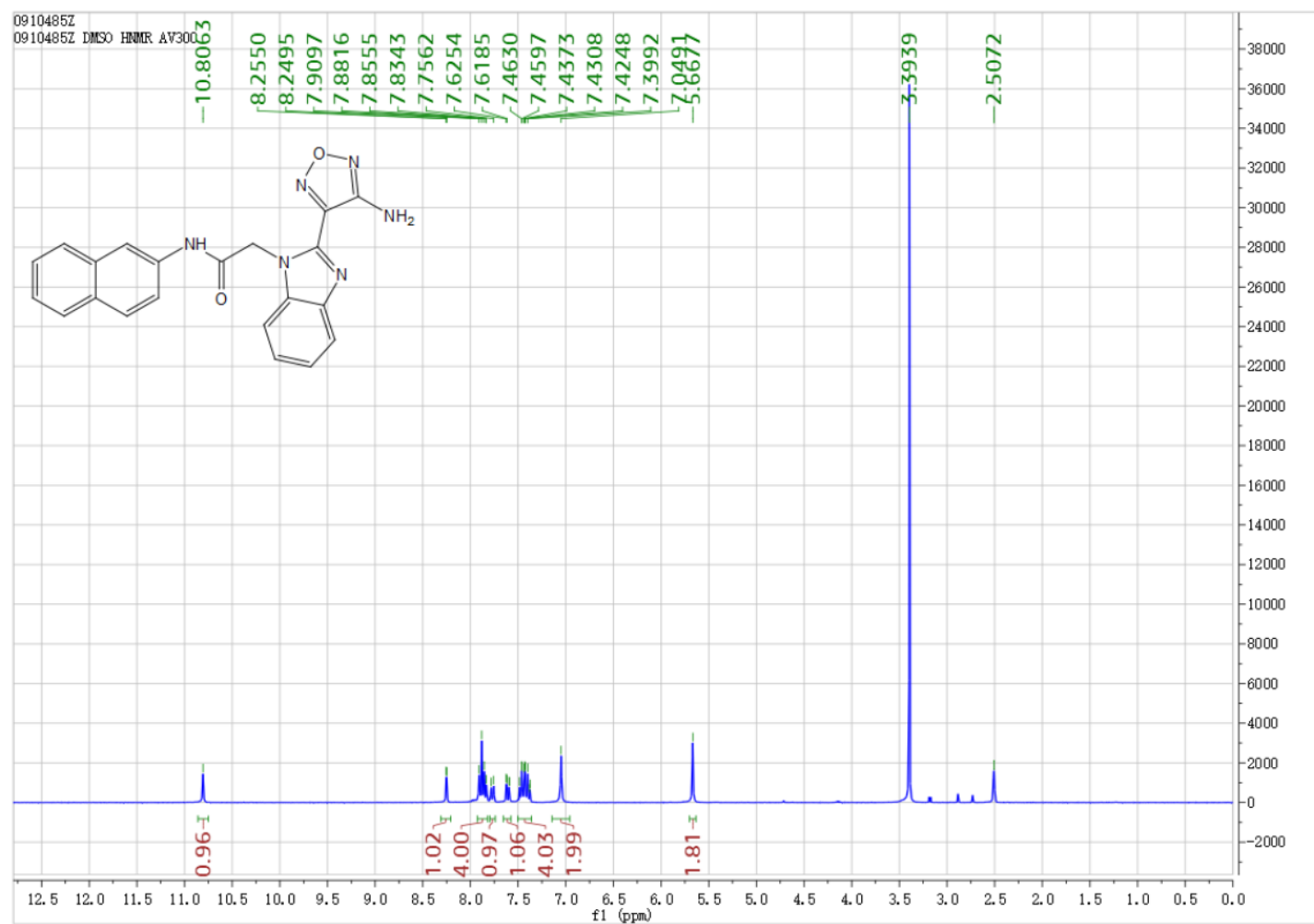

${ }^{13} \mathrm{C}$ NMR of compound S06-1013. 


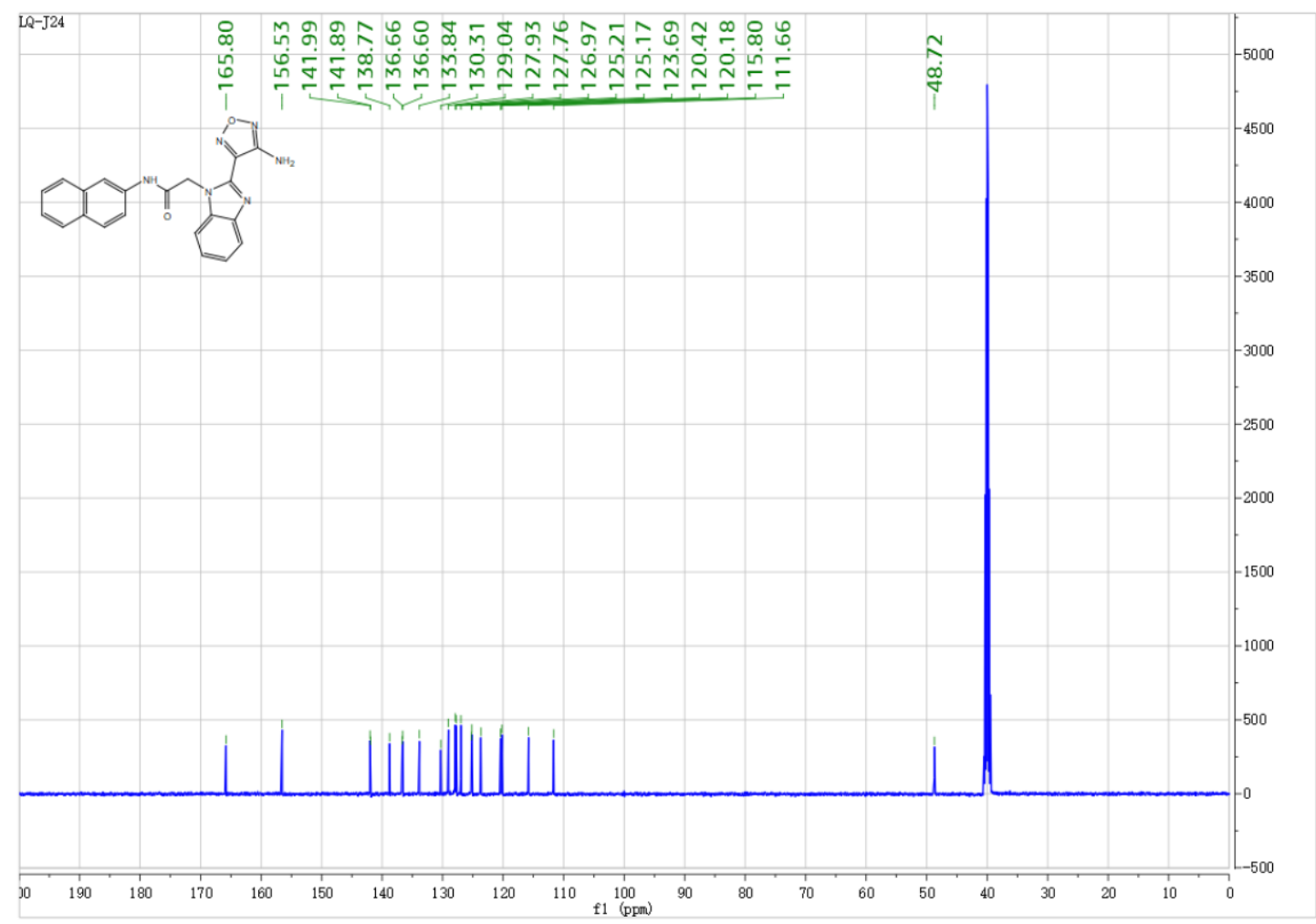

HRMS of compound S06-1013.

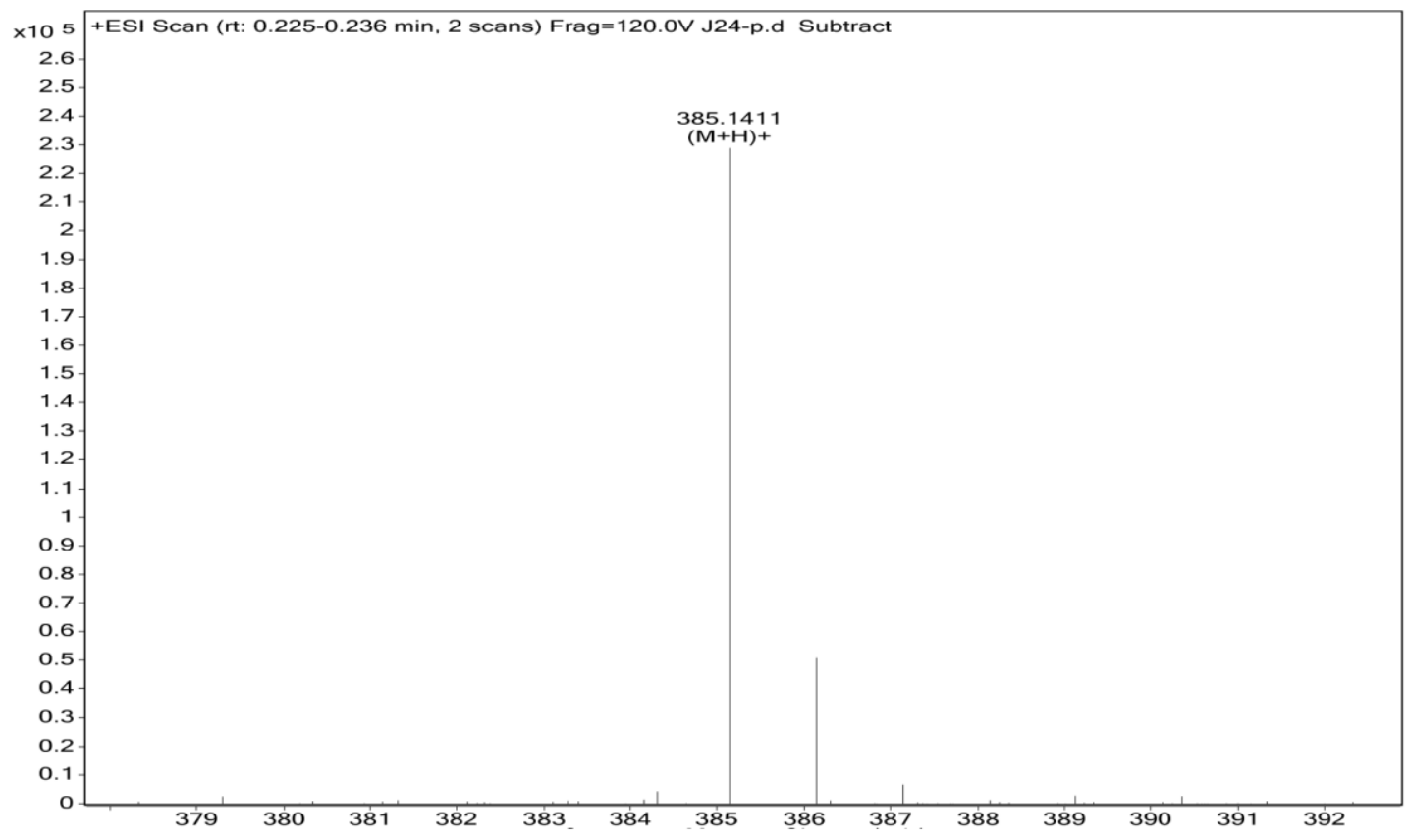


HPLC of compound S06-1014 $\left(t_{R}=6.71 \mathrm{~min}\right)$.

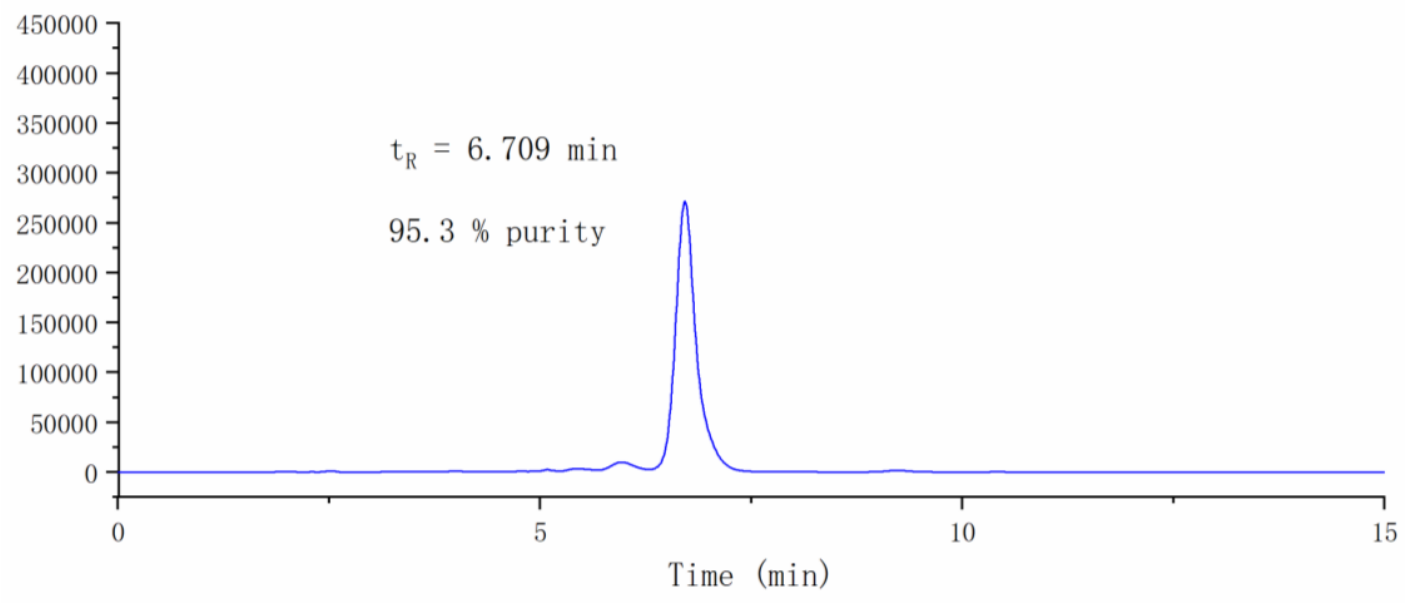

${ }^{1} \mathrm{H}$ NMR of compound S06-1014.

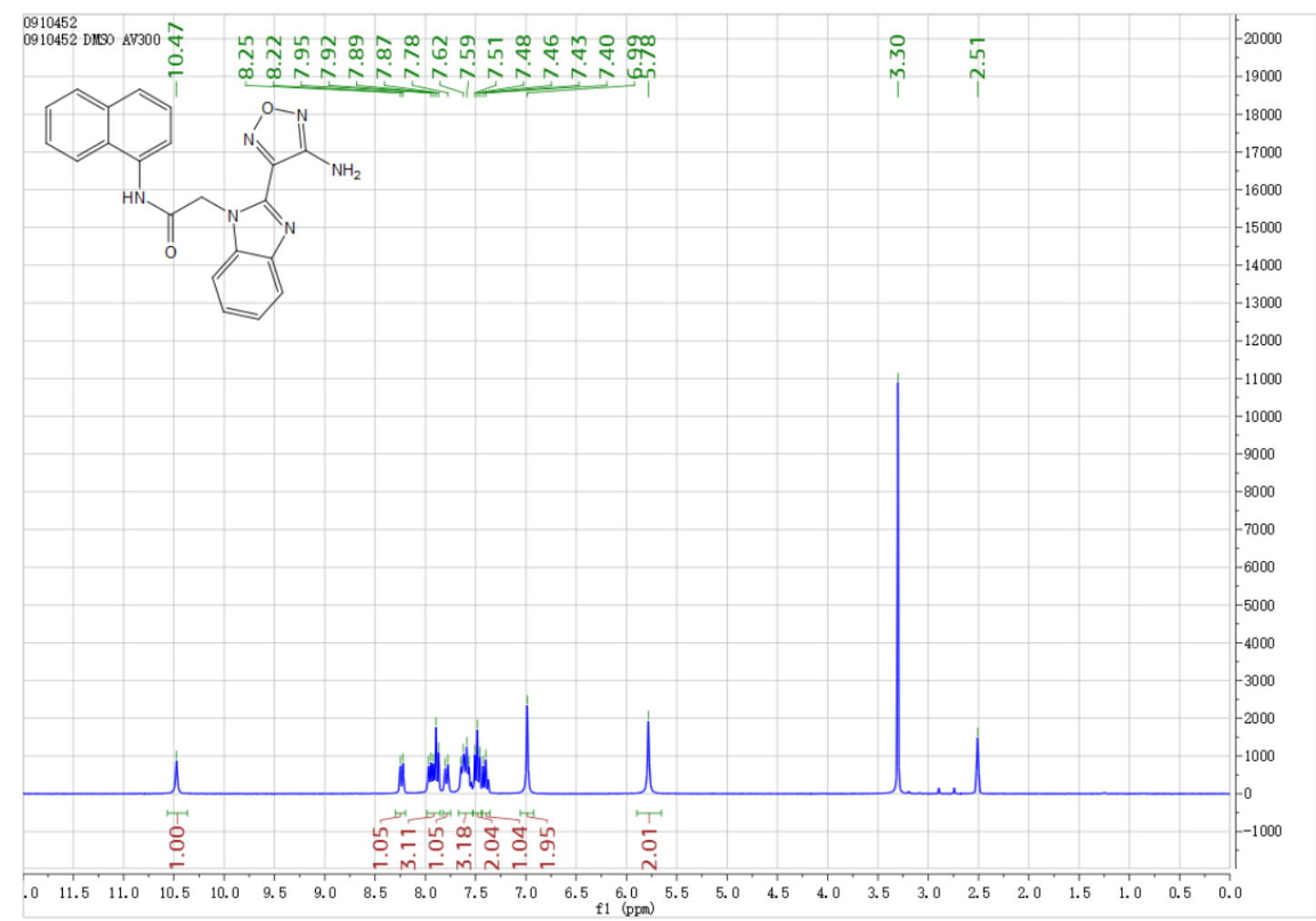

${ }^{13} \mathrm{C}$ NMR of compound S06-1014. 


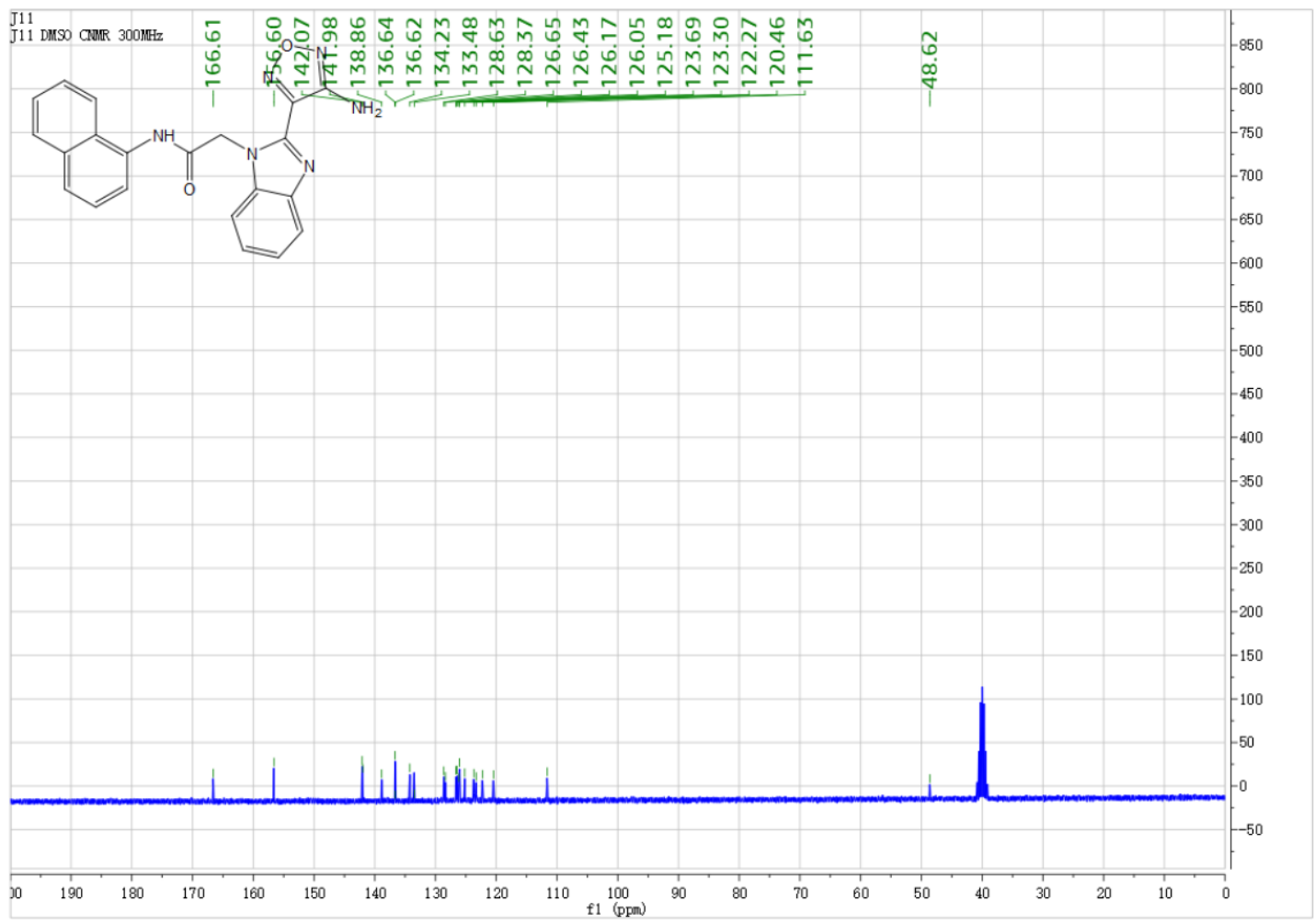

HRMS of compound S06-1014.

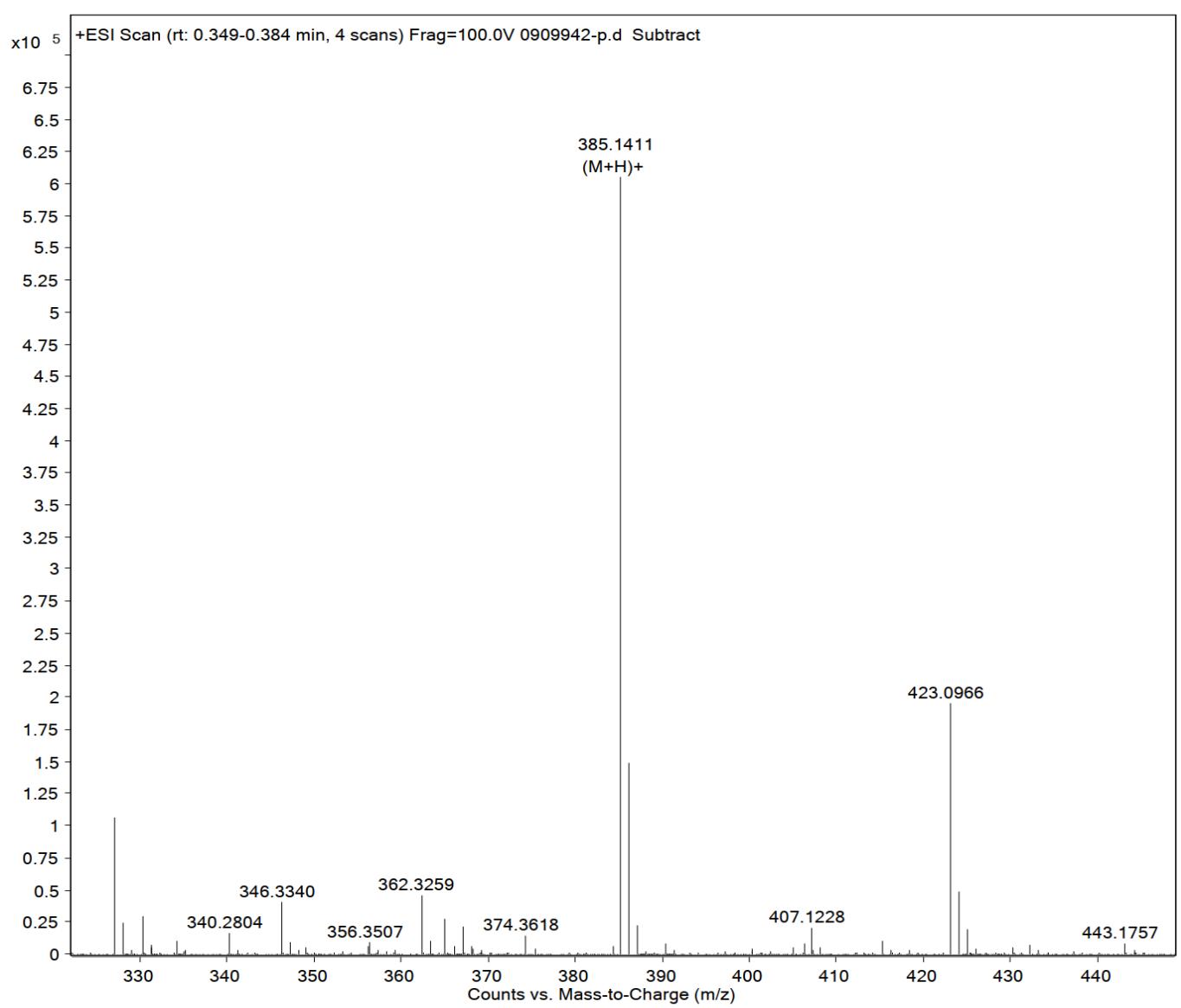


HPLC of compound S06-1015 $\left(t_{R}=7.72 \mathrm{~min}\right)$.

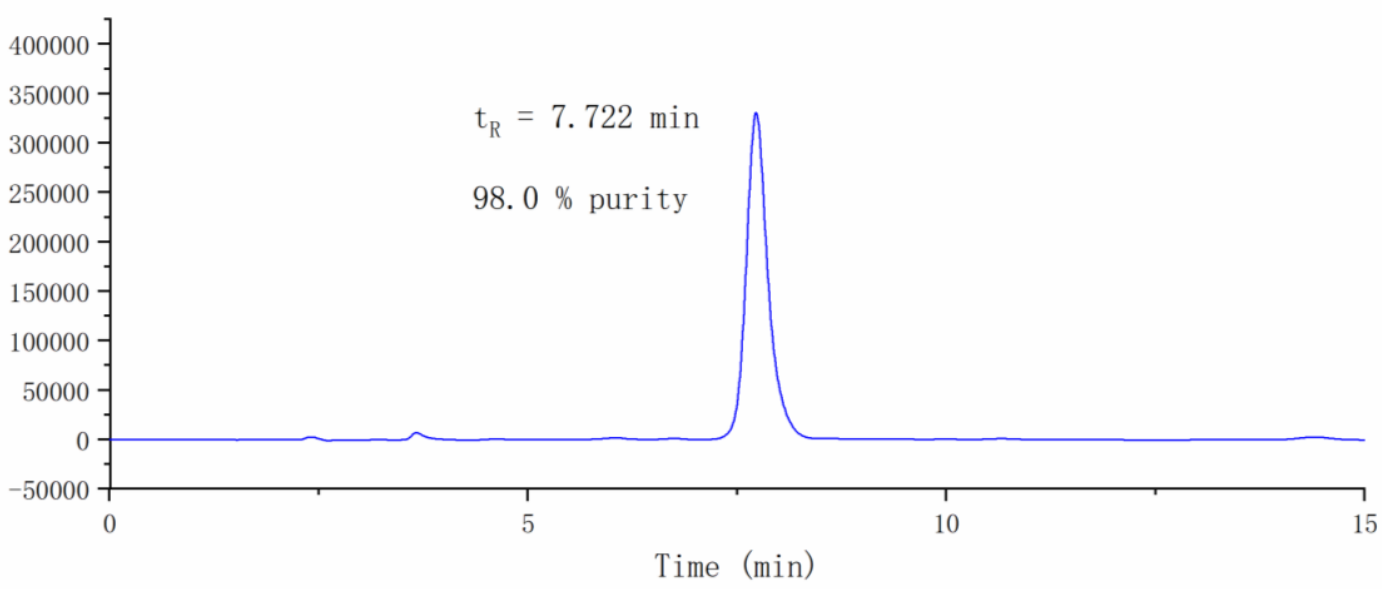

${ }^{1} \mathrm{H}$ NMR of compound S06-1015.

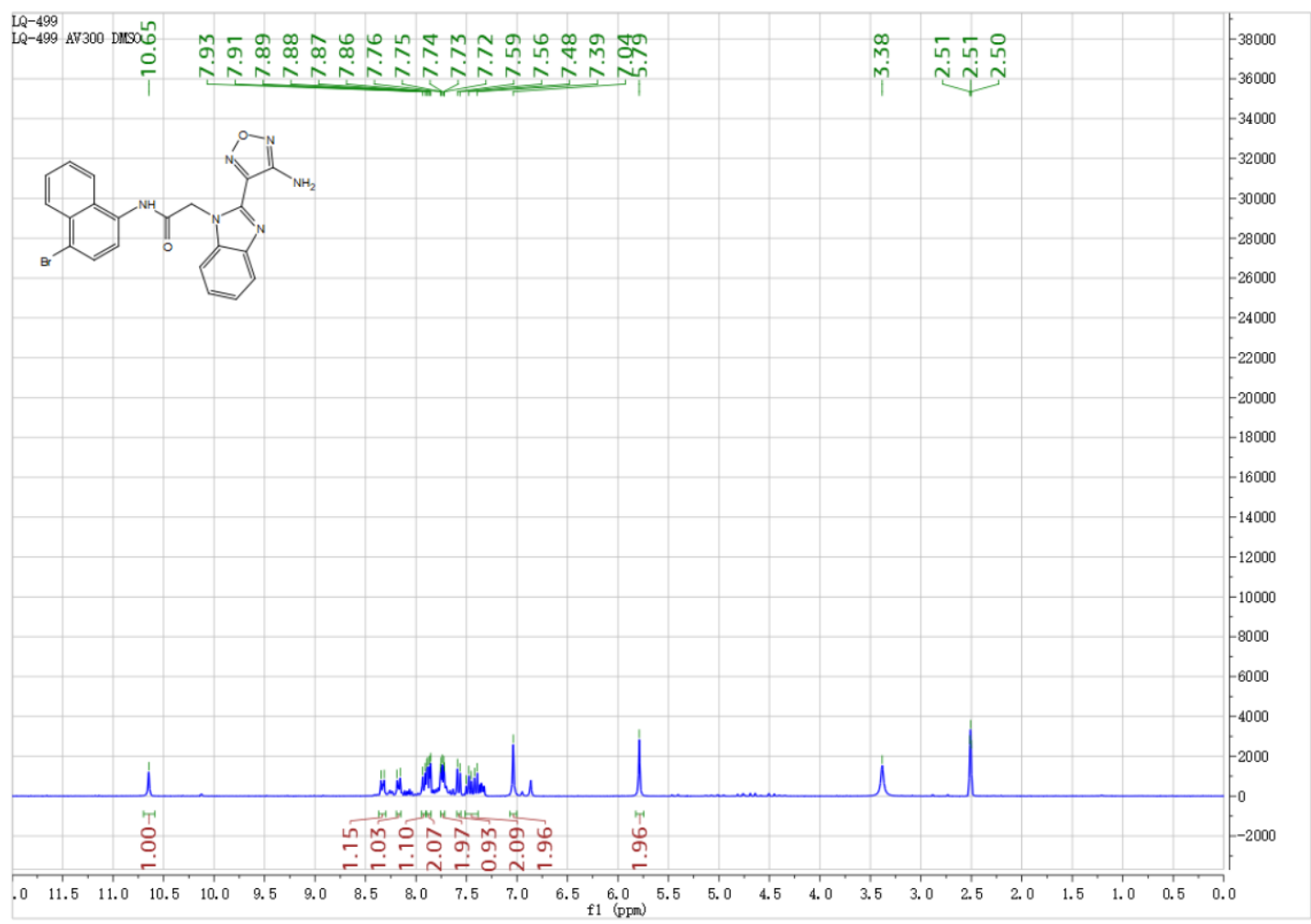

${ }^{13} \mathrm{C}$ NMR of compound S06-1015. 


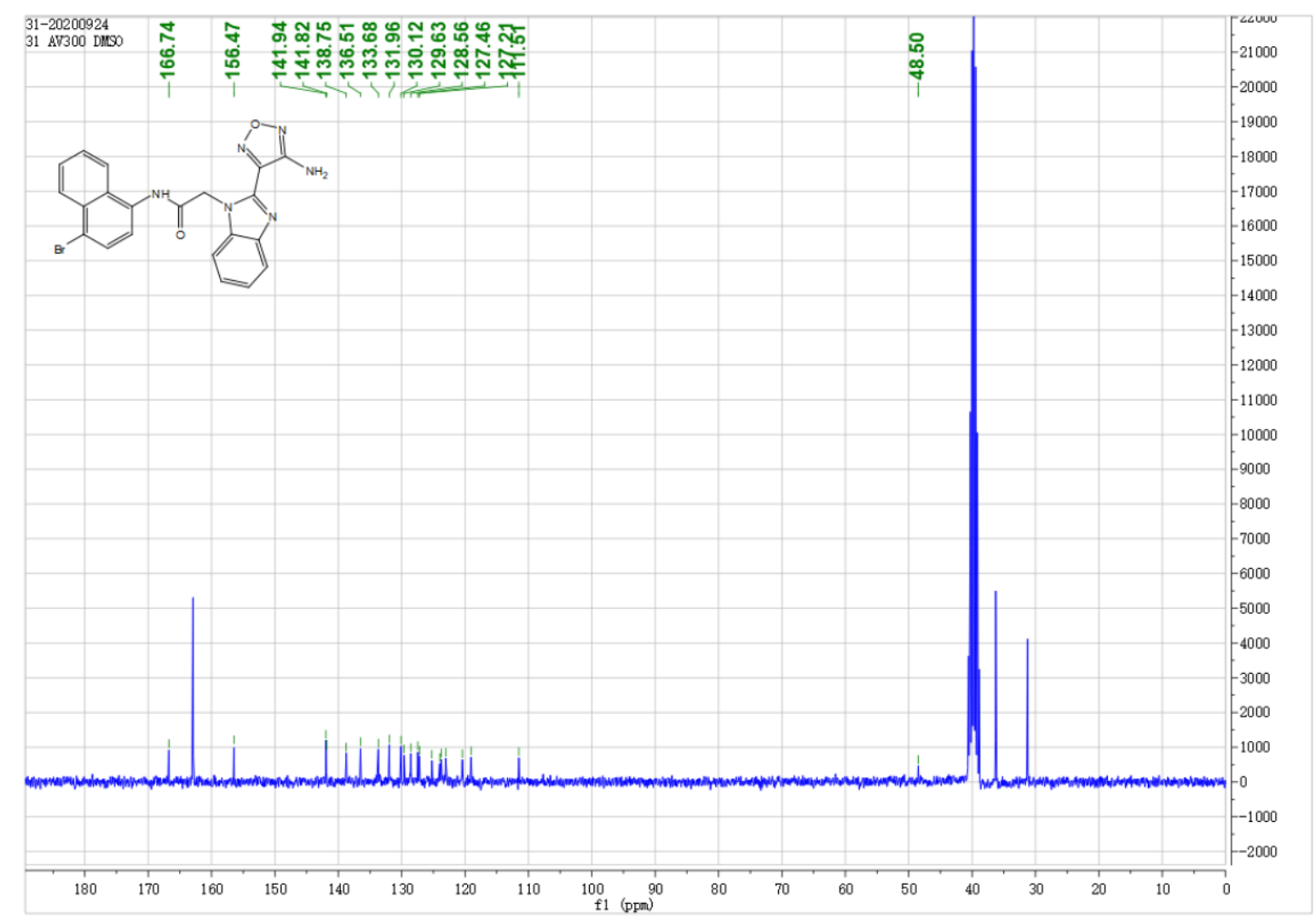

HRMS of compound S06-1015.

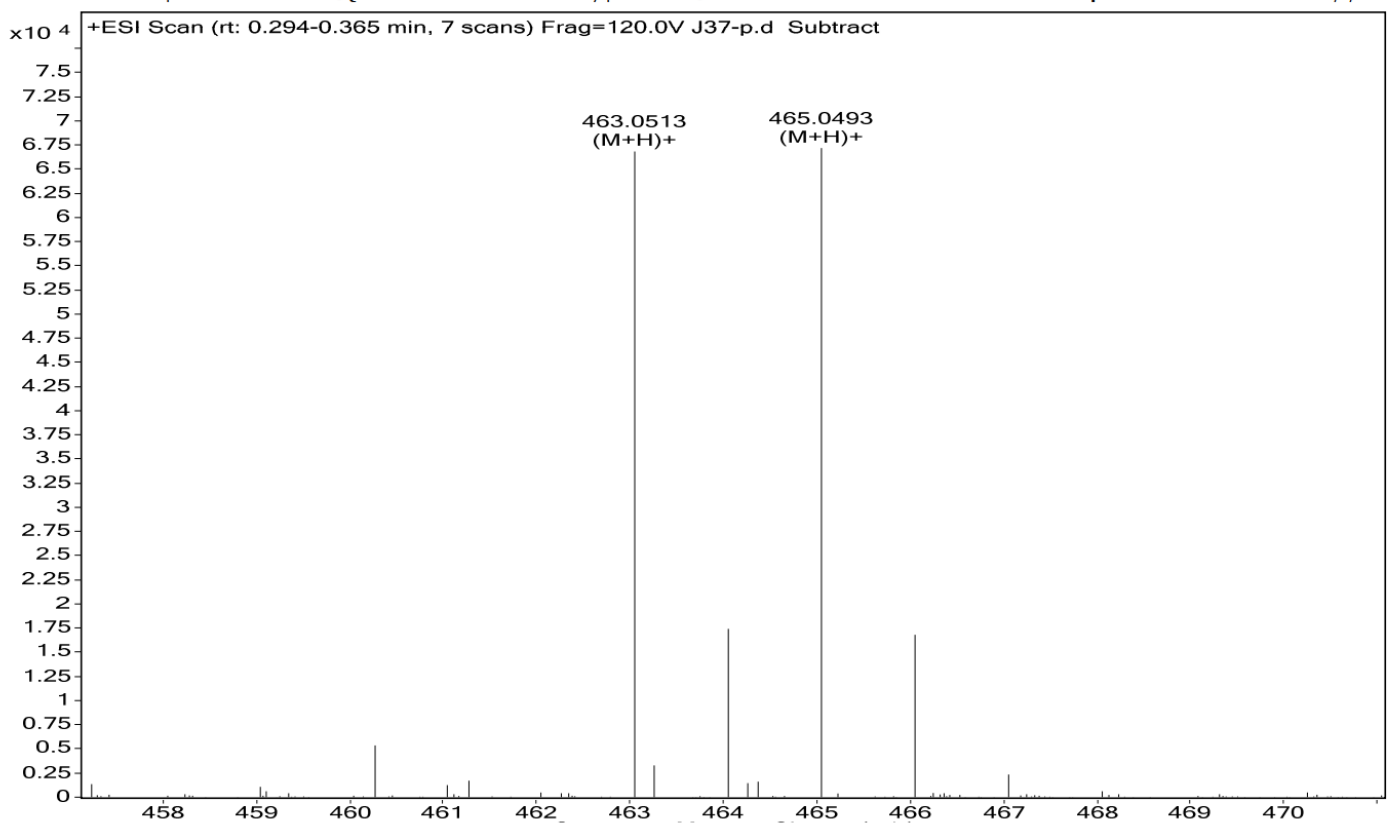


HPLC of compound S06-1016 $\left(t_{R}=5.38 \mathrm{~min}\right)$.

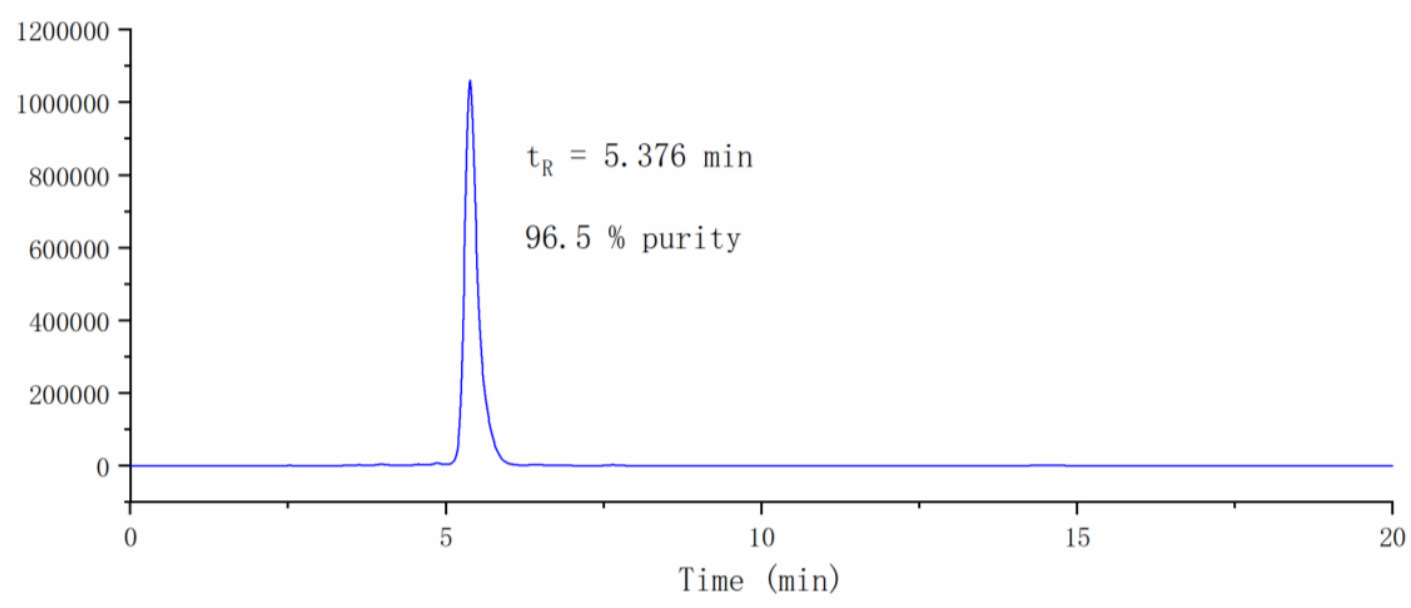

${ }^{1} \mathrm{H}$ NMR of compound S06-1016.

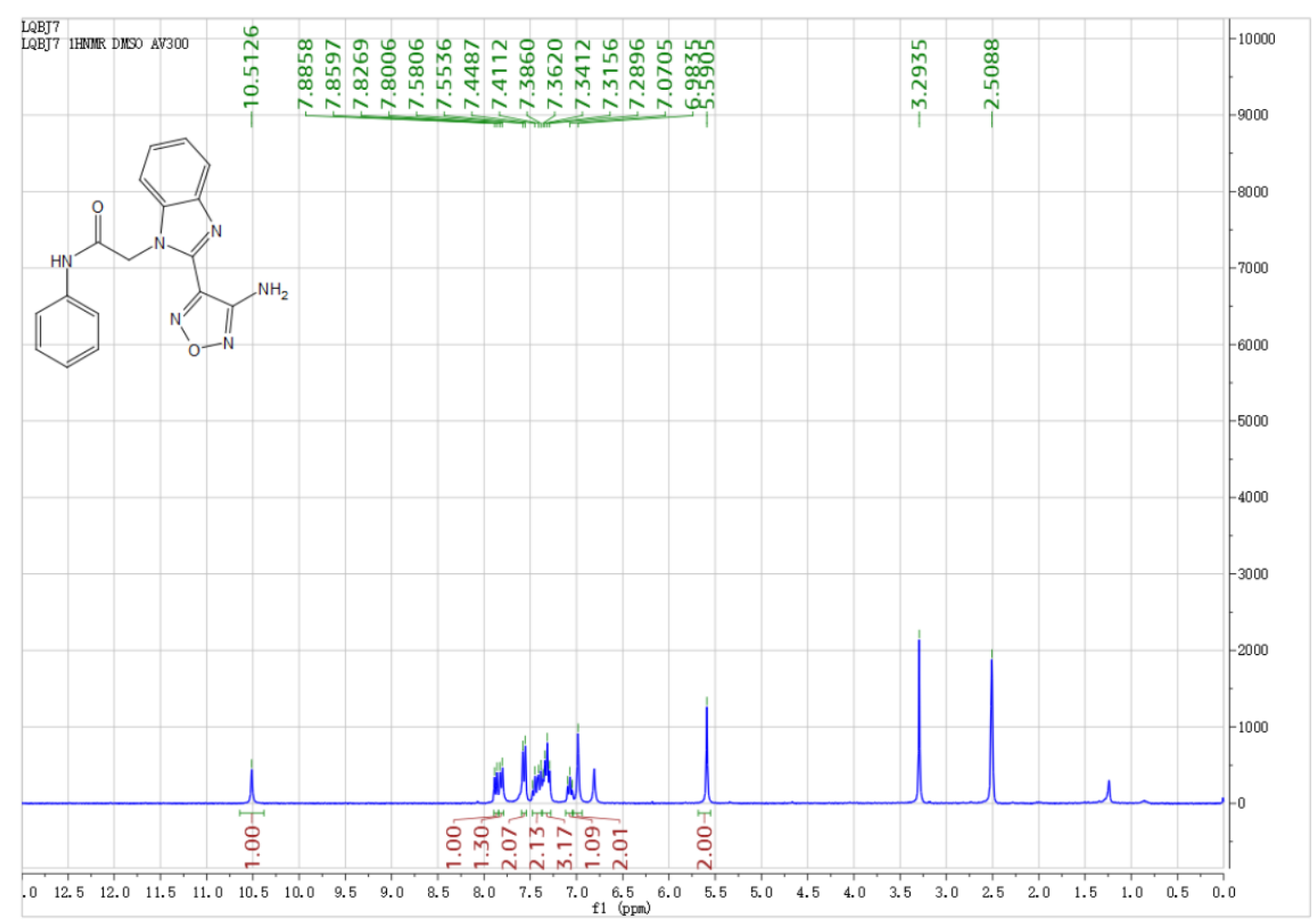

${ }^{13} \mathrm{C}$ NMR of compound S06-1016. 


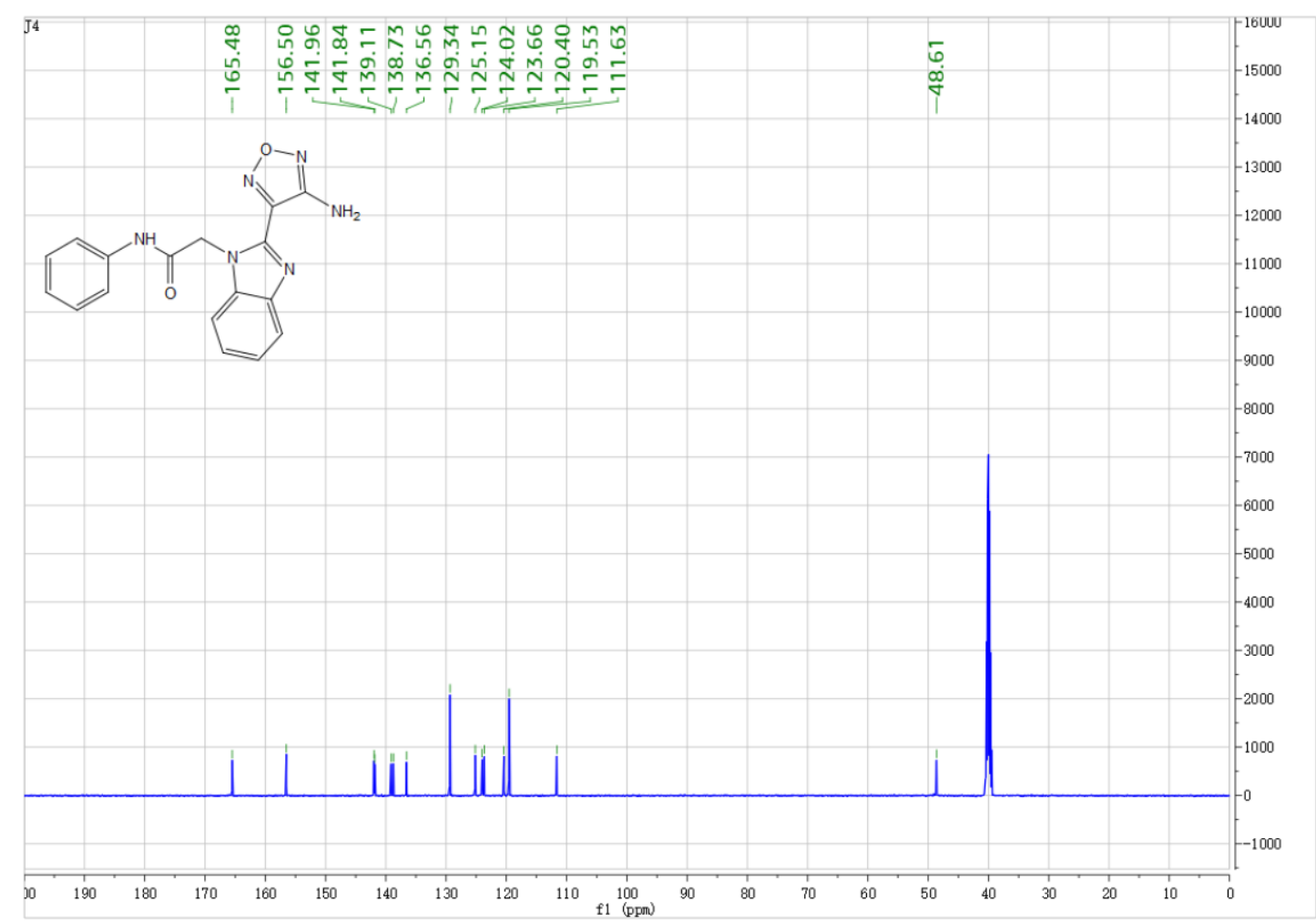

HRMS of compound S06-1016.

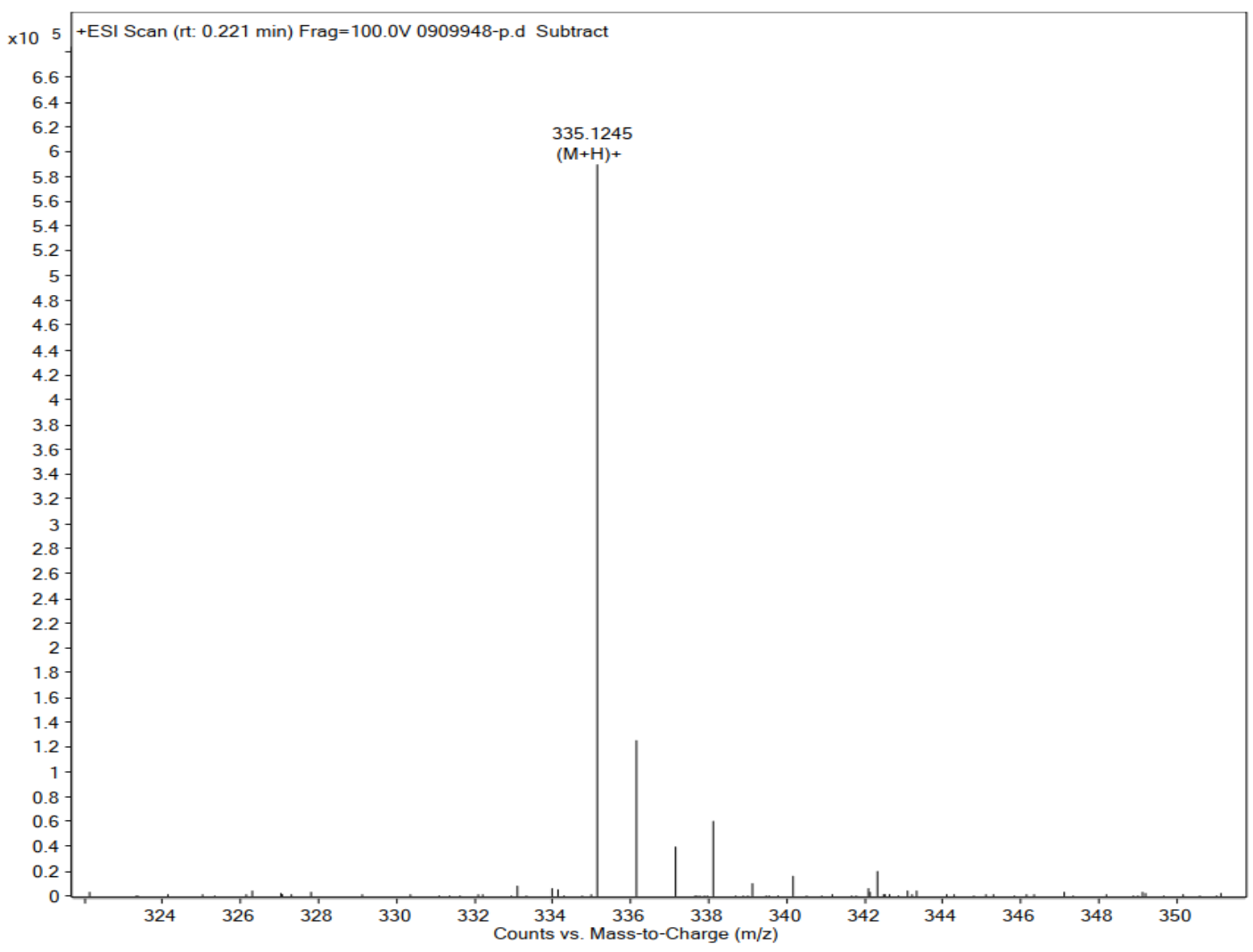


HPLC of compound S06-1017 $\left(t_{R}=9.04 \mathrm{~min}\right)$.

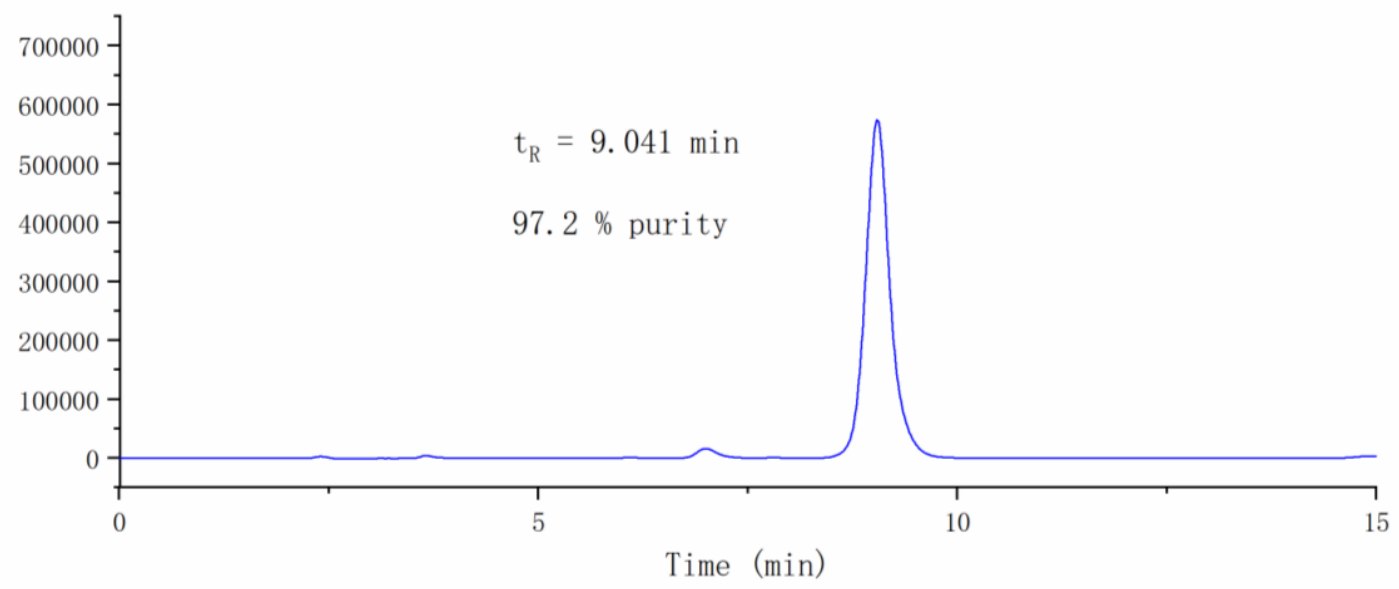

${ }^{1} \mathrm{H}$ NMR of compound S06-1017.

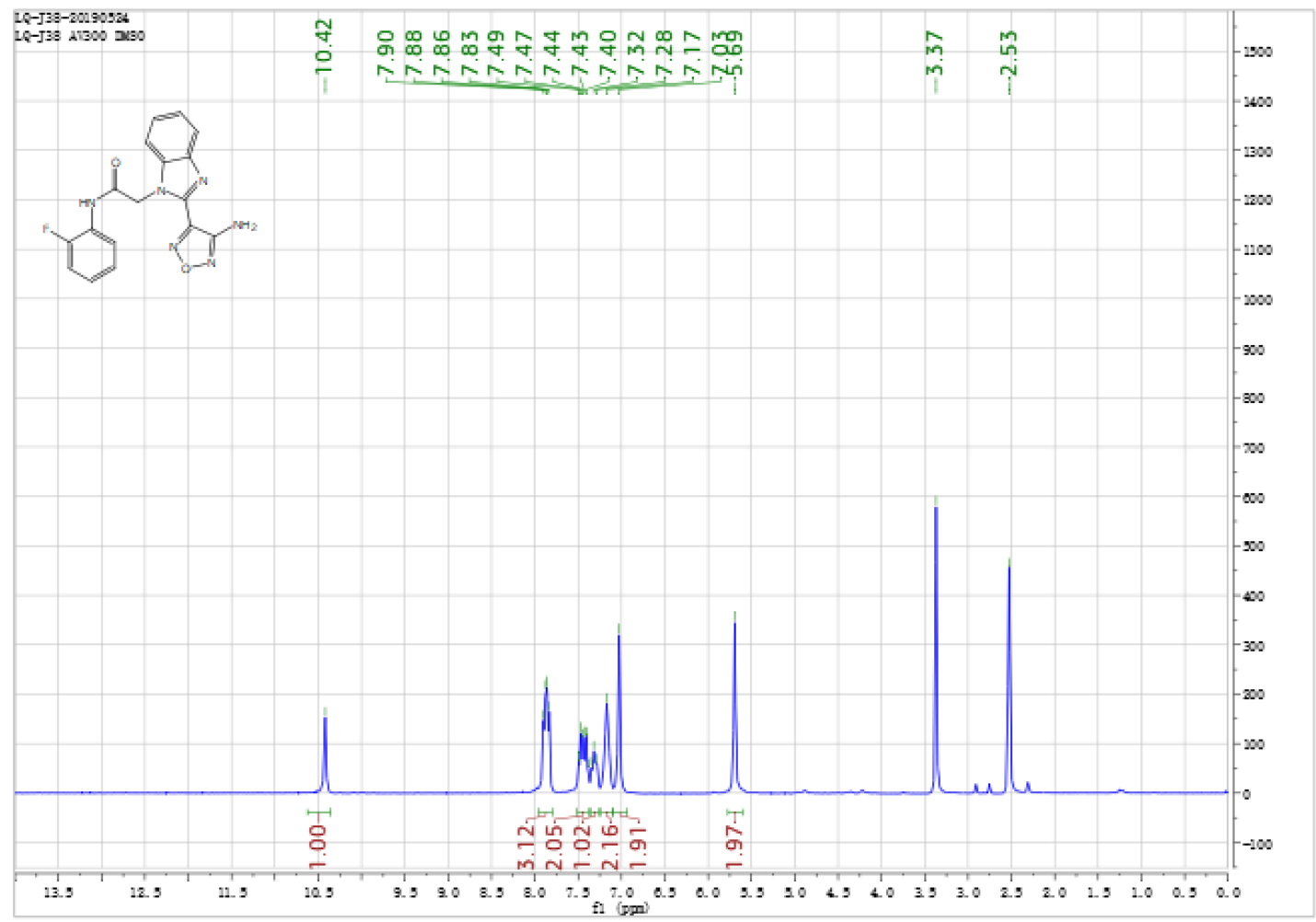

${ }^{13} \mathrm{C}$ NMR of compound S06-1017. 


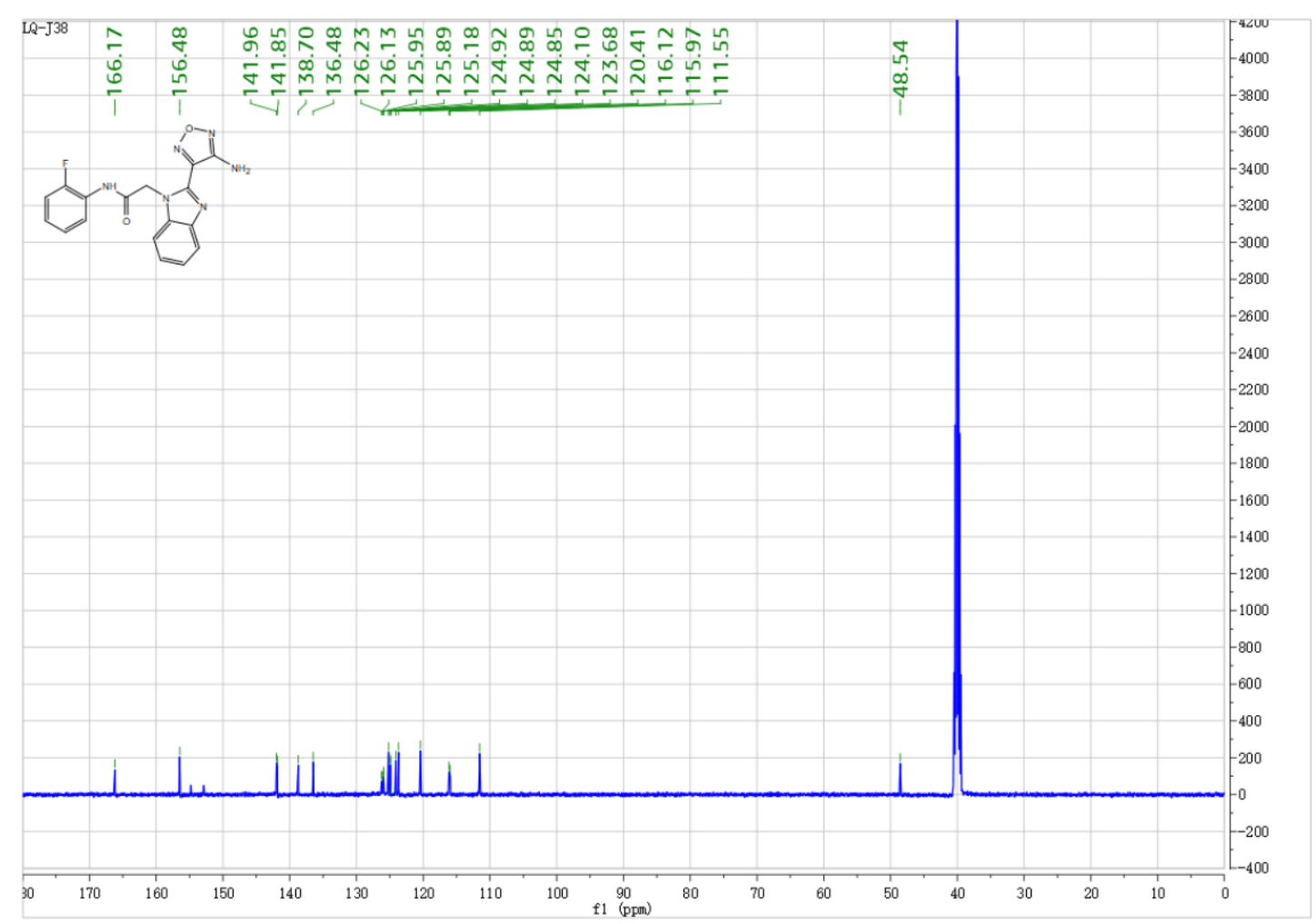

HRMS of compound S06-1017.

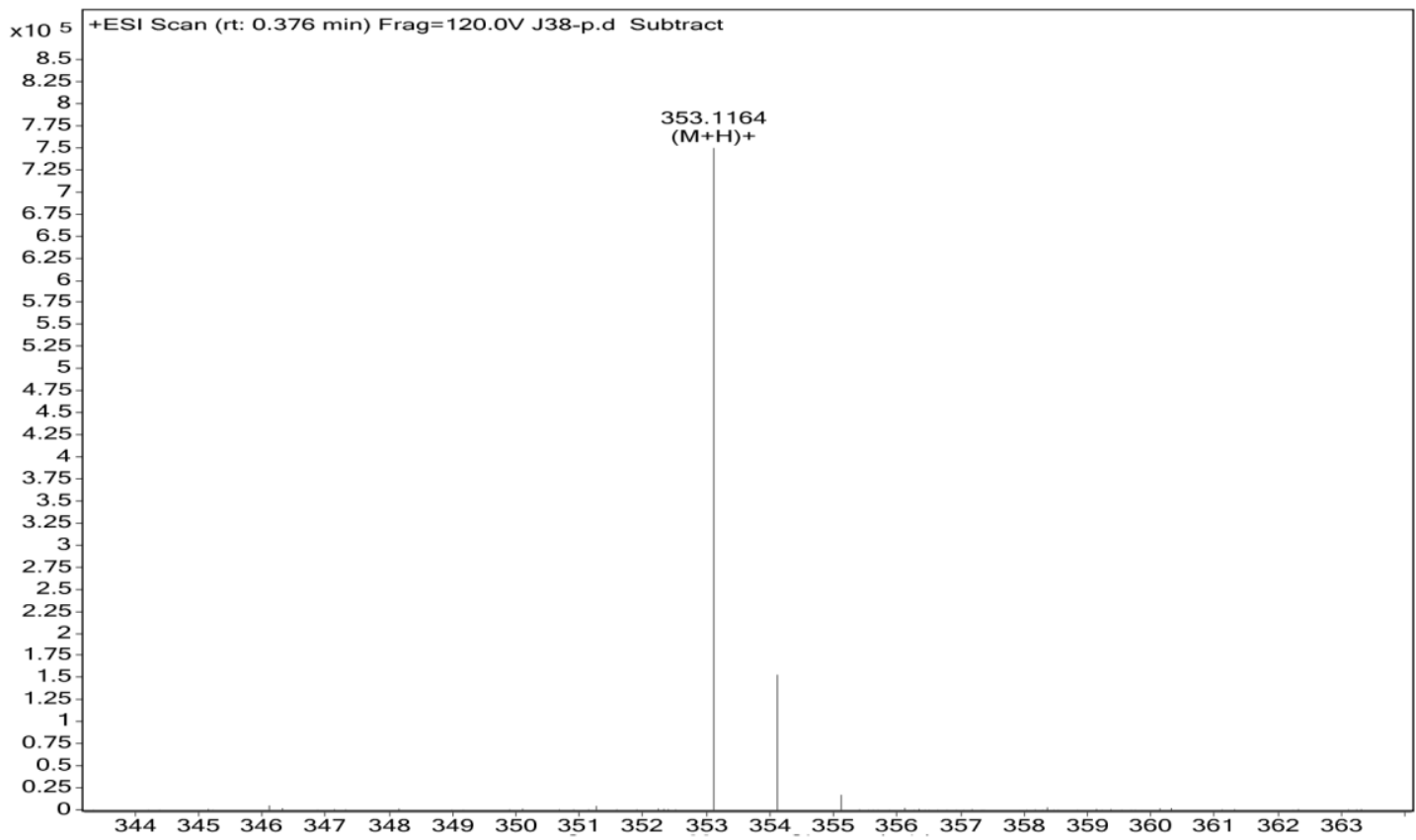


HPLC of compound S06-1018 $\left(t_{R}=6.21 \mathrm{~min}\right)$.

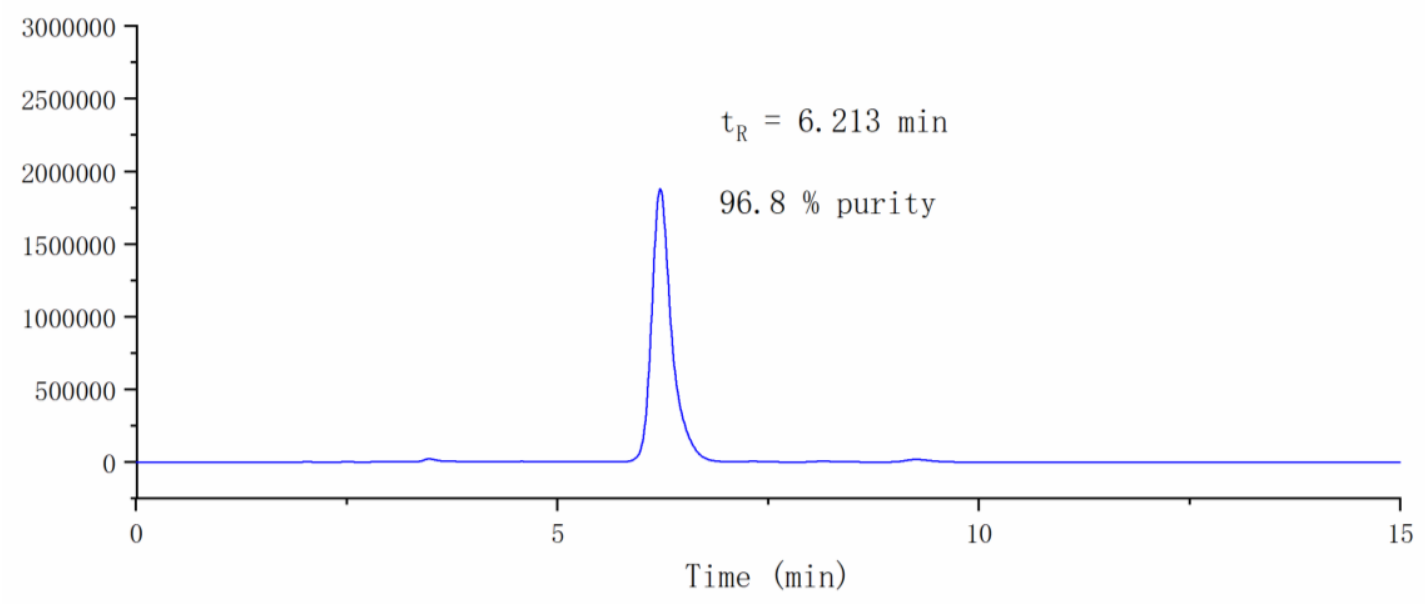

${ }^{1} \mathrm{H}$ NMR of compound S06-1018.

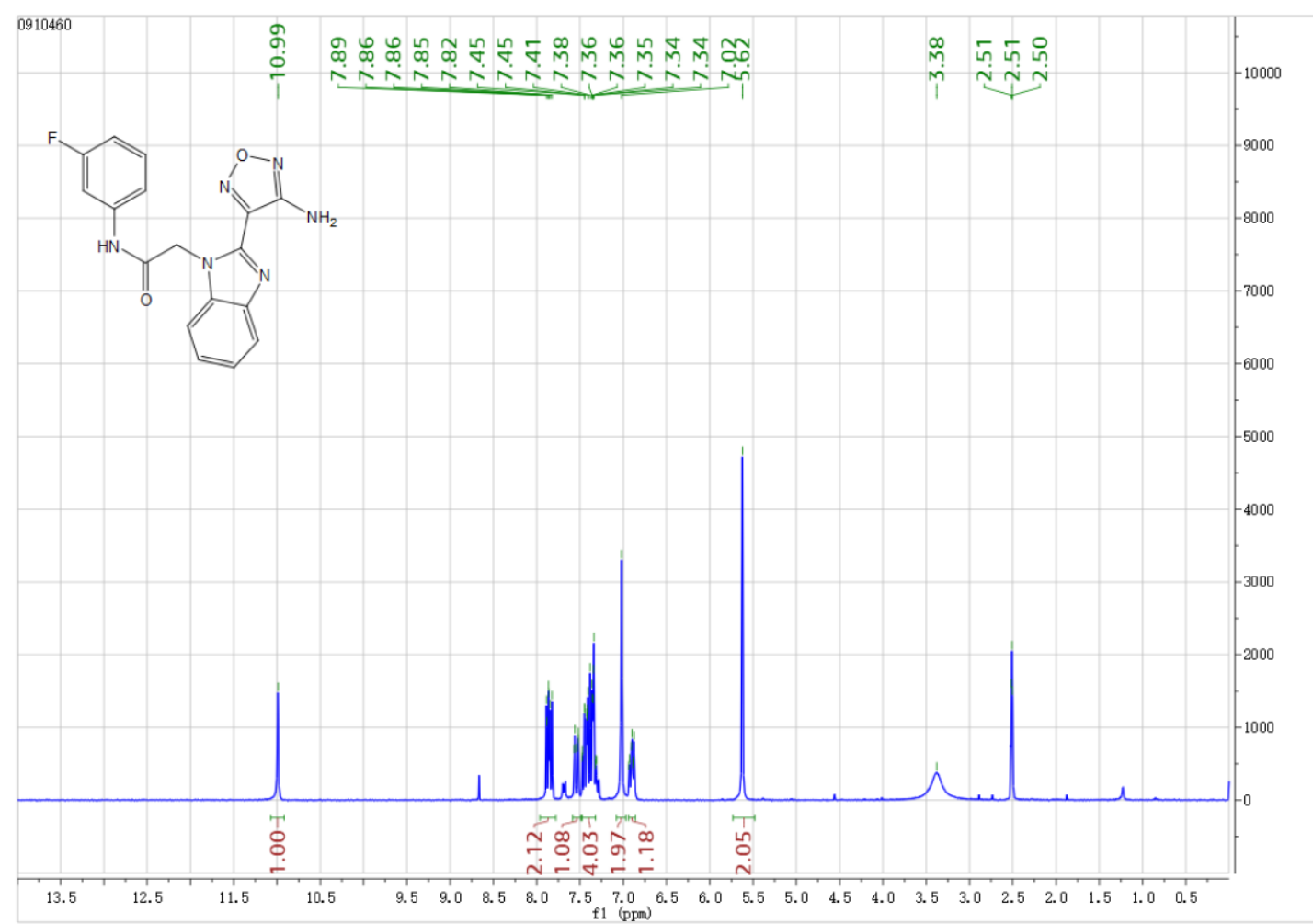

${ }^{13} \mathrm{C}$ NMR of compound S06-1018. 


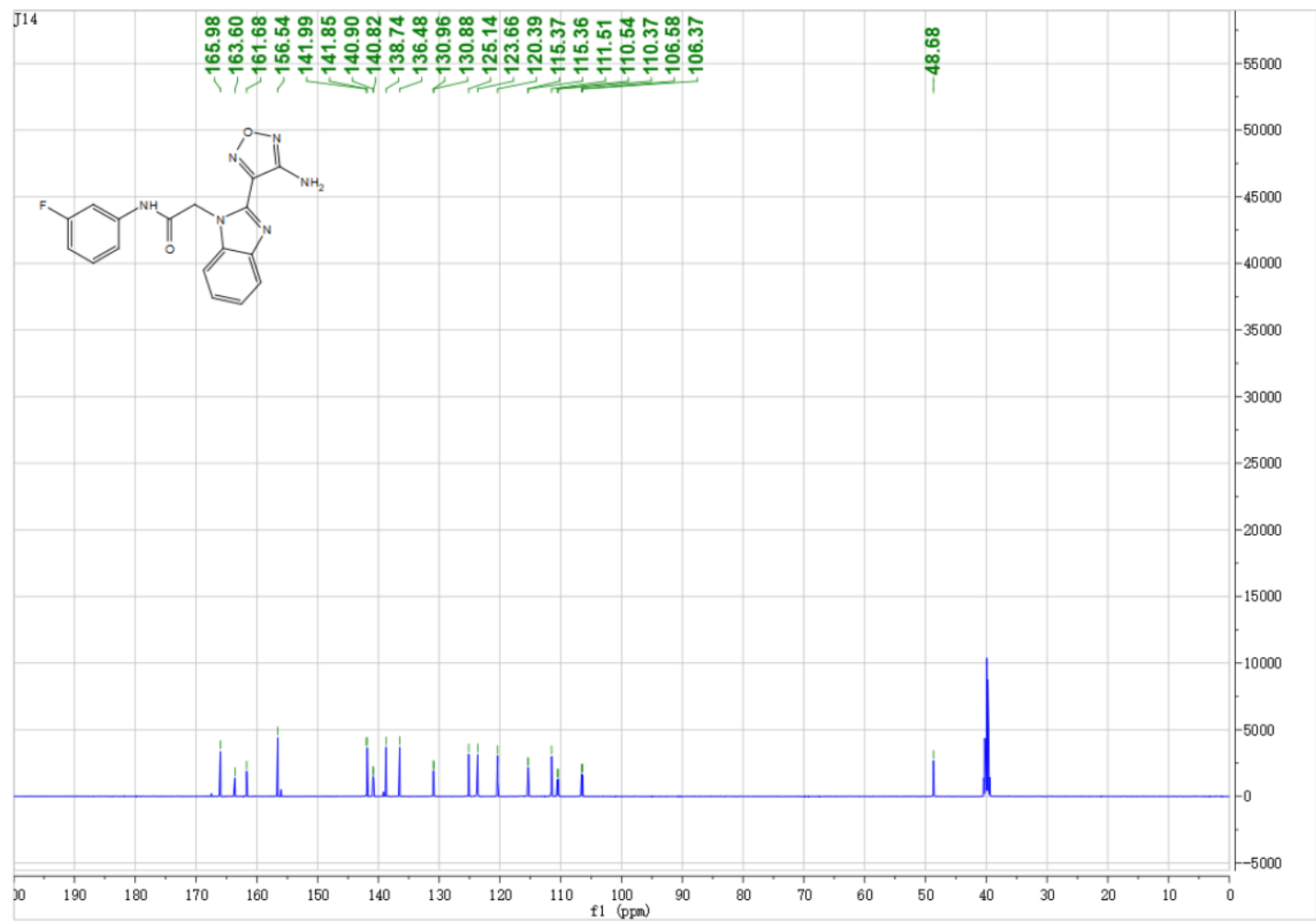

HRMS of compound S06-1018.

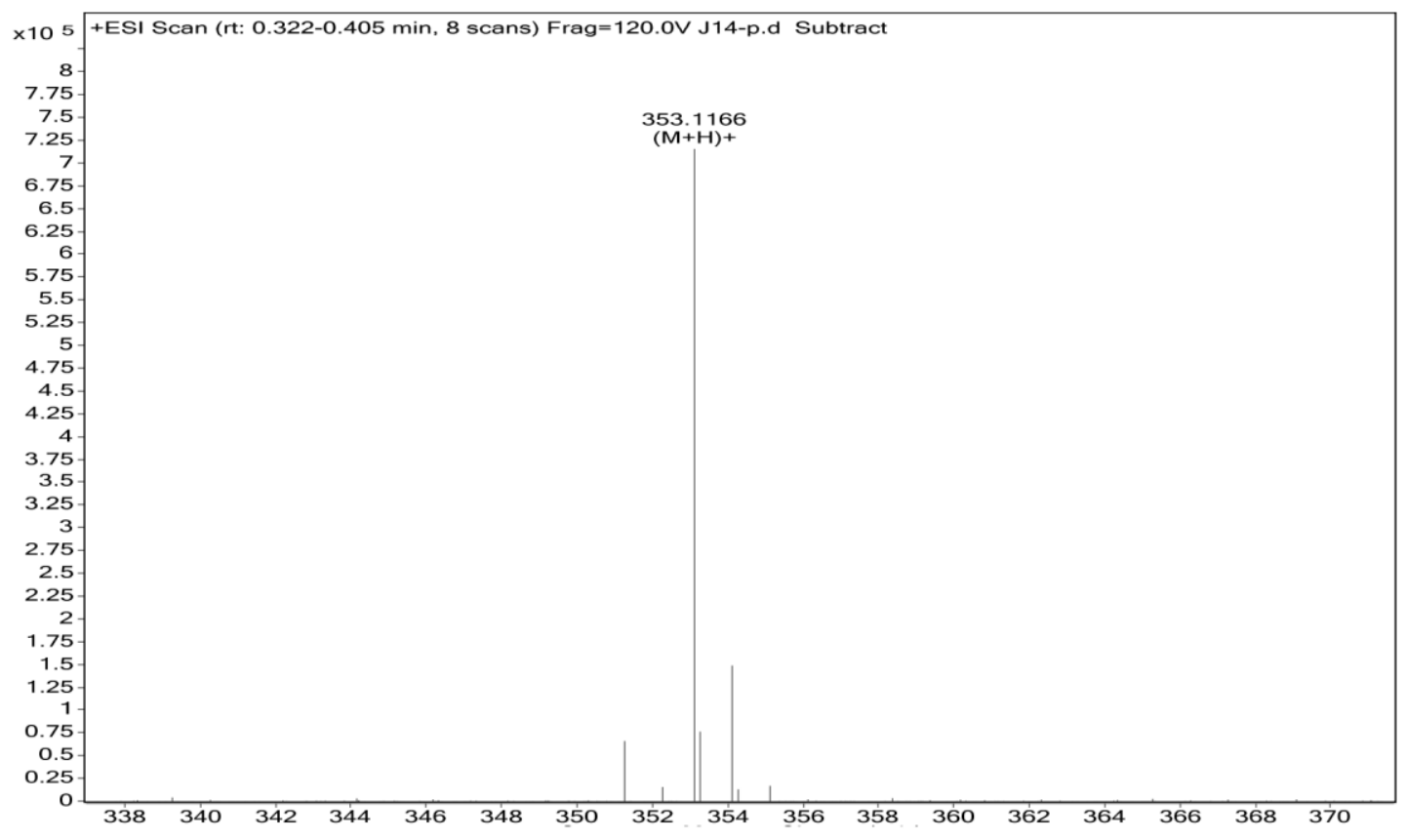

S45 
HPLC of compound S06-1019 $\left(t_{R}=9.41 \mathrm{~min}\right)$.

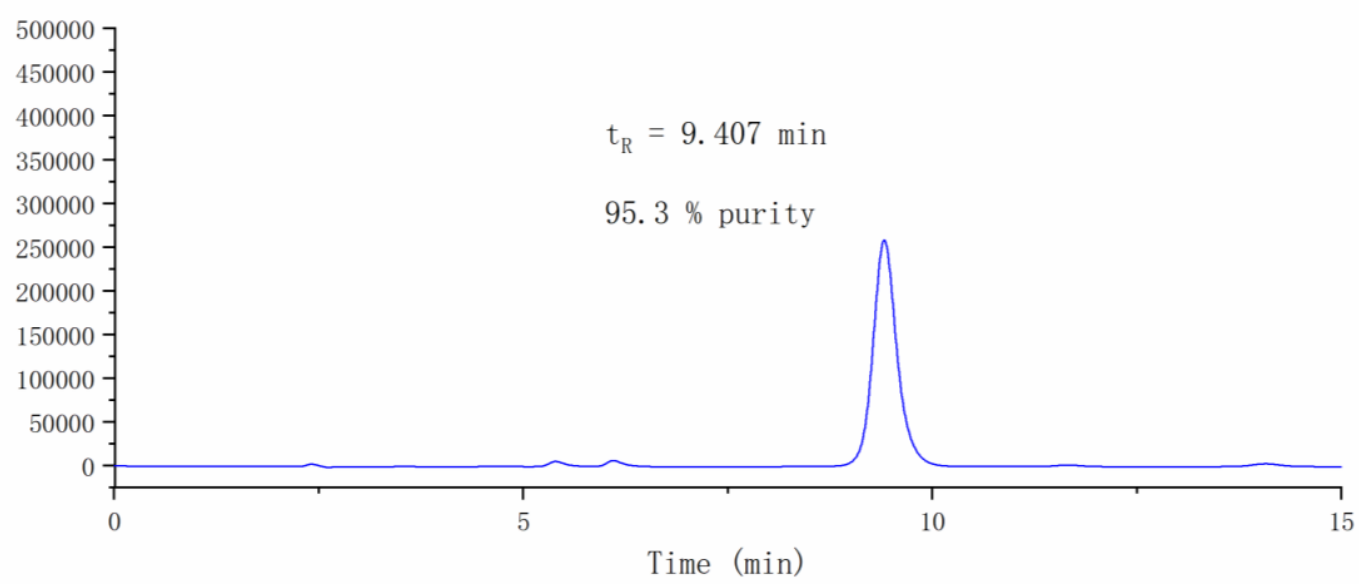

${ }^{1} \mathrm{H}$ NMR of compound S06-1019.

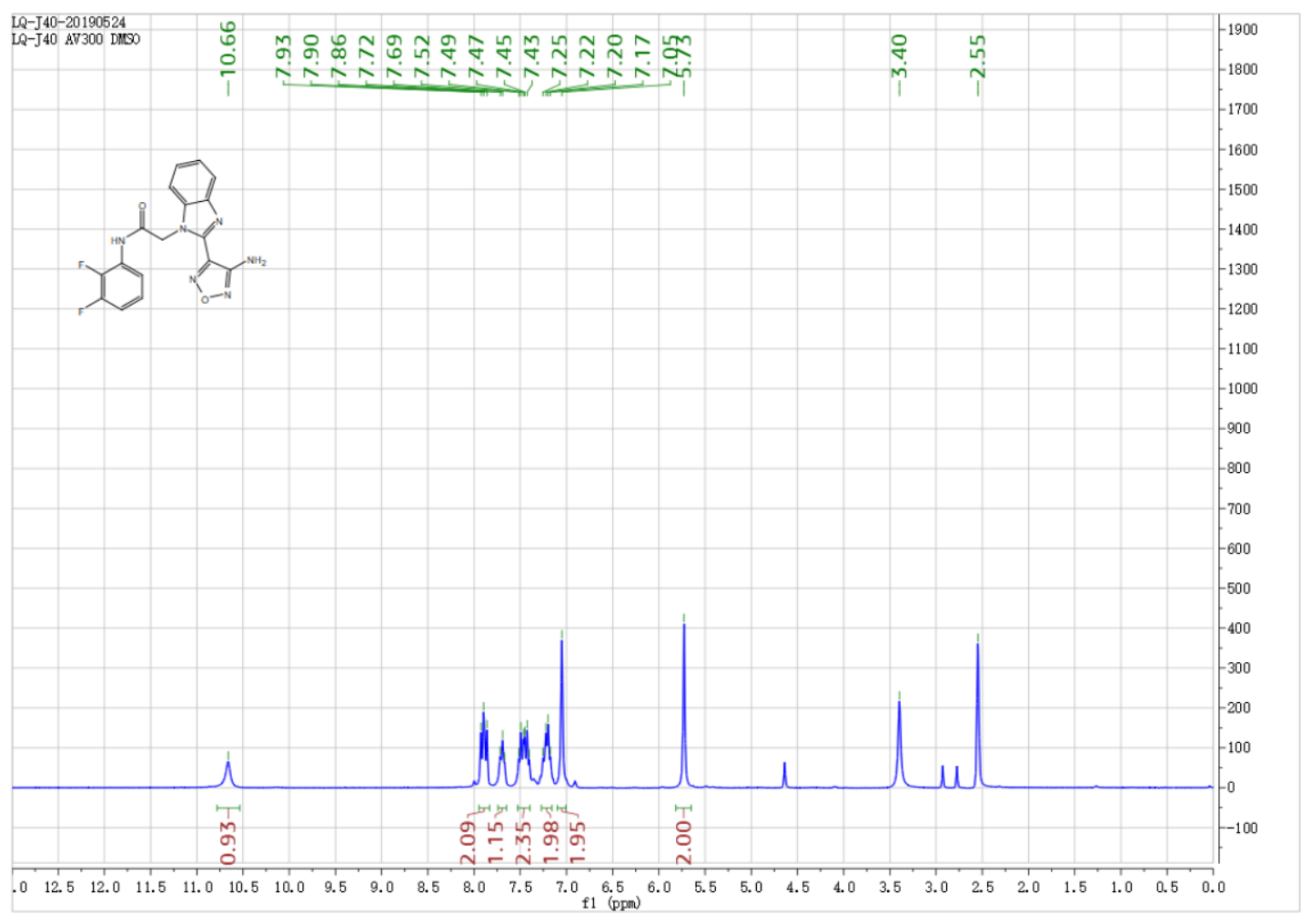

${ }^{13} \mathrm{C}$ NMR of compound S06-1019. 


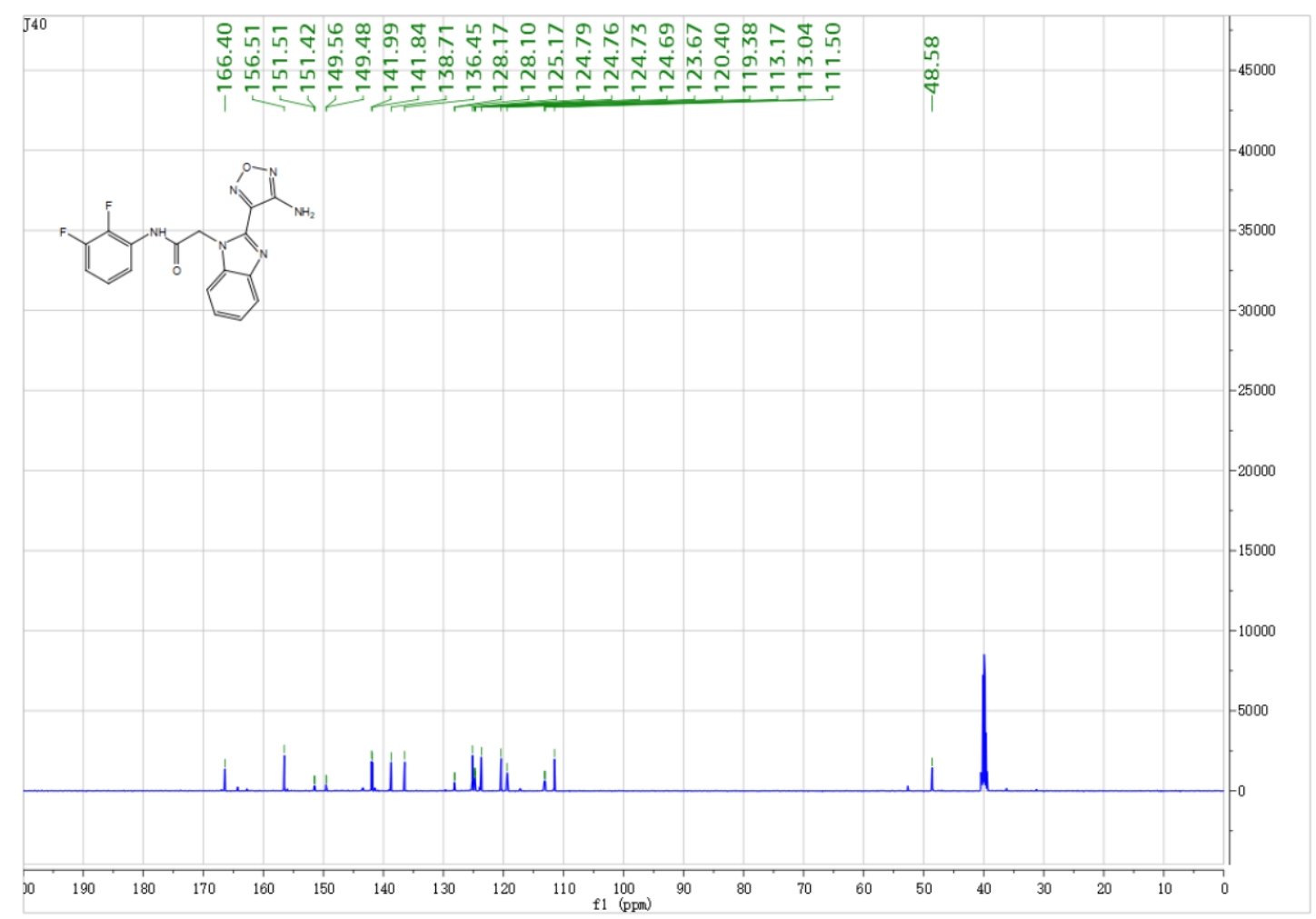

HRMS of compound S06-1019.

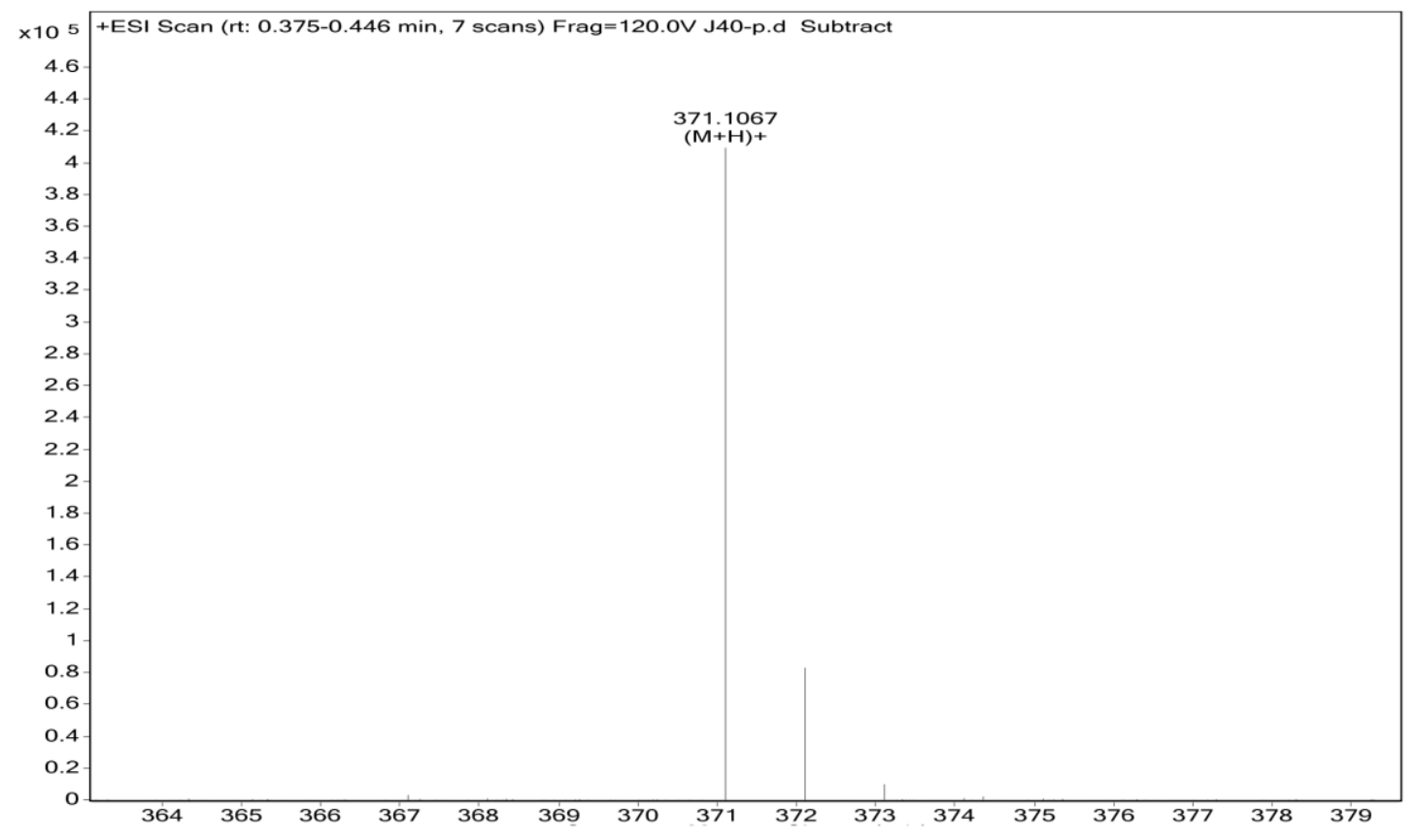


HPLC of compound S06-1020 $\left(t_{R}=3.85 \mathrm{~min}\right)$.

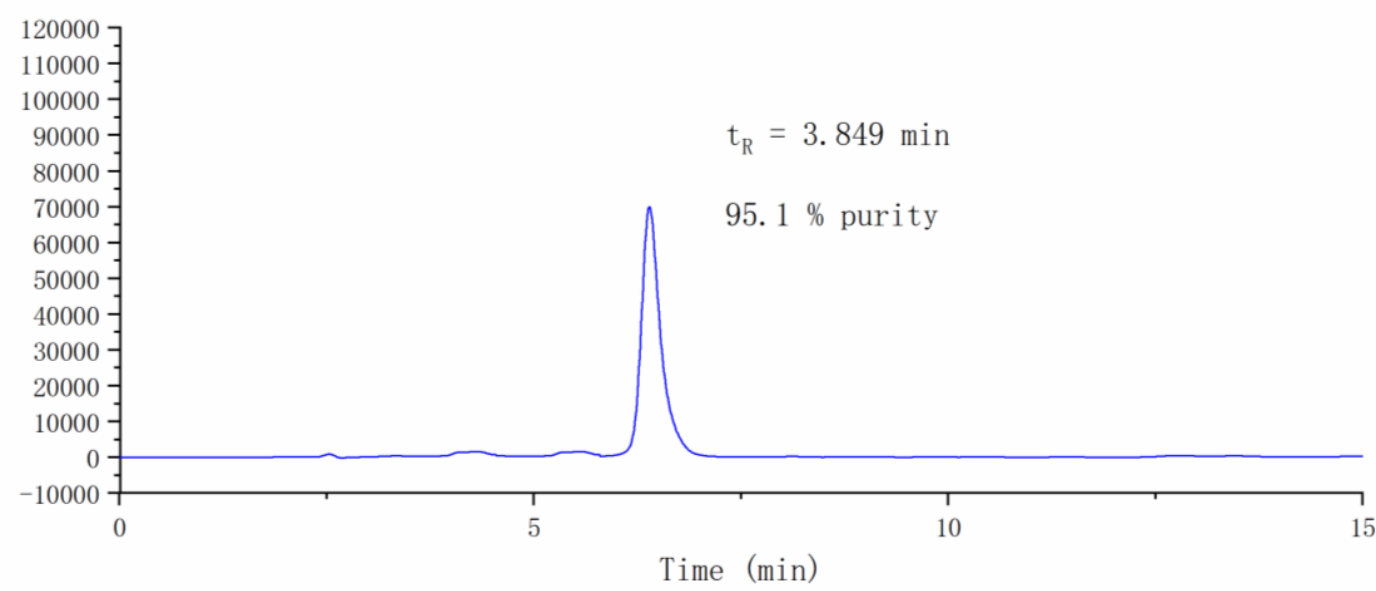

${ }^{1} \mathrm{H}$ NMR of compound S06-1020.

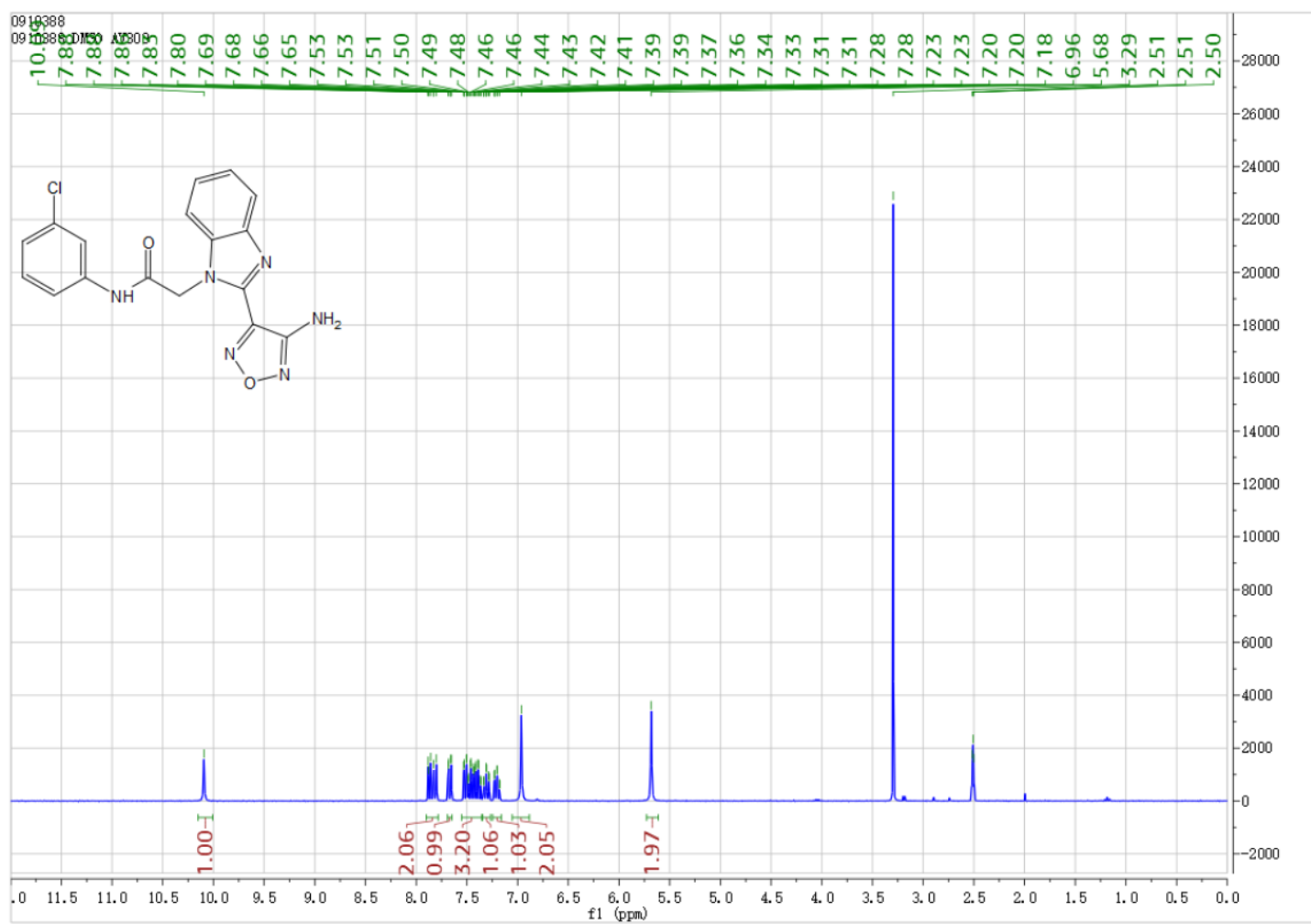

${ }^{13} \mathrm{C}$ NMR of compound S06-1020. 


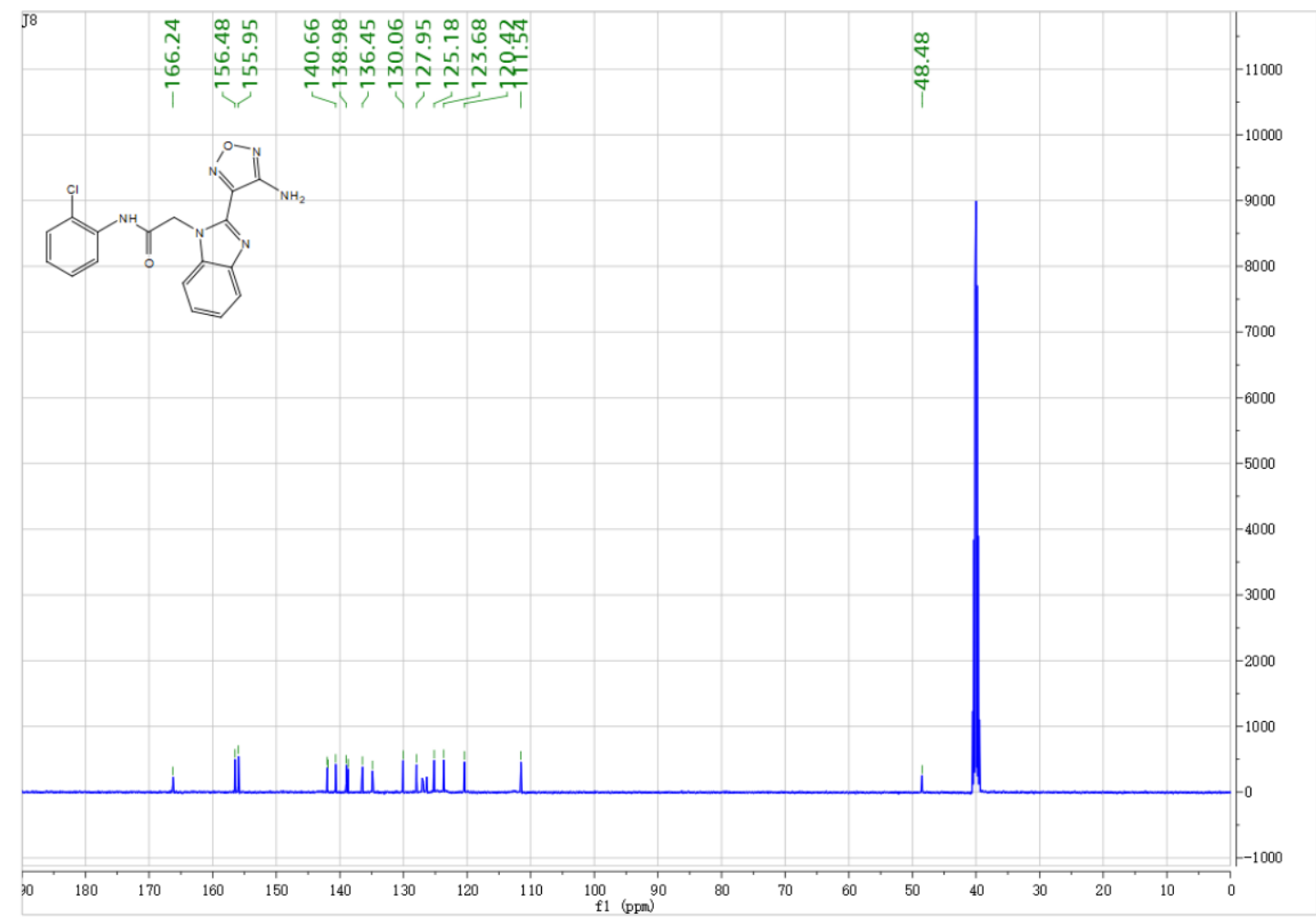

HRMS of compound S06-1020.

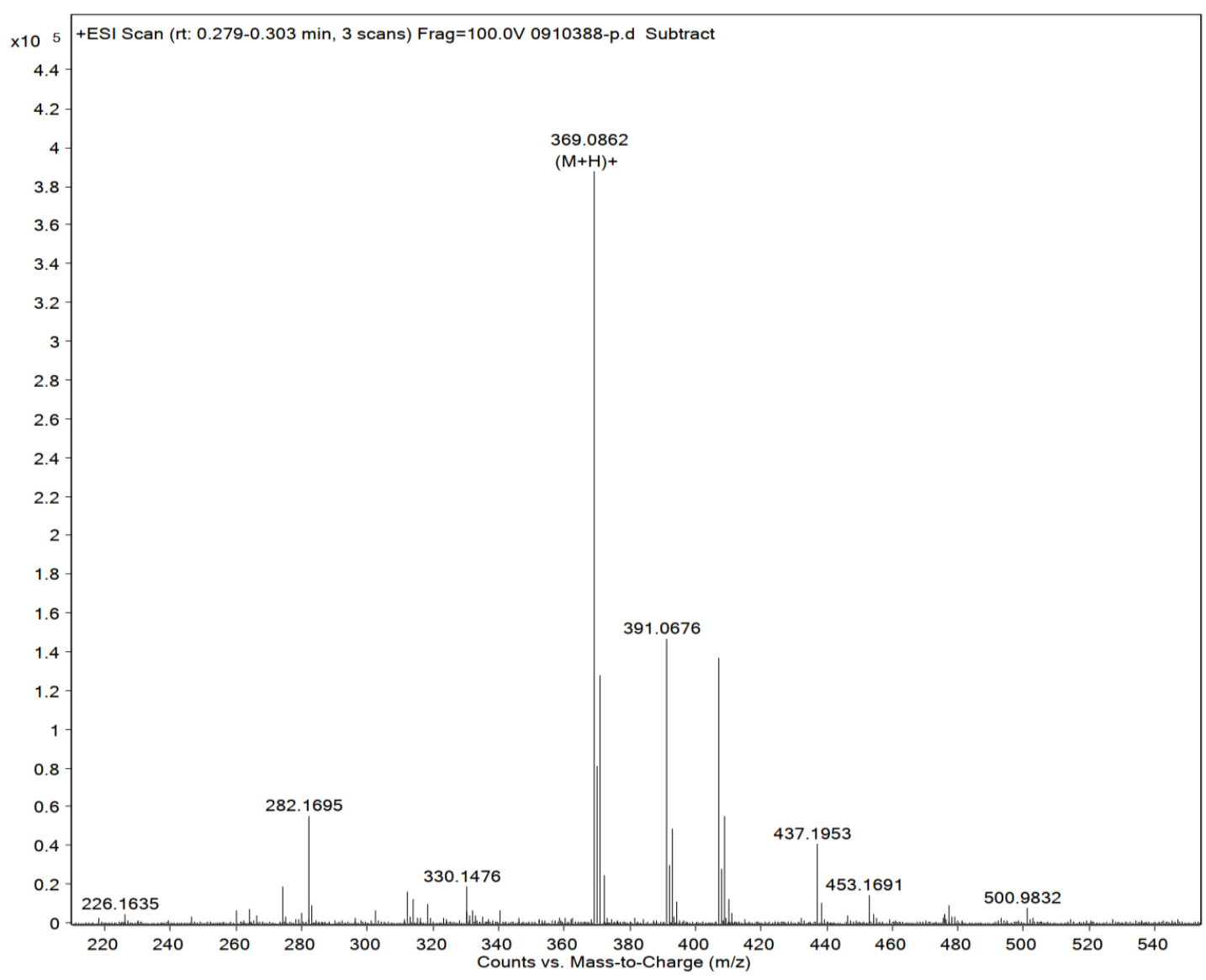


HPLC of compound S06-1021 $\left(t_{R}=24.52 \mathrm{~min}\right)$.

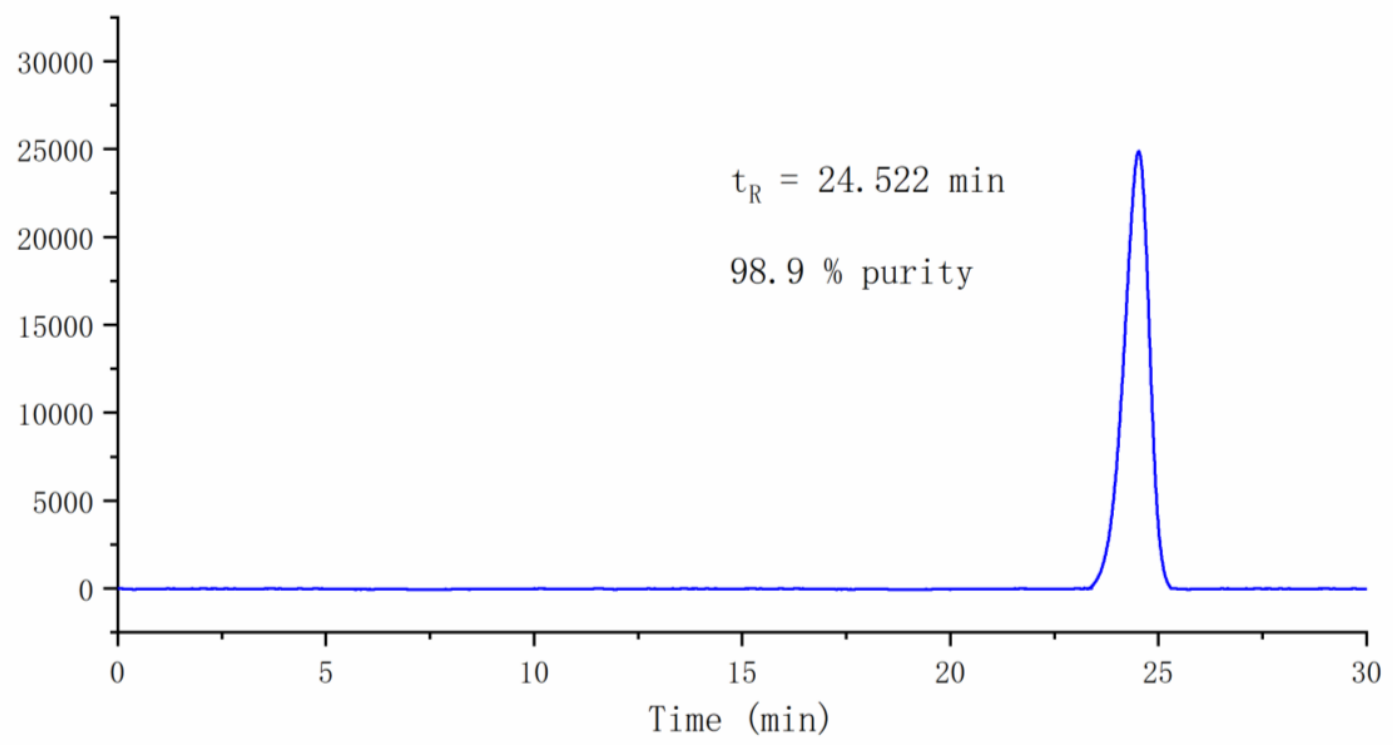

${ }^{1} \mathrm{H}$ NMR of compound S06-1021.

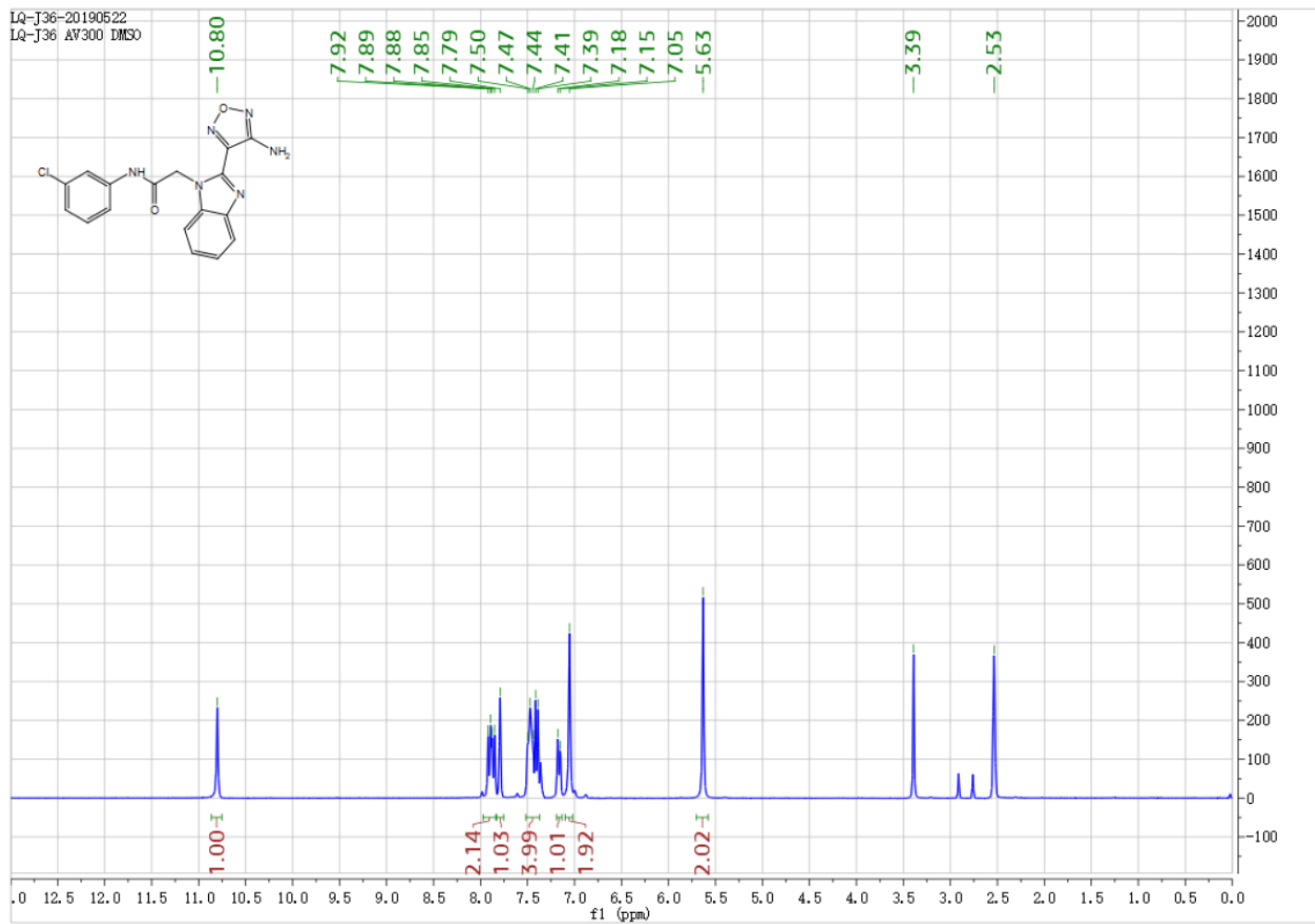

${ }^{13} \mathrm{C}$ NMR of compound S06-1021. 


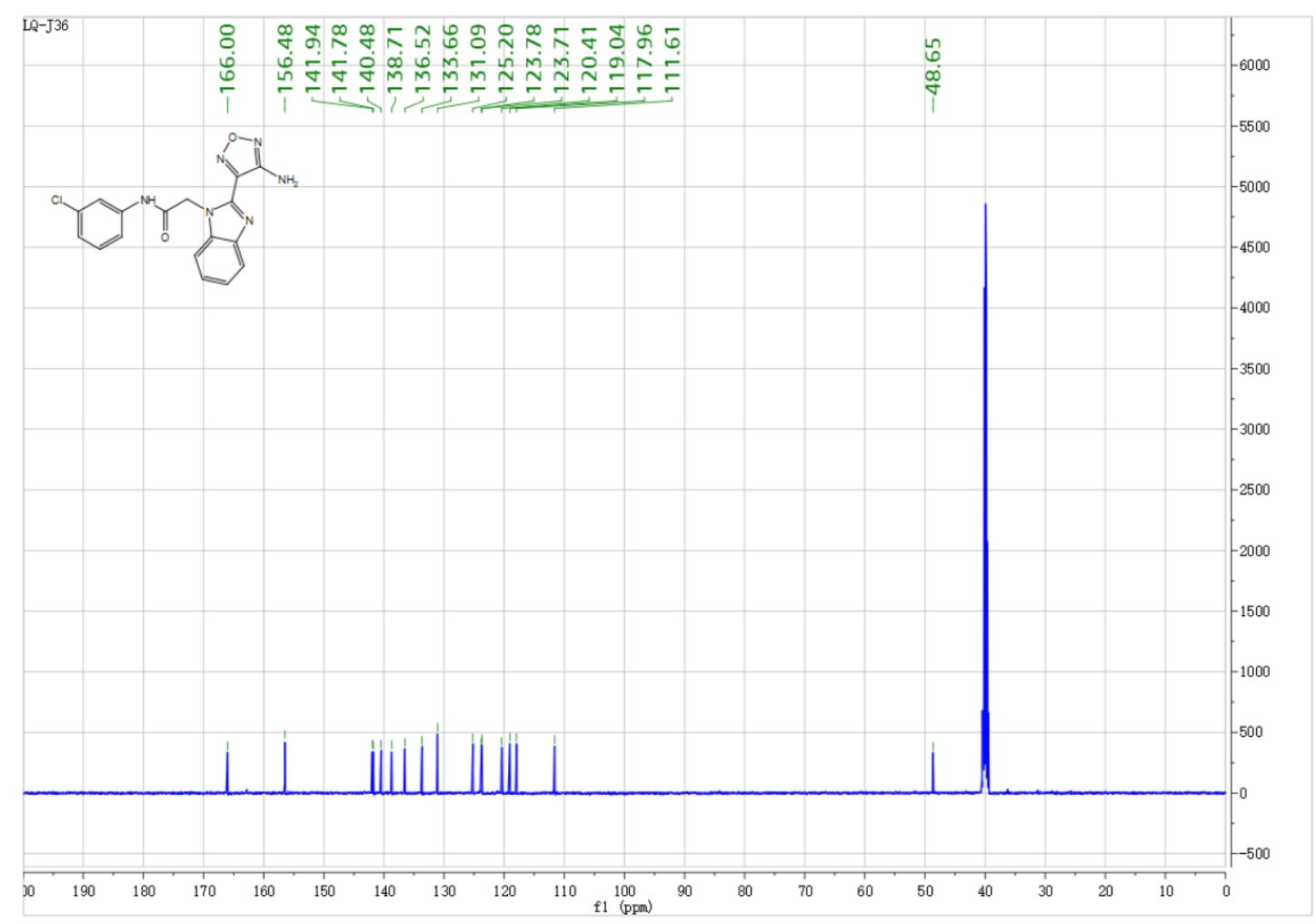

HRMS of compound S06-1021.

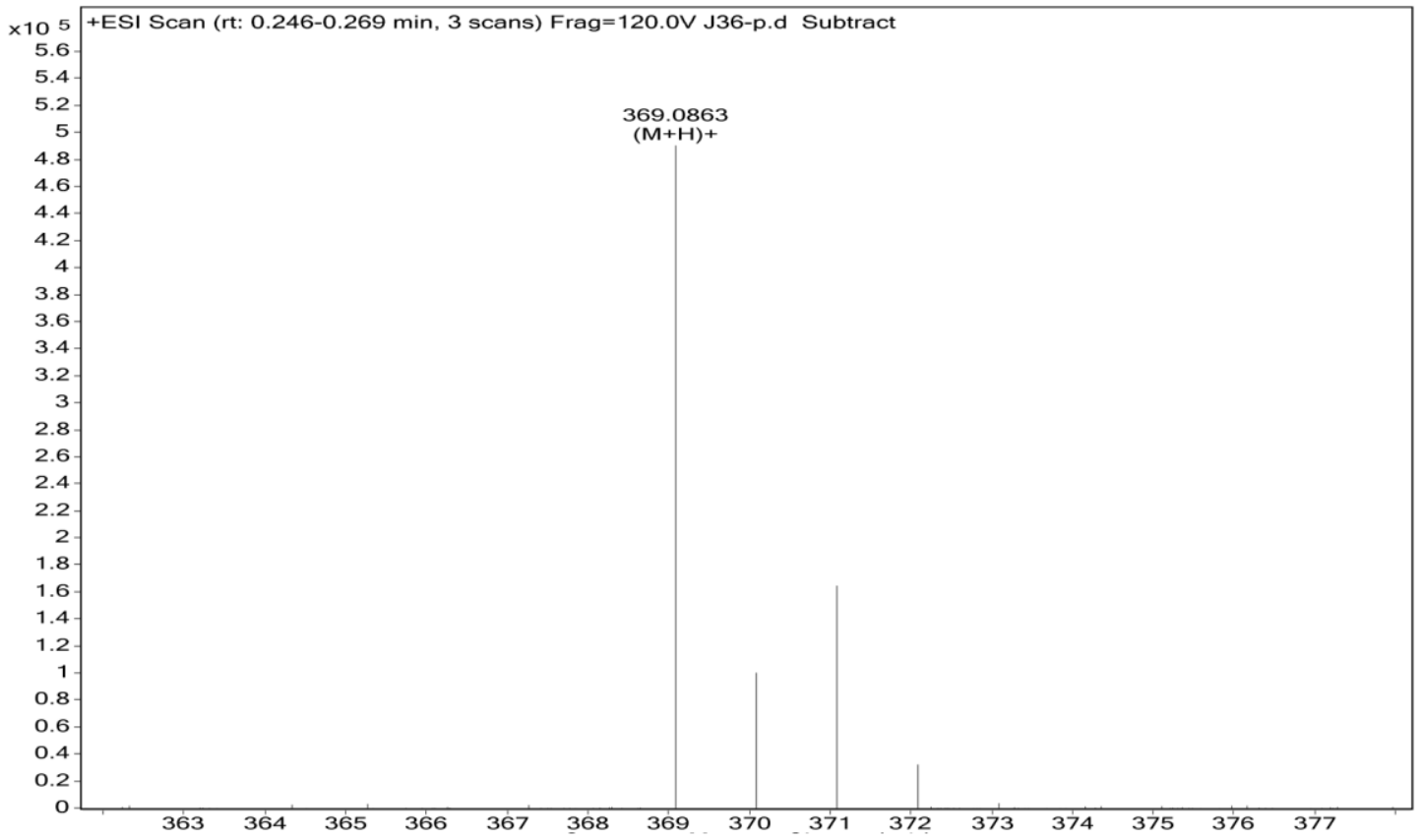


HPLC of compound S06-1022 $\left(t_{R}=9.00 \mathrm{~min}\right)$.

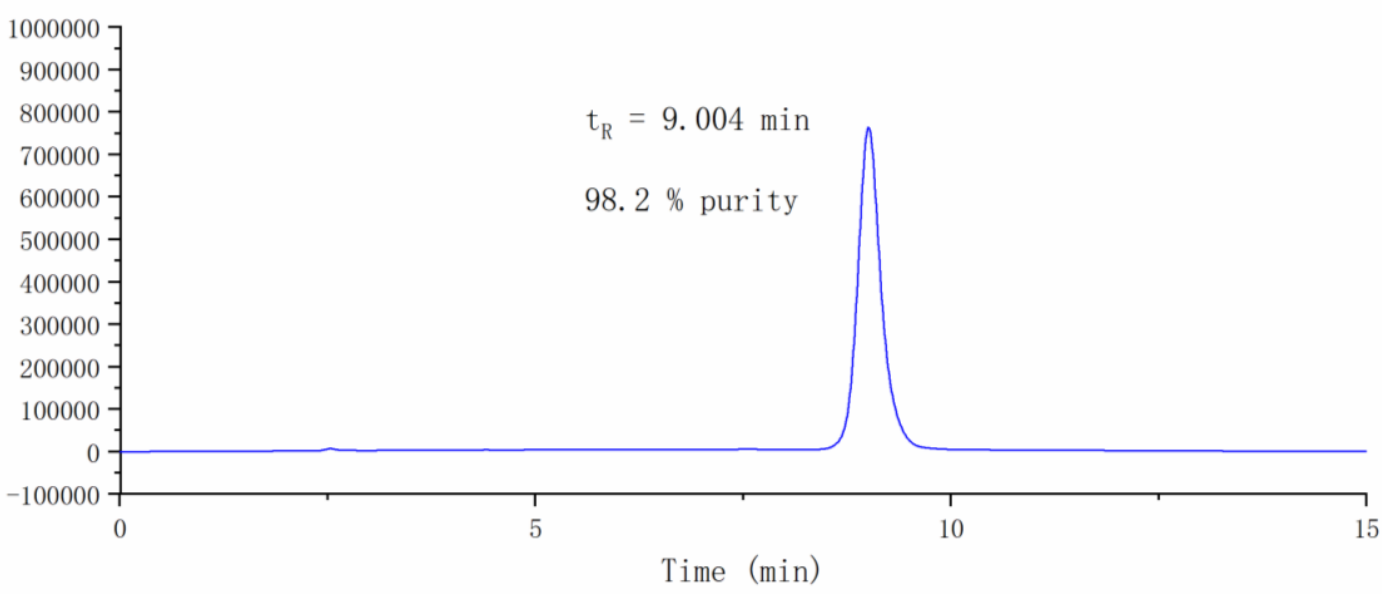

${ }^{1} \mathrm{H}$ NMR of compound S06-1022.

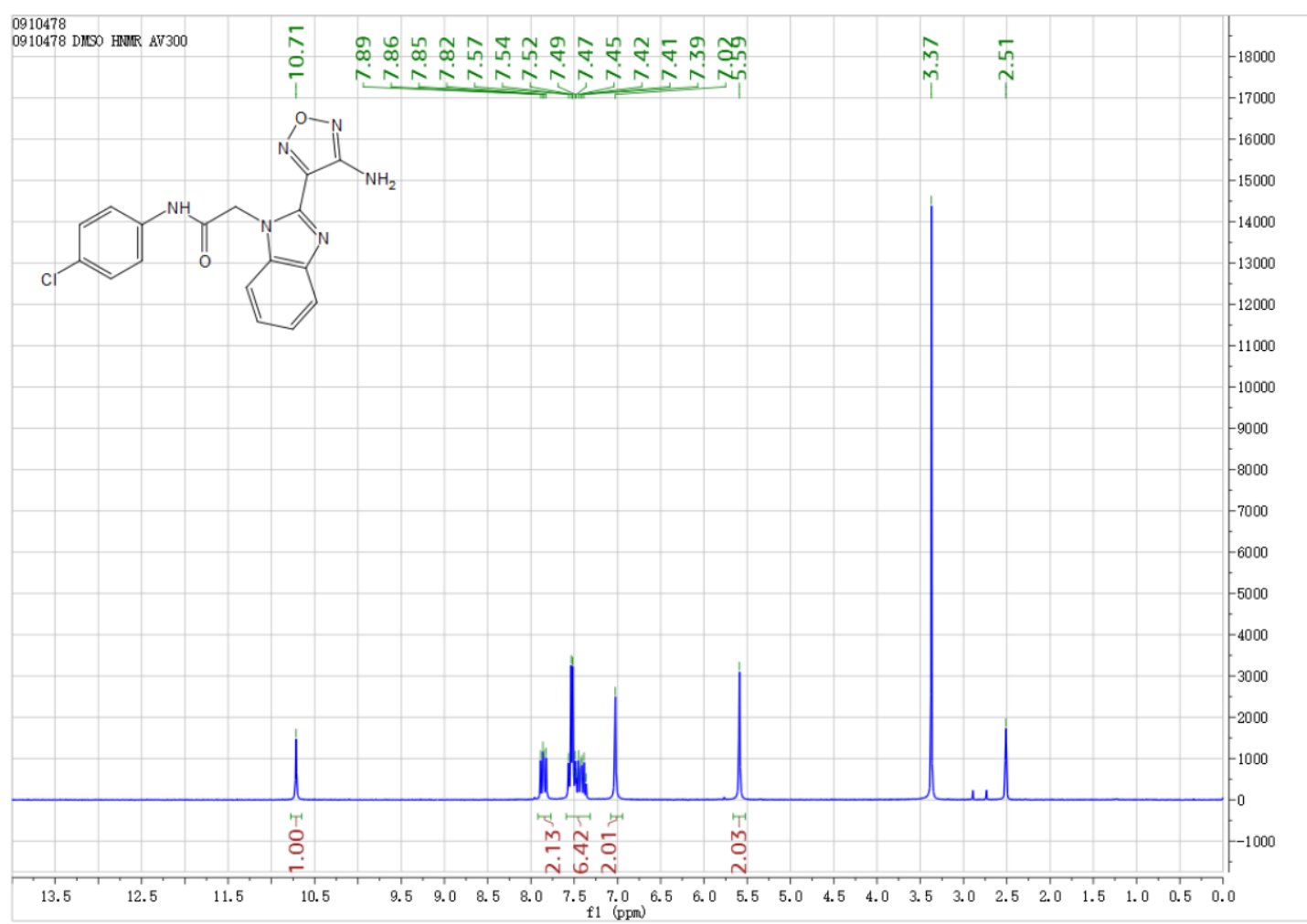

${ }^{13} \mathrm{C}$ NMR of compound S06-1022. 


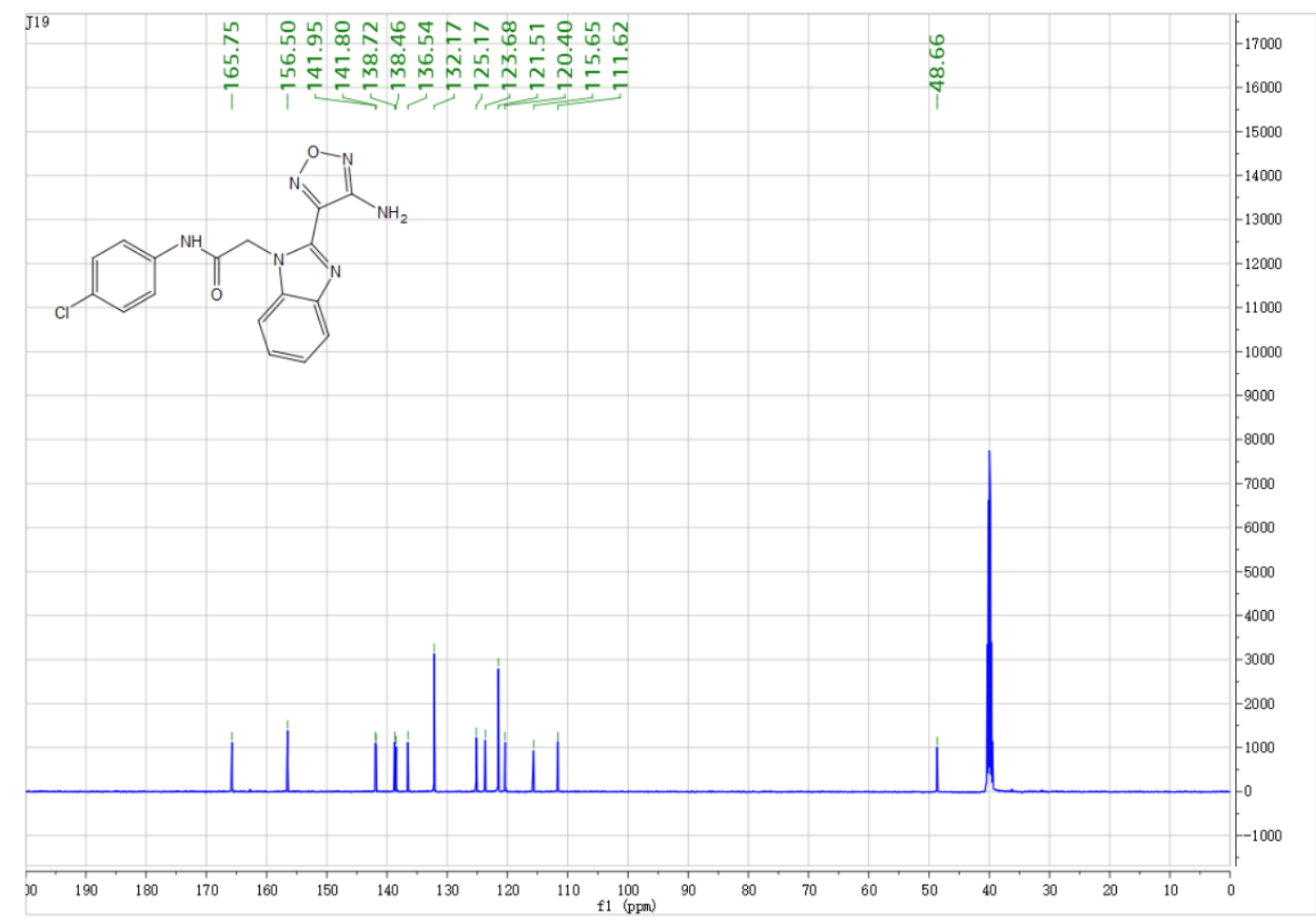

HRMS of compound S06-1022.

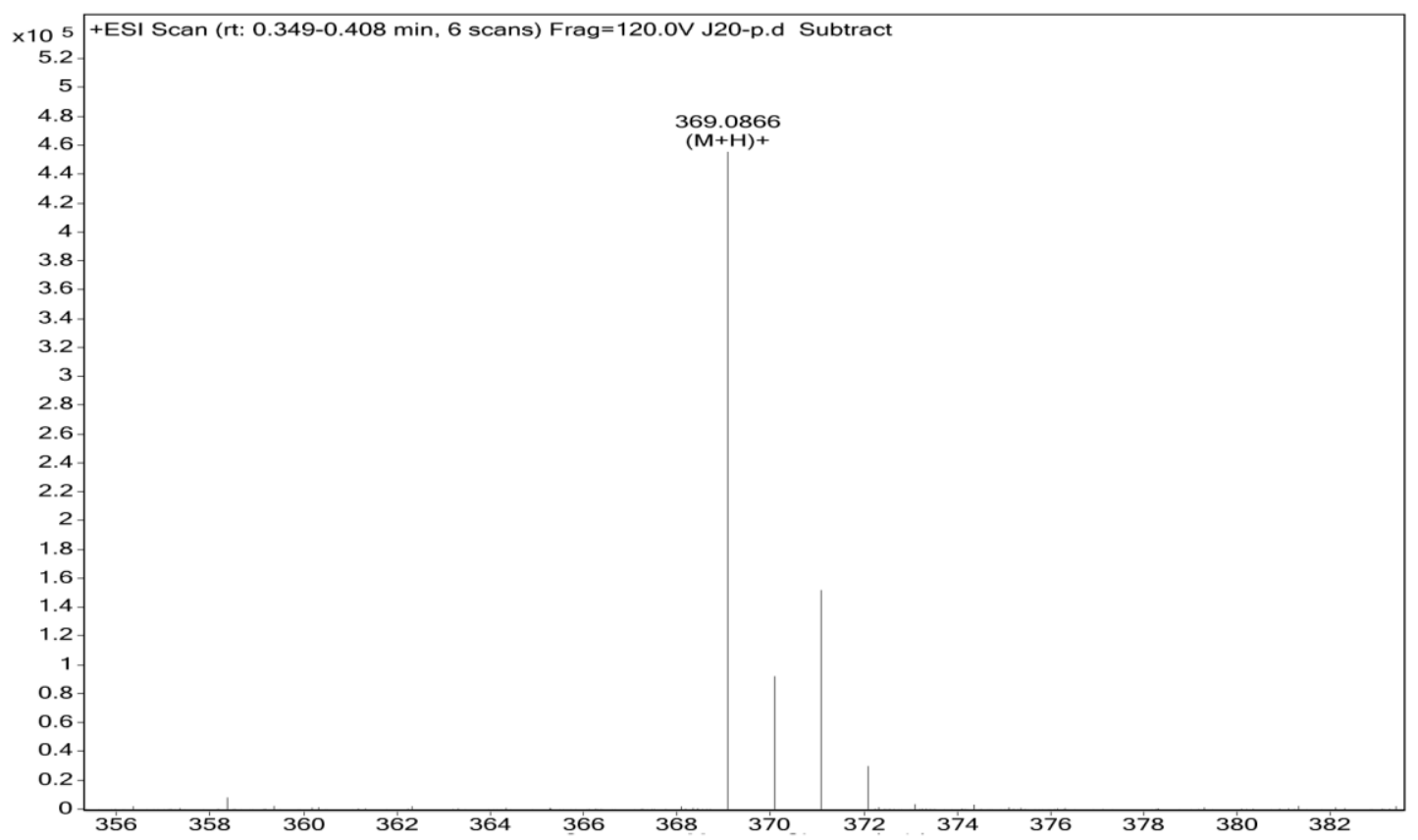


HPLC of compound S06-1023 $\left(t_{R}=20.09 \mathrm{~min}\right)$.

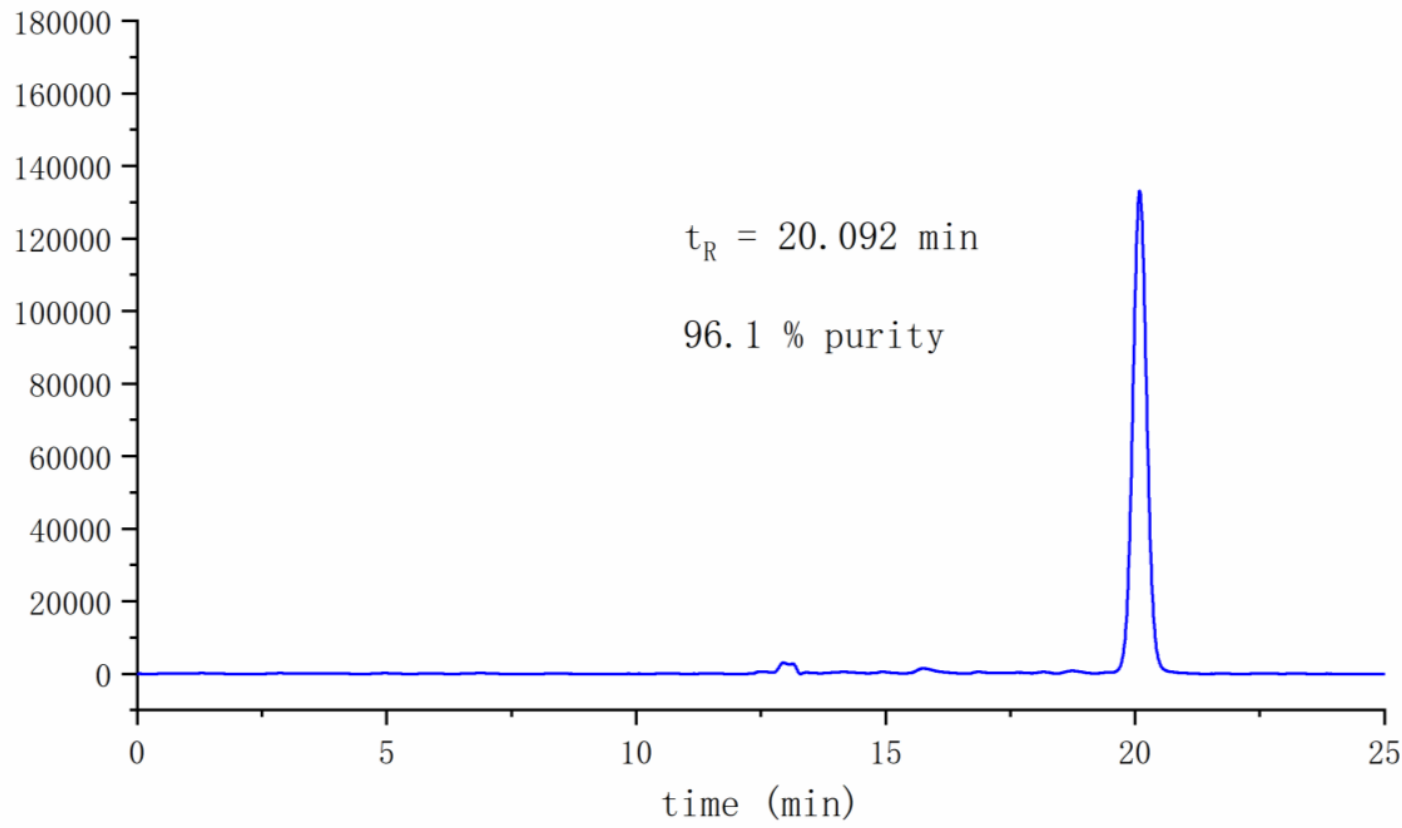

${ }^{1} \mathrm{H}$ NMR of compound S06-1023.

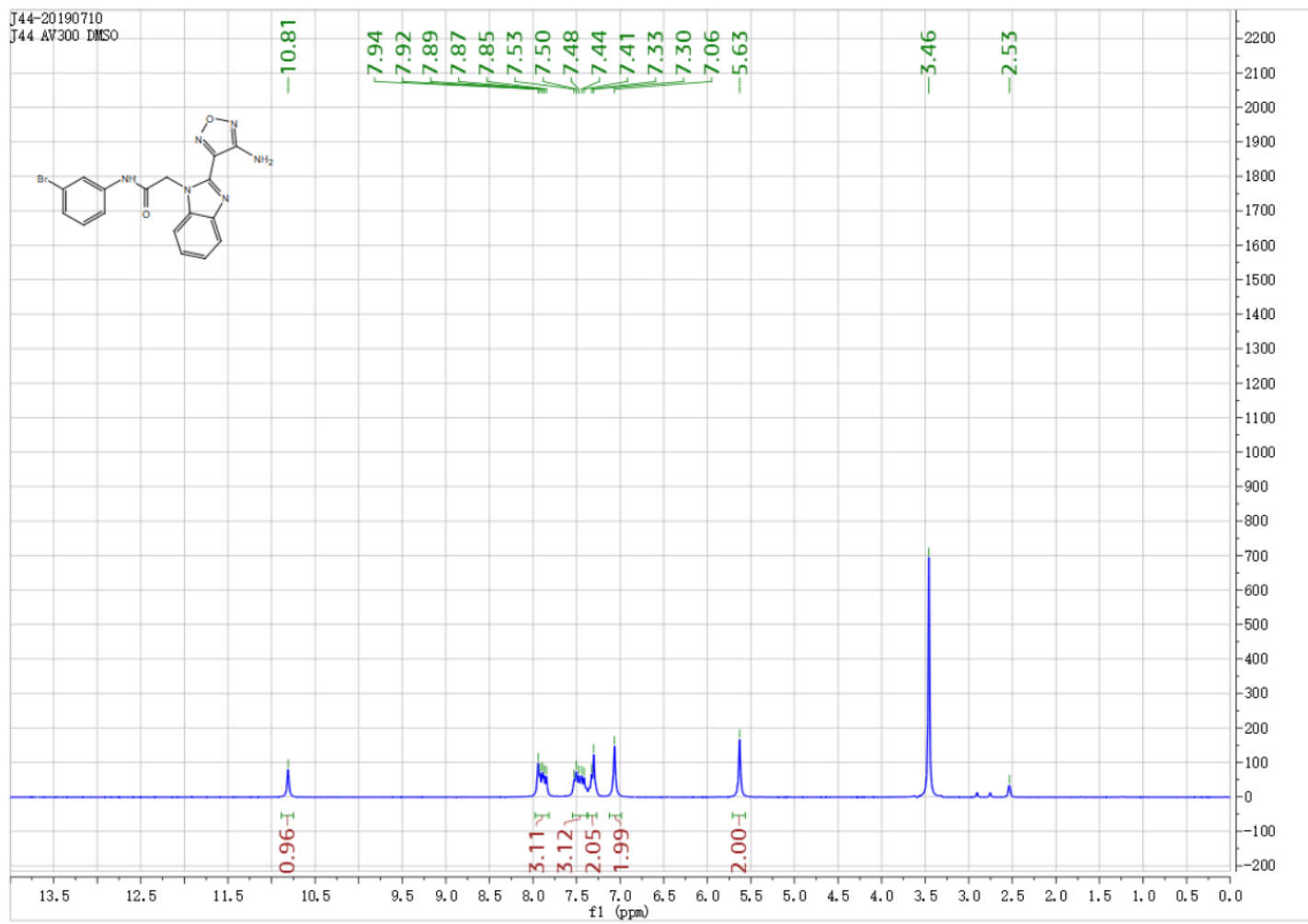

${ }^{13} \mathrm{C}$ NMR of compound S06-1023. 


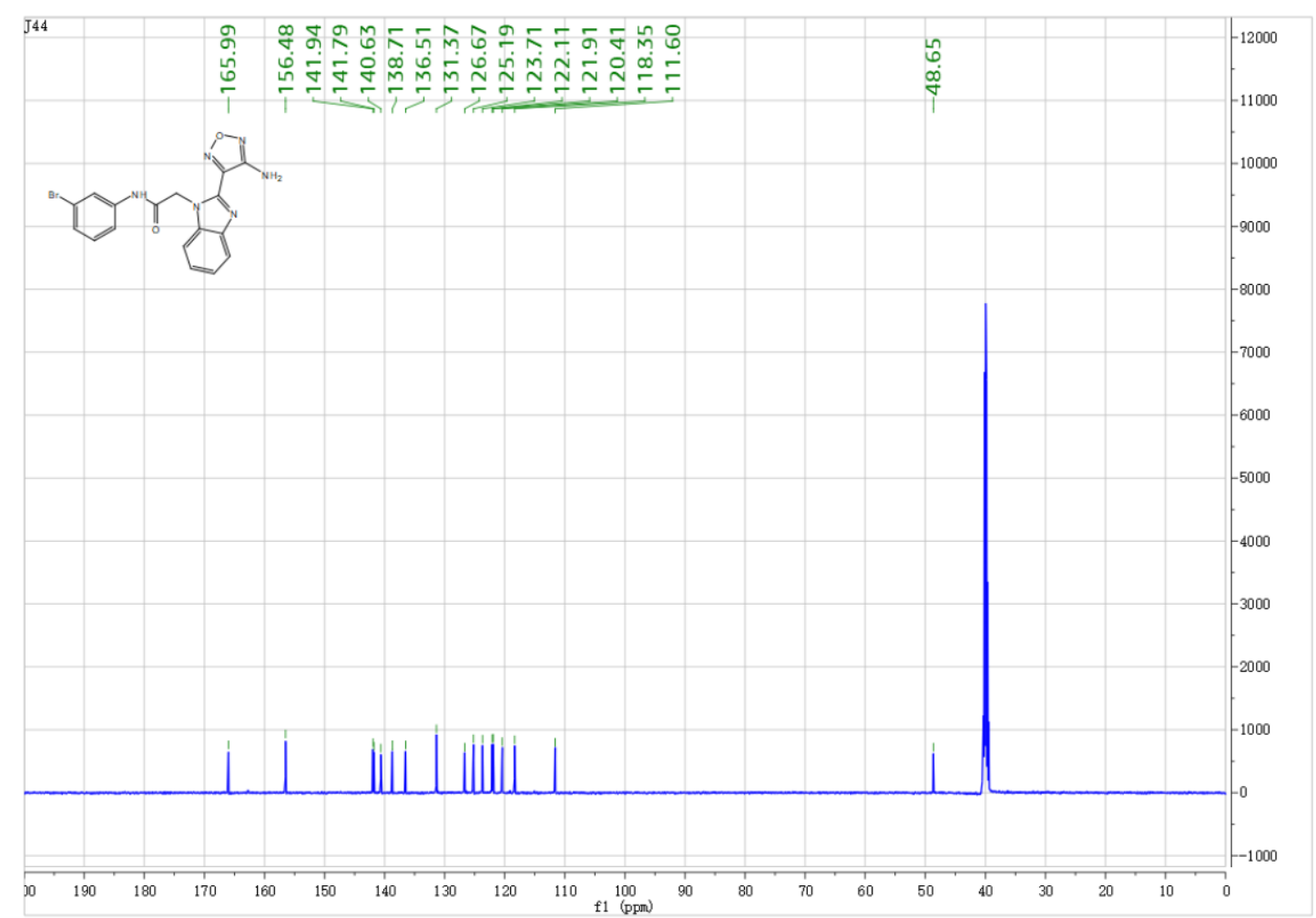

HRMS of compound S06-1023.

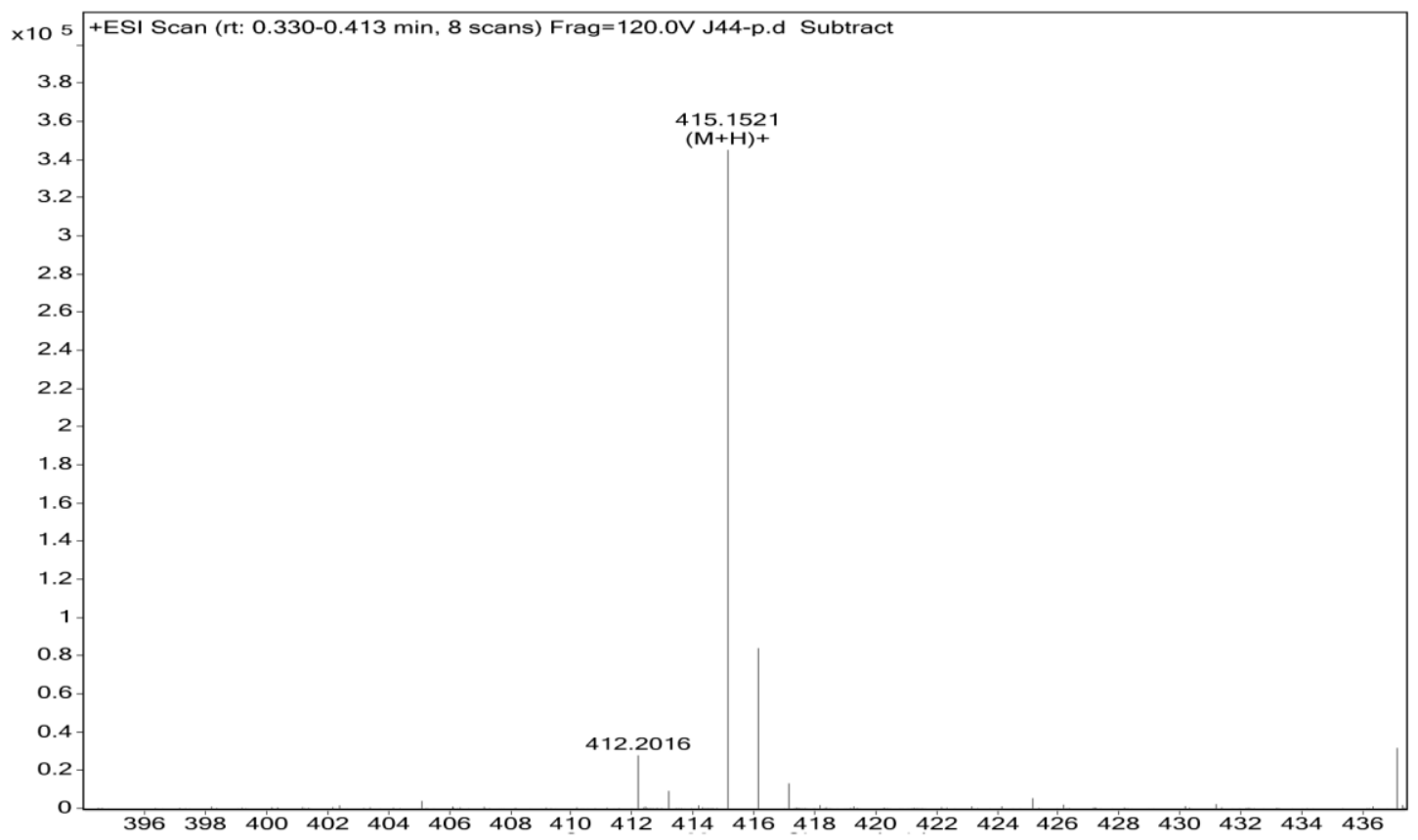


HPLC of compound S06-1024 $\left(t_{R}=8.11 \mathrm{~min}\right)$.

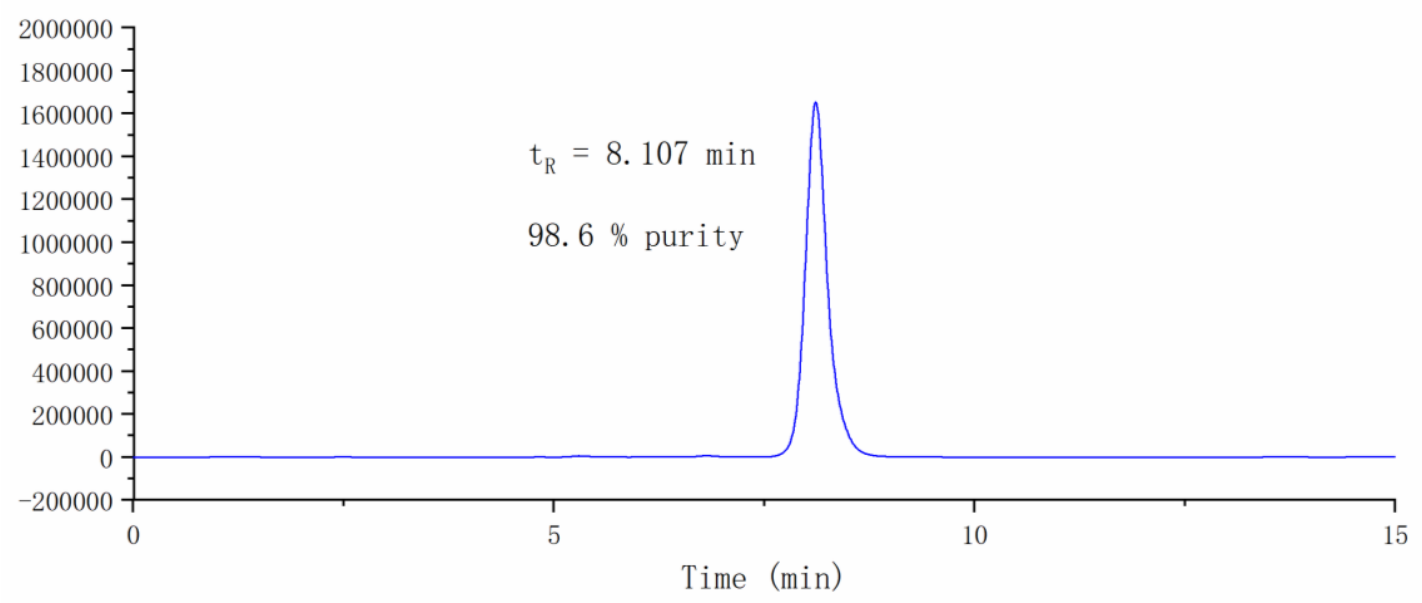

${ }^{1} \mathrm{H}$ NMR of compound S06-1024.

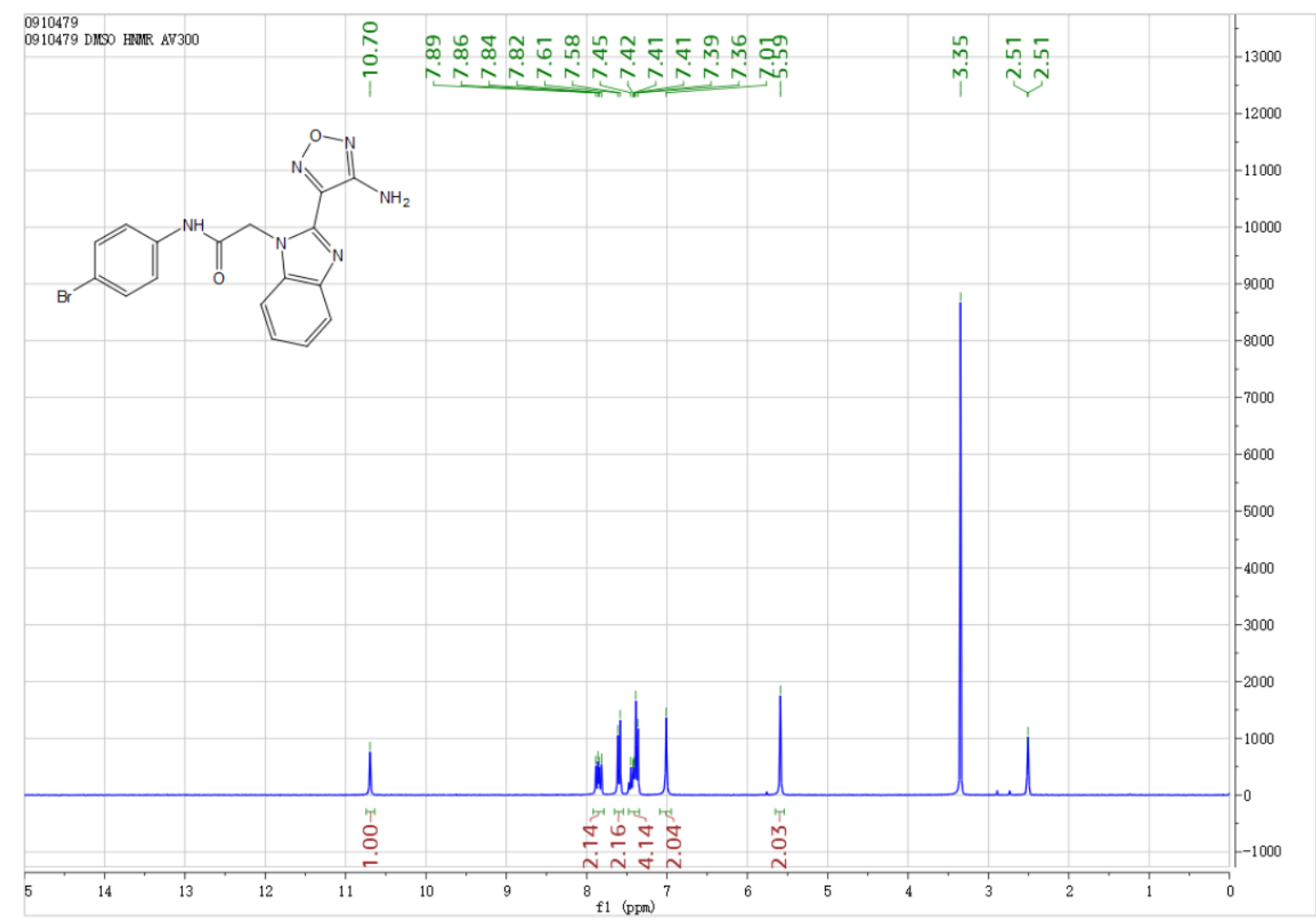

${ }^{13} \mathrm{C}$ NMR of compound S06-1024. 


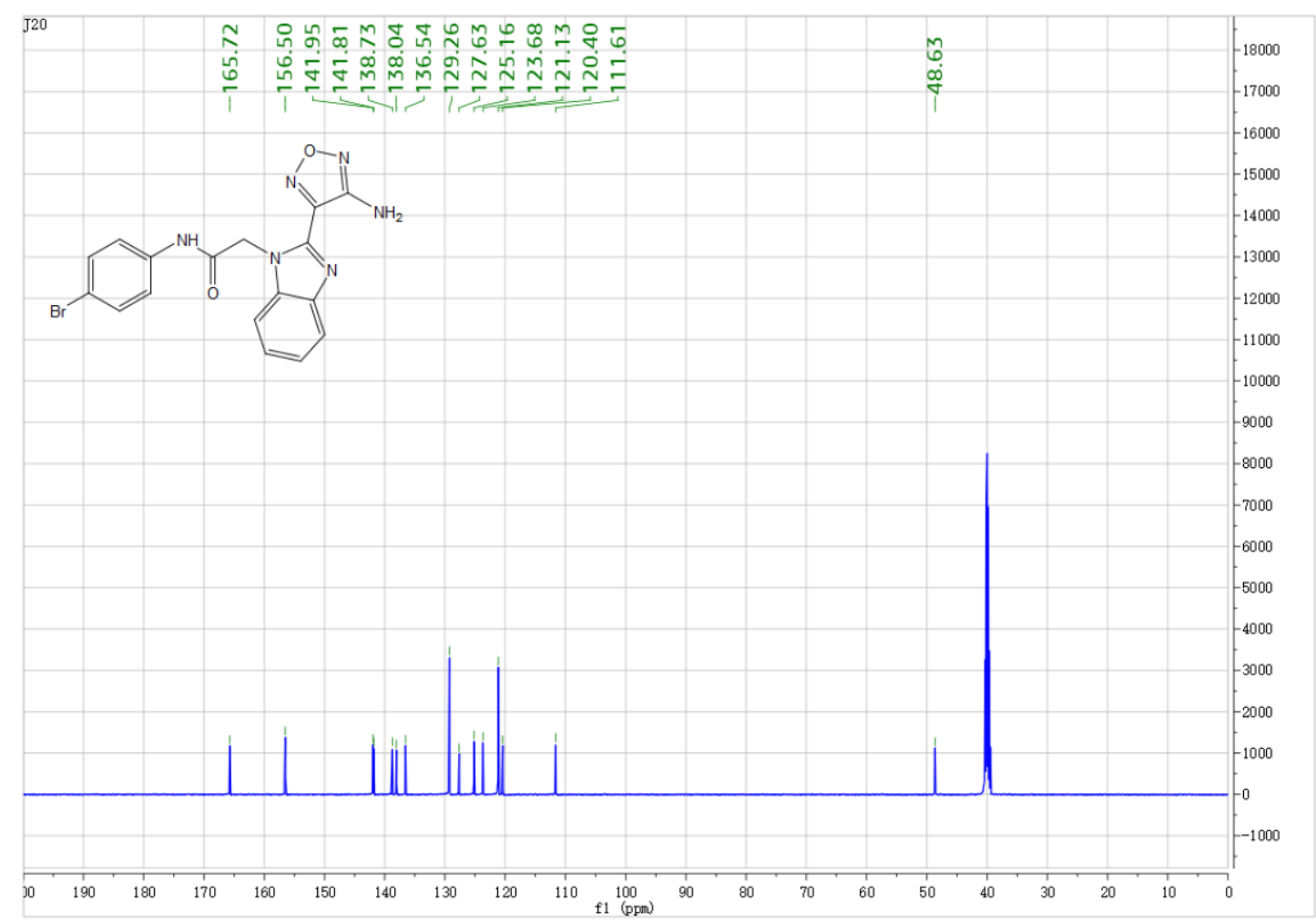

HRMS of compound S06-1024.

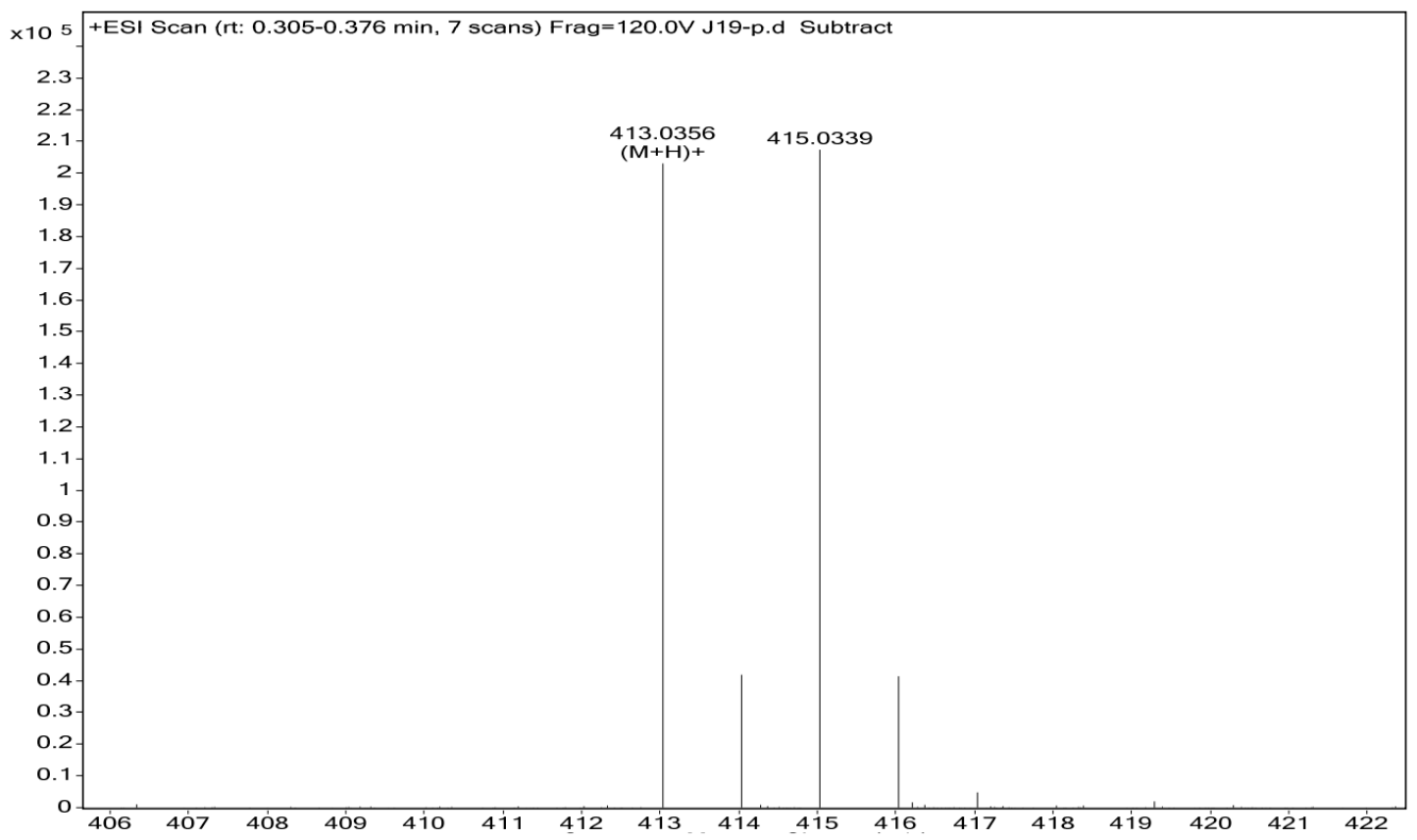


HPLC of compound S06-1025 $\left(t_{R}=6.81 \mathrm{~min}\right)$.

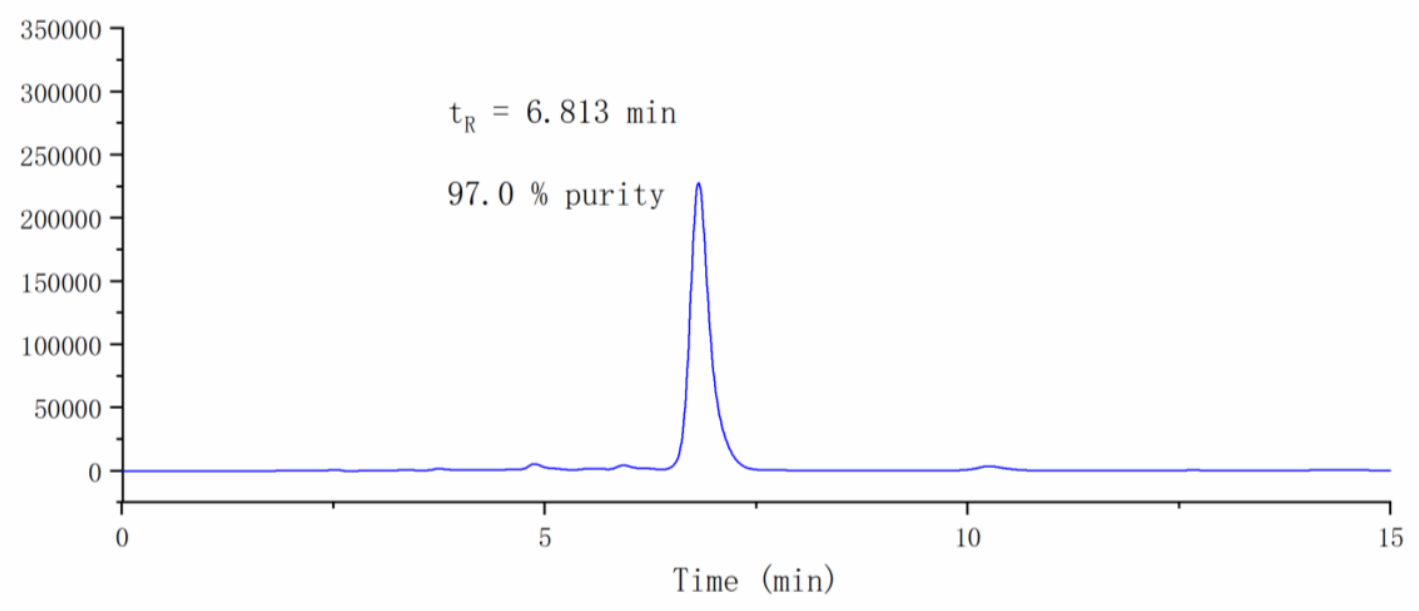

${ }^{1} \mathrm{H}$ NMR of compound S06-1025.

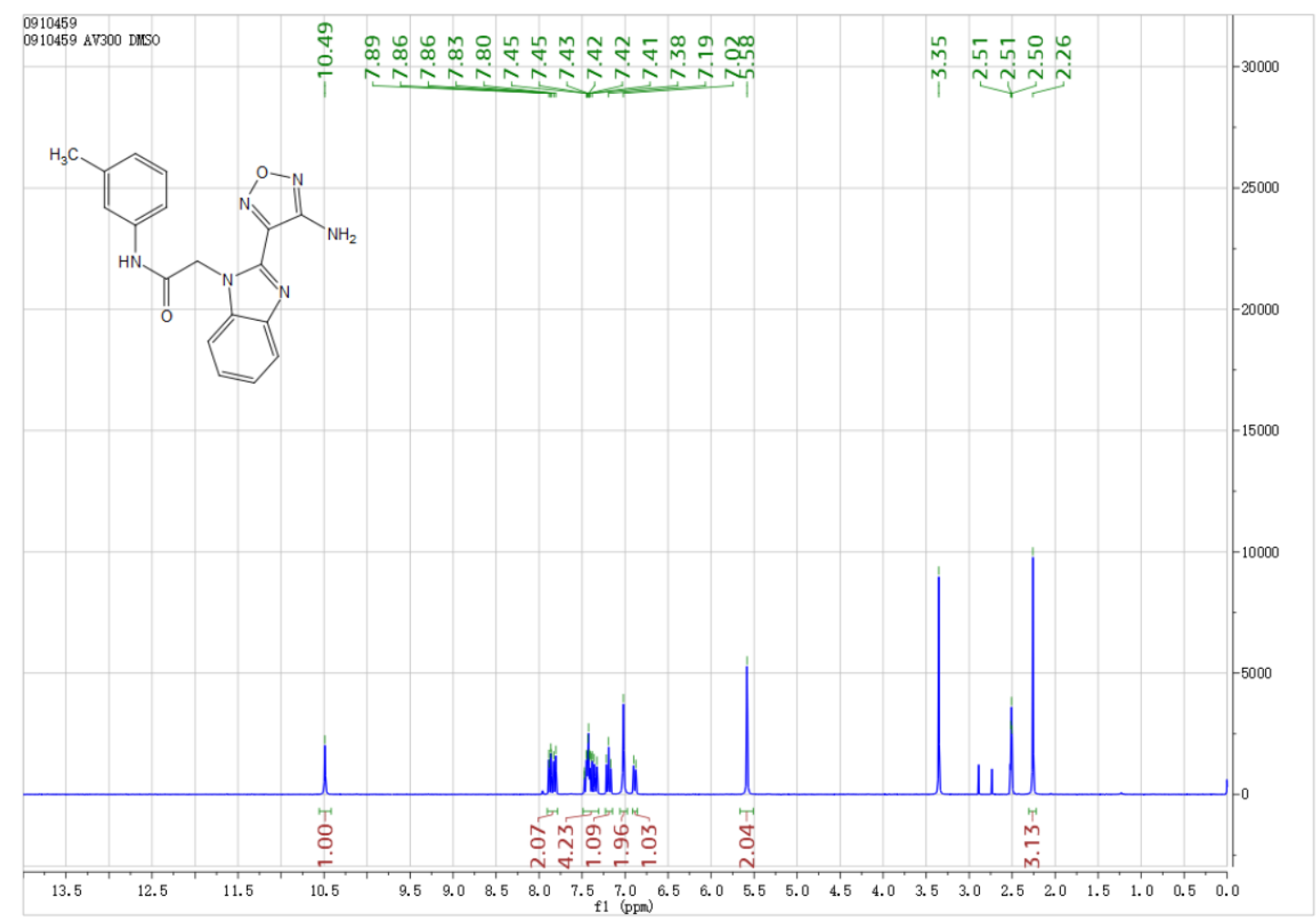

${ }^{13} \mathrm{C}$ NMR of compound S06-1025. 


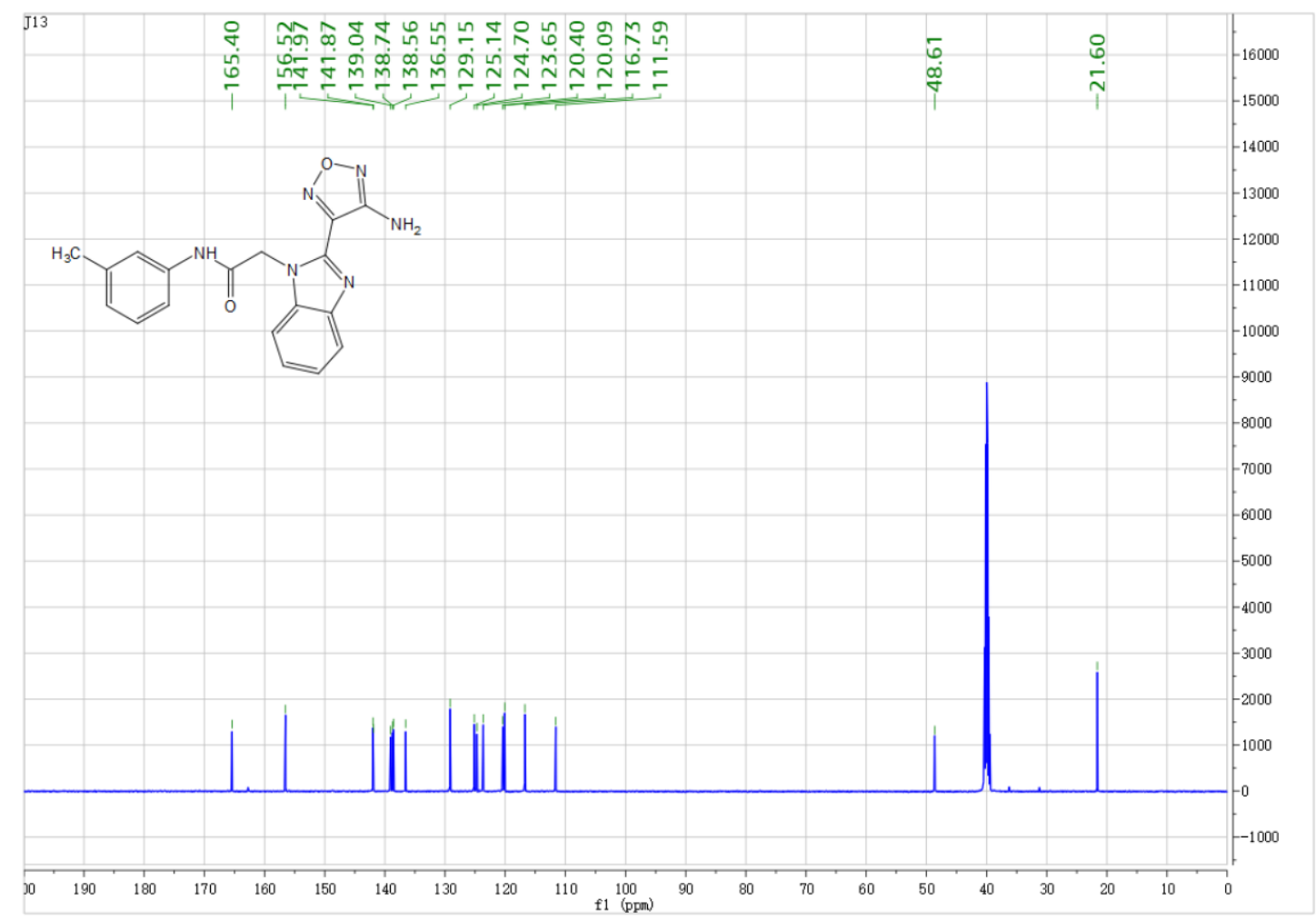

HRMS of compound S06-1025.

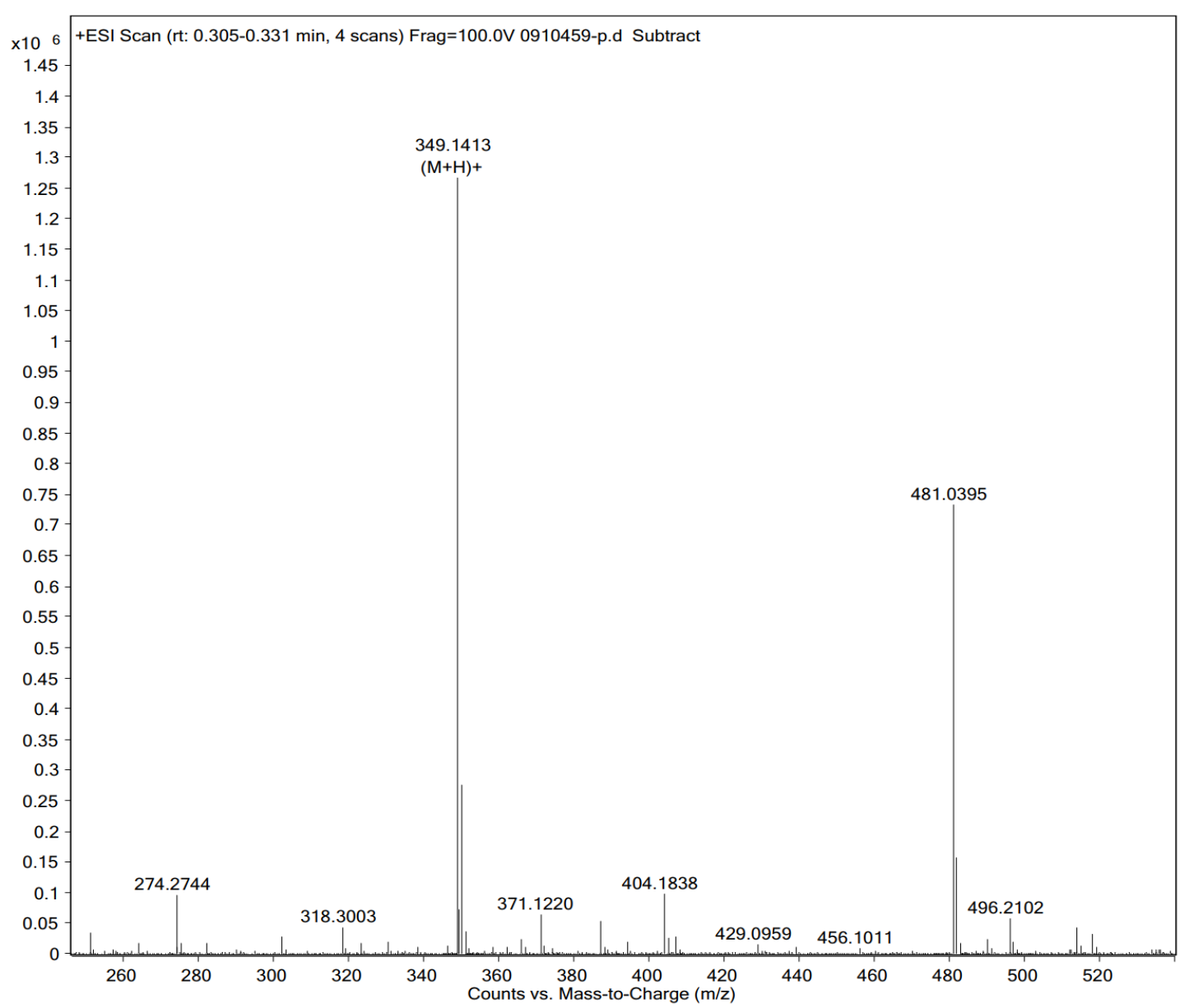


HPLC of compound S06-1026 $\left(t_{R}=6.71 \mathrm{~min}\right)$.

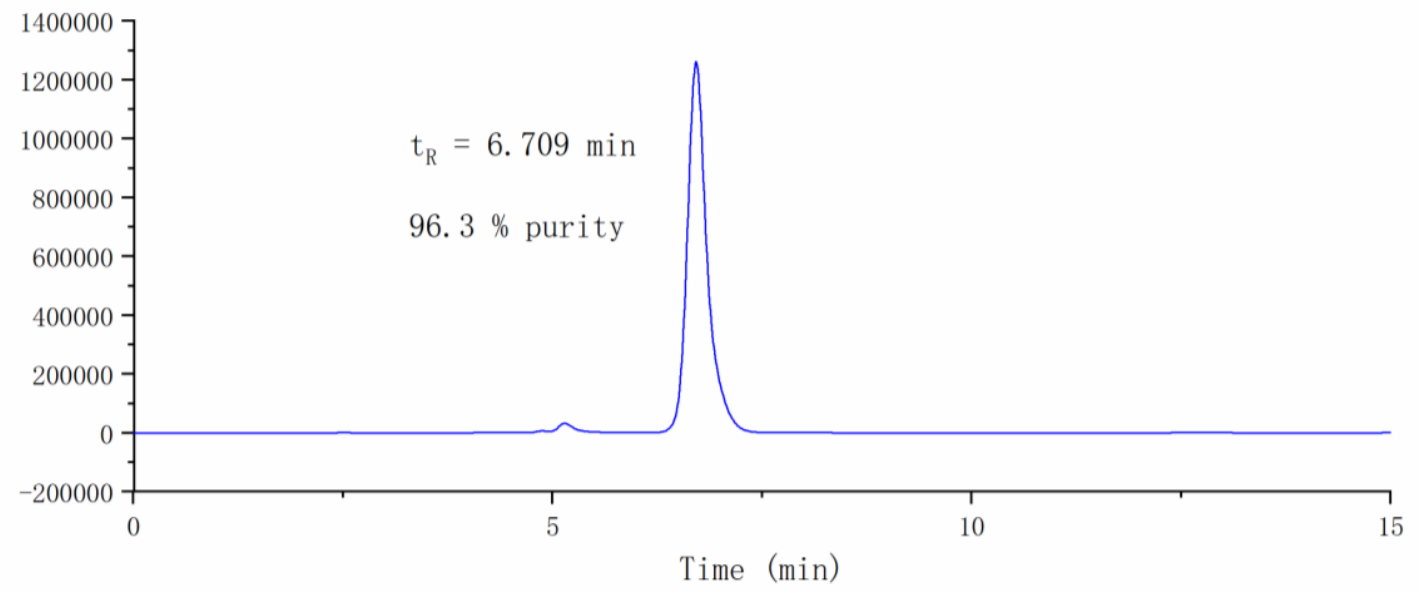

${ }^{1} \mathrm{H}$ NMR of compound S06-1026.

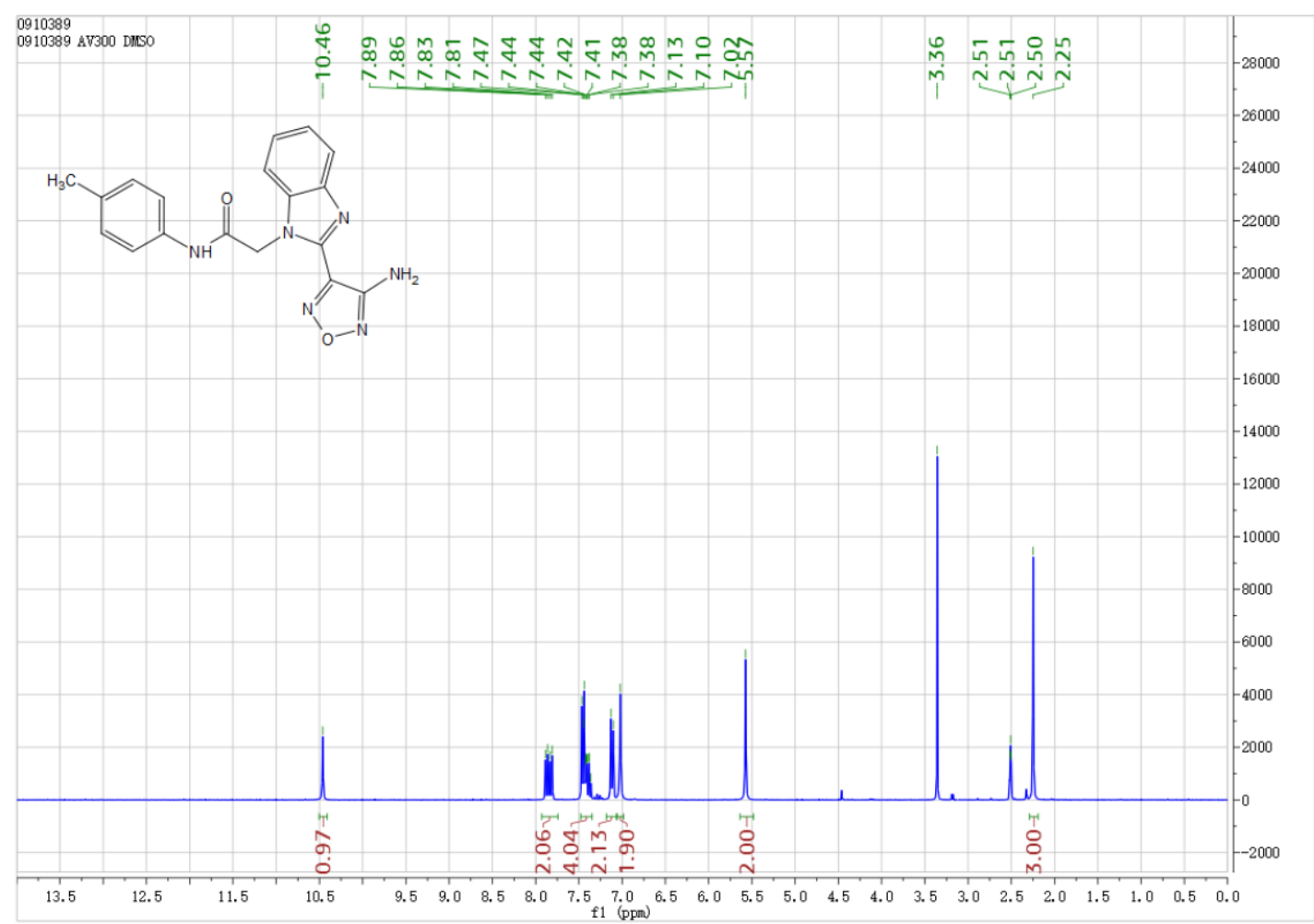

${ }^{13} \mathrm{C}$ NMR of compound S06-1026. 


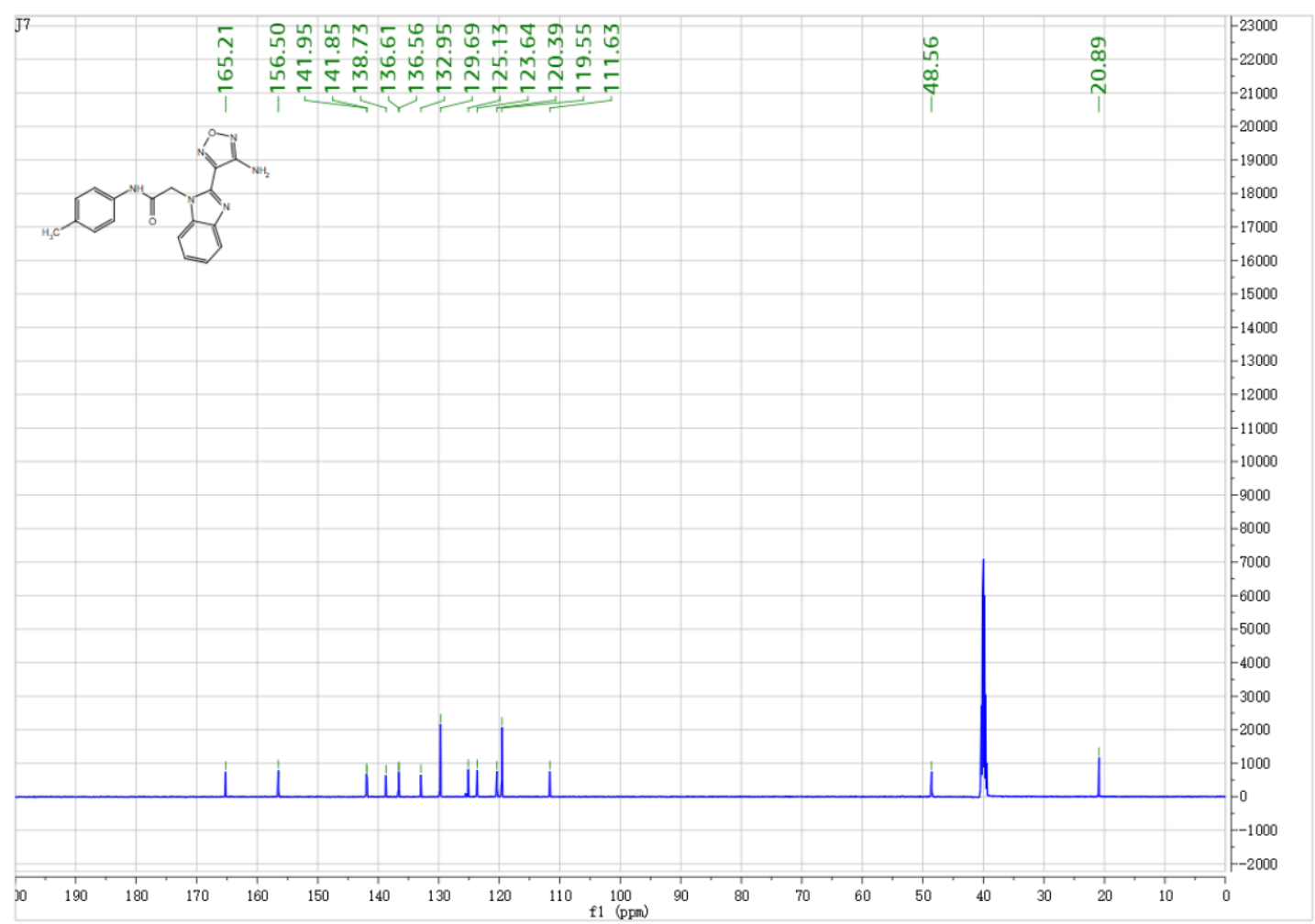

HRMS of compound S06-1026.

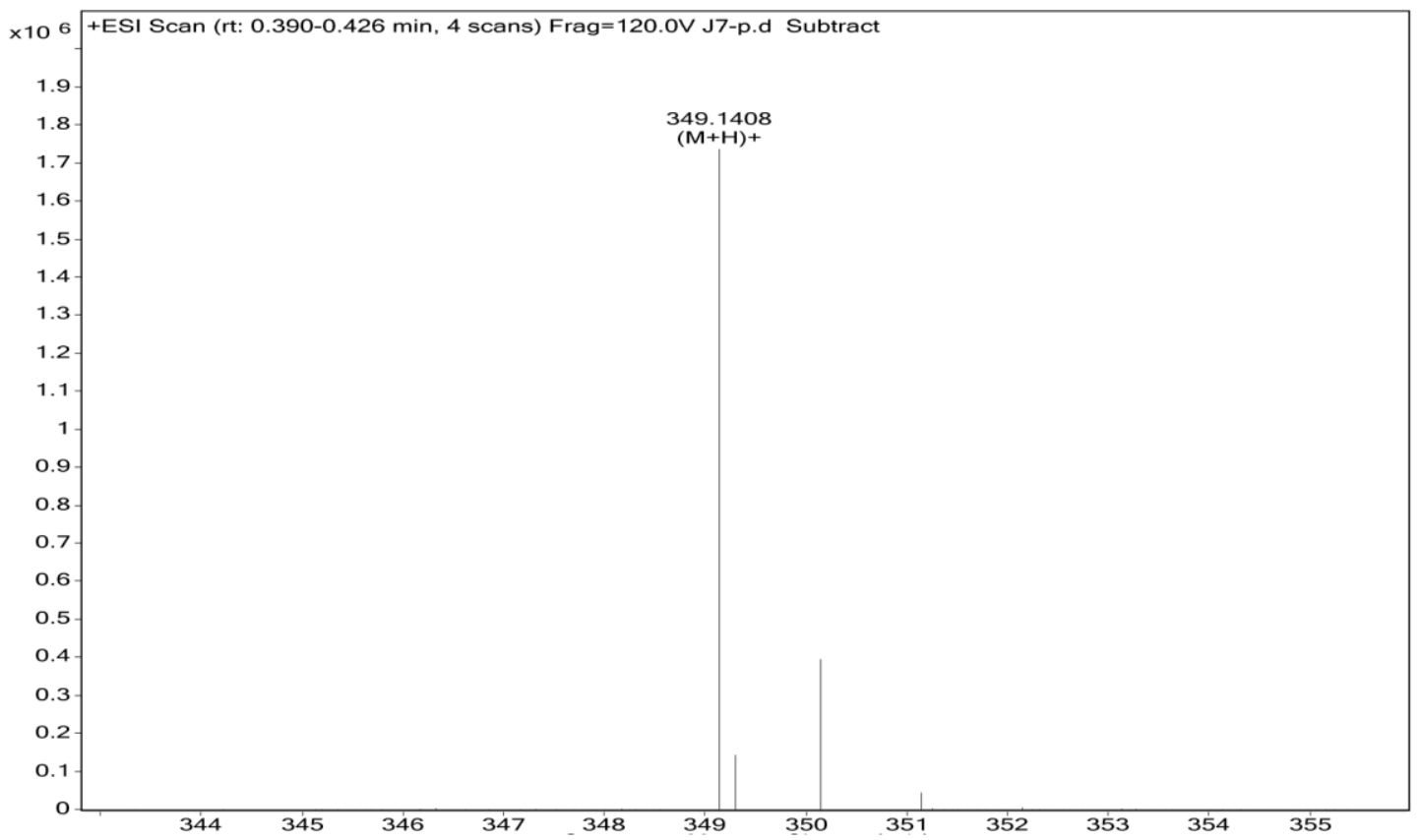


HPLC of compound S06-1027 $\left(t_{R}=6.24 \mathrm{~min}\right)$.

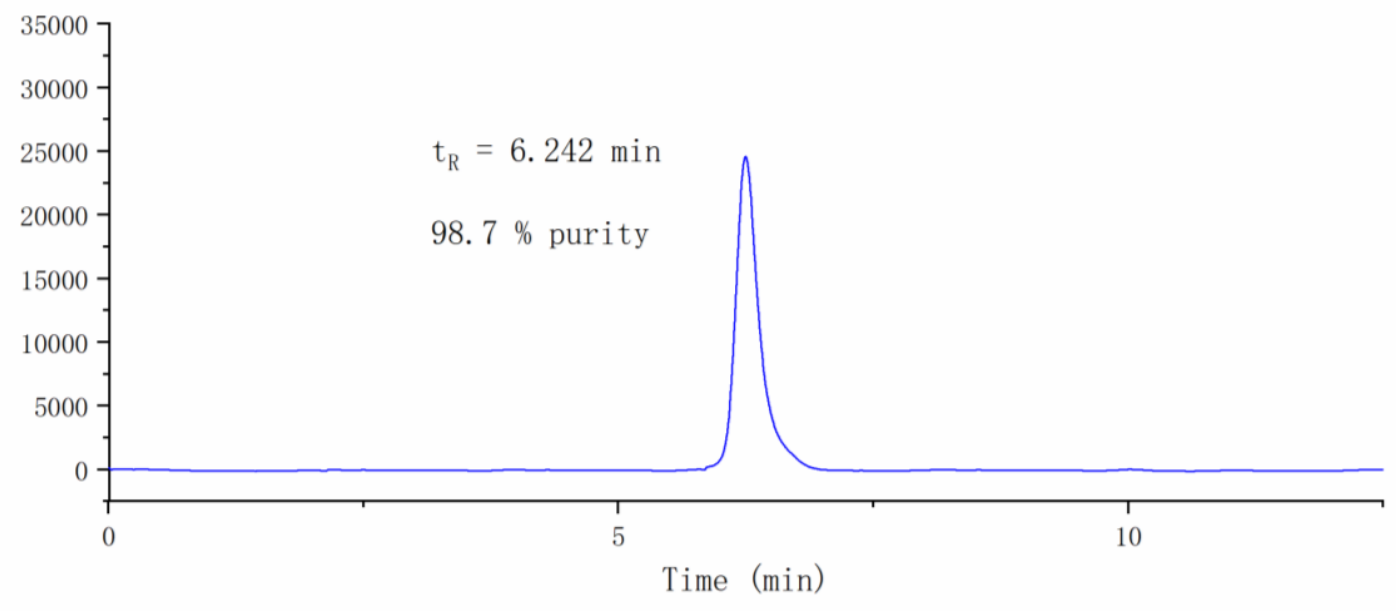

${ }^{1} \mathrm{H}$ NMR of compound S06-1027.

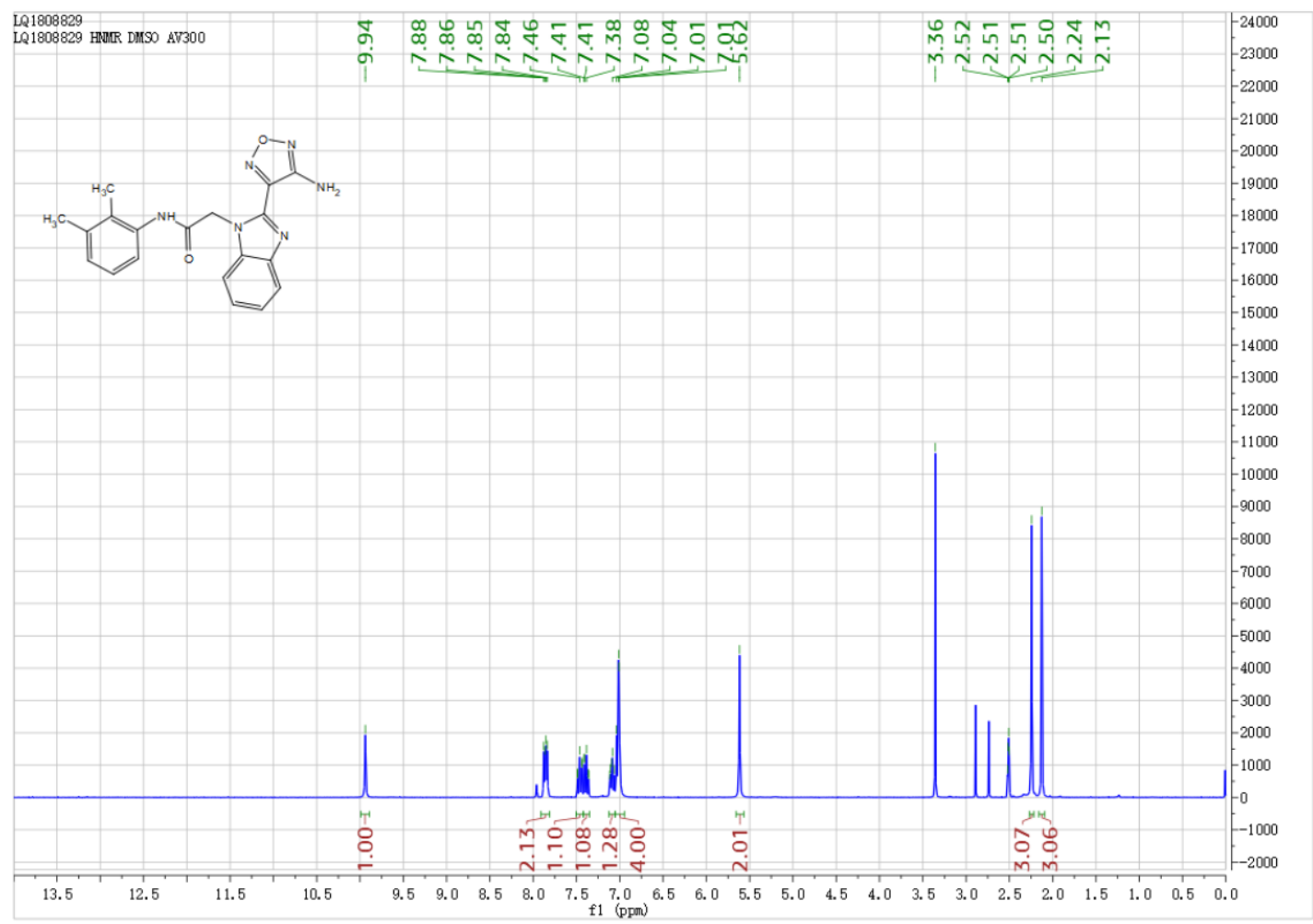

${ }^{13} \mathrm{C}$ NMR of compound S06-1027. 


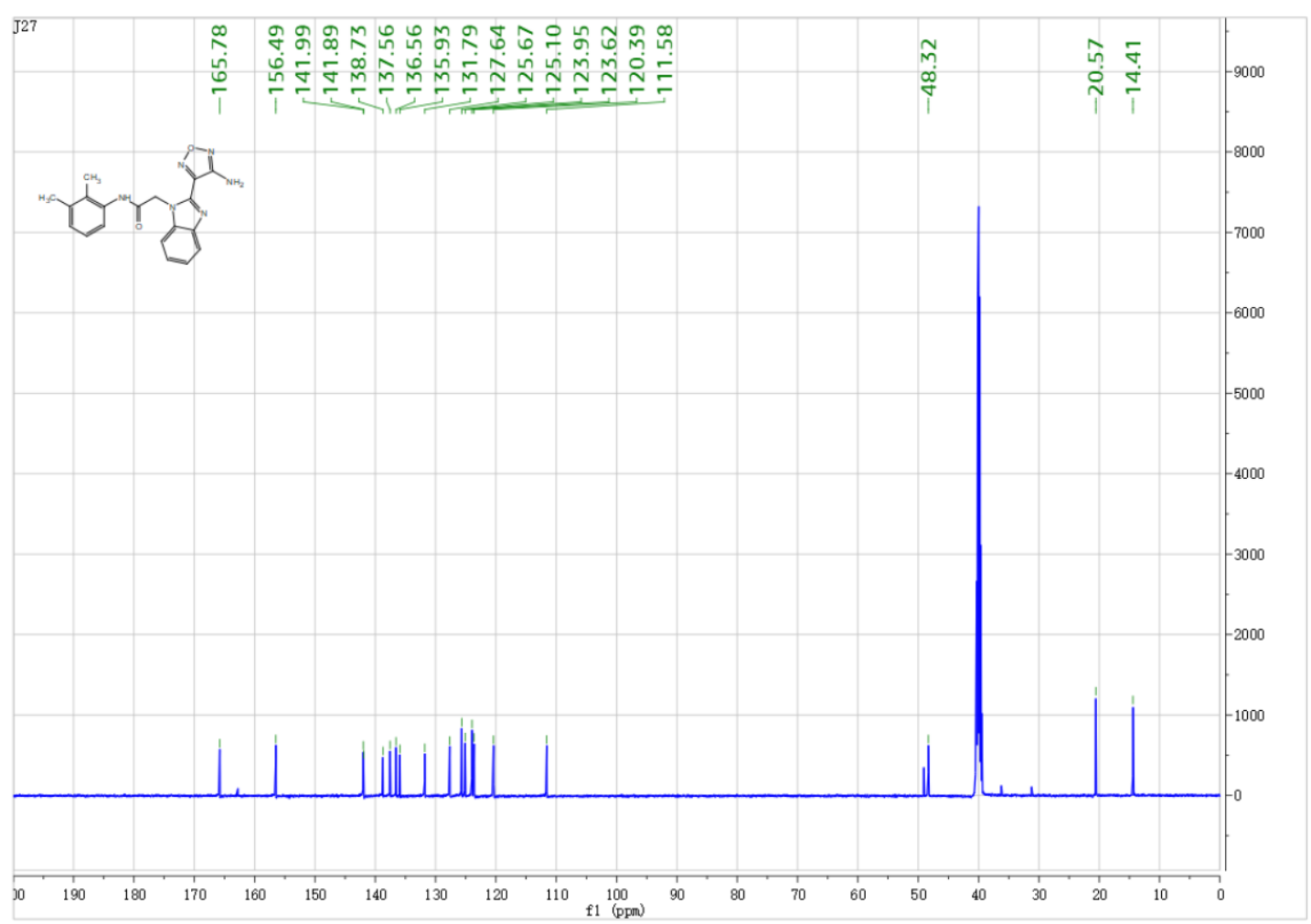

HRMS of compound S06-1027.

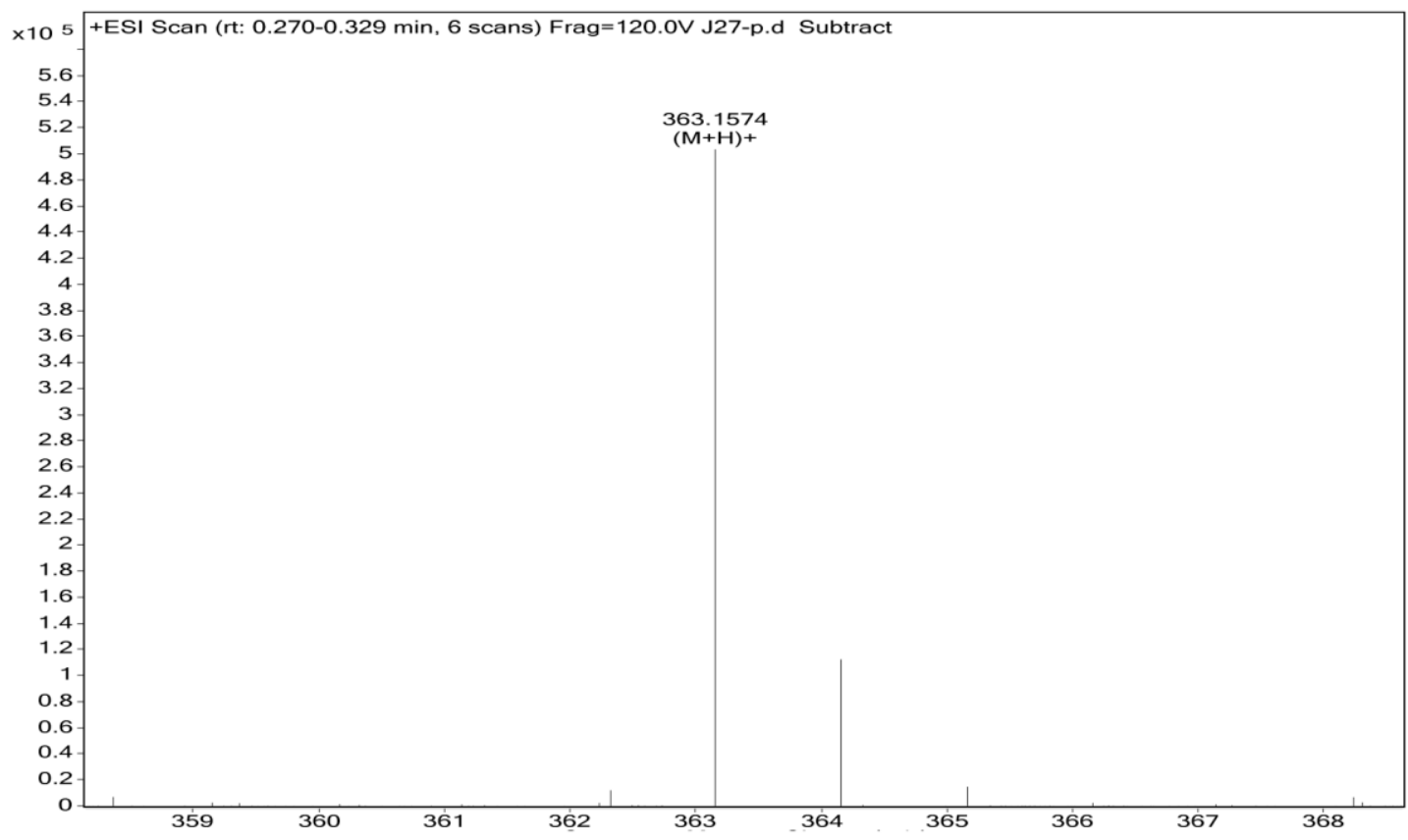


HPLC of compound S06-1028 $\left(t_{R}=5.05 \mathrm{~min}\right)$.

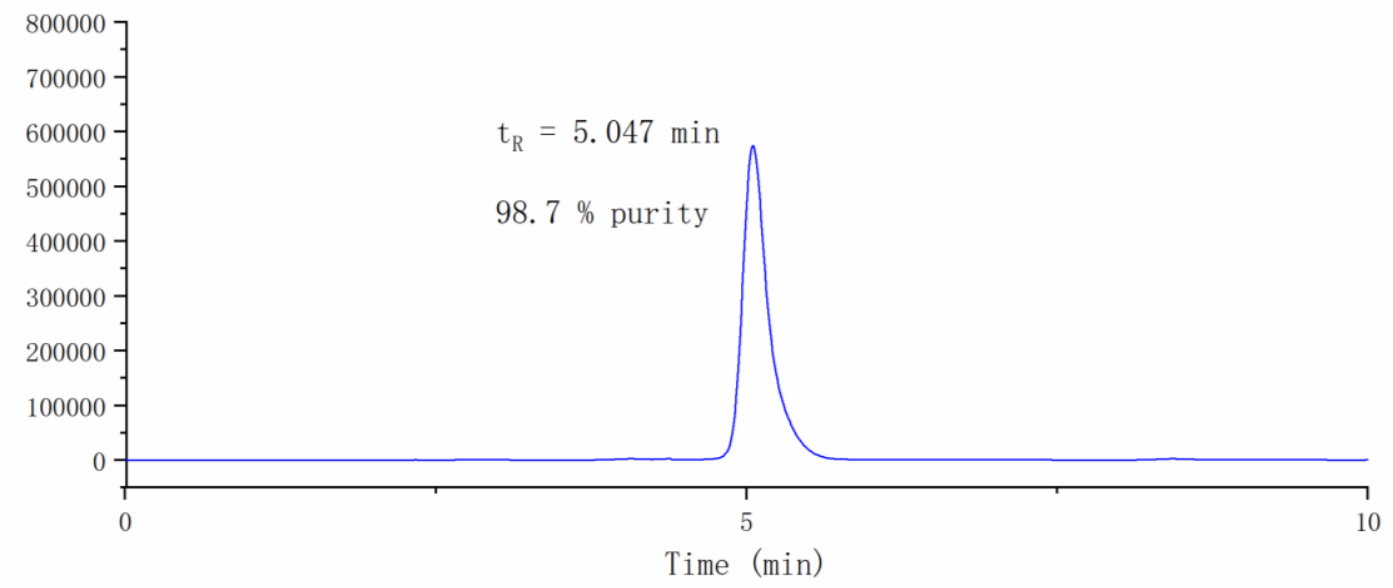

${ }^{1} \mathrm{H}$ NMR of compound S06-1028.

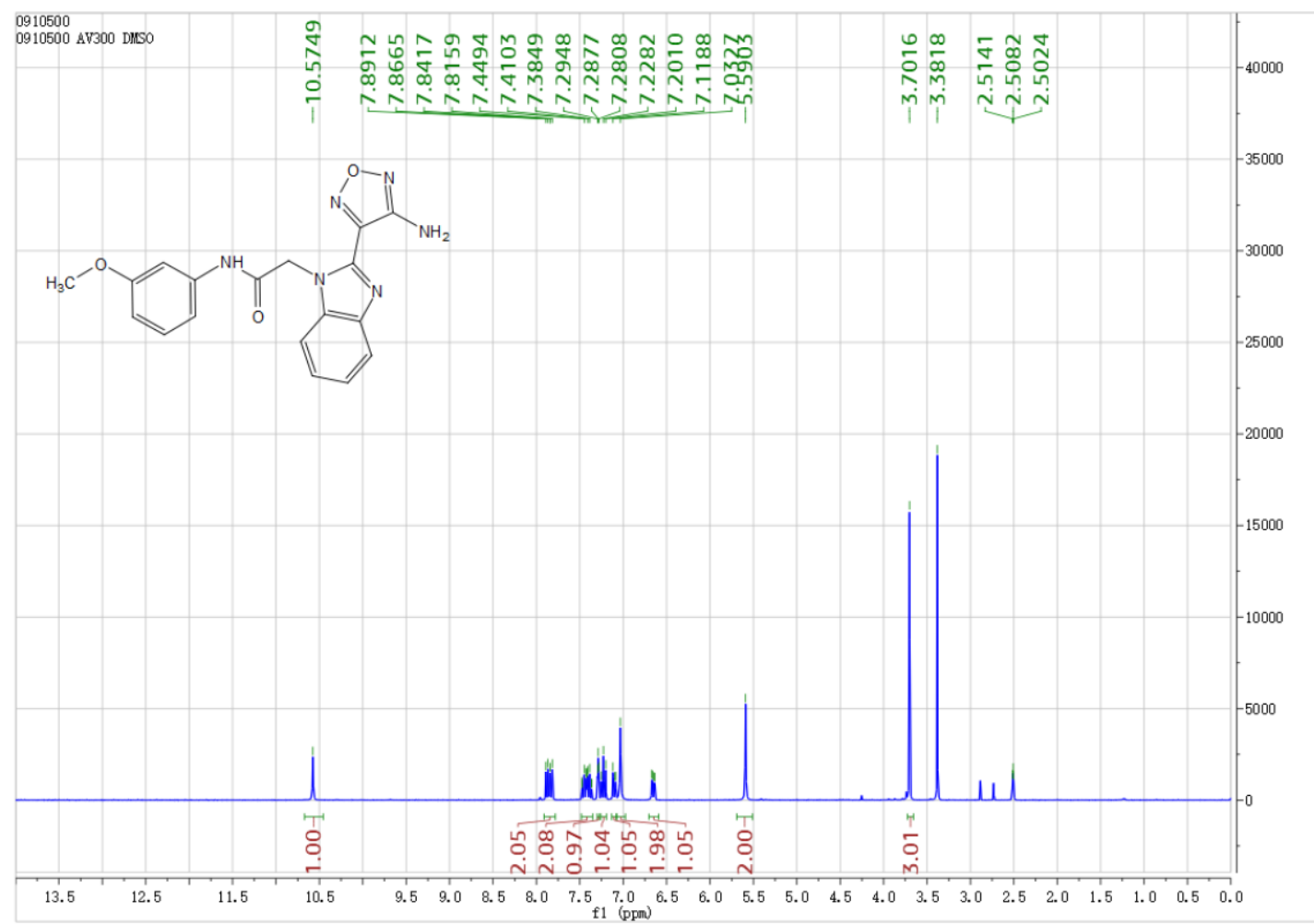

${ }^{13} \mathrm{C}$ NMR of compound S06-1028. 


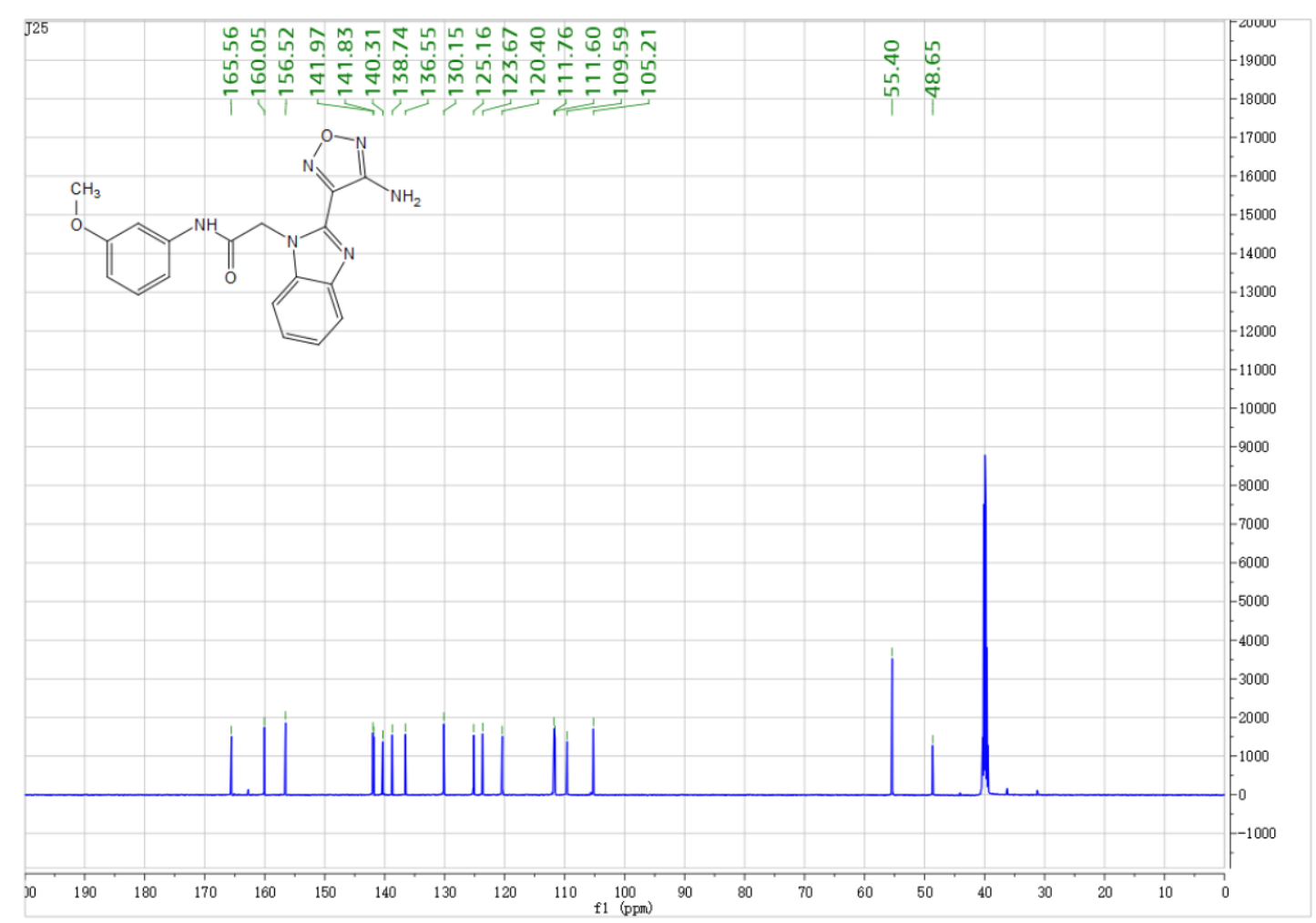

HRMS of compound S06-1028.

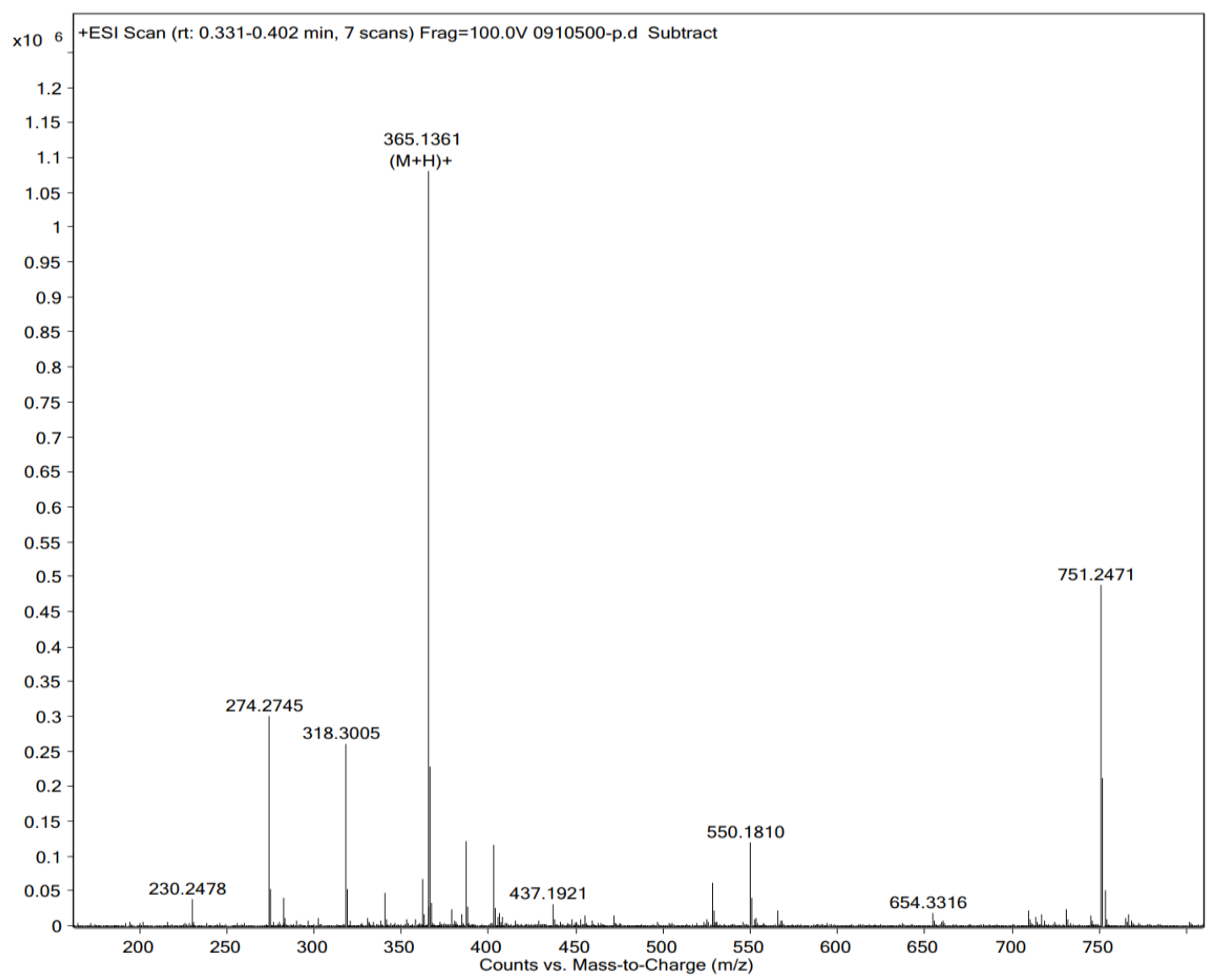


HPLC of compound S06-1029 $\left(t_{R}=5.15 \mathrm{~min}\right)$.

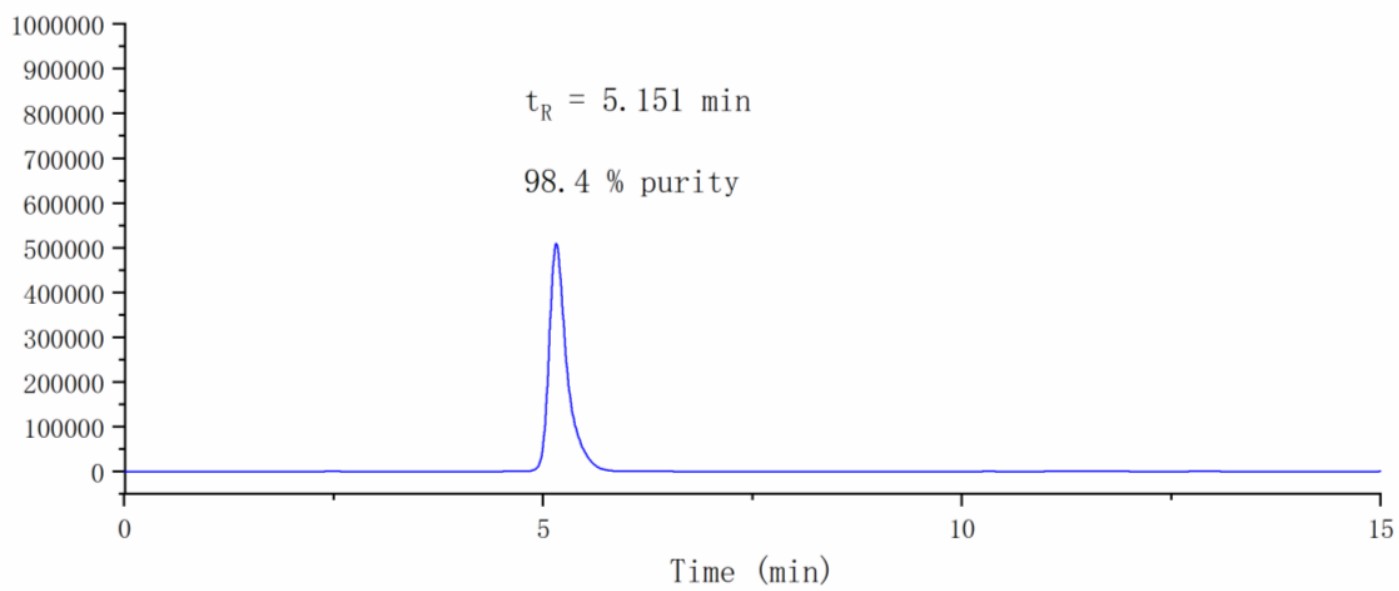

${ }^{1} \mathrm{H}$ NMR of compound S06-1029.

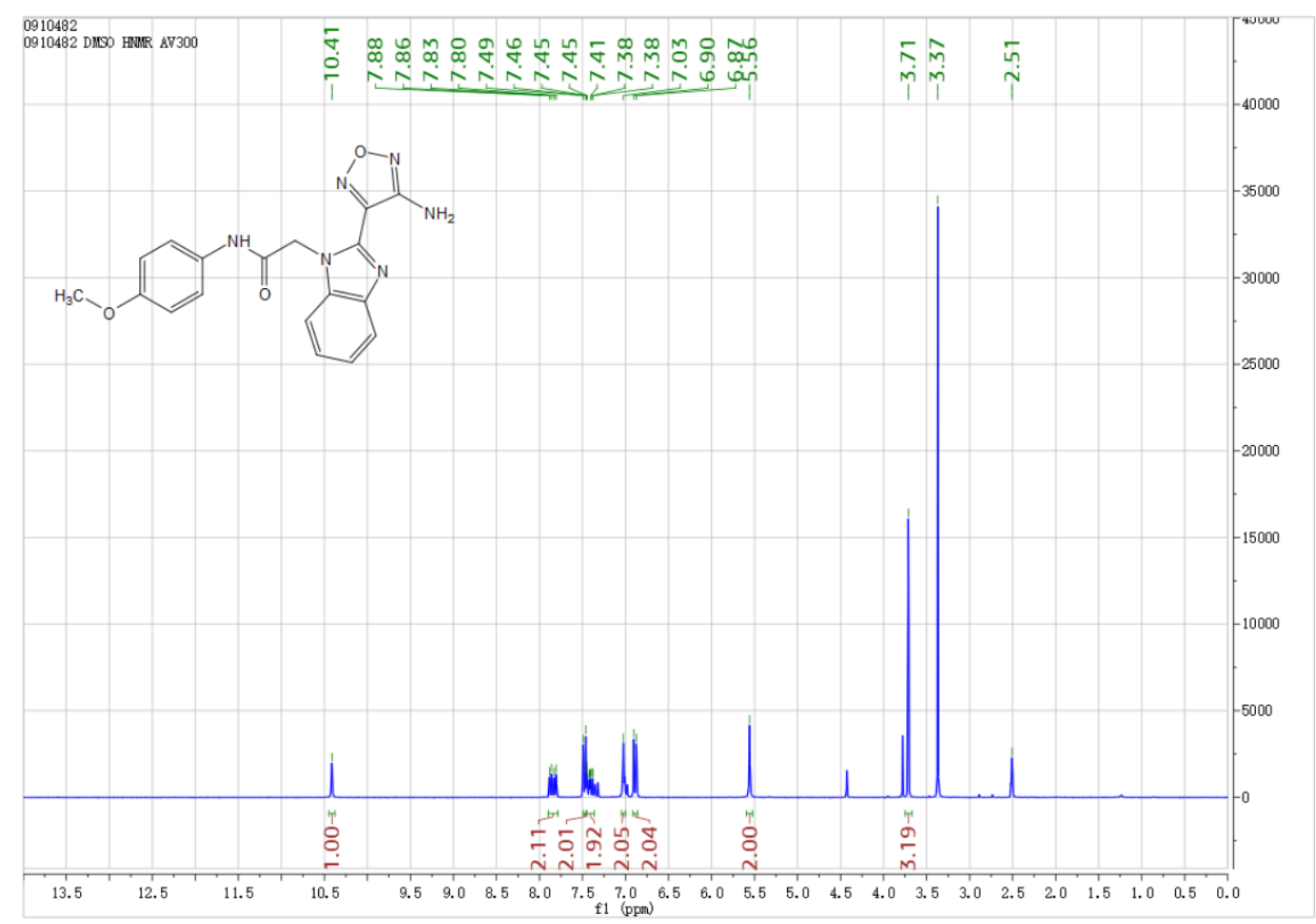

${ }^{13} \mathrm{C}$ NMR of compound S06-1029. 


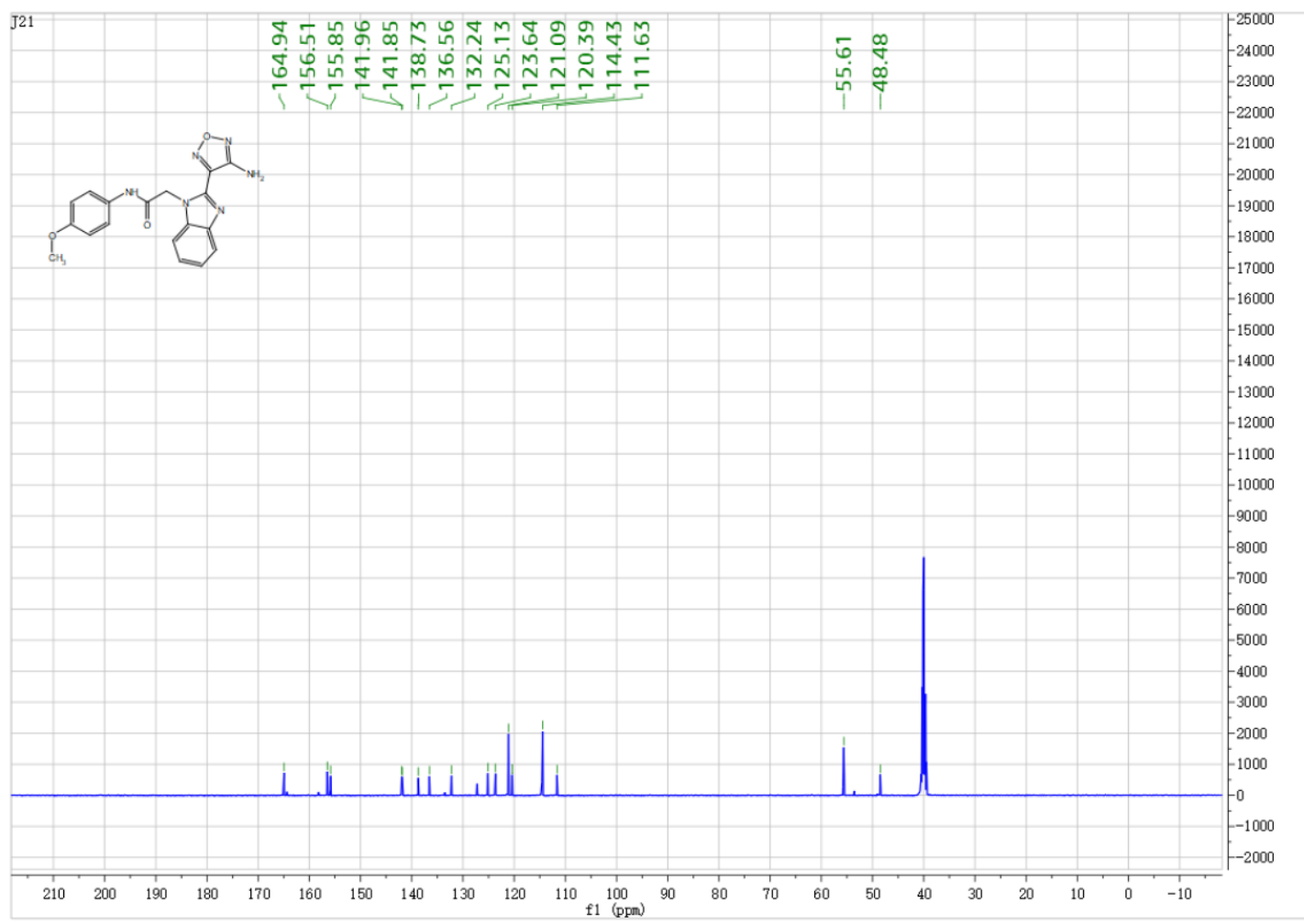

HRMS of compound S06-1029.

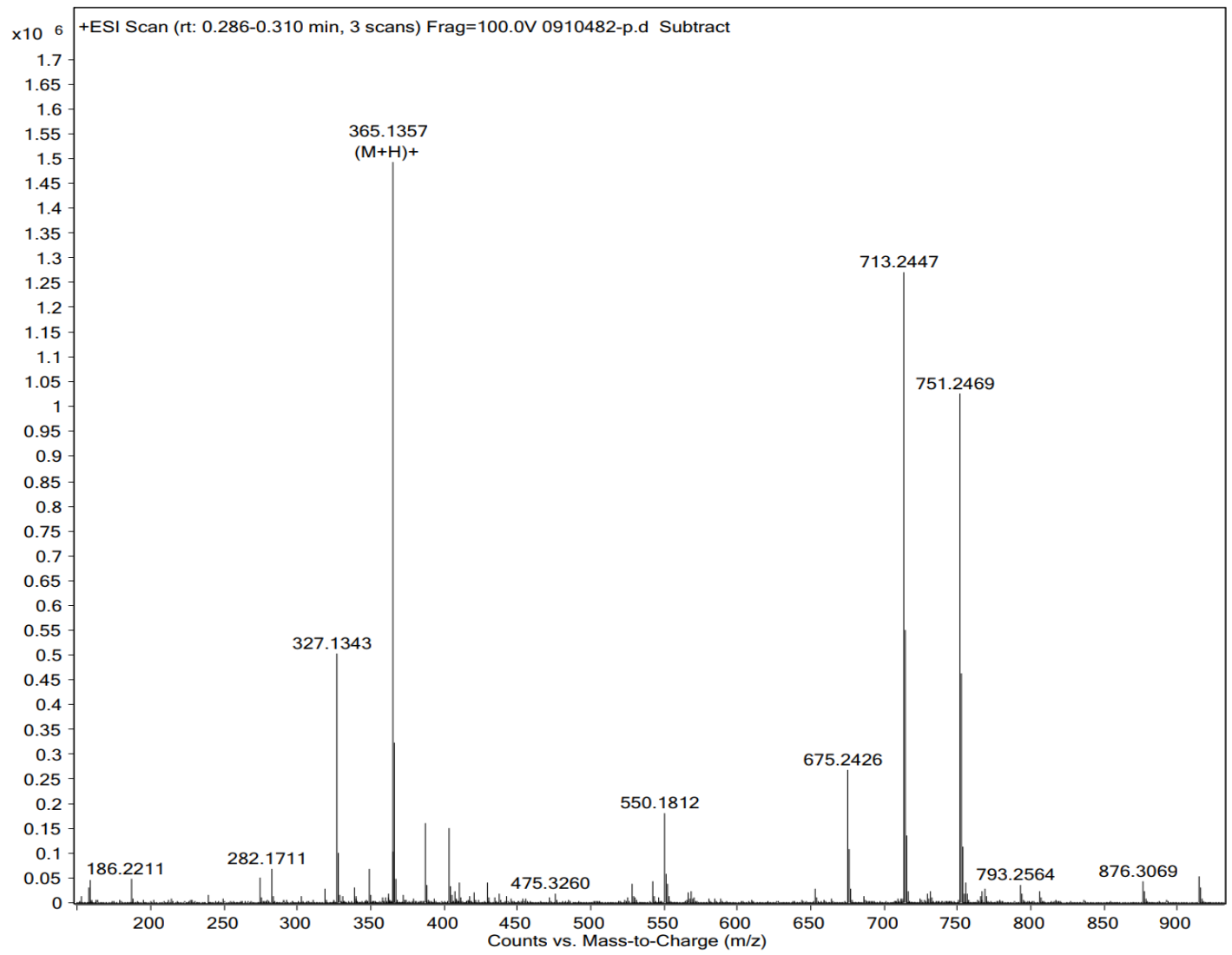


HPLC of compound S06-1030 $\left(t_{R}=4.95 \mathrm{~min}\right)$.

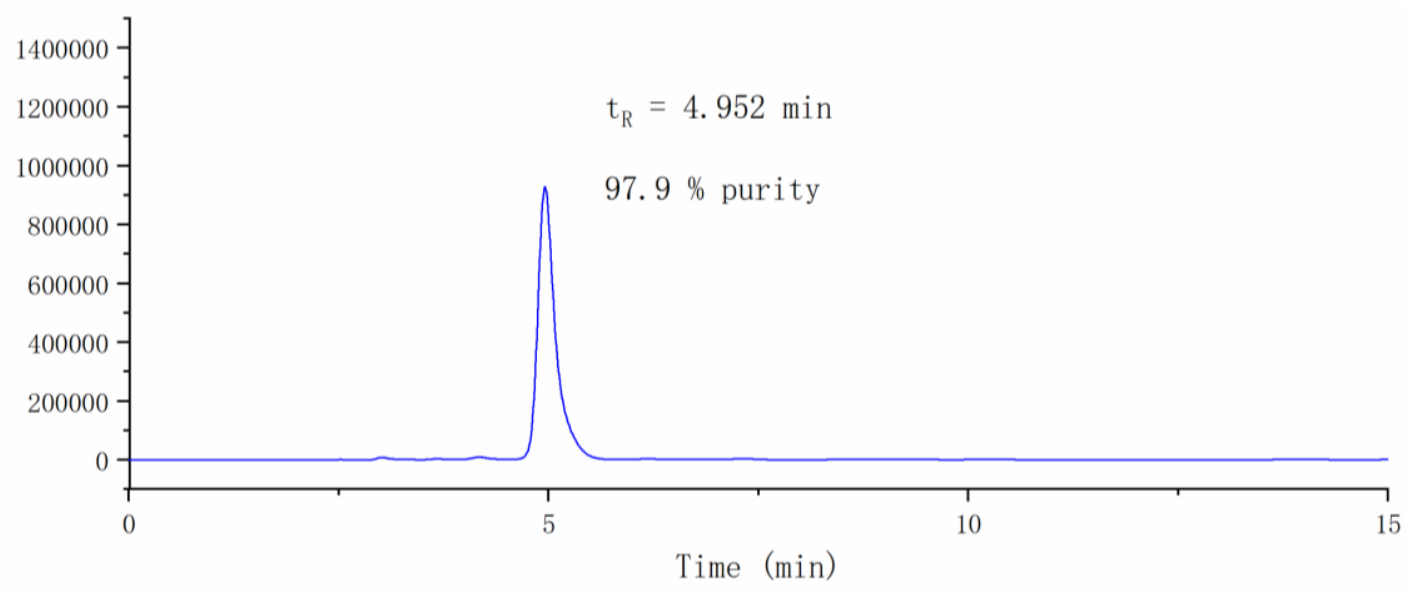

${ }^{1} \mathrm{H}$ NMR of compound S06-1030.

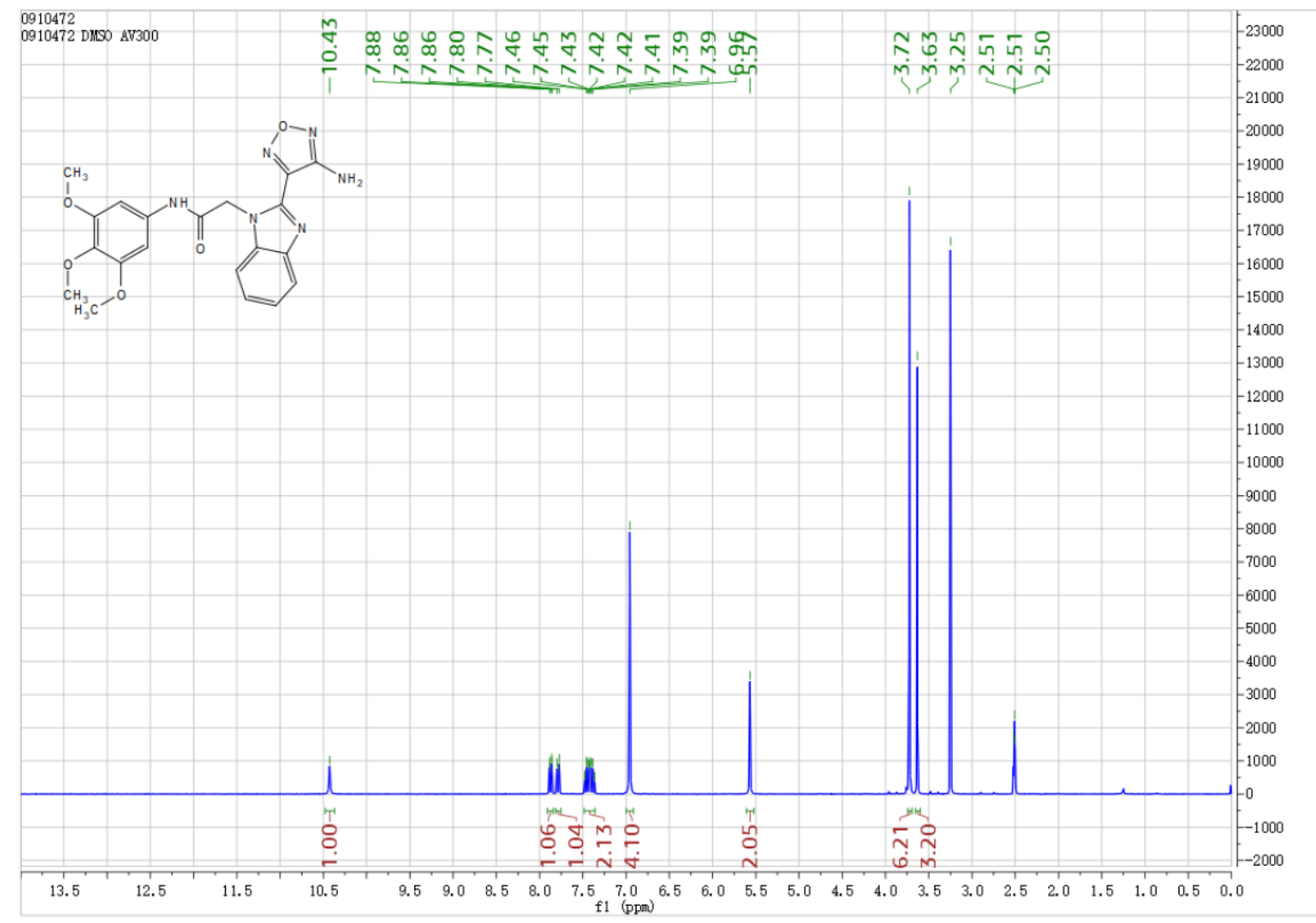

${ }^{13} \mathrm{C}$ NMR of compound S06-1030. 


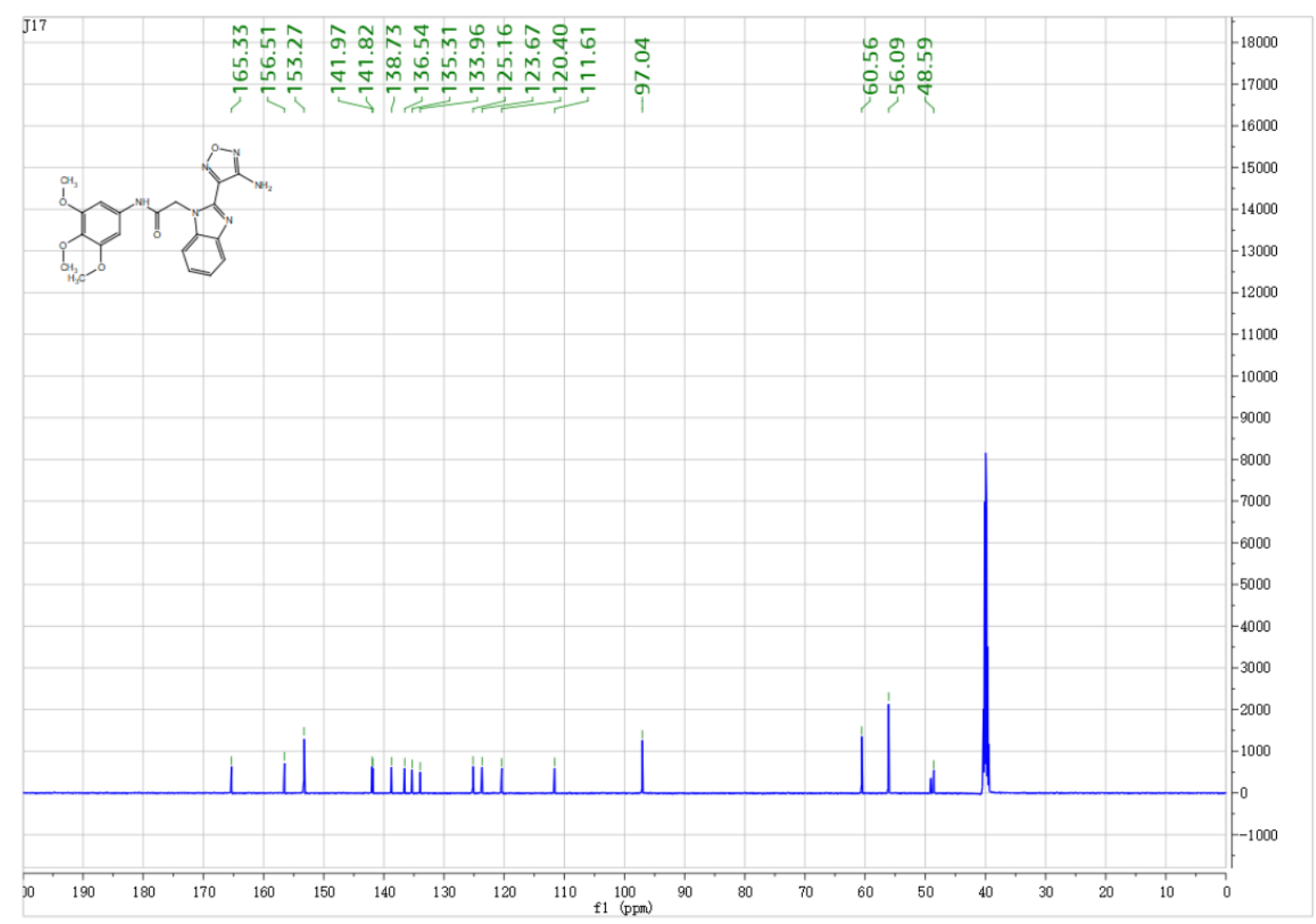

HRMS of compound S06-1030.

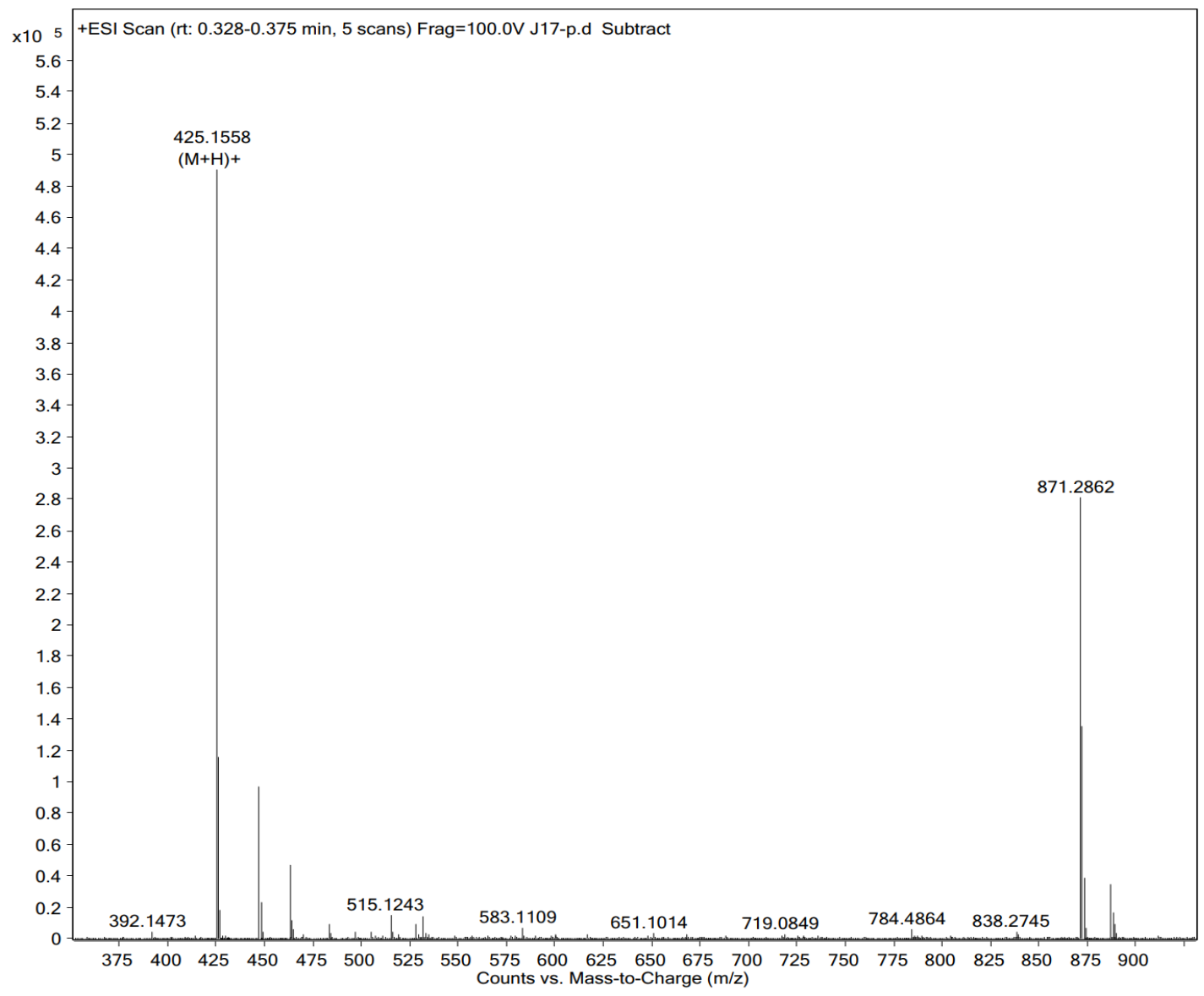


HPLC of compound S06-1031 $\left(t_{R}=13.72 \mathrm{~min}\right)$.

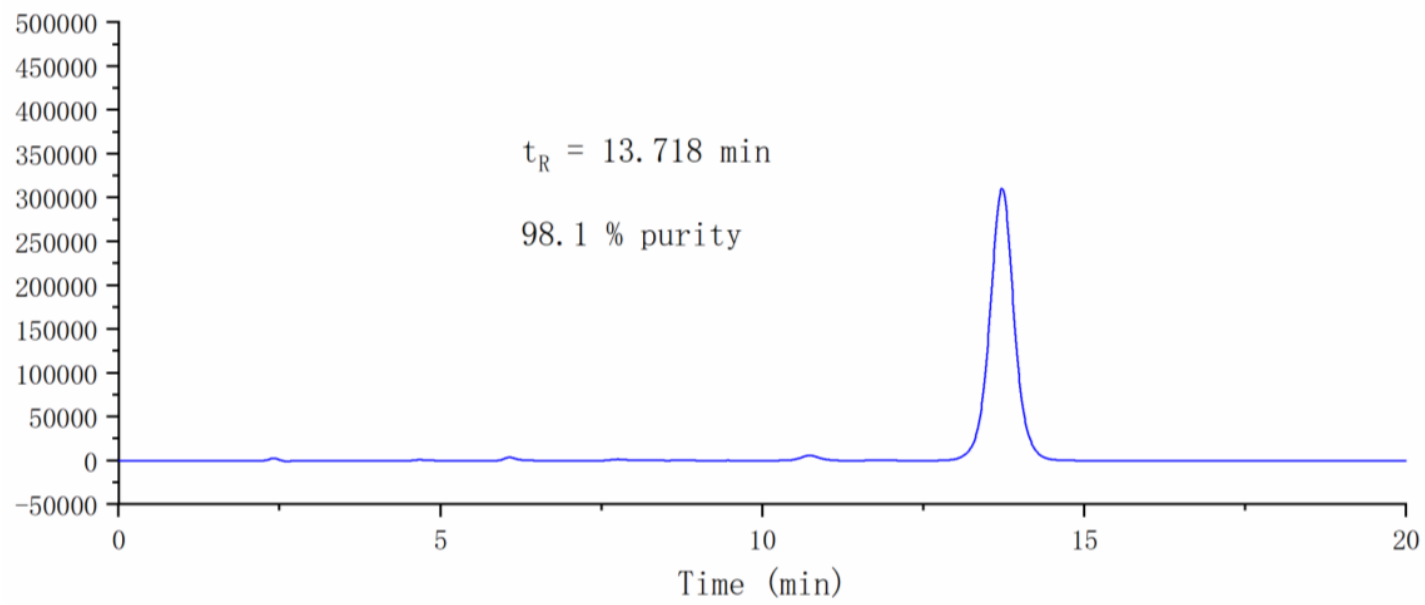

${ }^{1} \mathrm{H}$ NMR of compound S06-1031.

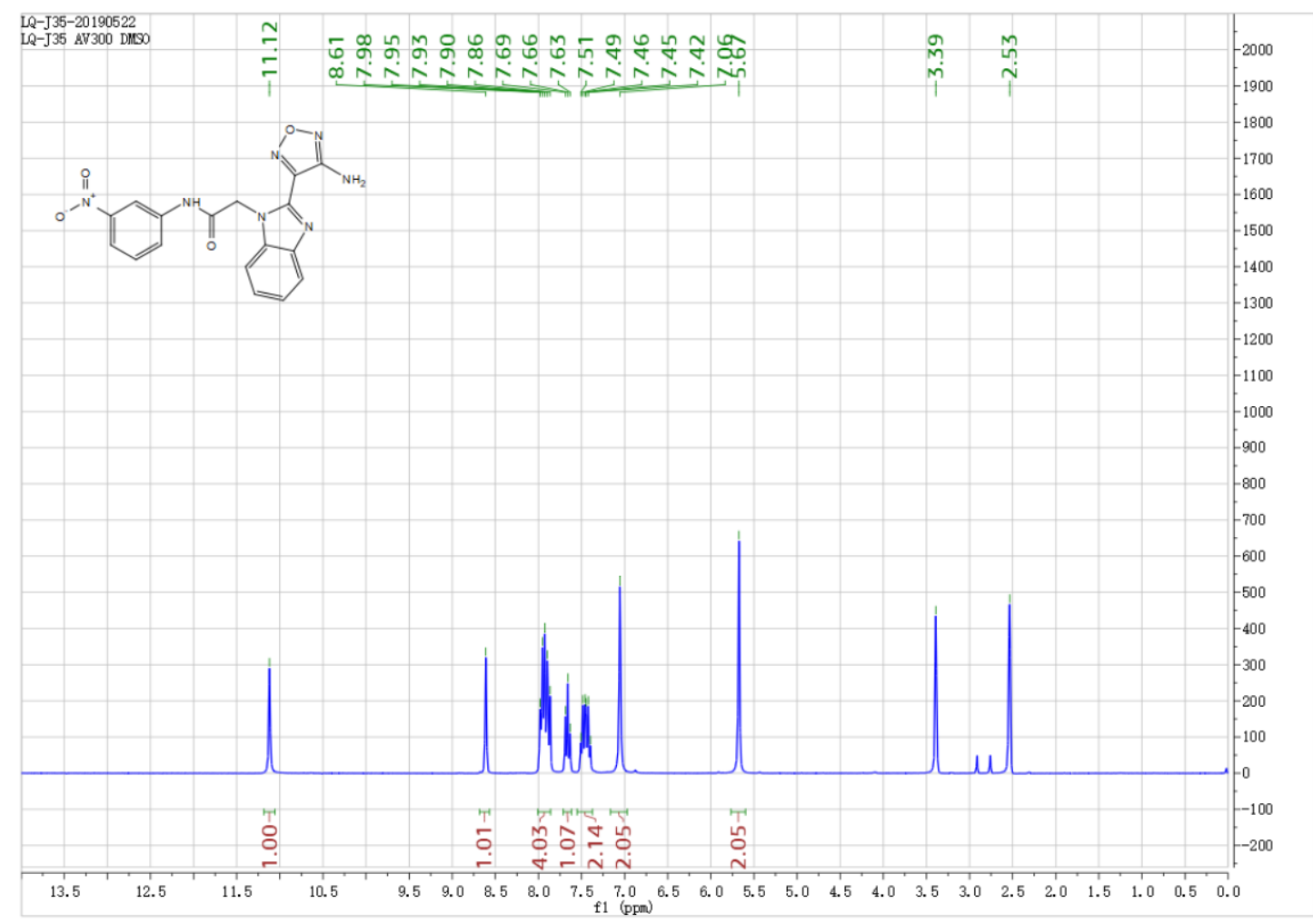

${ }^{13} \mathrm{C}$ NMR of compound S06-1031. 


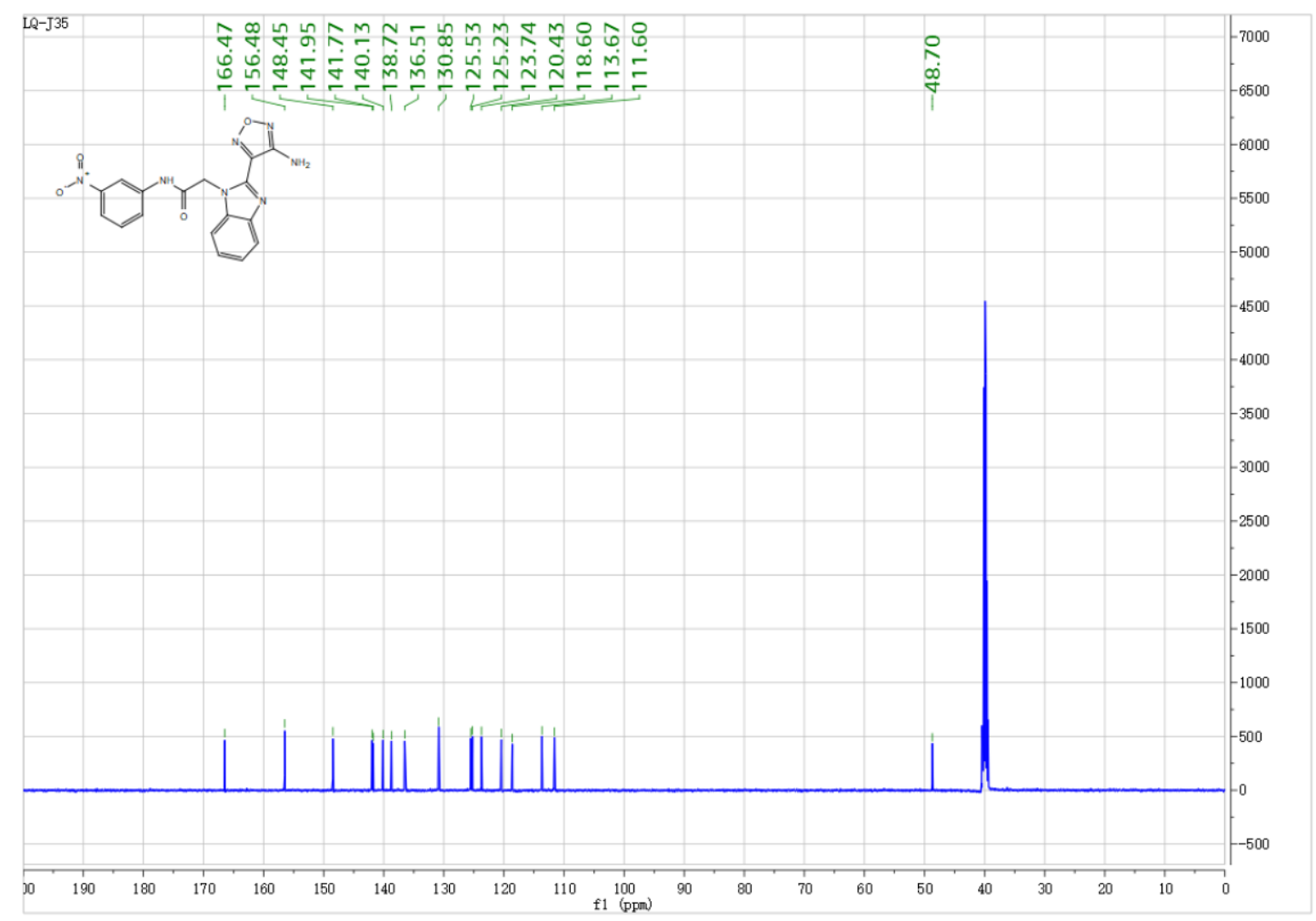

HRMS of compound S06-1031.

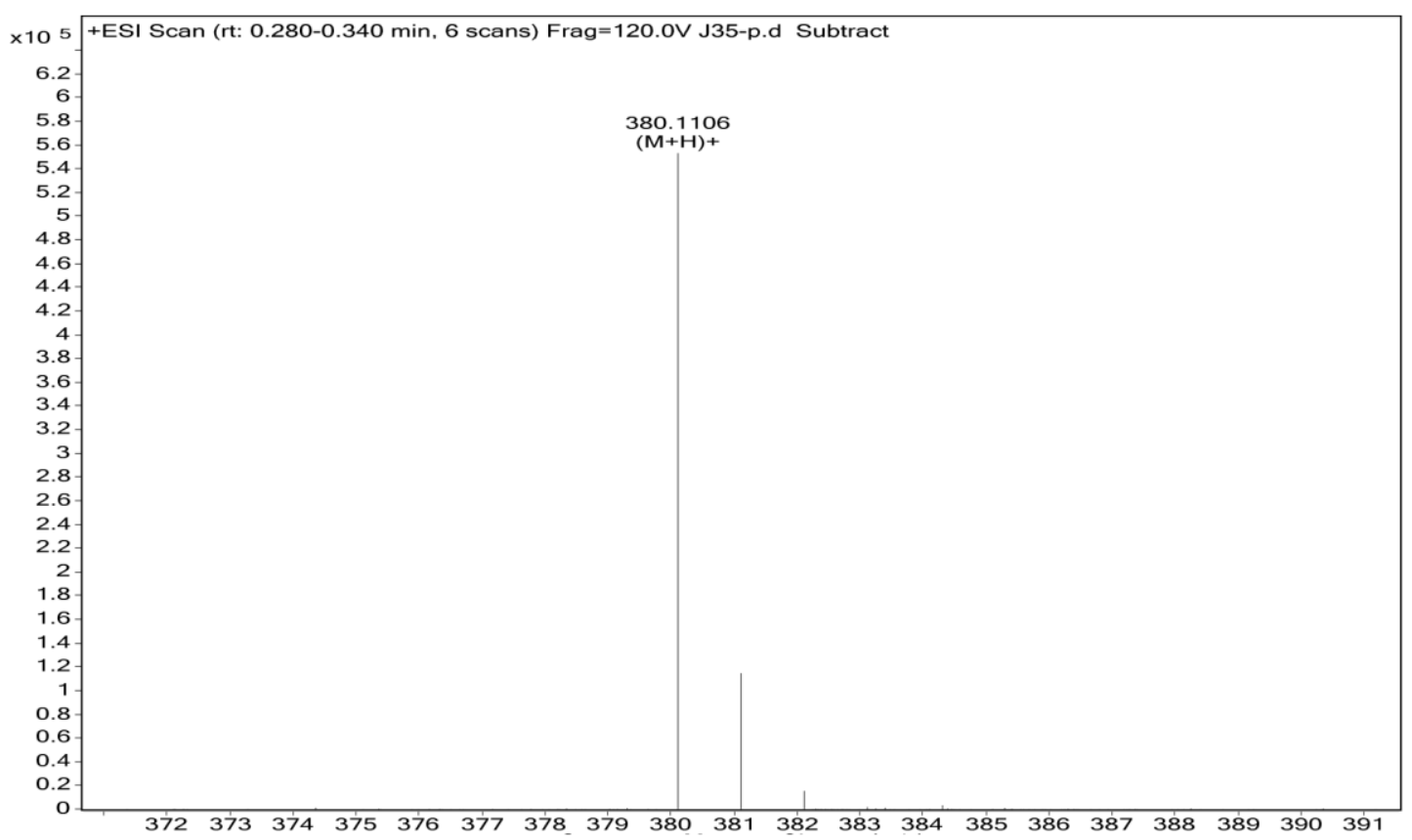


HPLC of compound S06-1032 $\left(t_{R}=6.60 \mathrm{~min}\right)$.

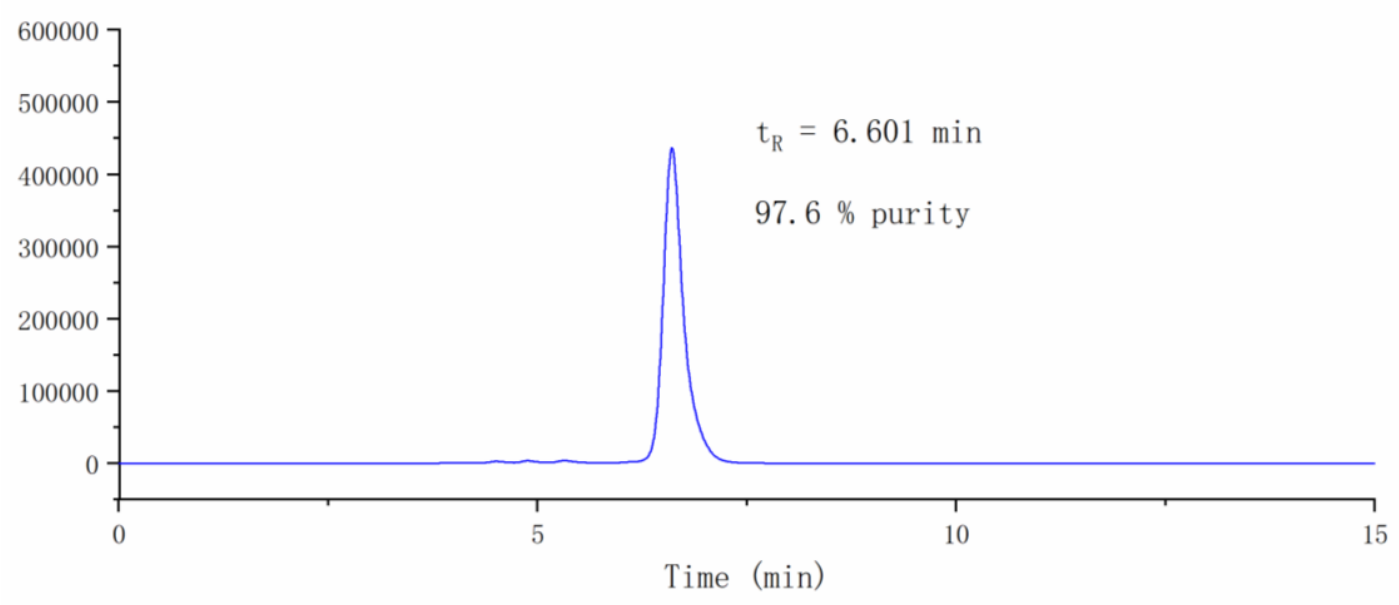

${ }^{1} \mathrm{H}$ NMR of compound S06-1032.

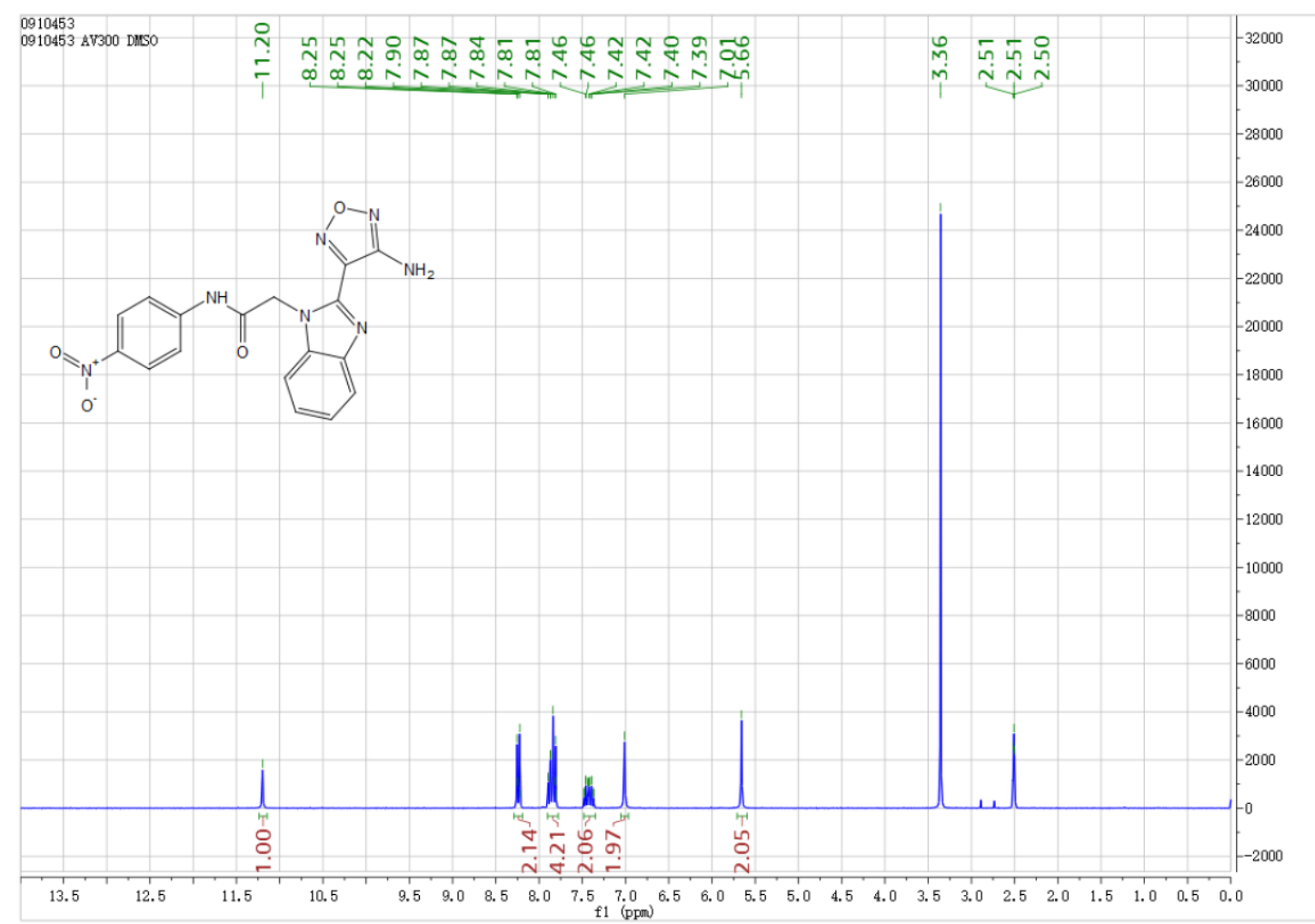

${ }^{13} \mathrm{C}$ NMR of compound S06-1032. 


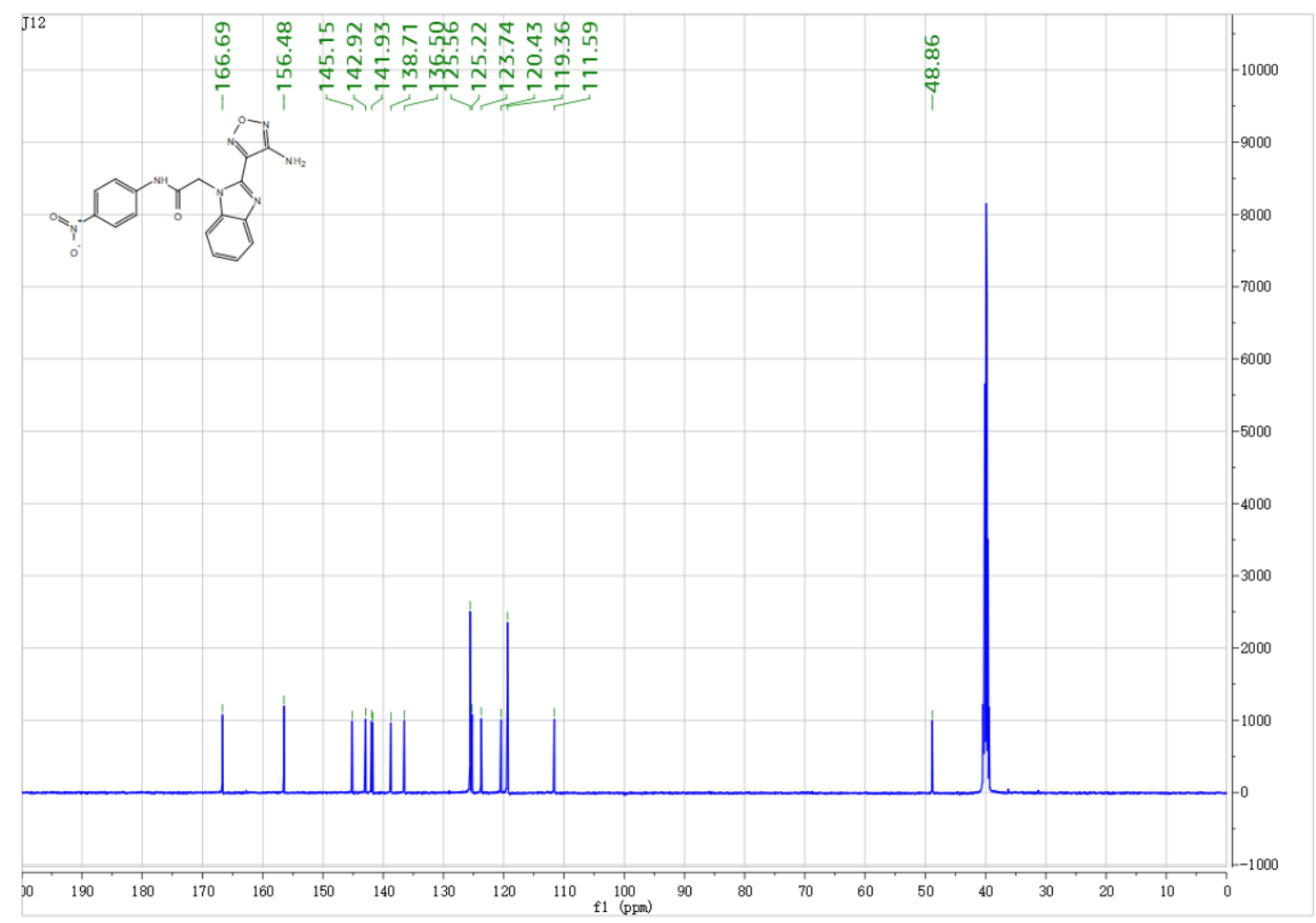

HRMS of compound S06-1032.

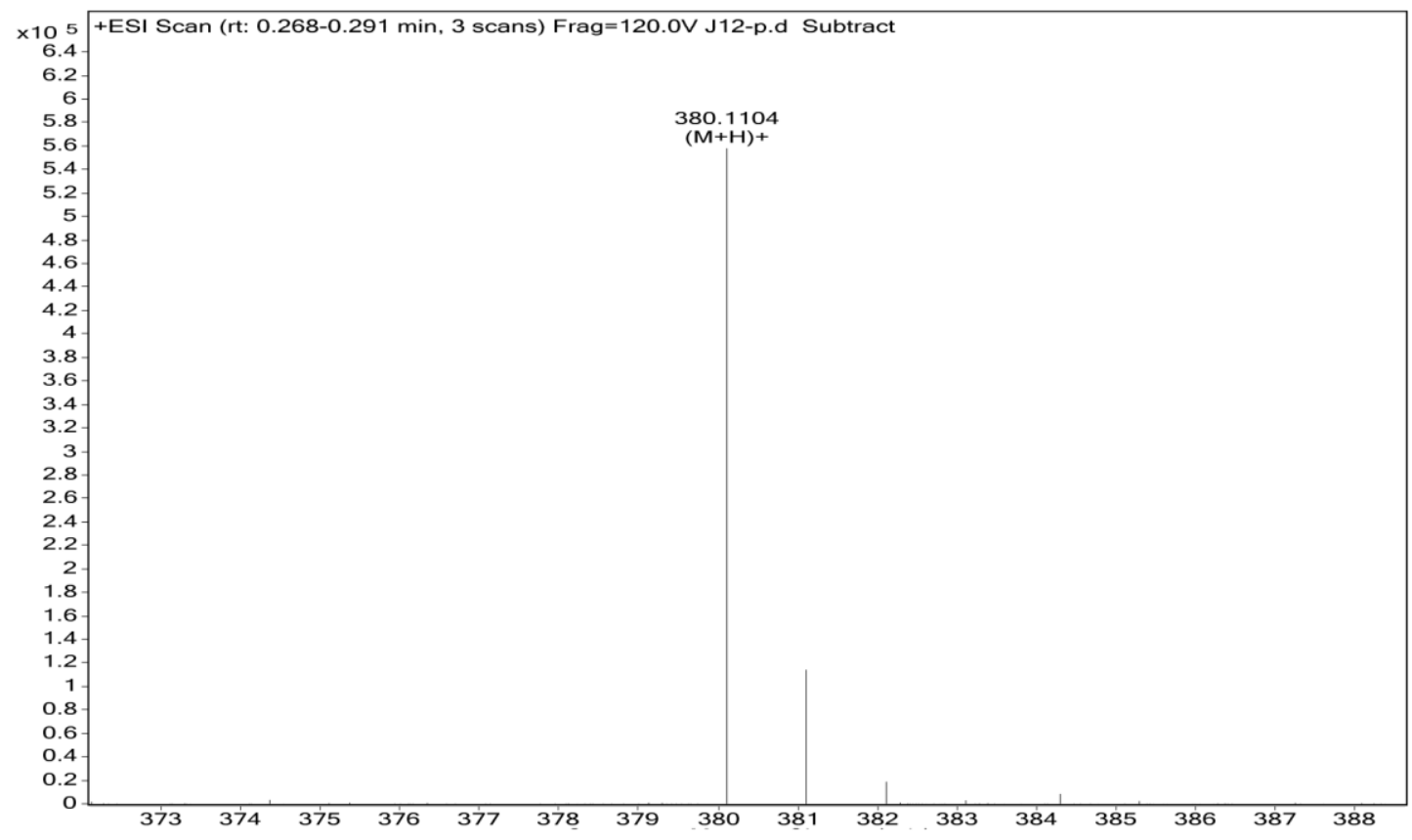


HPLC of compound S06-1033 $\left(t_{R}=2.50 \mathrm{~min}\right)$.

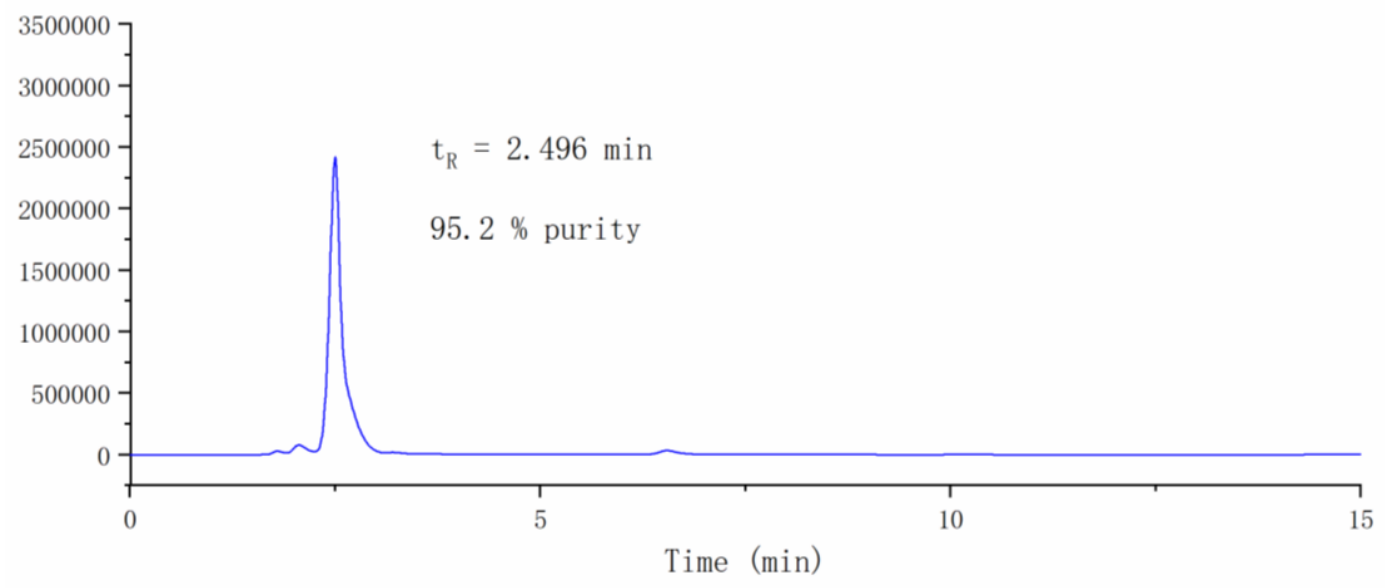

${ }^{1} \mathrm{H}$ NMR of compound S06-1033.

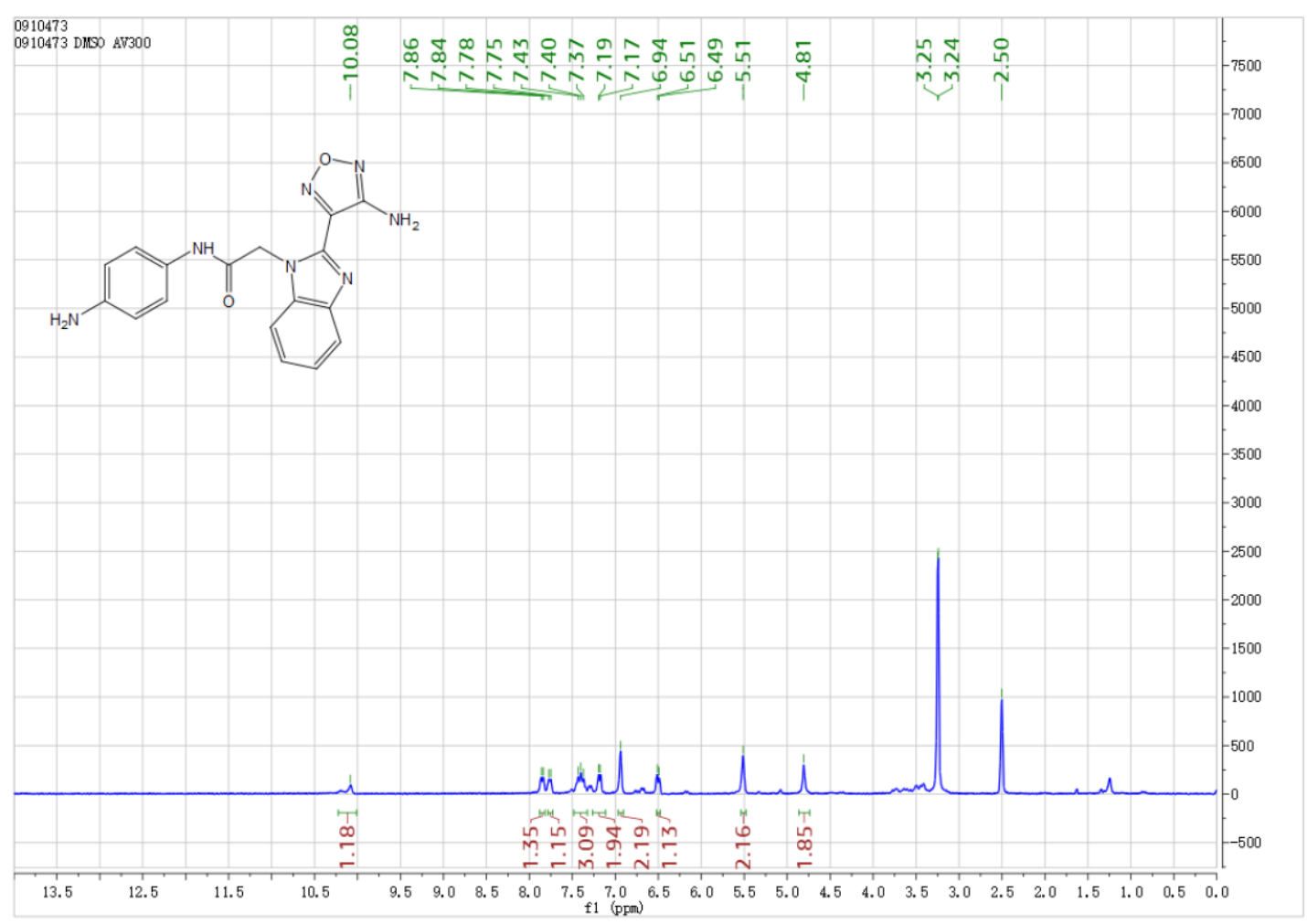

${ }^{13} \mathrm{C}$ NMR of compound S06-1033. 


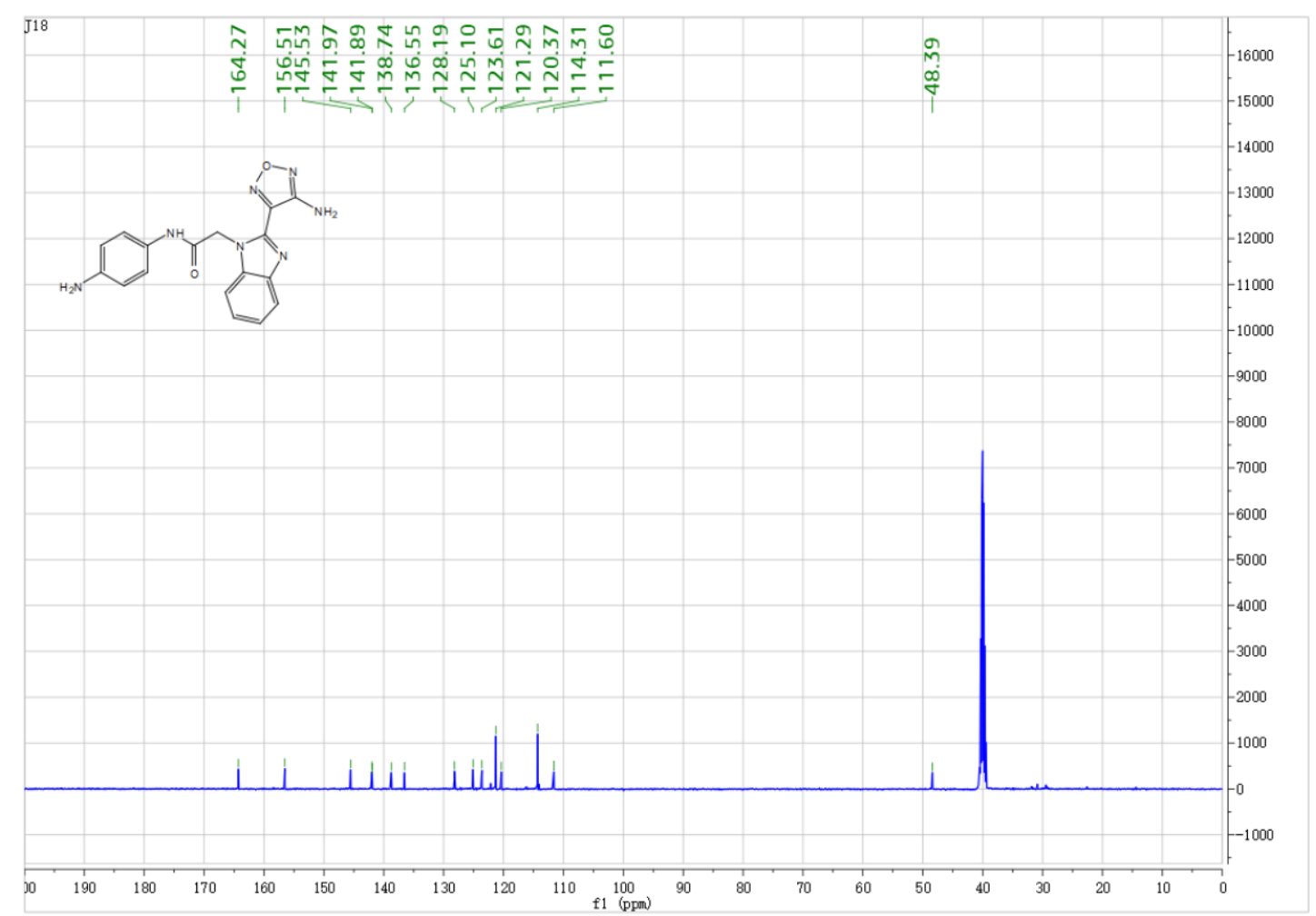

HRMS of compound S06-1033.

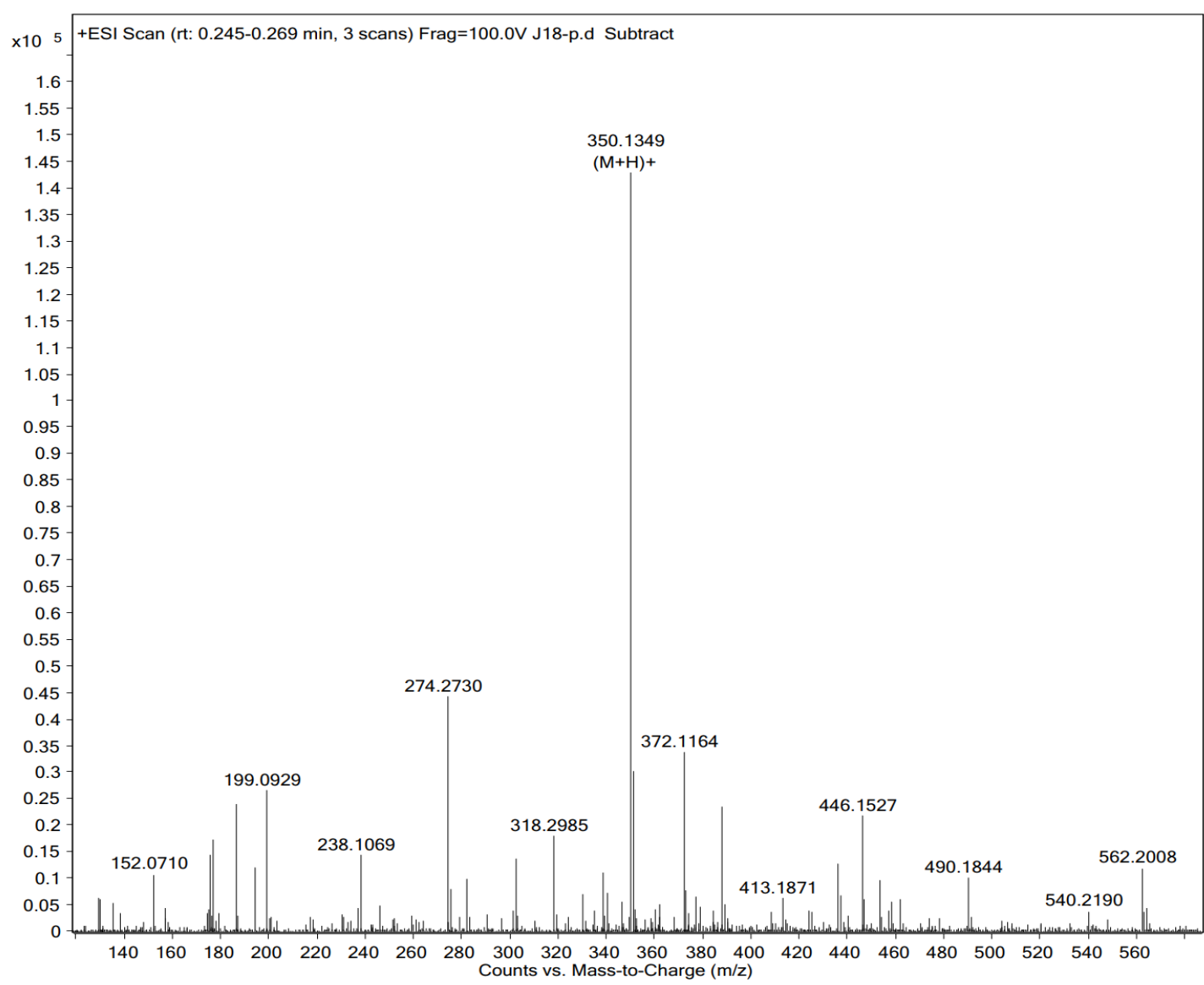


HPLC of compound S06-1034 $\left(t_{R}=5.28 \mathrm{~min}\right)$.

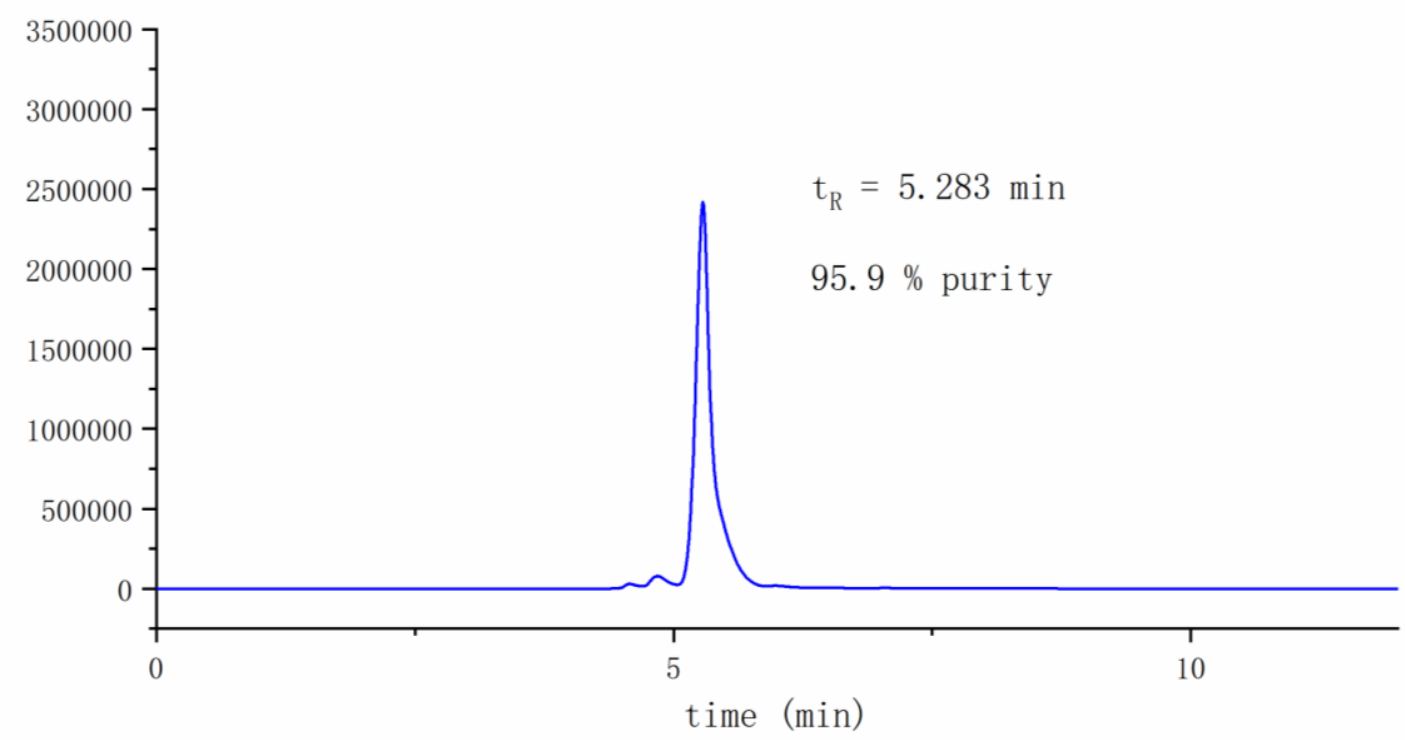

${ }^{1} \mathrm{H}$ NMR of compound S06-1034.

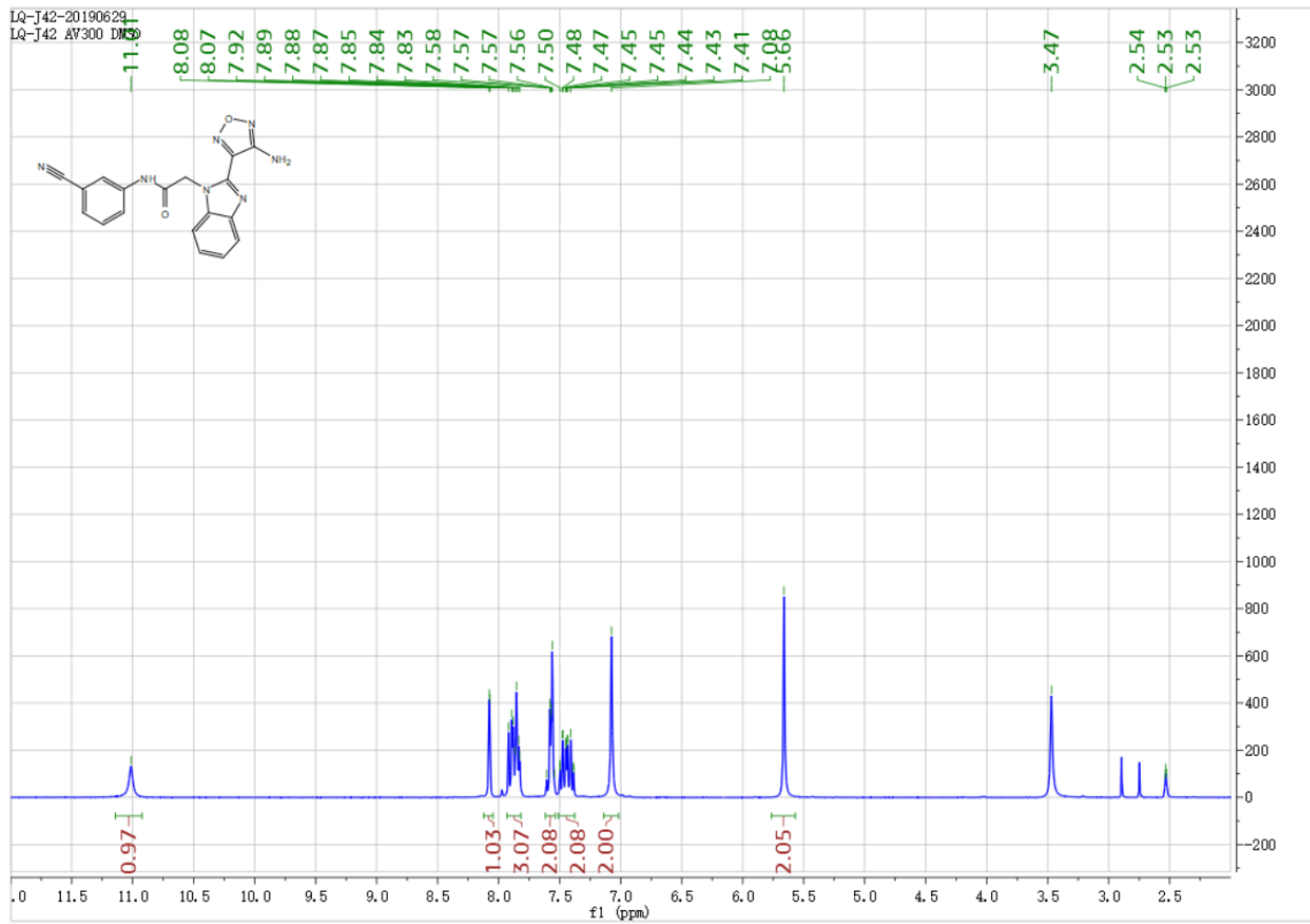

${ }^{13} \mathrm{C}$ NMR of compound S06-1034. 


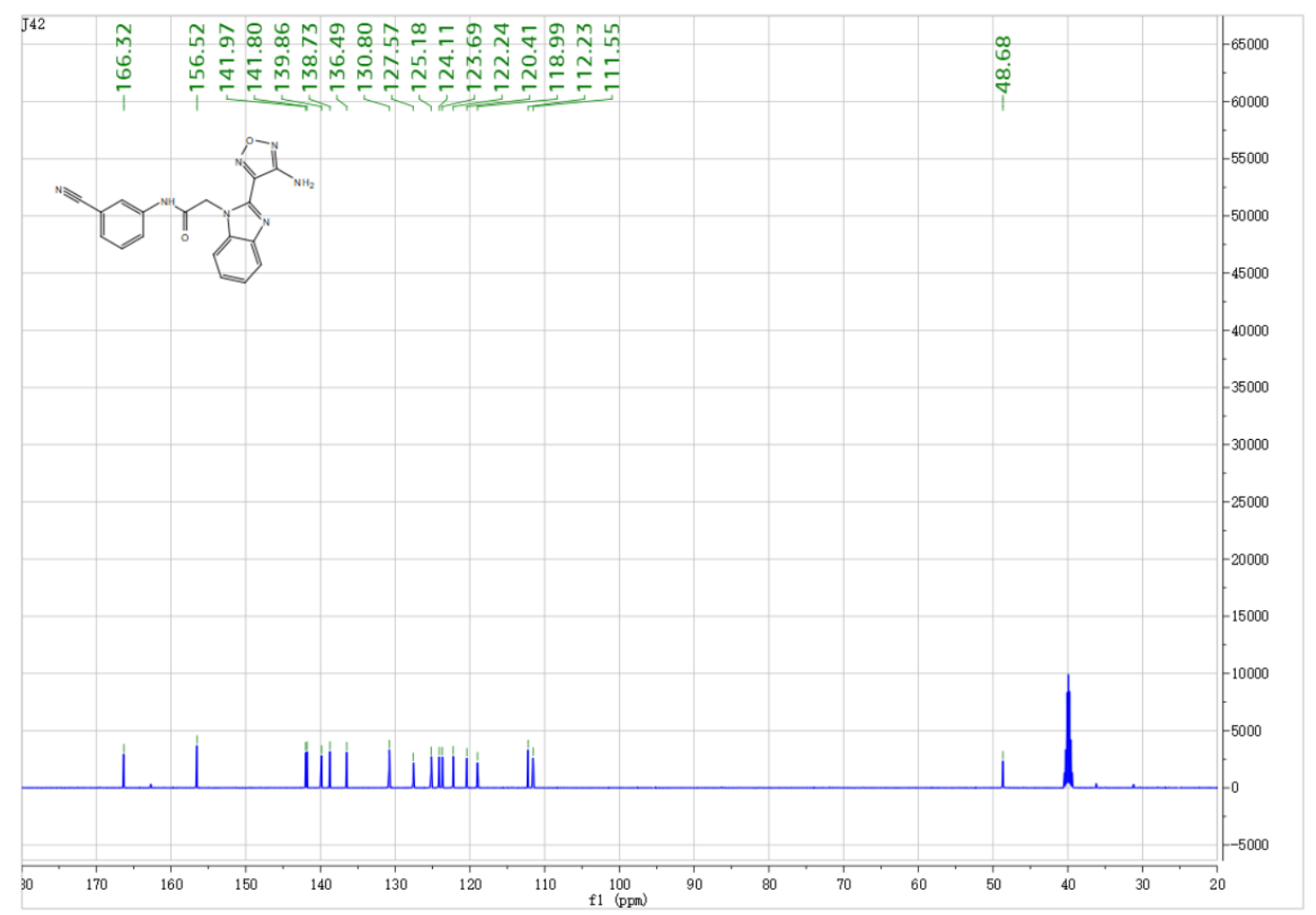

HRMS of compound S06-1034.

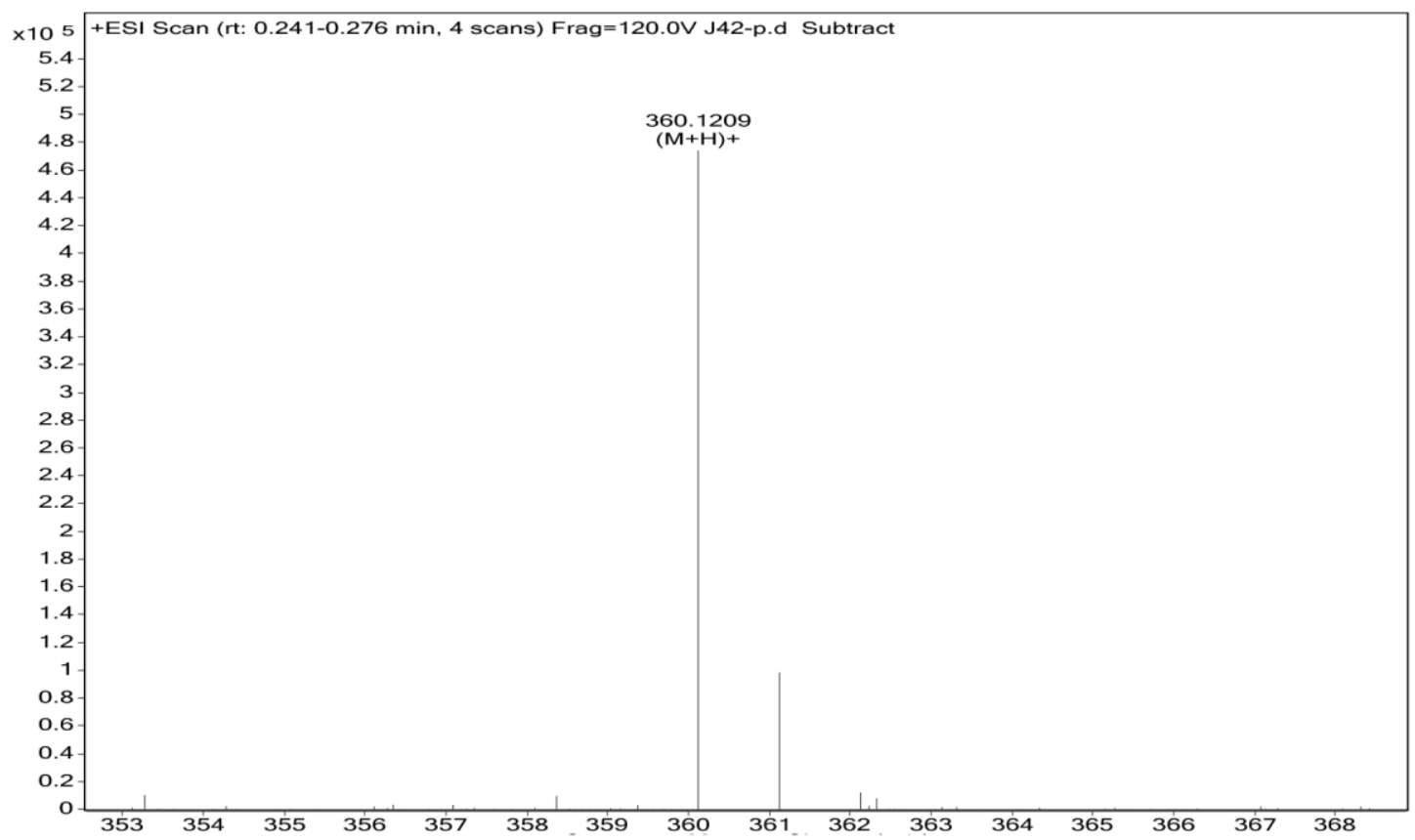


HPLC of compound S06-1035 $\left(t_{R}=7.19 \mathrm{~min}\right)$.

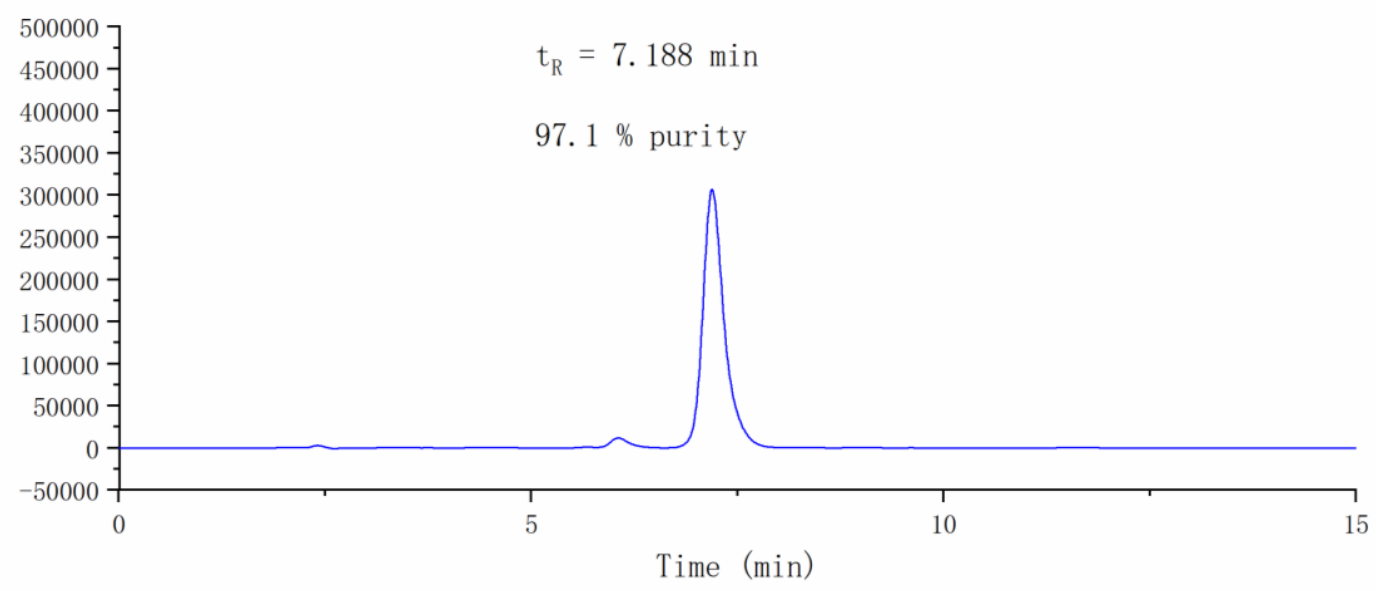

${ }^{1} \mathrm{H}$ NMR of compound S06-1035.

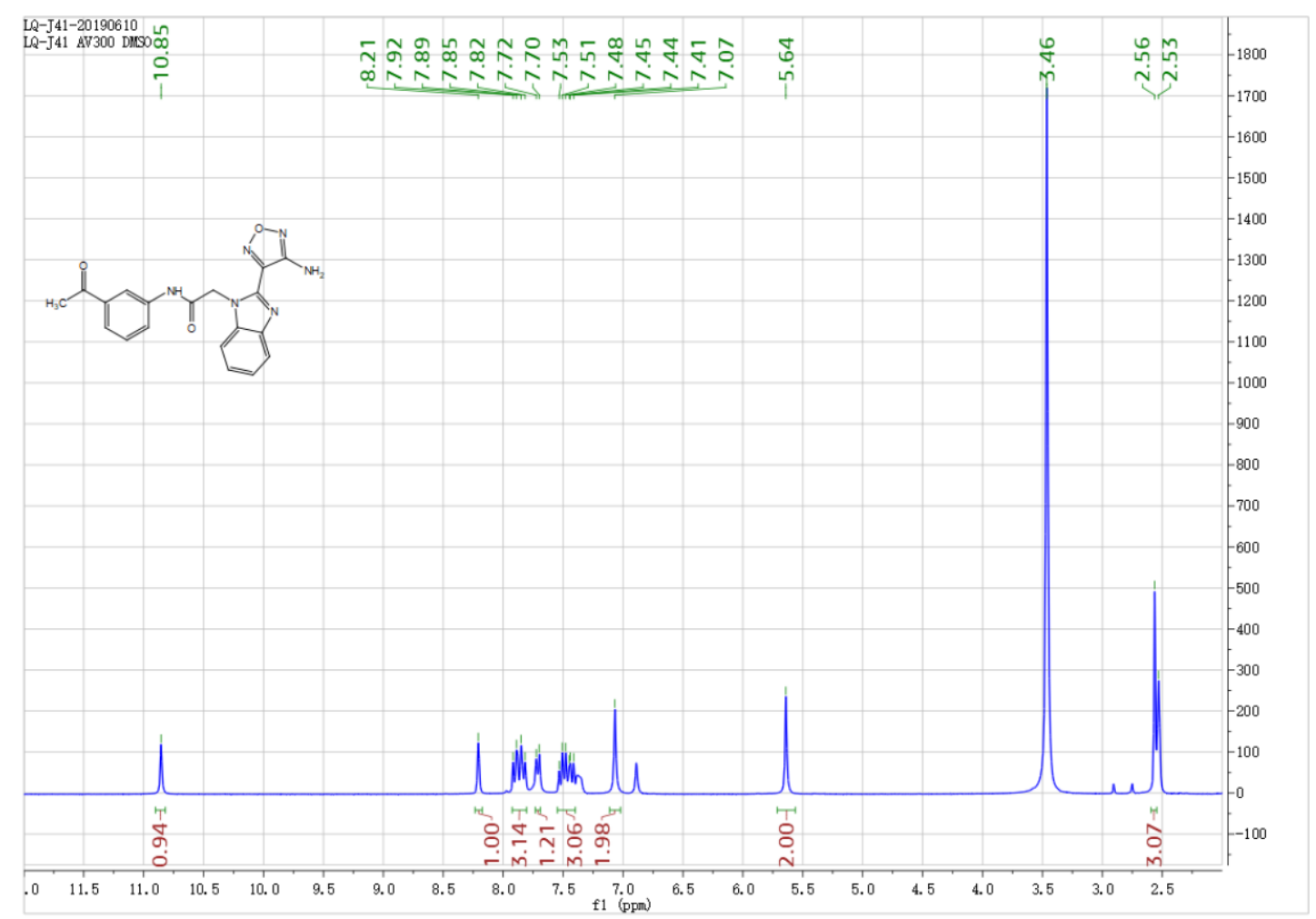

${ }^{13} \mathrm{C}$ NMR of compound S06-1035. 


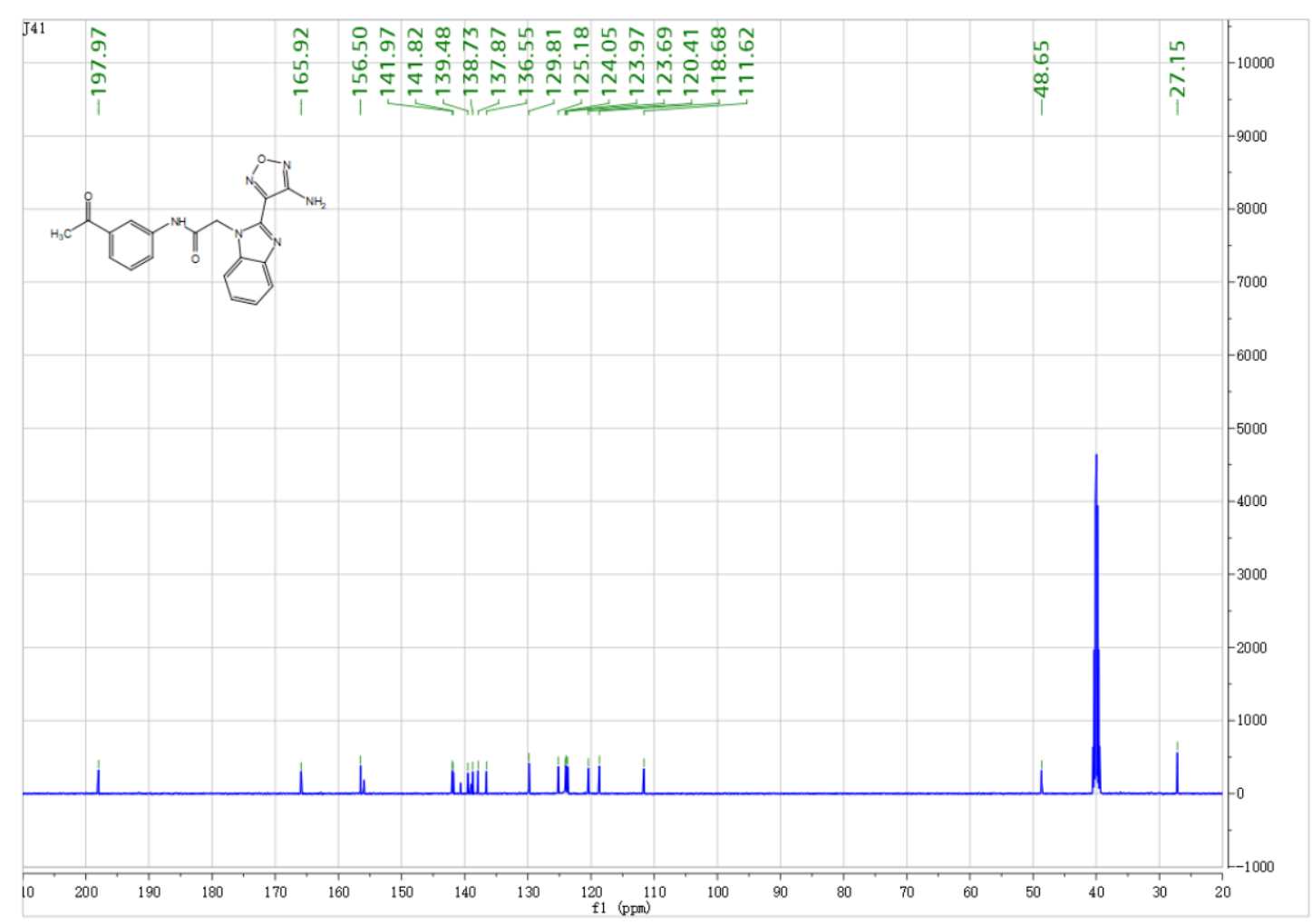

HRMS of compound S06-1035.

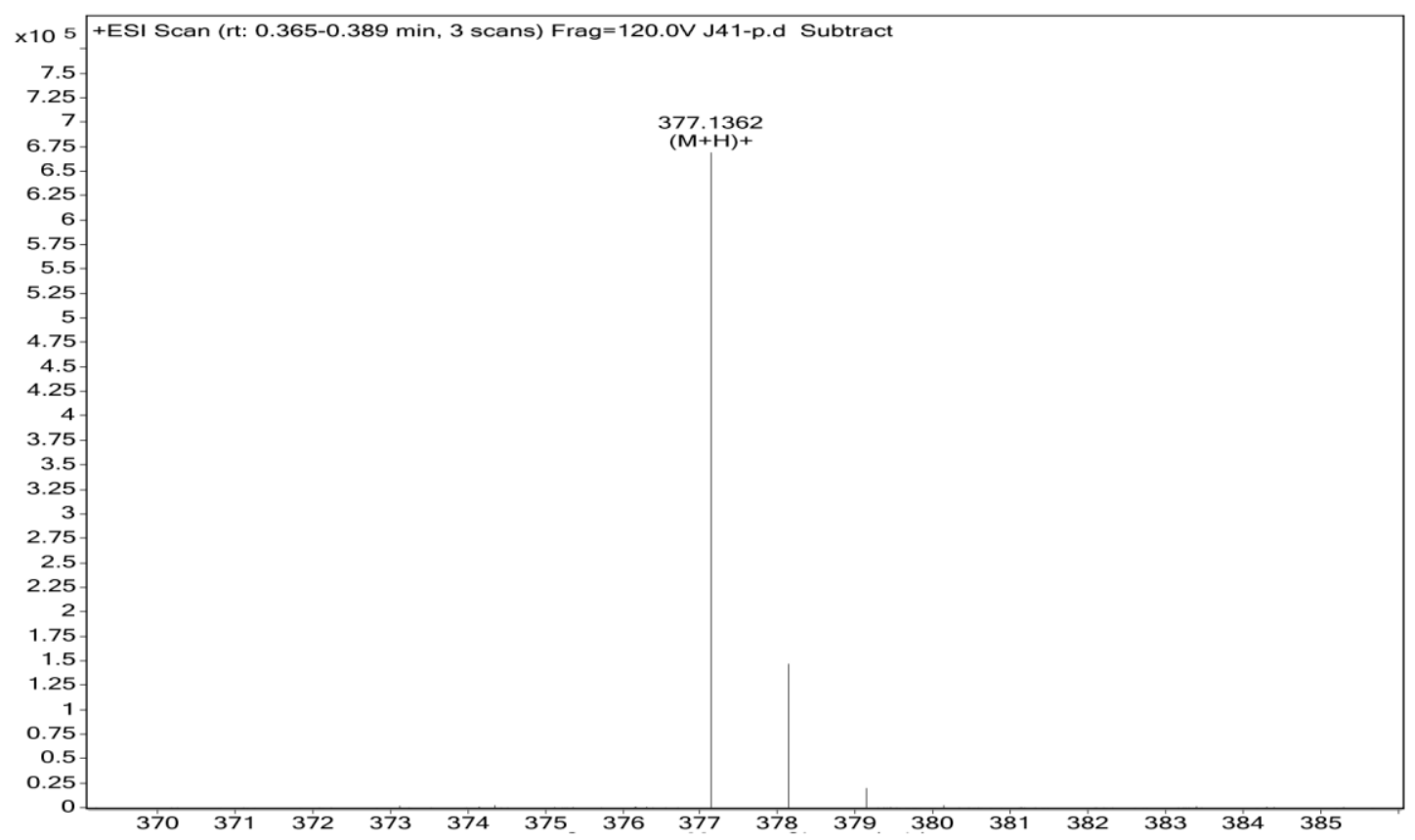


HPLC of compound S06-1036 $\left(t_{R}=4.88 \mathrm{~min}\right)$.

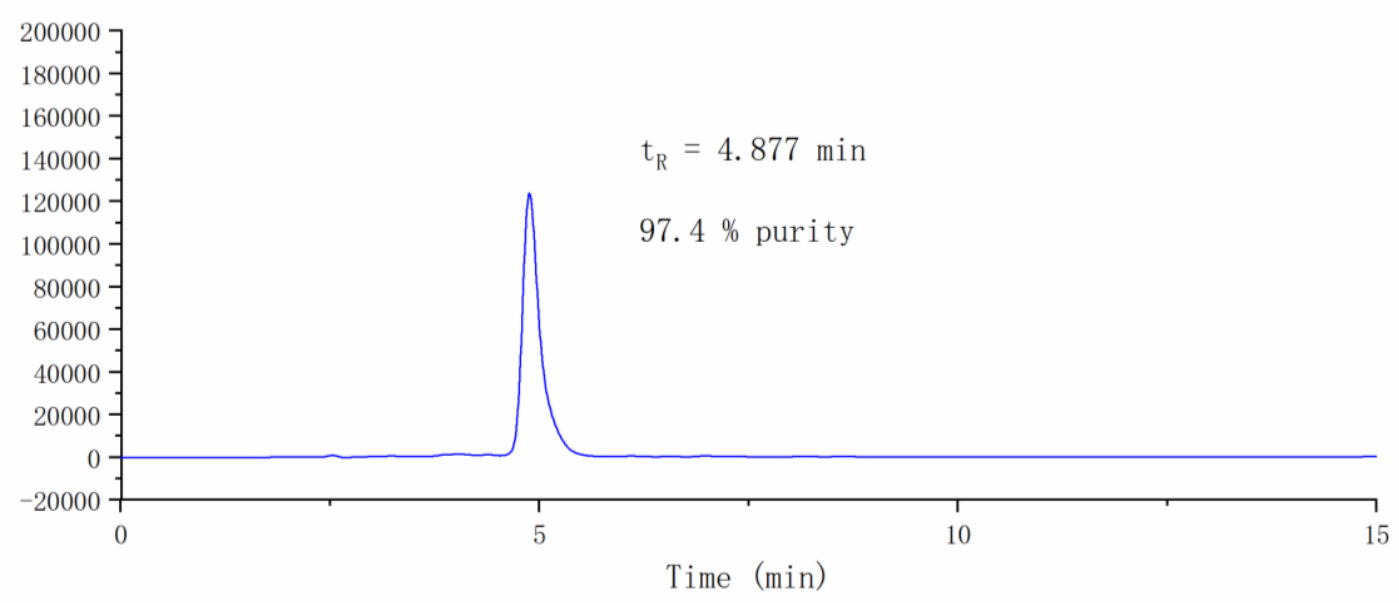

${ }^{1} \mathrm{H}$ NMR of compound S06-1036.

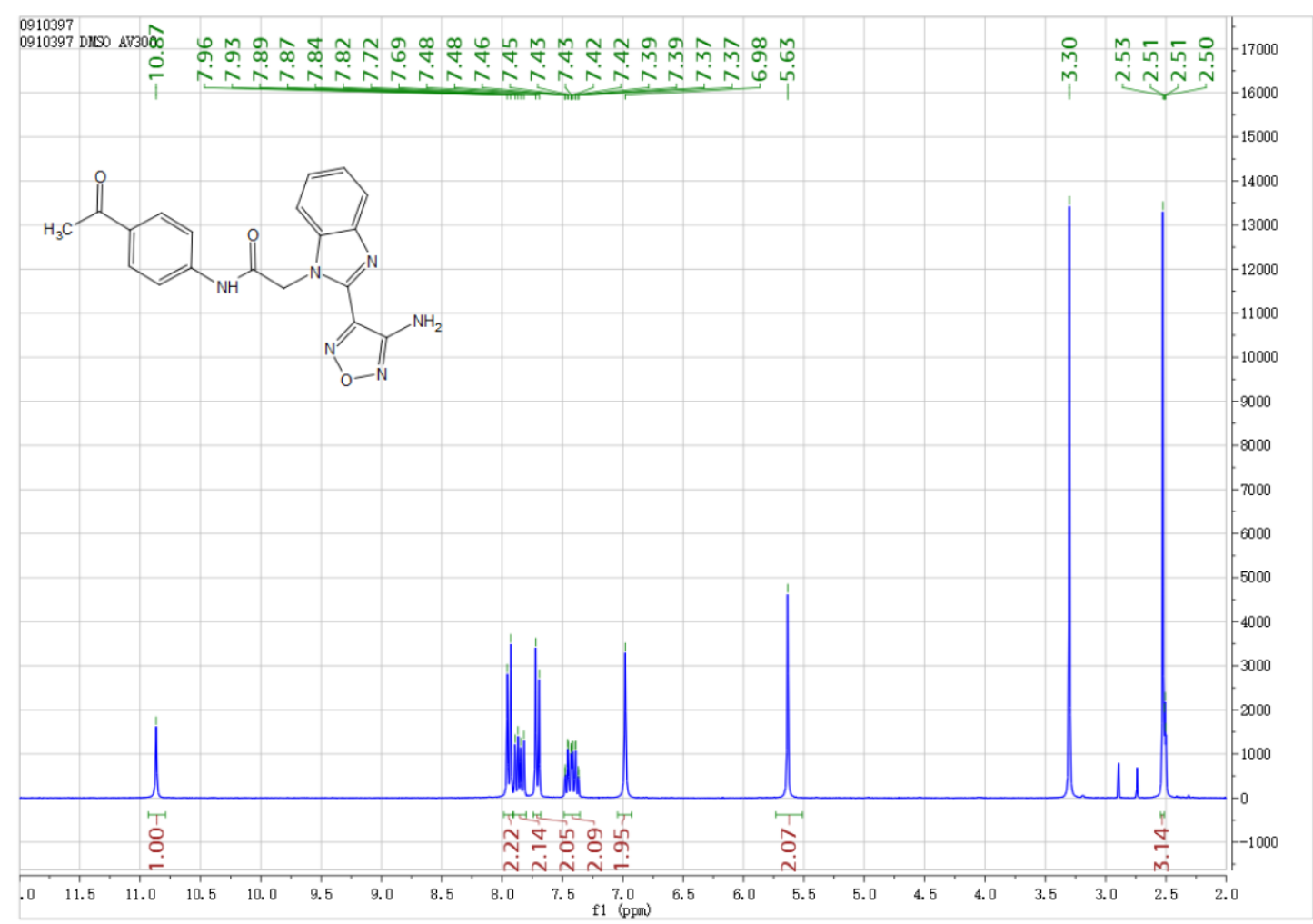

${ }^{13} \mathrm{C}$ NMR of compound S06-1036. 


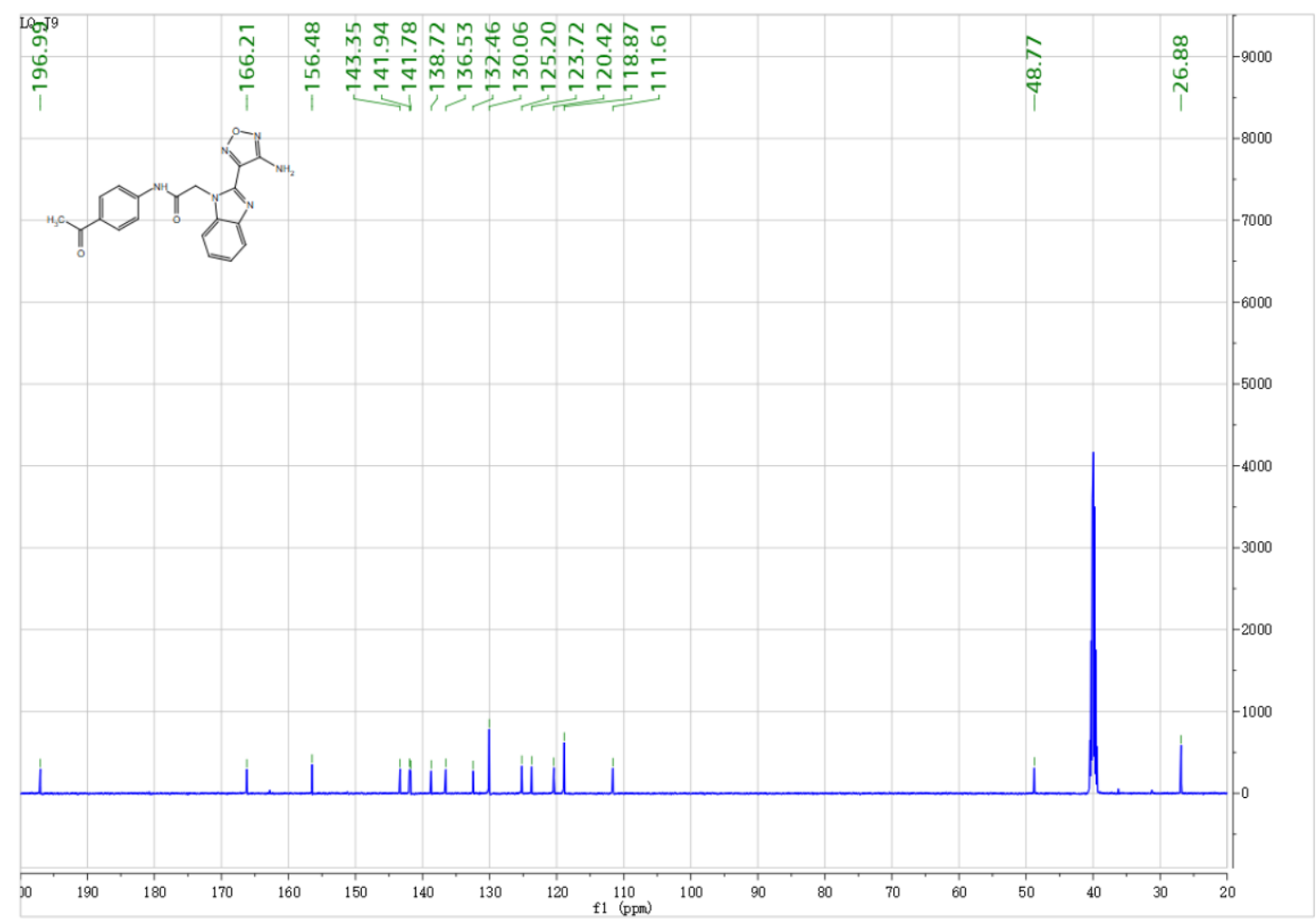

HRMS of compound S06-1036.

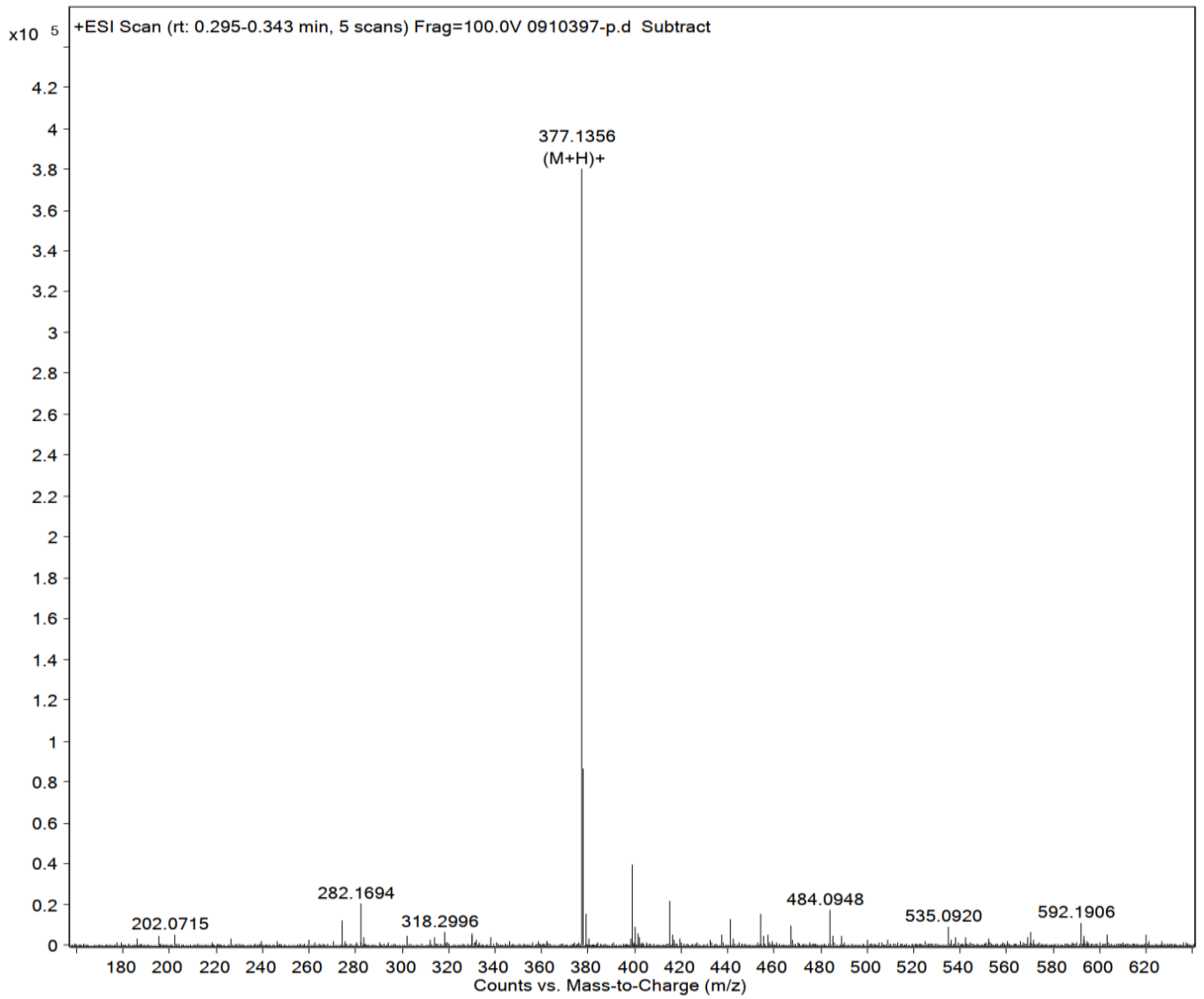


HPLC of compound S06-1037 $\left(t_{R}=9.41 \mathrm{~min}\right)$.

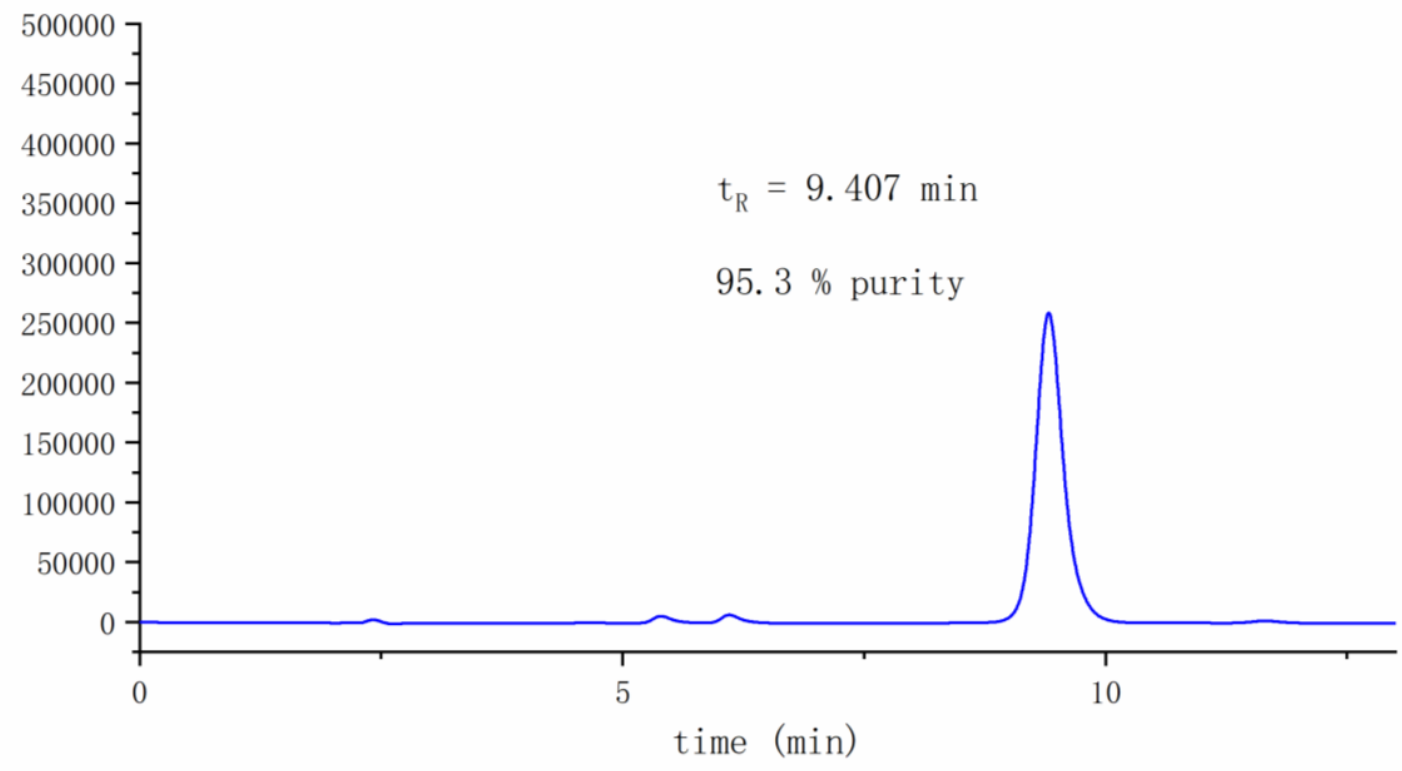

${ }^{1} \mathrm{H}$ NMR of compound S06-1037.

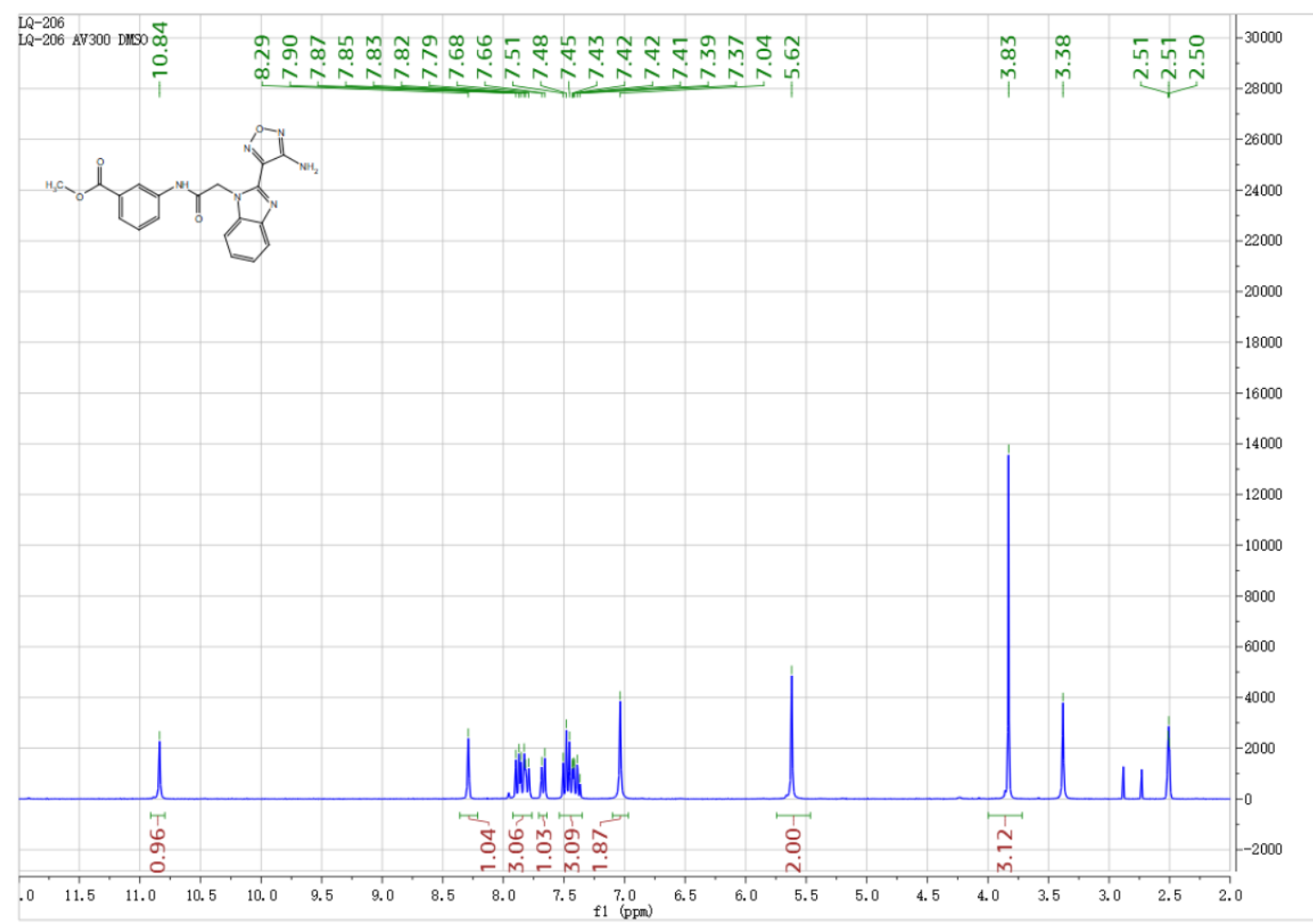

${ }^{13} \mathrm{C}$ NMR of compound S06-1037. 


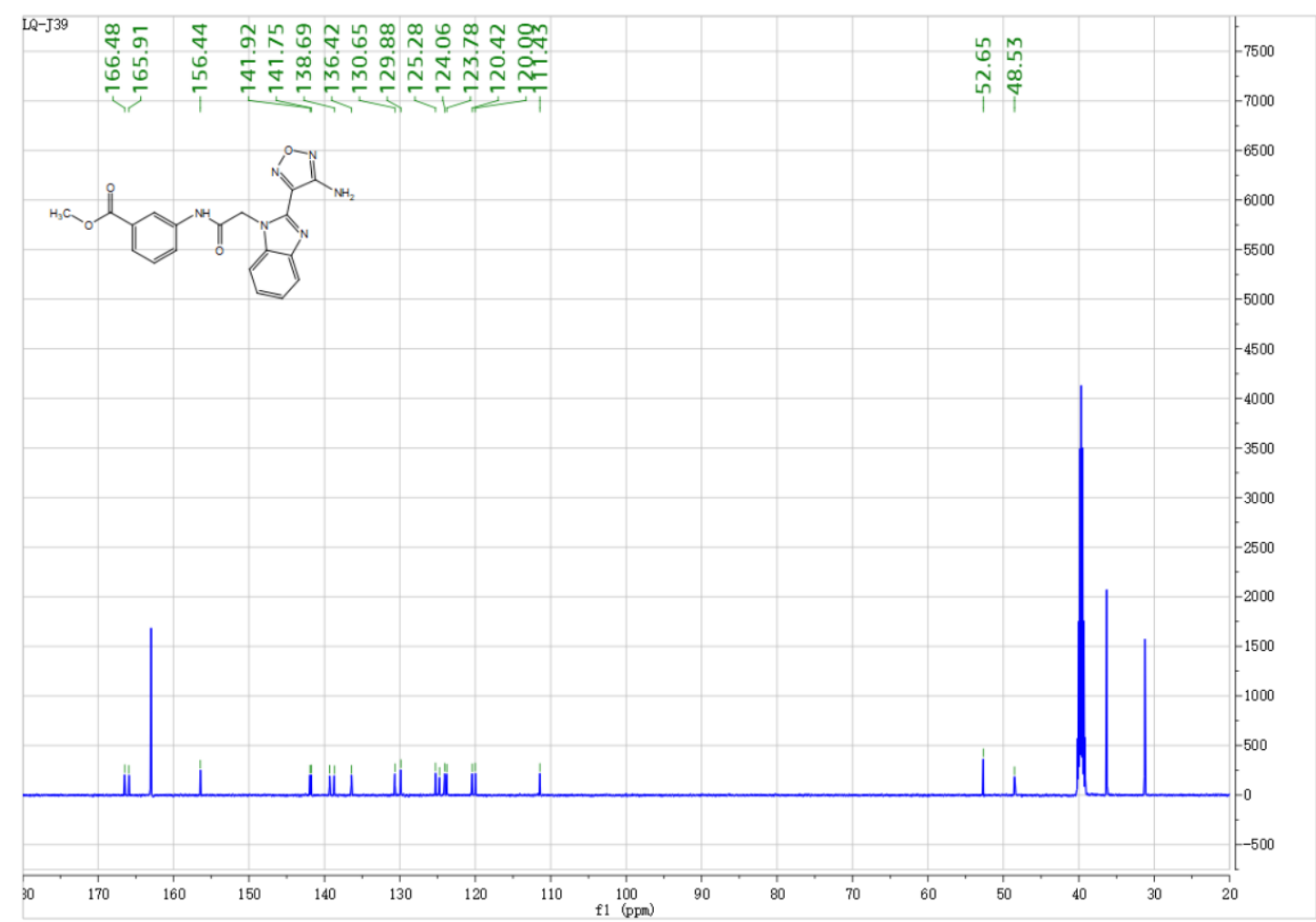

HRMS of compound S06-1037.

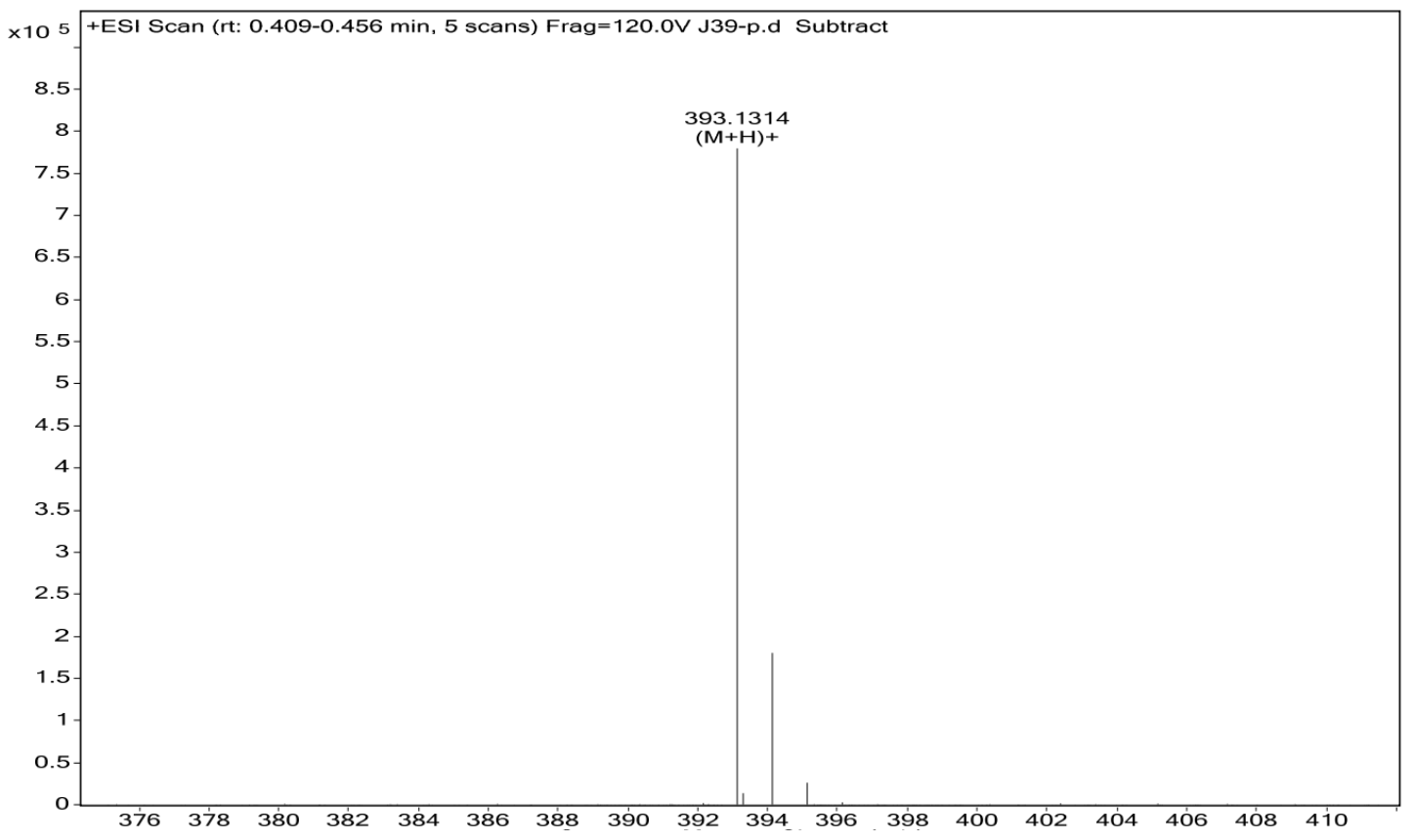


HPLC of compound S06-1038 $\left(t_{R}=6.14 \mathrm{~min}\right)$.

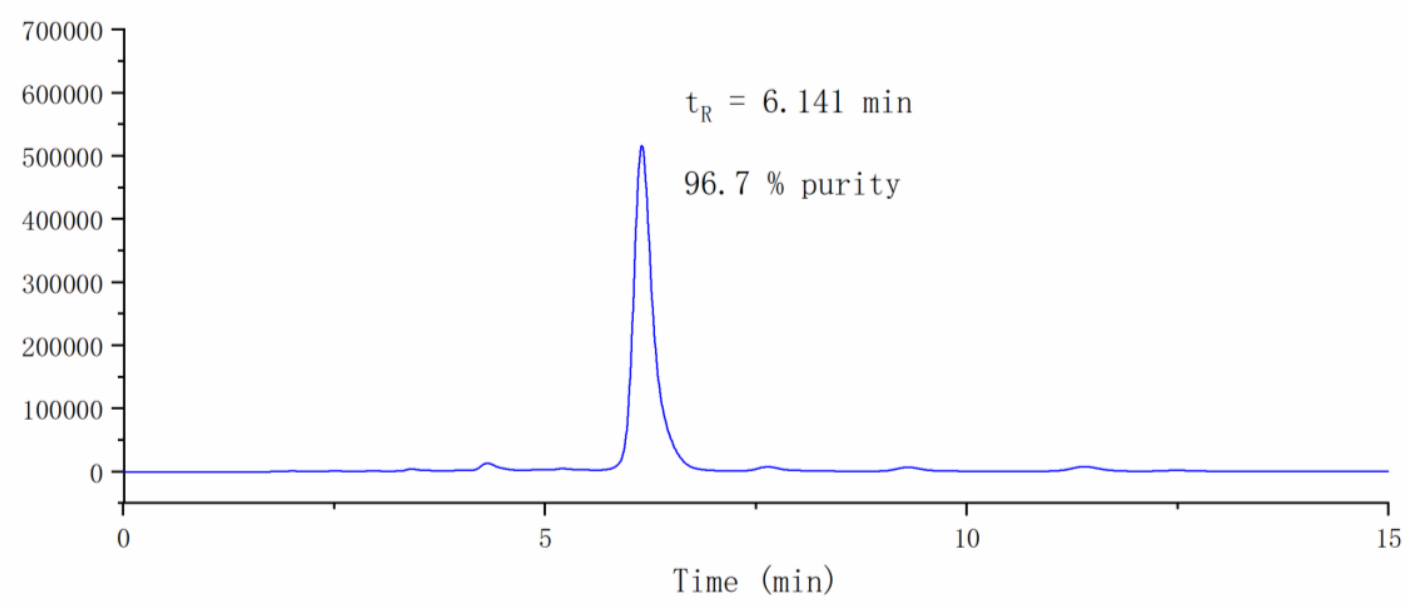

${ }^{1} \mathrm{H}$ NMR of compound S06-1038.

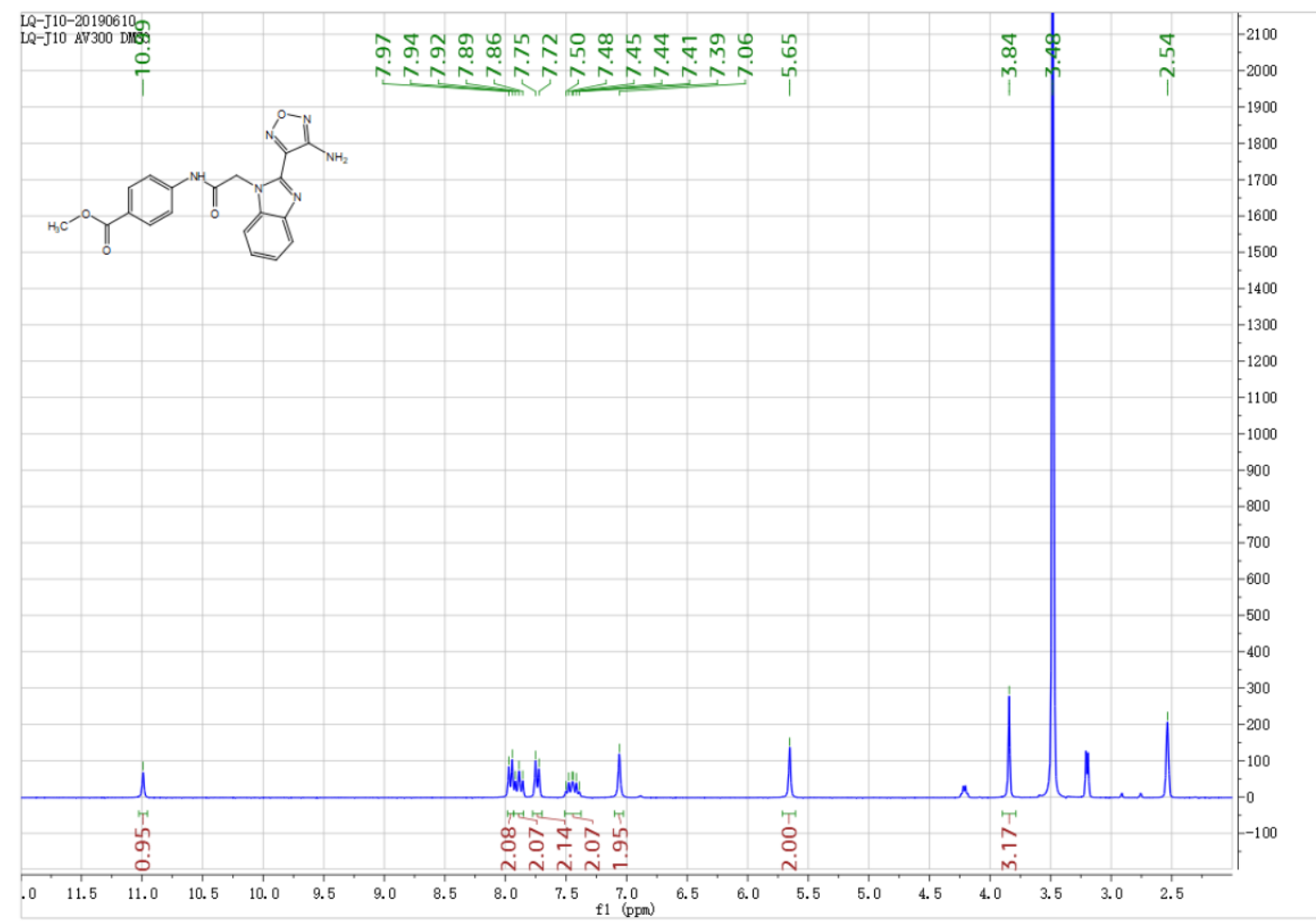

${ }^{13} \mathrm{C}$ NMR of compound S06-1038. 


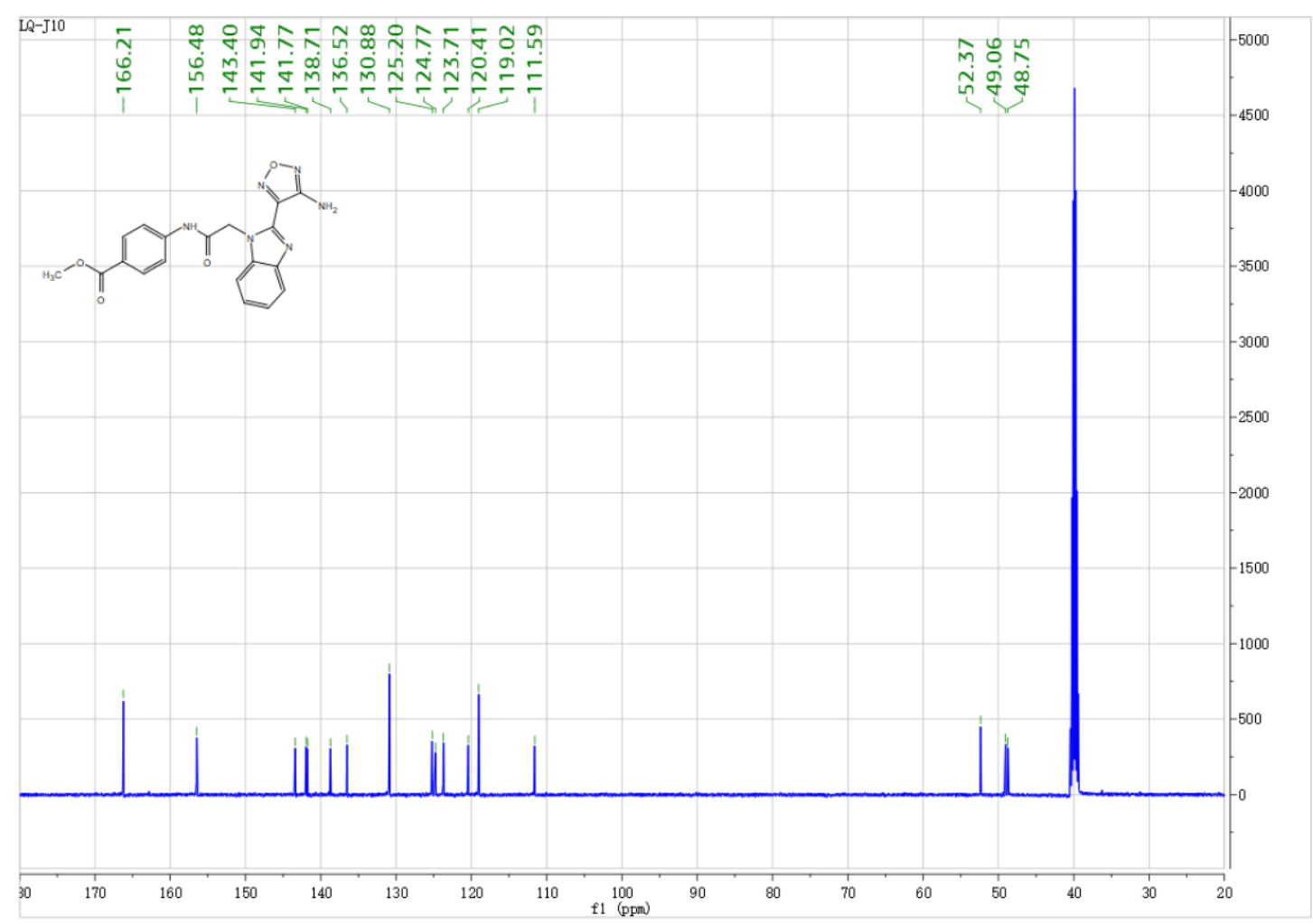

HRMS of compound S06-1038.

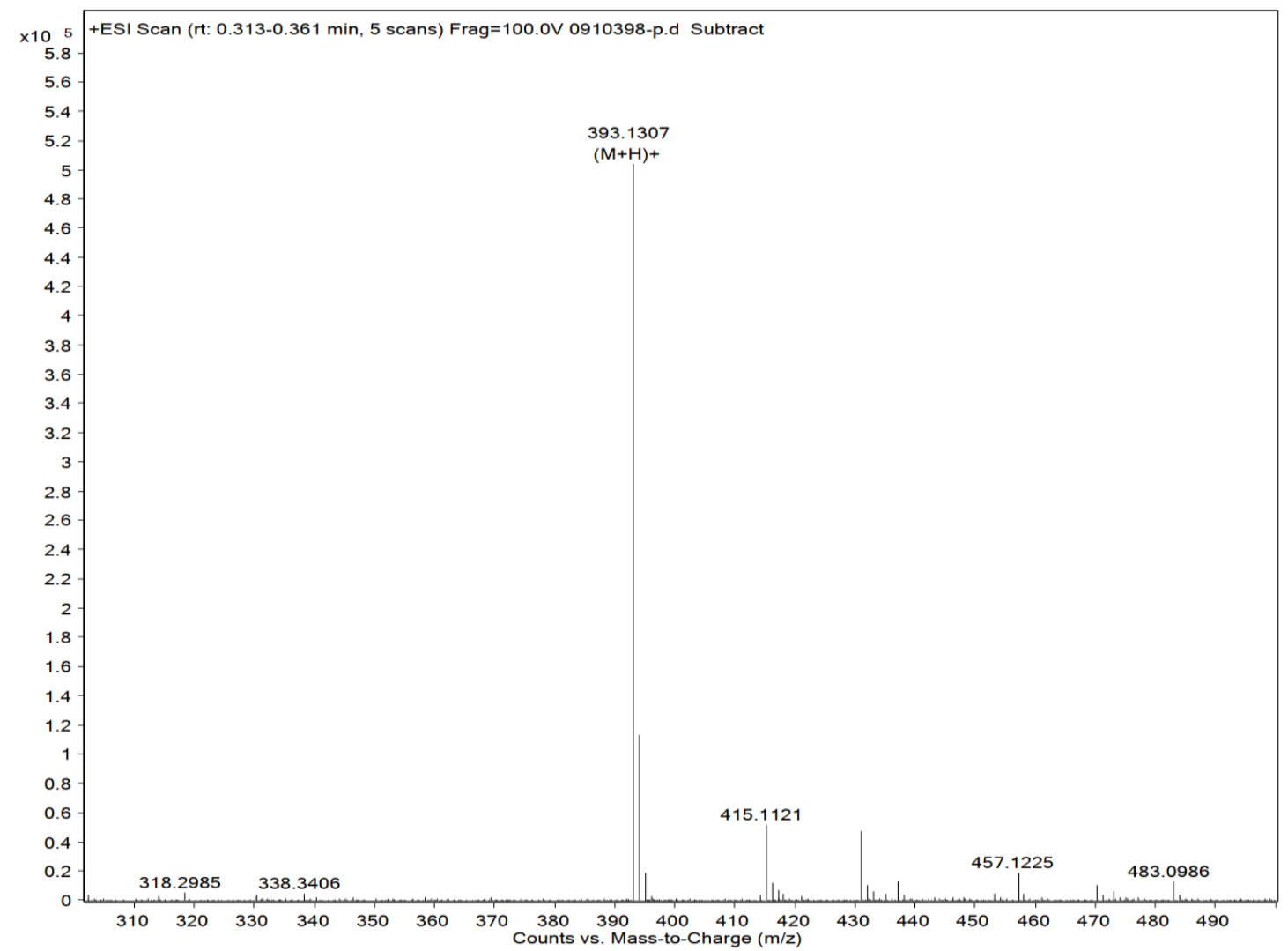


HPLC of compound S06-1039 $\left(t_{R}=15.60 \mathrm{~min}\right)$.

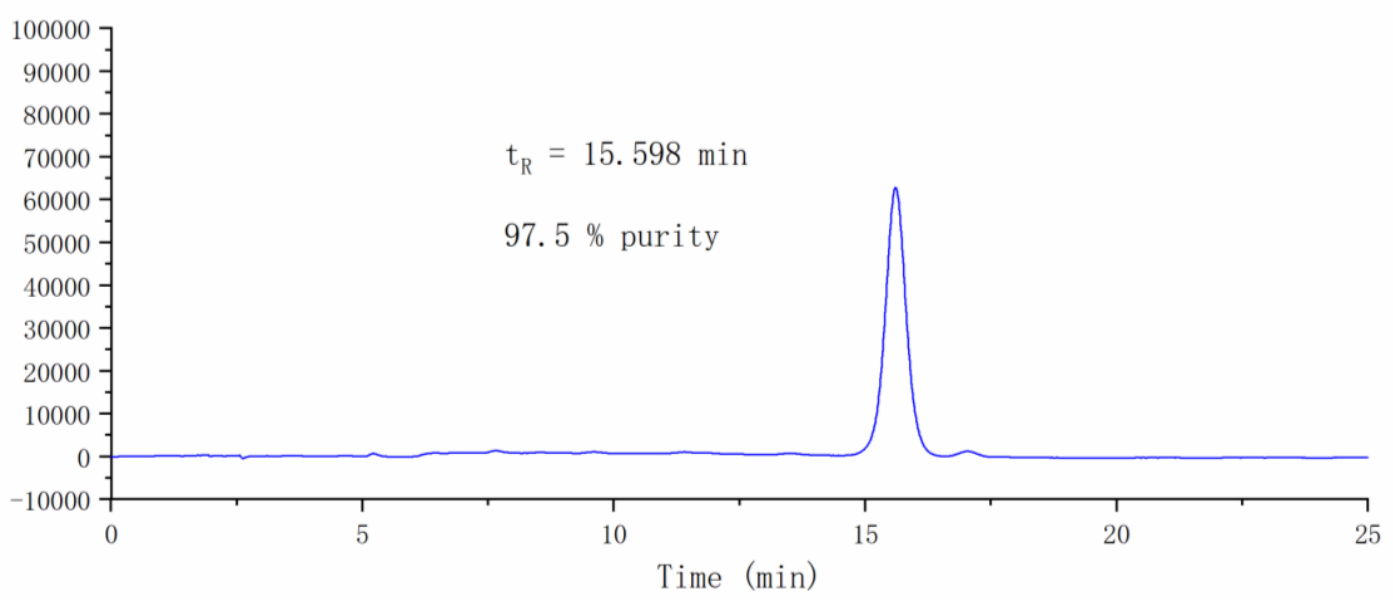

${ }^{1} \mathrm{H}$ NMR of compound S06-1039.

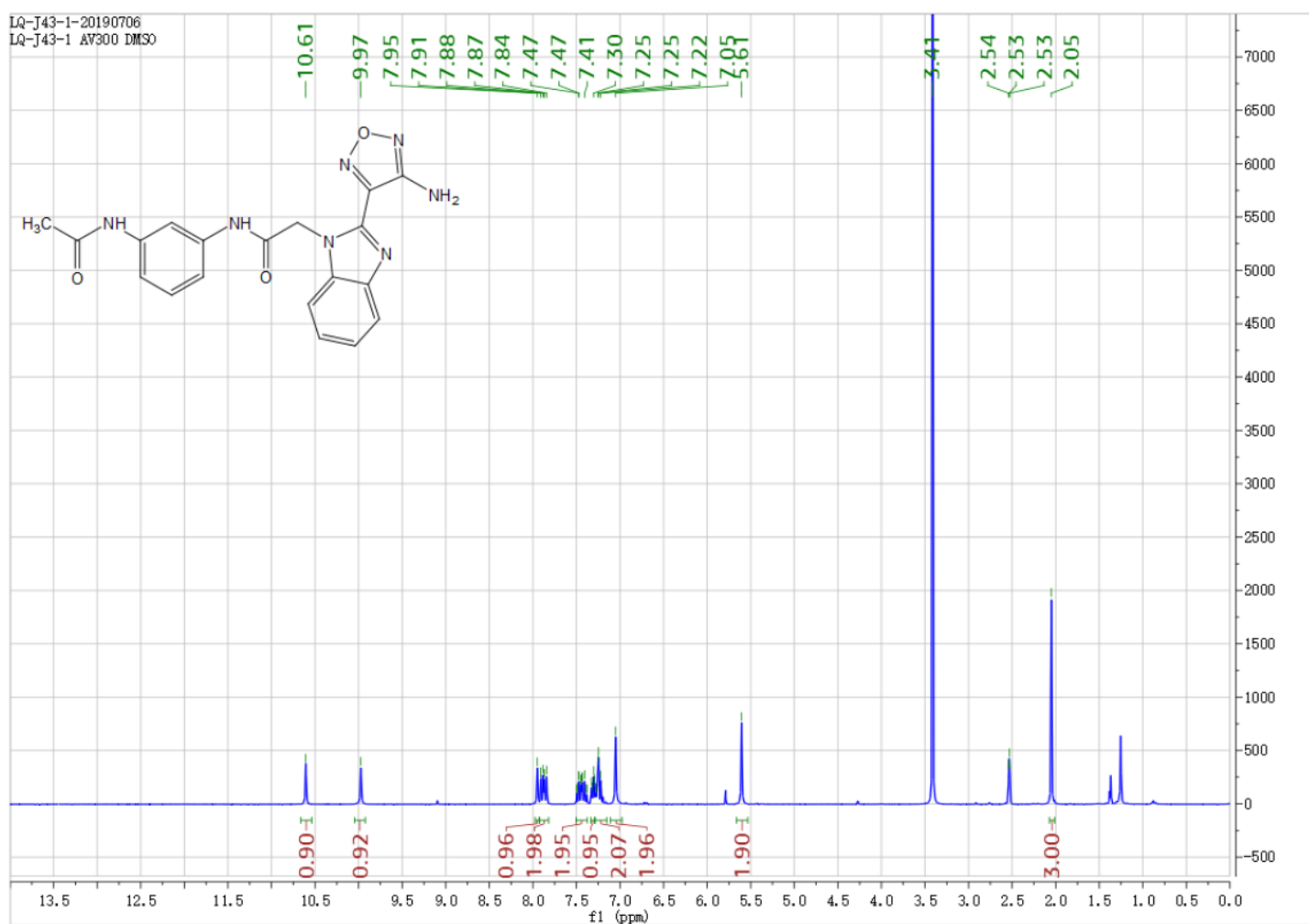

${ }^{13} \mathrm{C}$ NMR of compound S06-1039. 


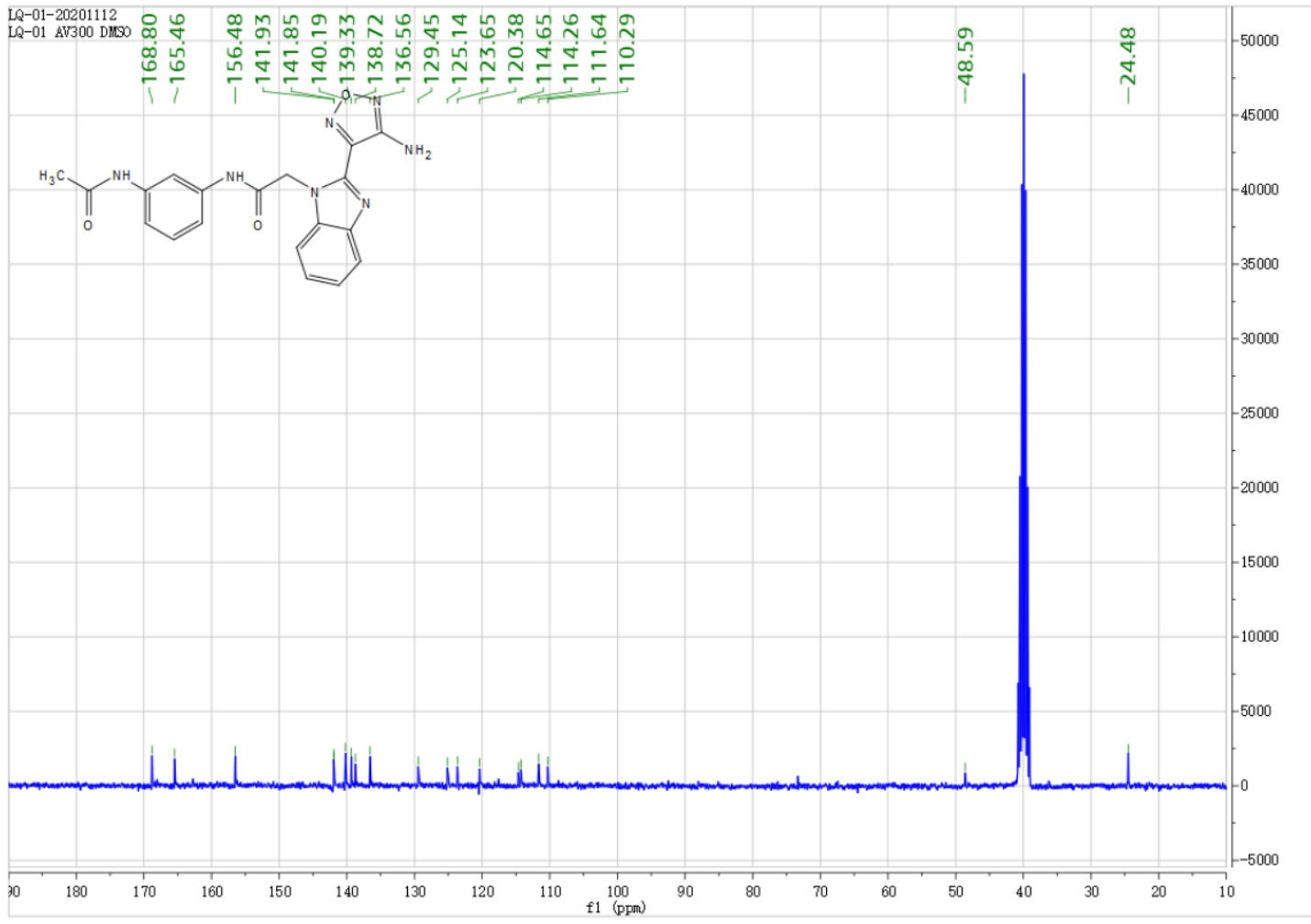

HRMS of compound S06-1039.

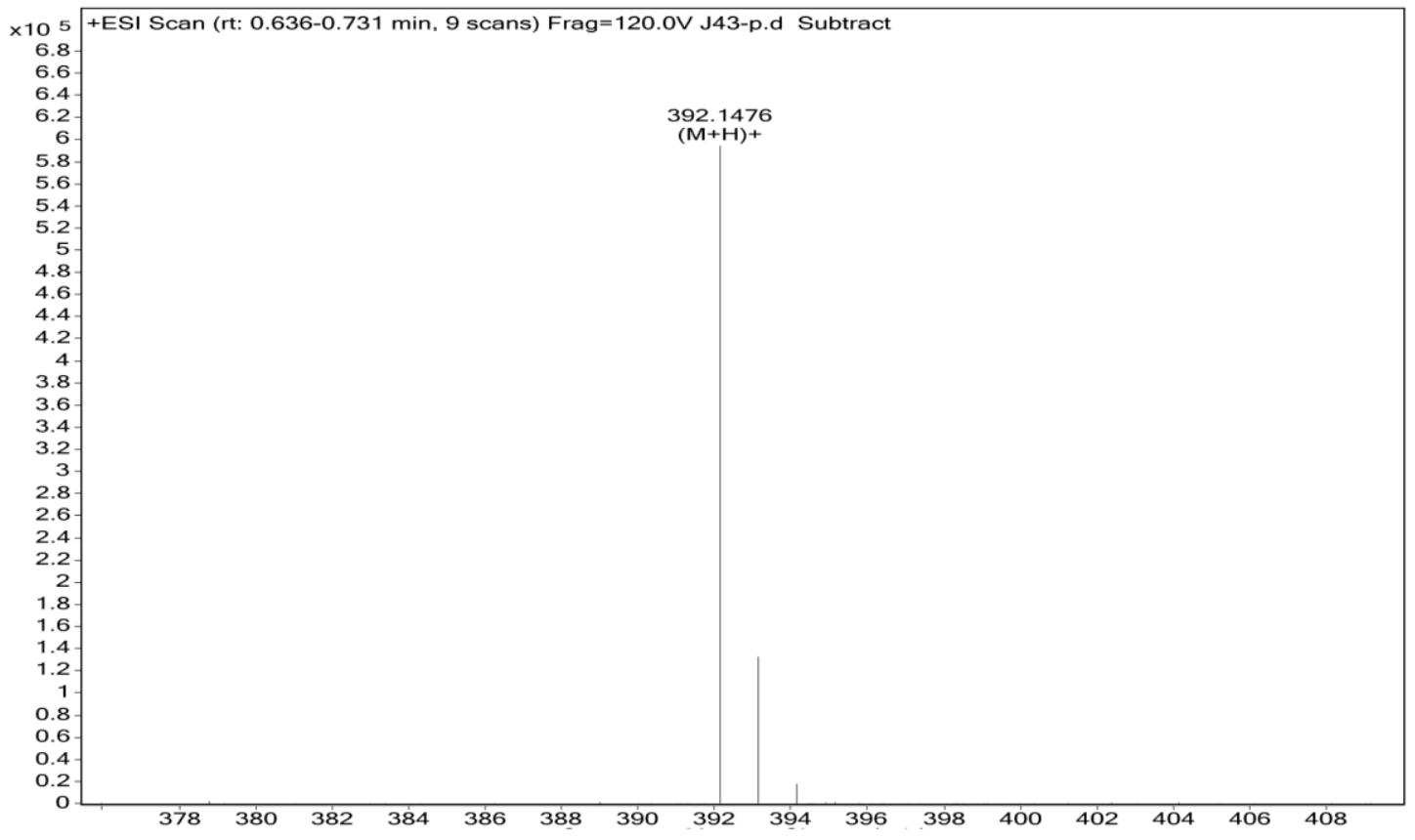


HPLC of compound S06-1040 $\left(t_{R}=3.82 \mathrm{~min}\right)$.

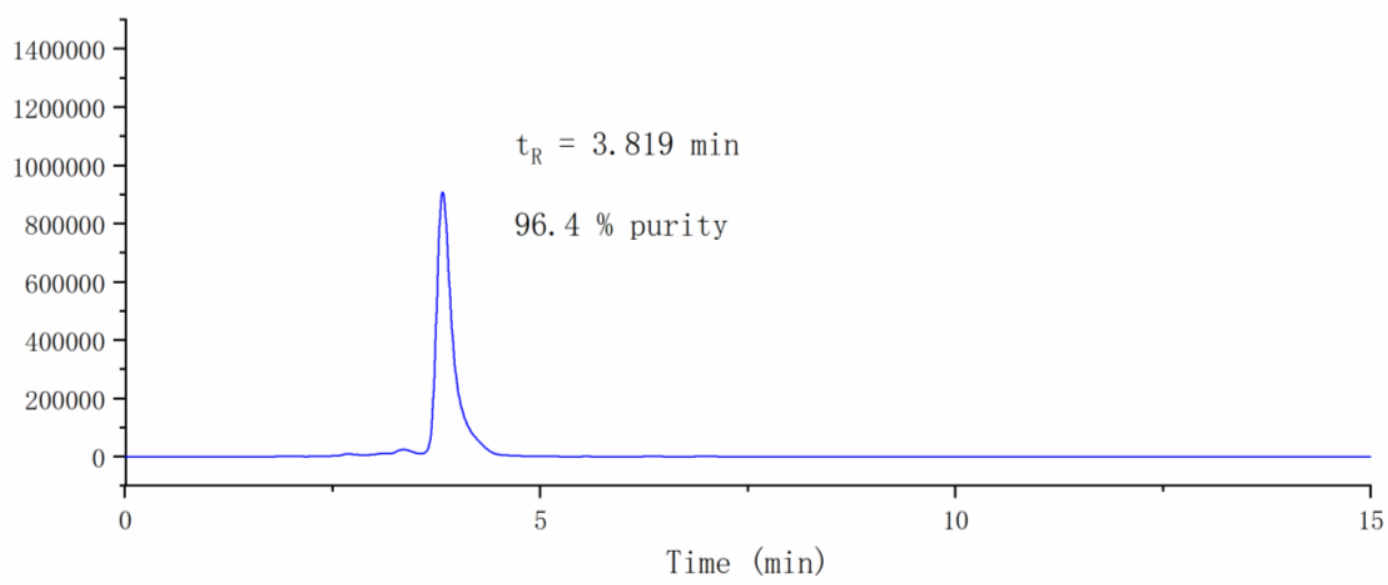

${ }^{1} \mathrm{H}$ NMR of compound S06-1040.

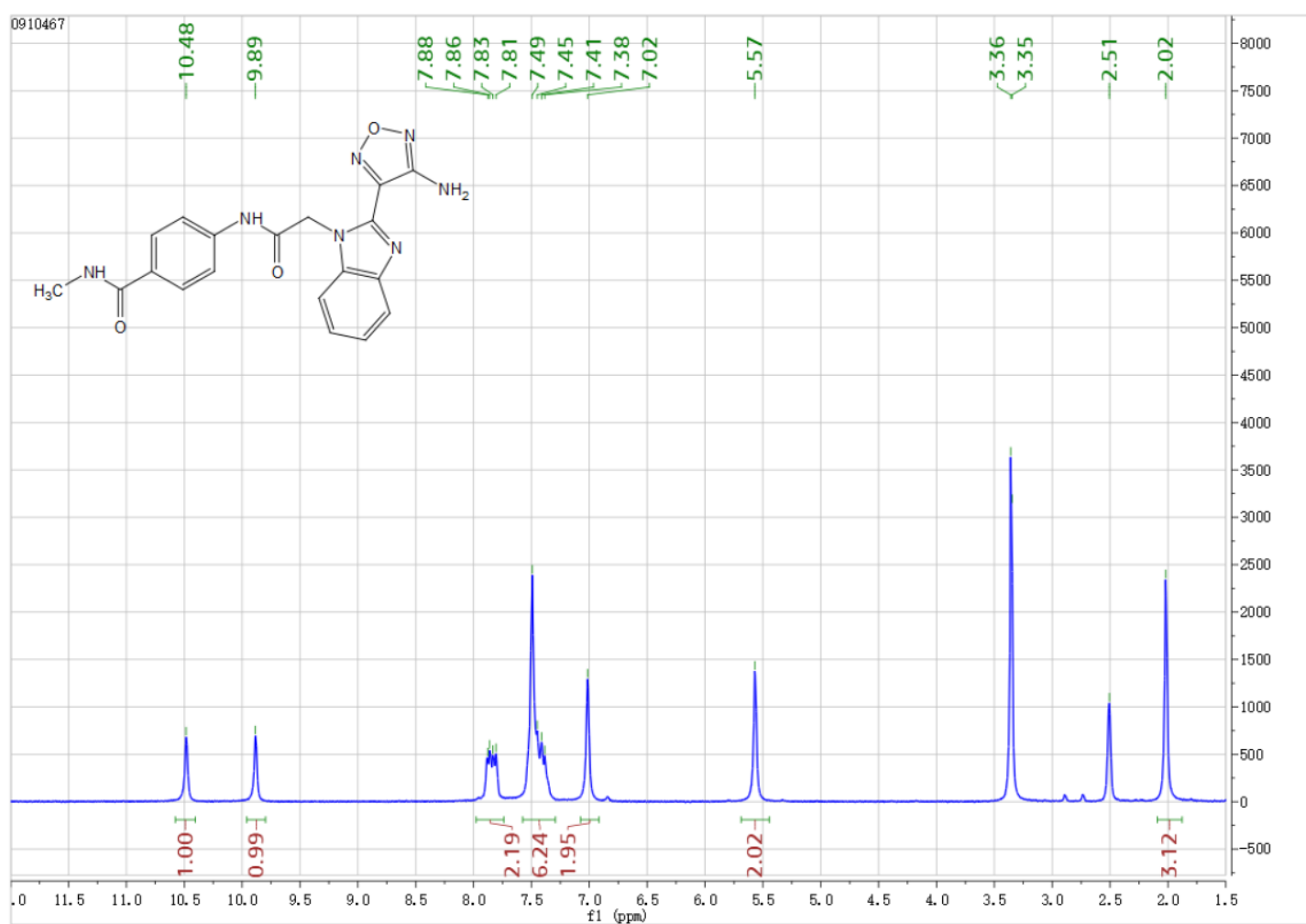

${ }^{13} \mathrm{C}$ NMR of compound S06-1040. 


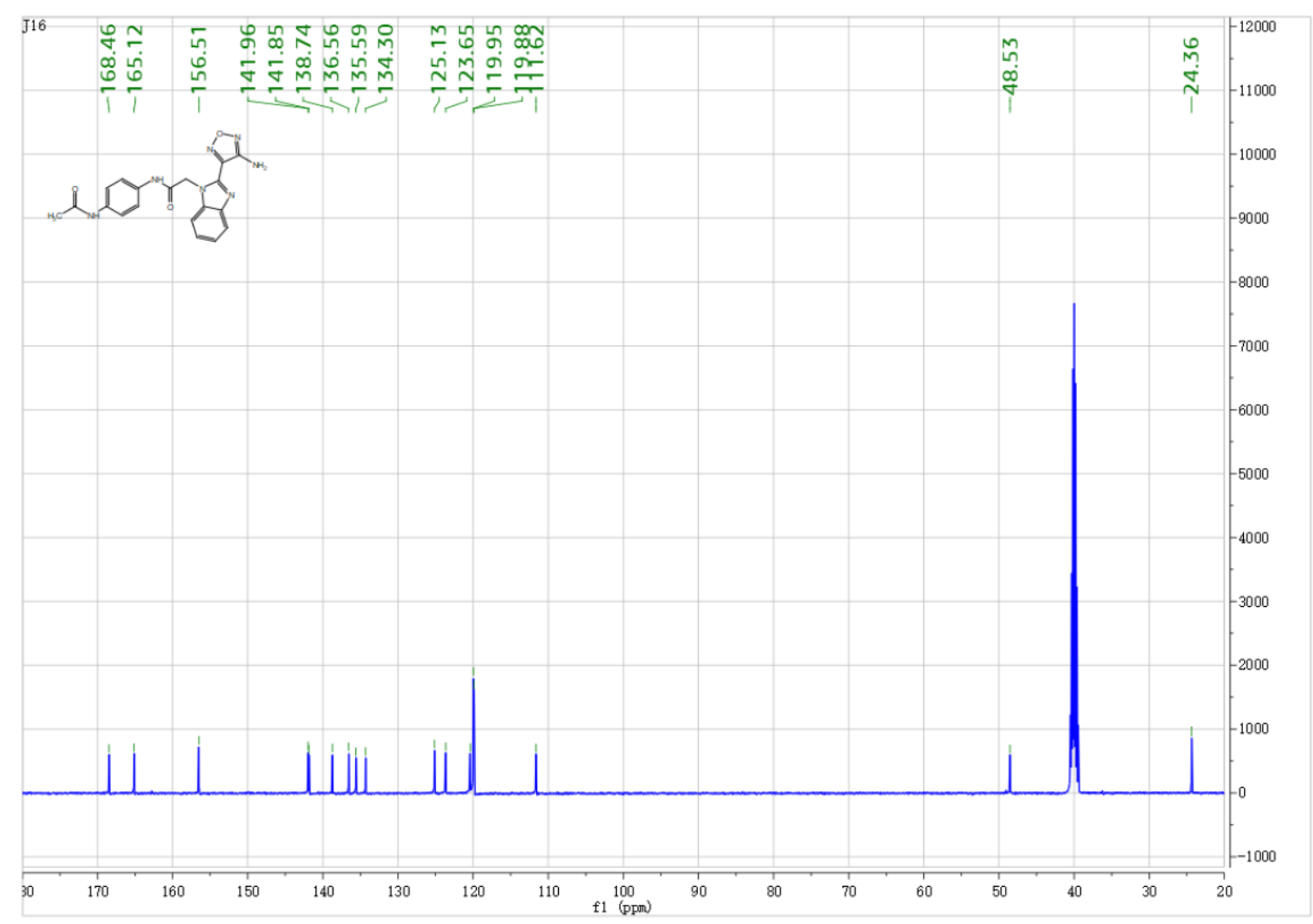

HRMS of compound S06-1040.

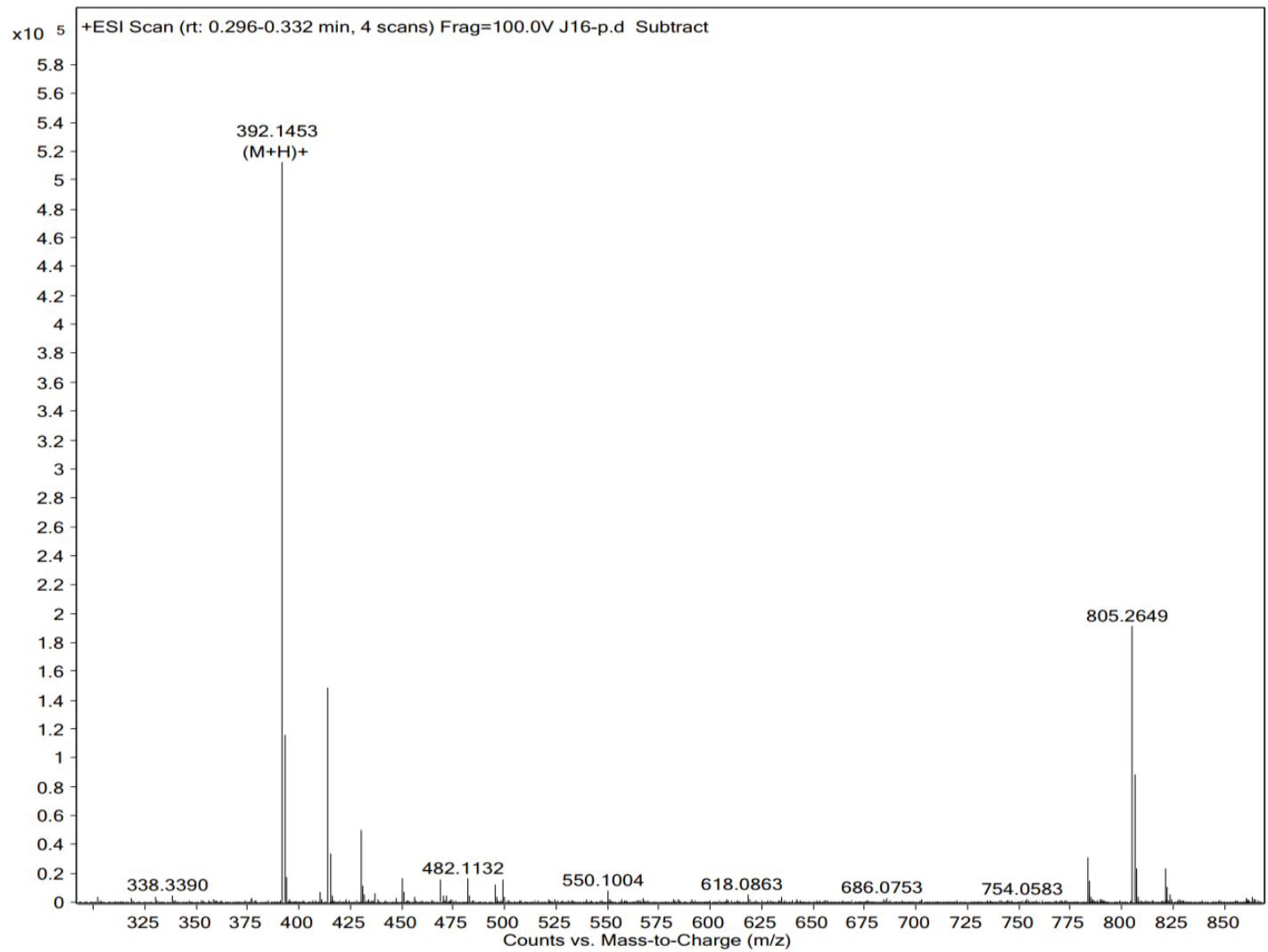


HPLC of compound S06-1041 $\left(t_{R}=8.82 \mathrm{~min}\right)$.

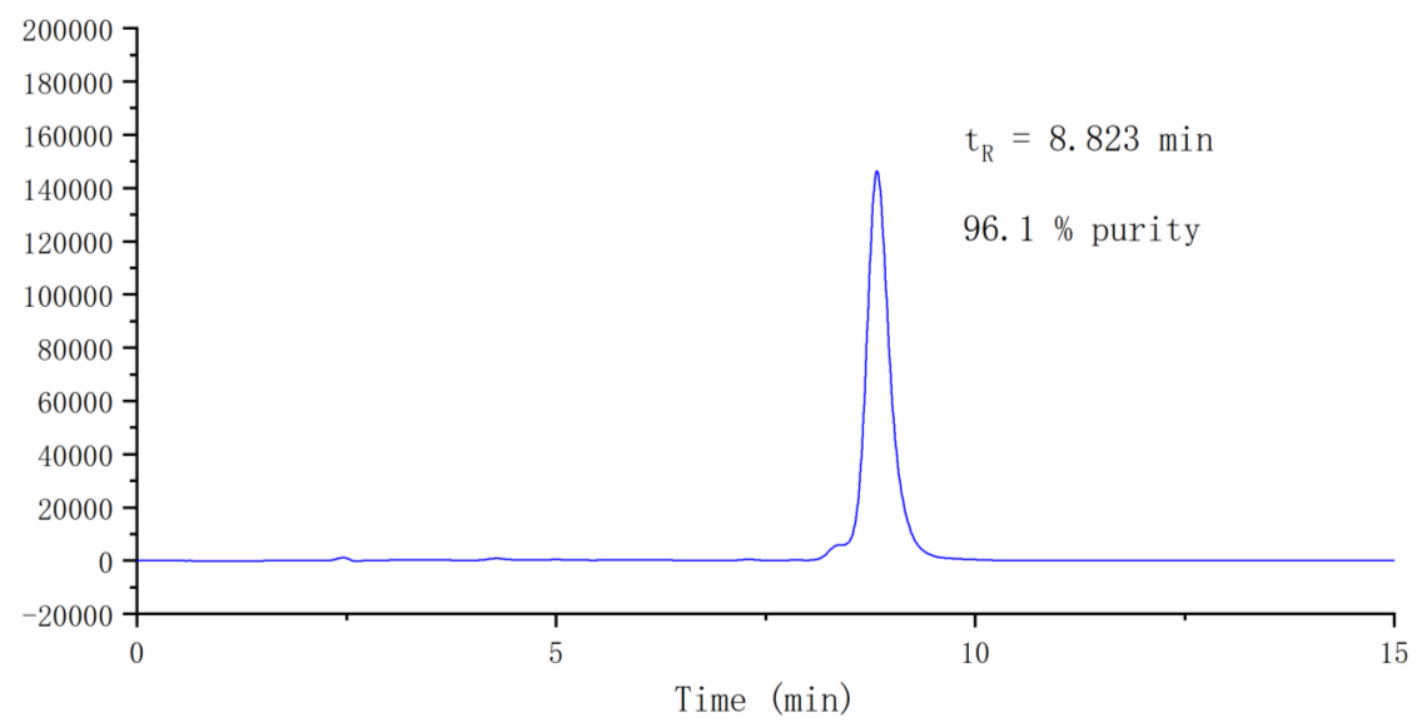

${ }^{1} \mathrm{H}$ NMR of compound S06-1041.

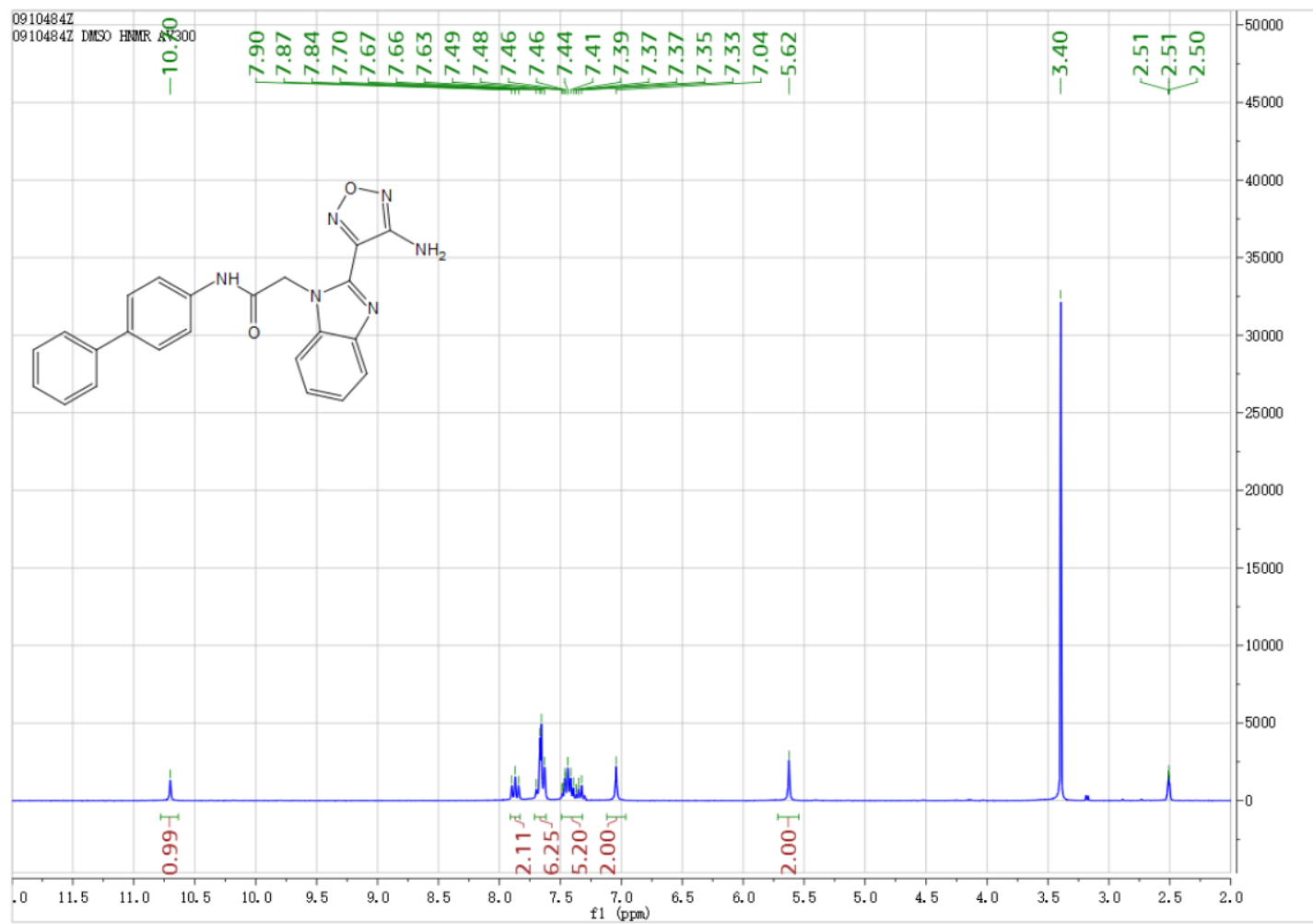

${ }^{13} \mathrm{C}$ NMR of compound S06-1041. 


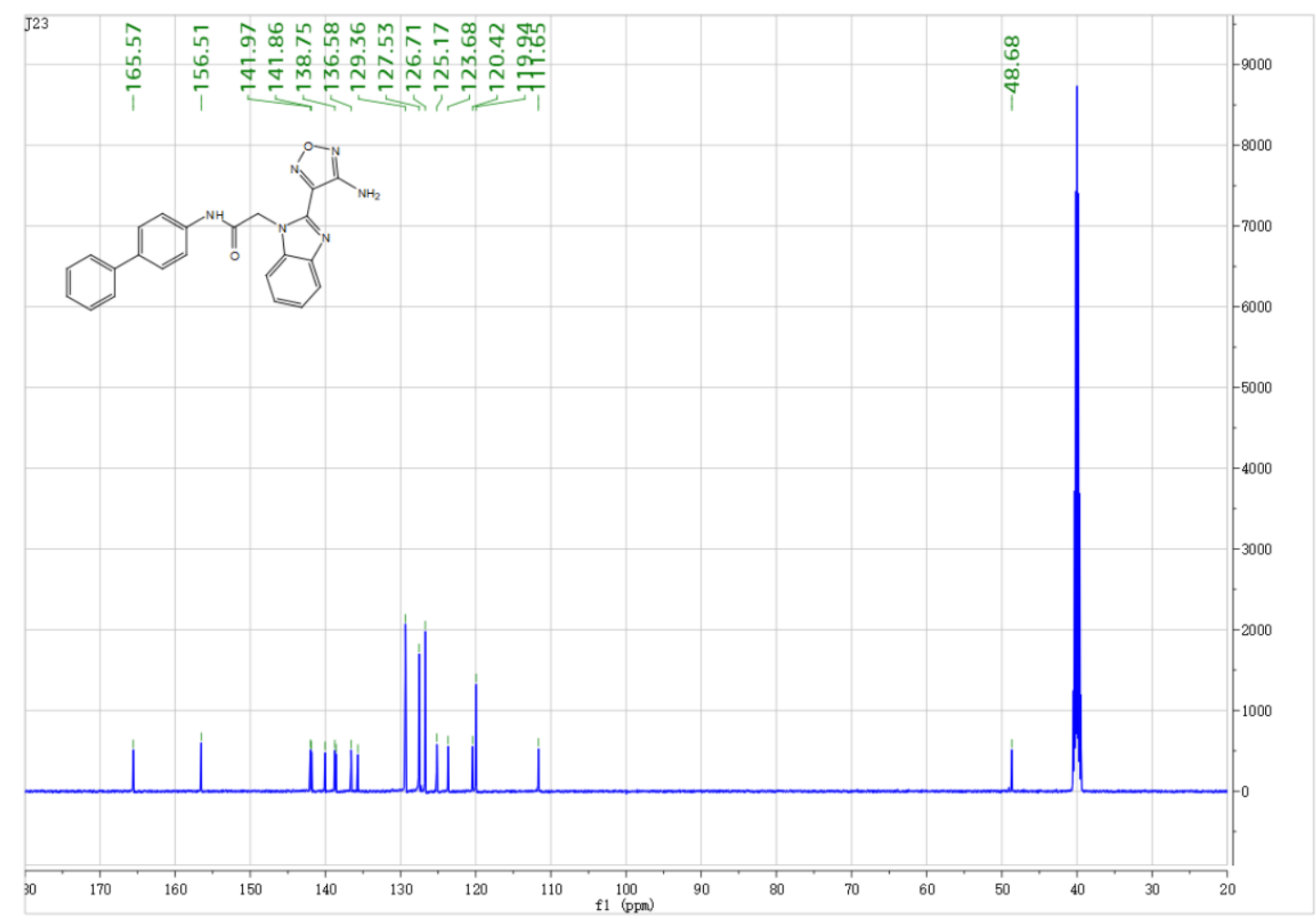

HRMS of compound S06-1041.

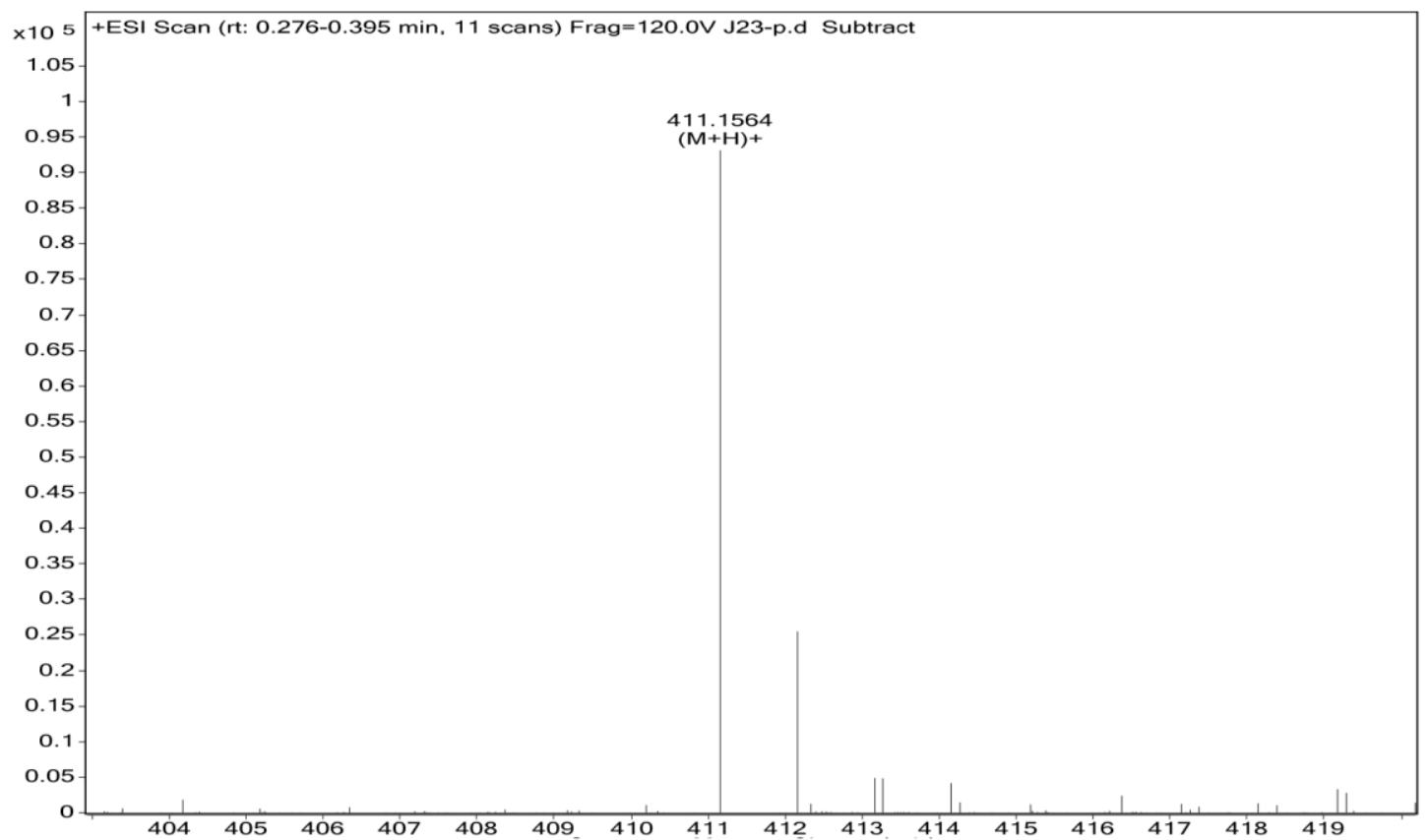


HPLC of compound S06-1042 $\left(t_{R}=6.24 \mathrm{~min}\right)$.

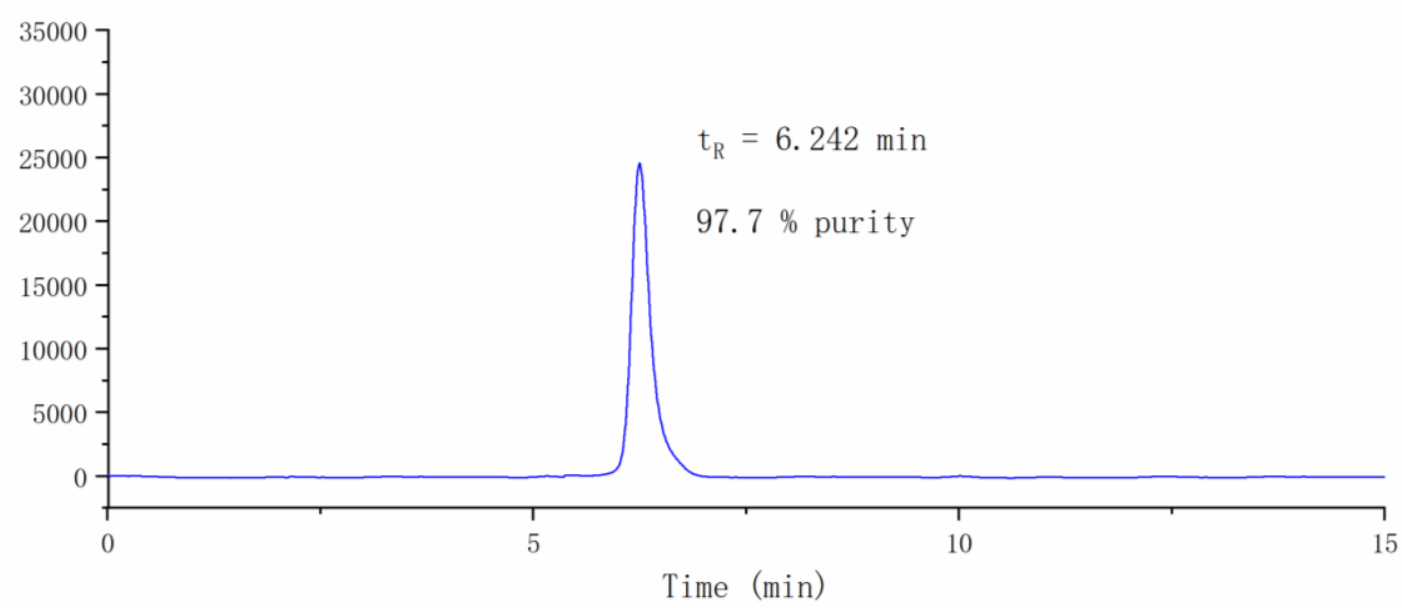

${ }^{1} \mathrm{H}$ NMR of compound S06-1042.

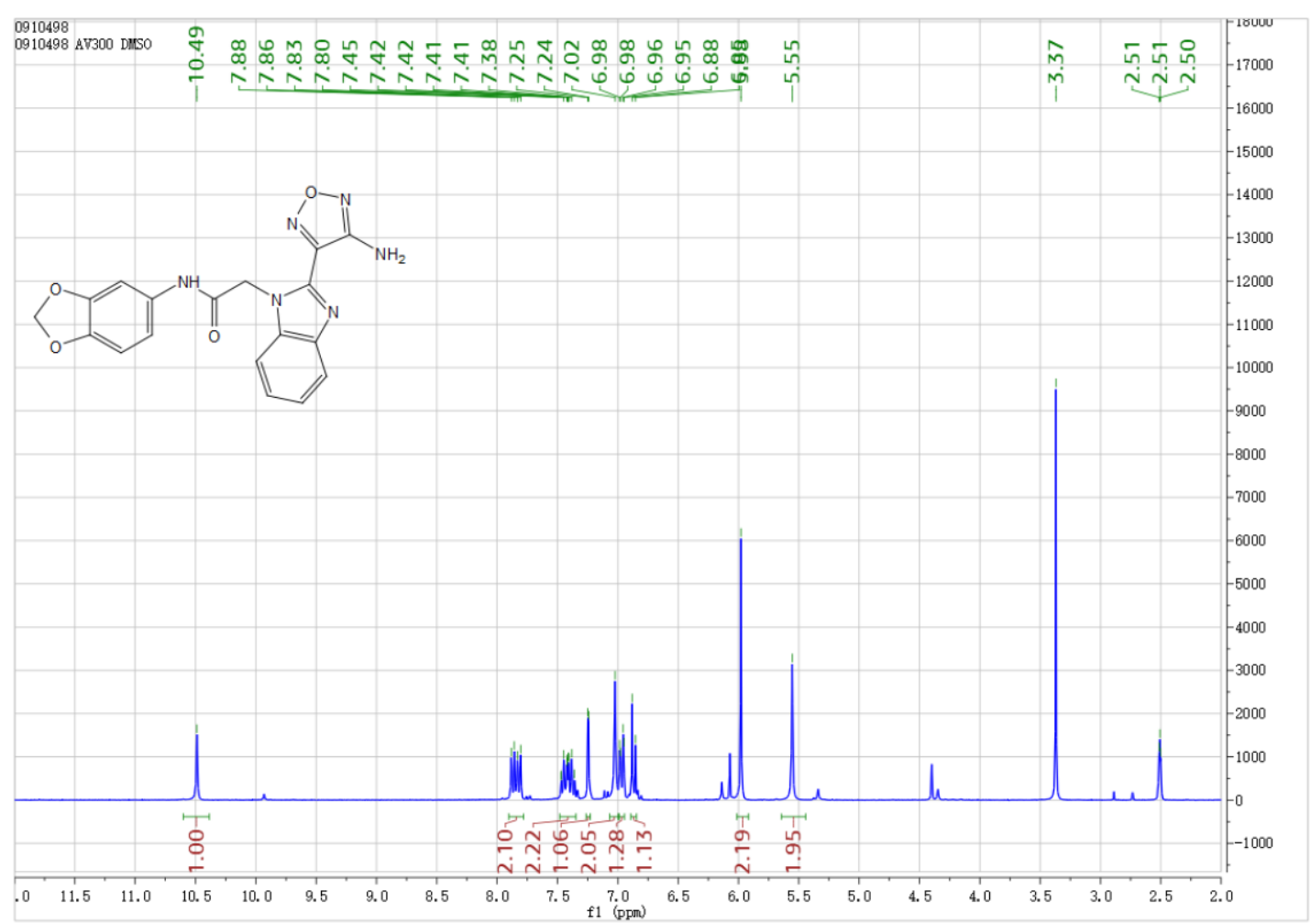

${ }^{13} \mathrm{C}$ NMR of compound S06-1042. 


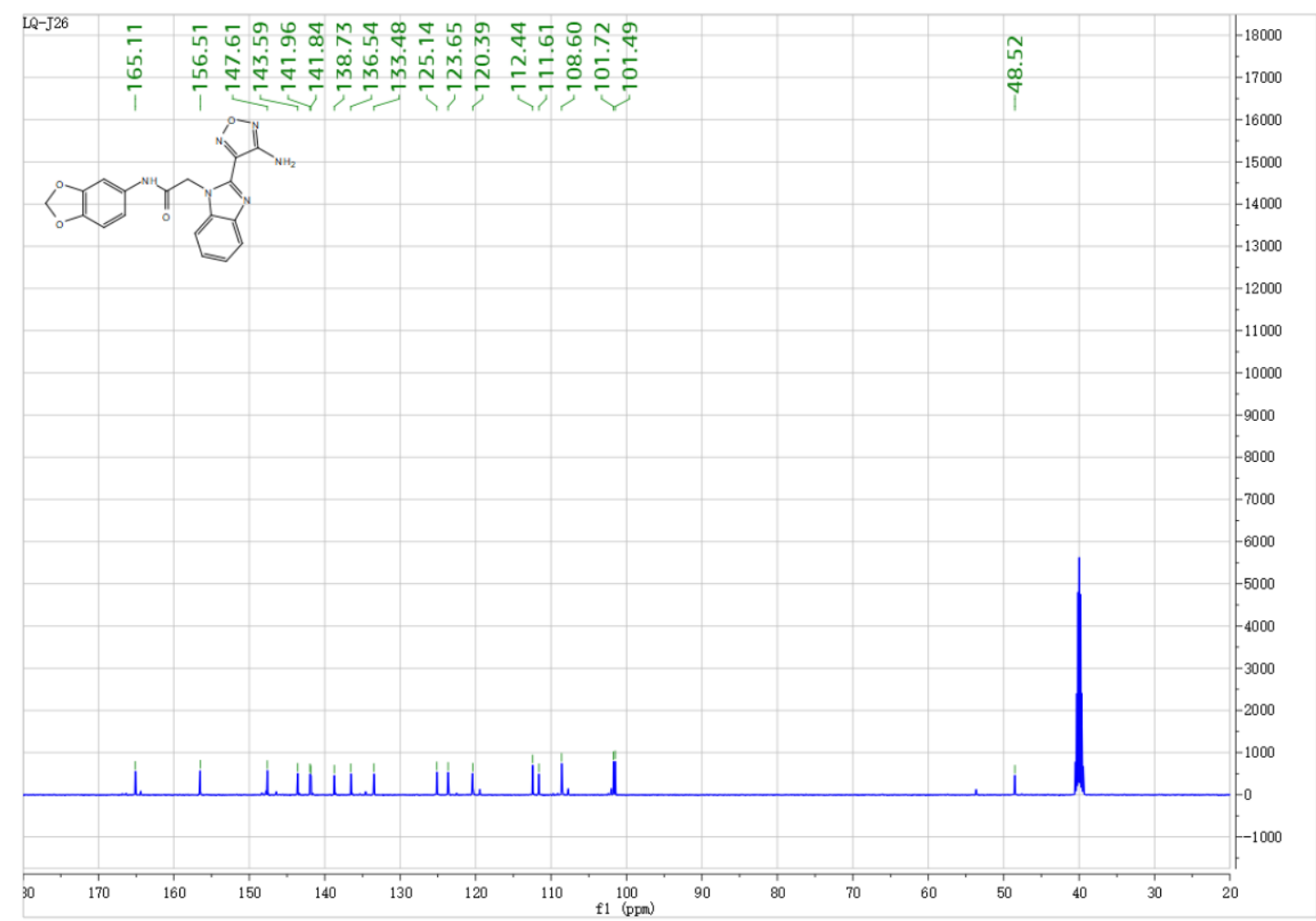

HRMS of compound S06-1042.

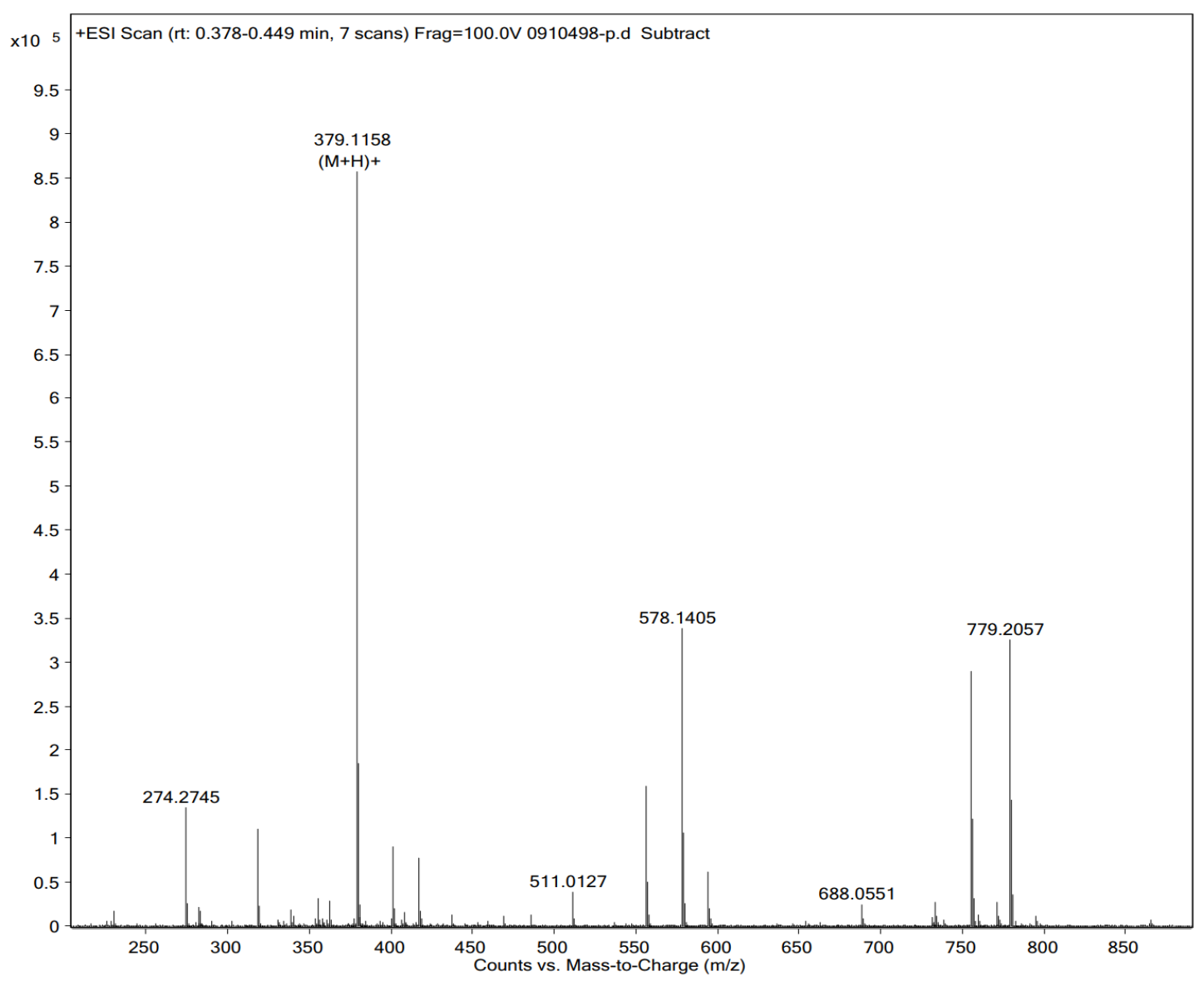


HPLC of compound S06-1043 $\left(t_{R}=8.56 \mathrm{~min}\right)$.

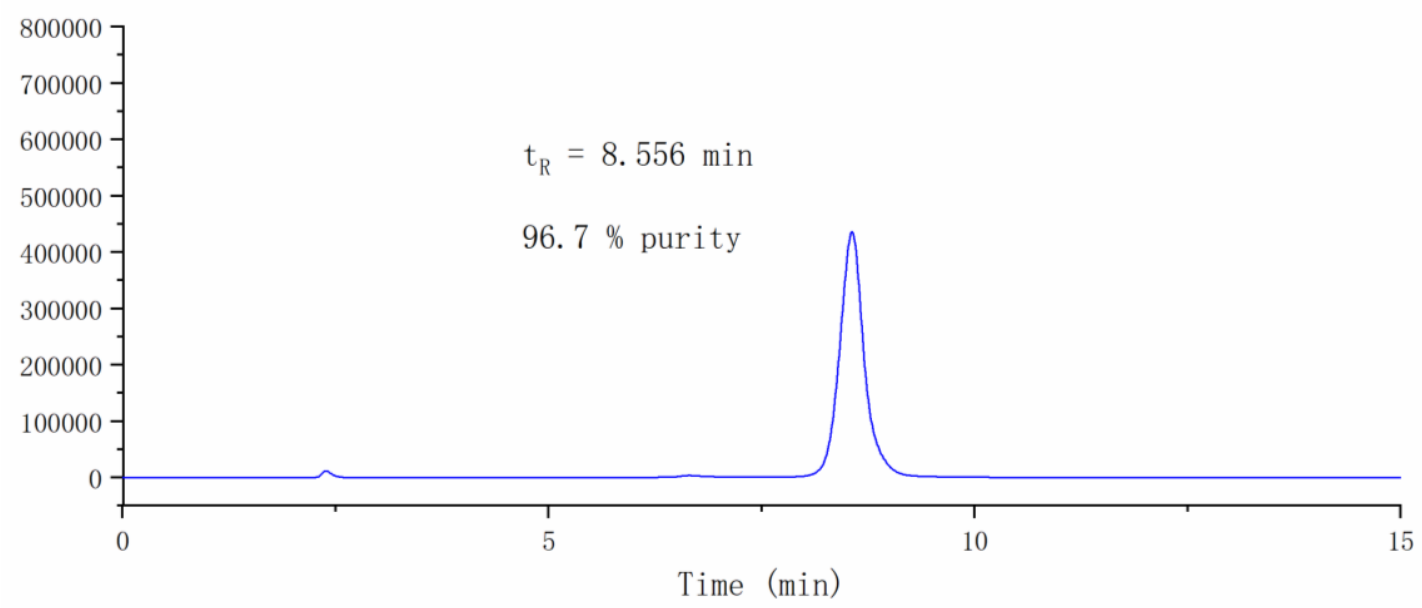

${ }^{1} \mathrm{H}$ NMR of compound S06-1043.

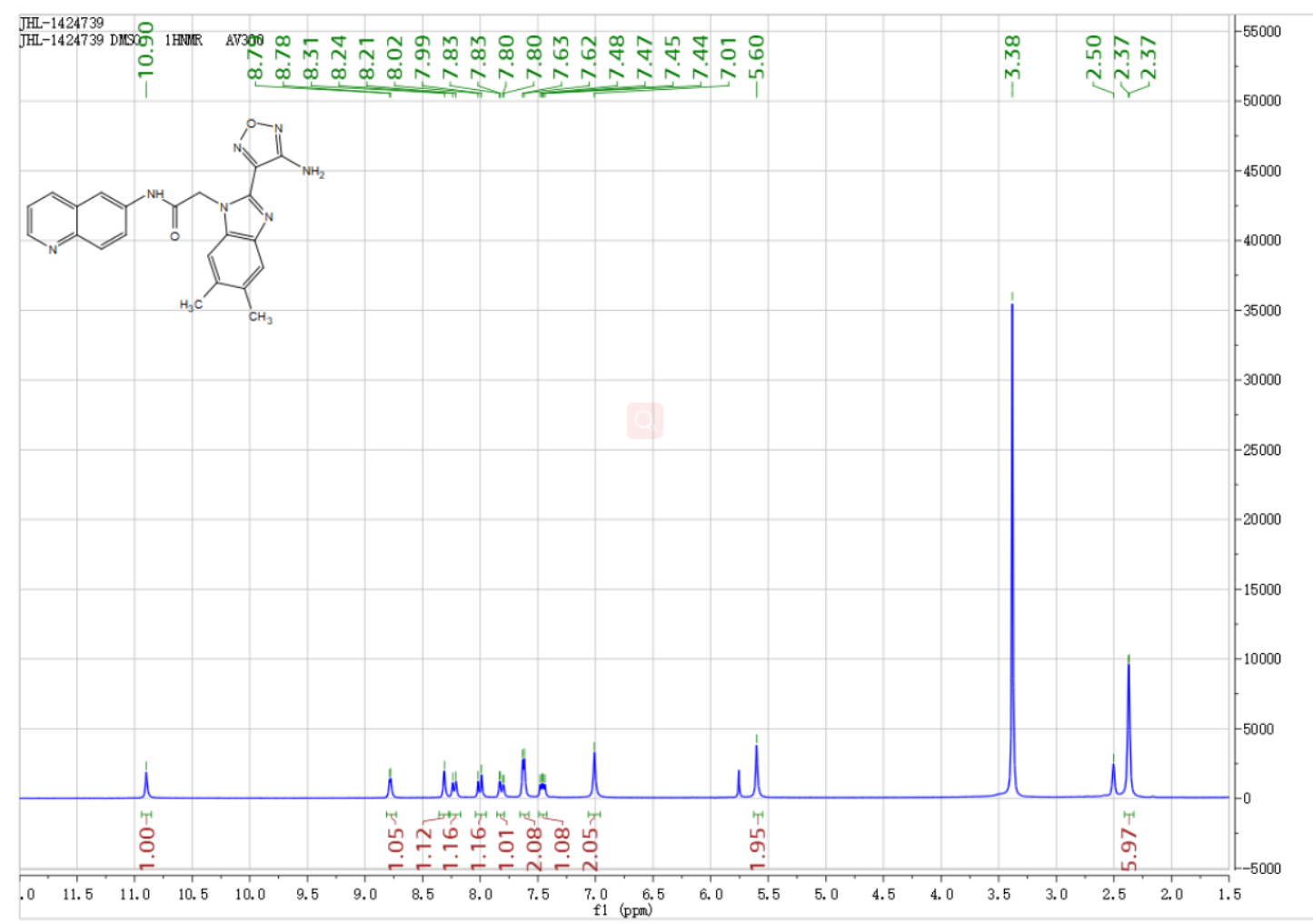

${ }^{13} \mathrm{C}$ NMR of compound S06-1043. 


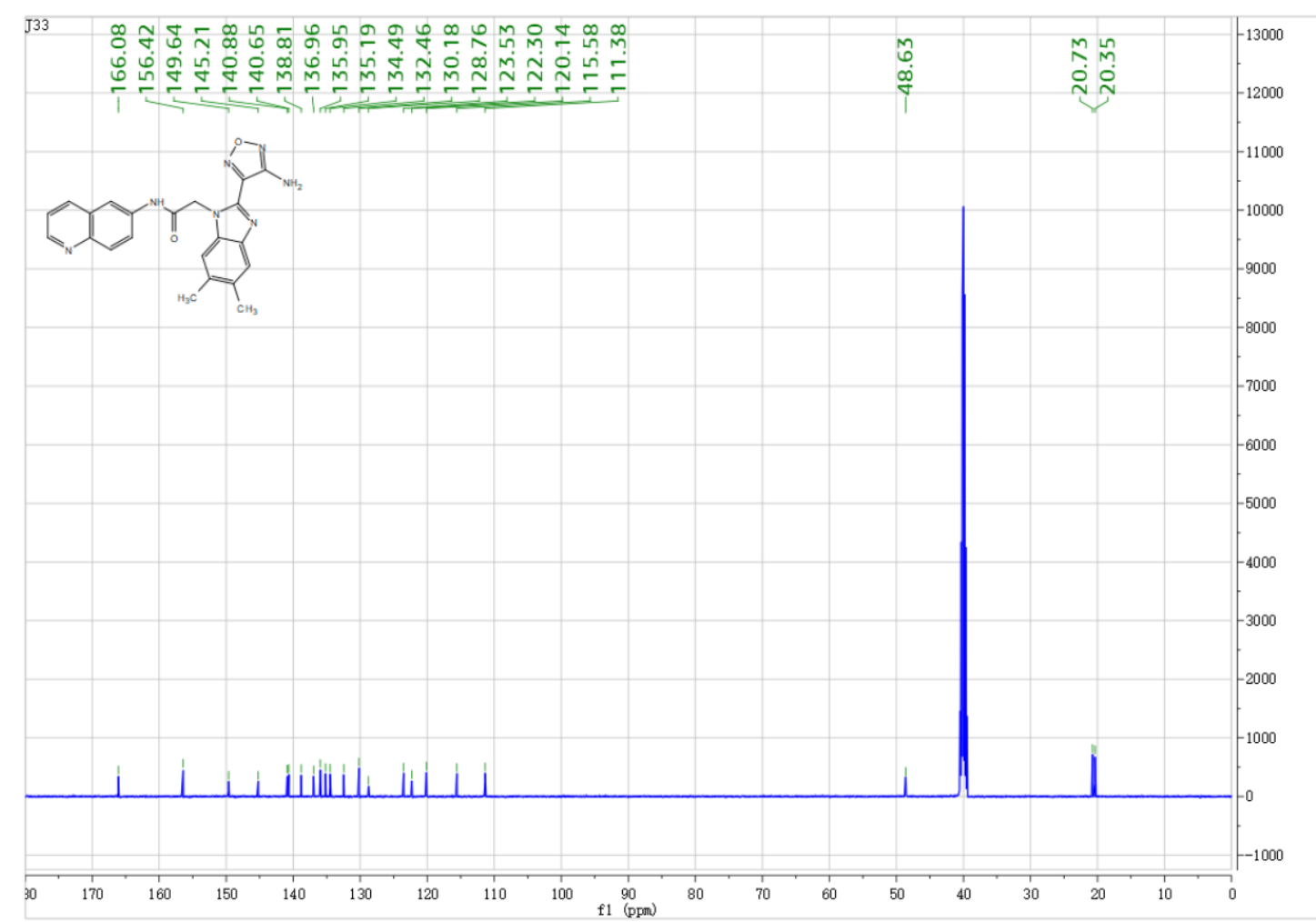

HRMS of compound S06-1043.

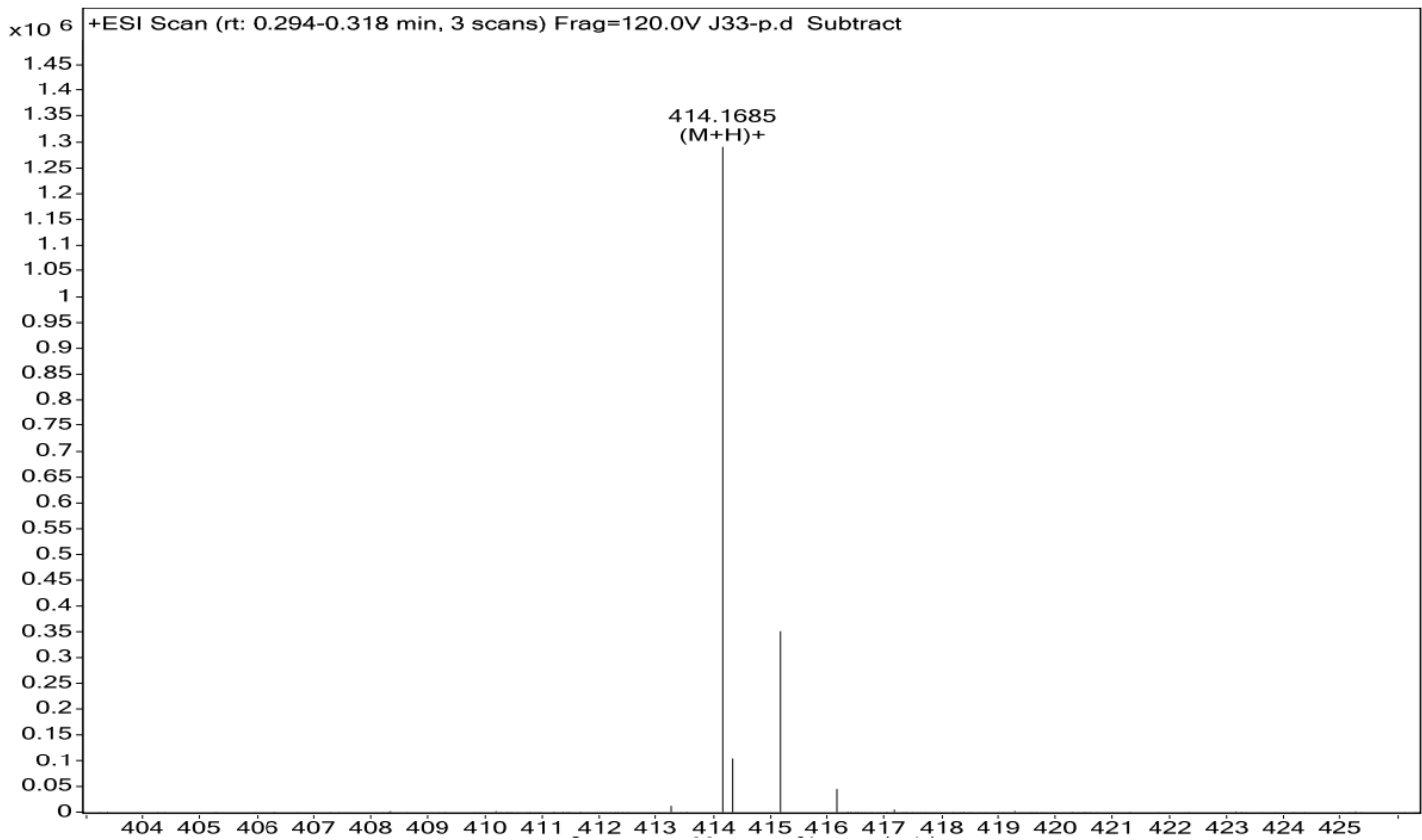


HPLC of compound S06-1044 $\left(t_{R}=9.39 \mathrm{~min}\right)$.

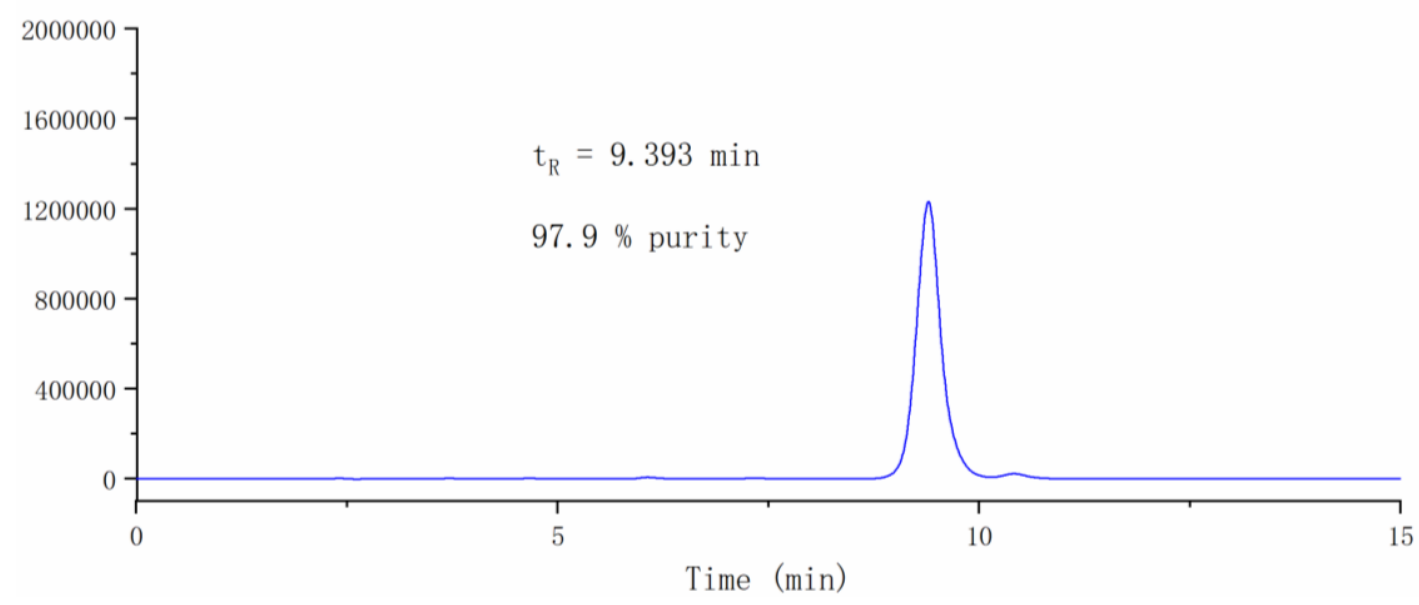

${ }^{1} \mathrm{H}$ NMR of compound S06-1044.

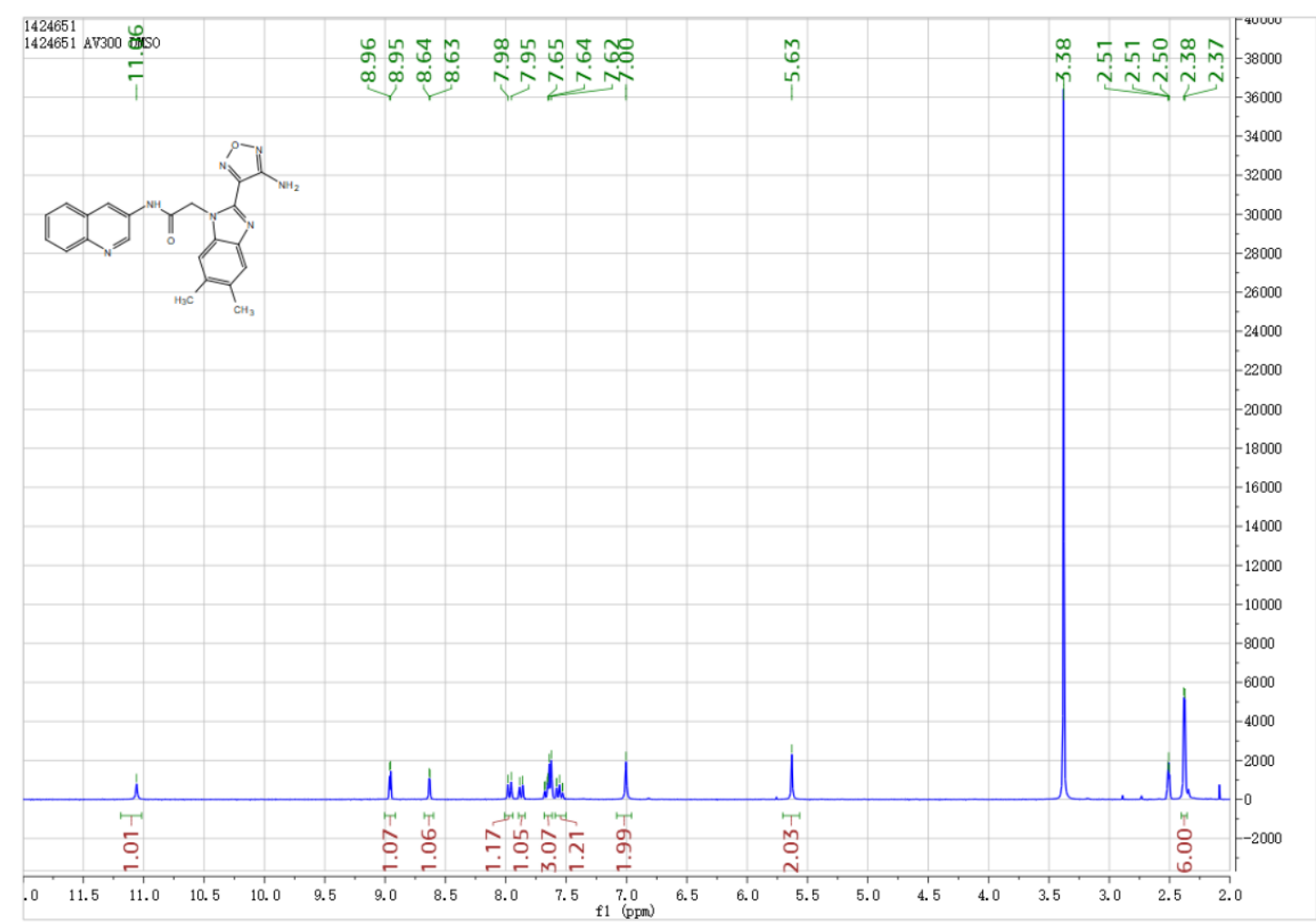

${ }^{13} \mathrm{C}$ NMR of compound S06-1044. 


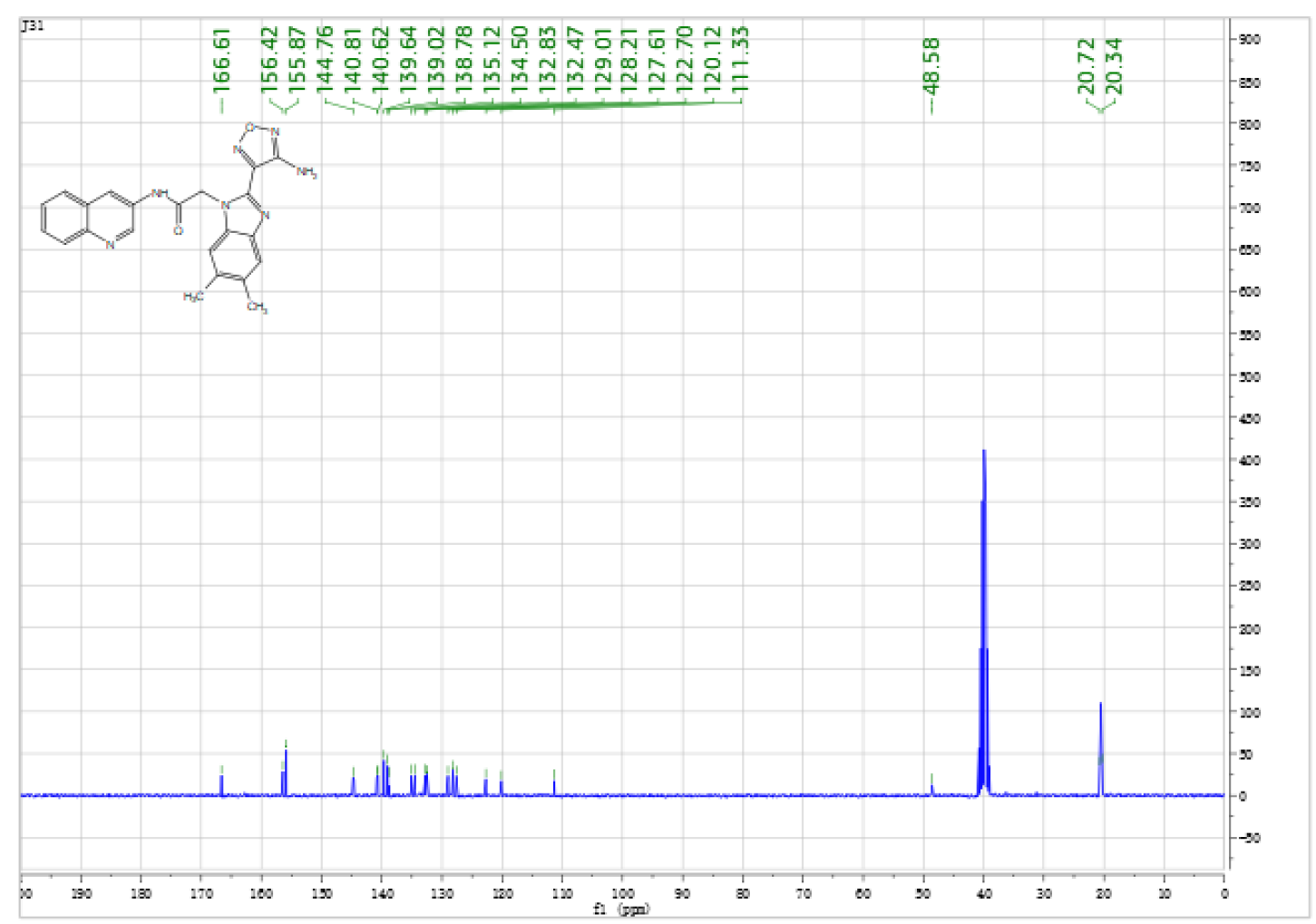

HRMS of compound S06-1044.

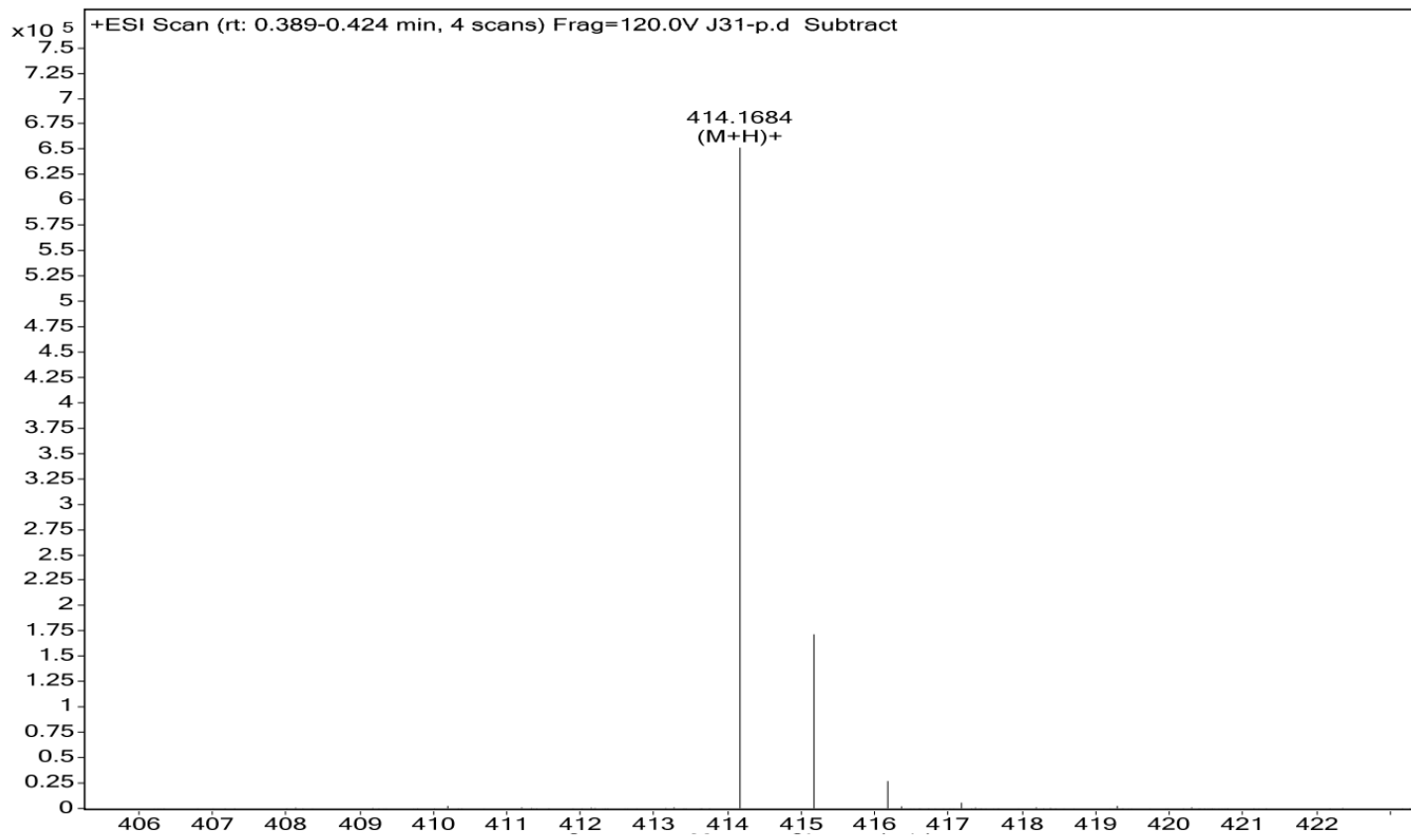


HPLC of compound S06-1045 $\left(t_{R}=9.48 \mathrm{~min}\right)$.

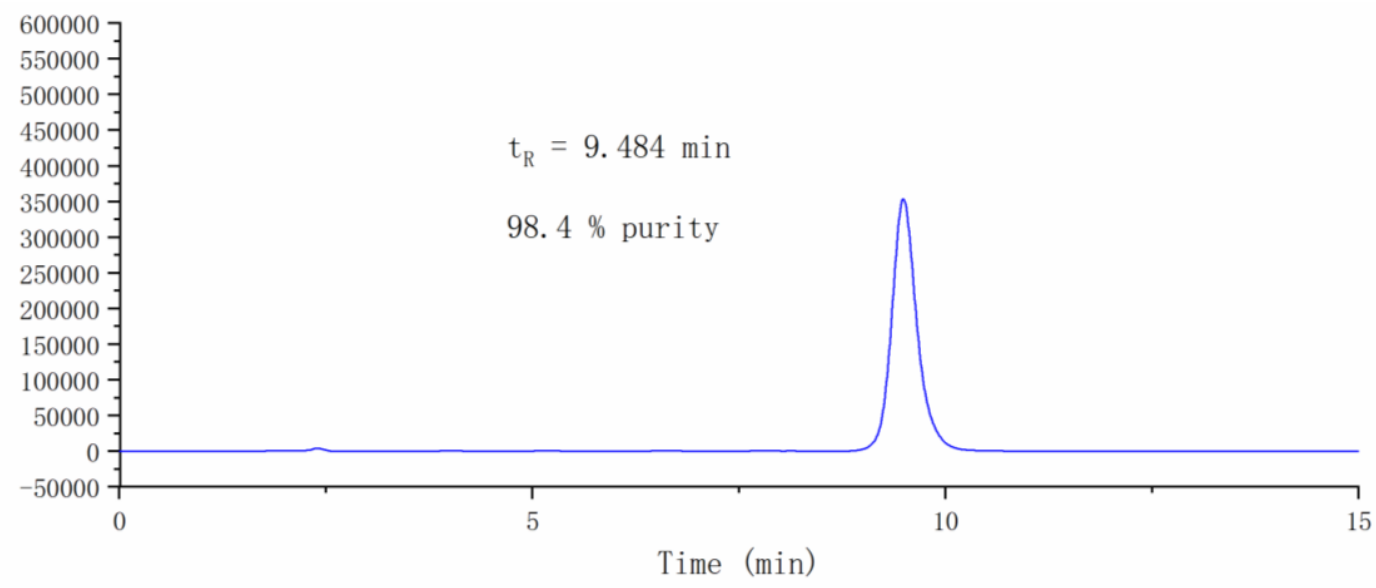

${ }^{1} \mathrm{H}$ NMR of compound S06-1045.

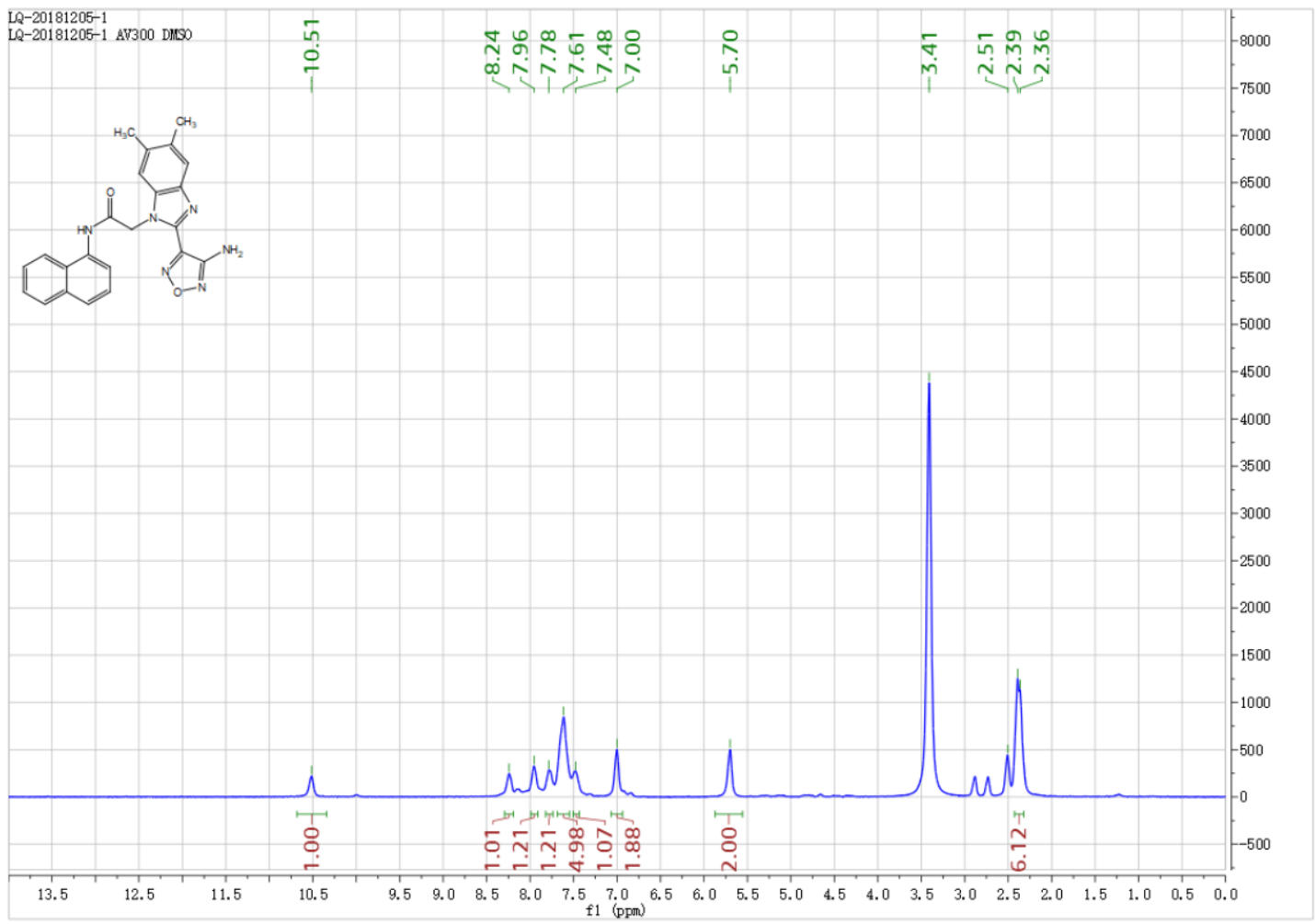

${ }^{13} \mathrm{C}$ NMR of compound S06-1045. 


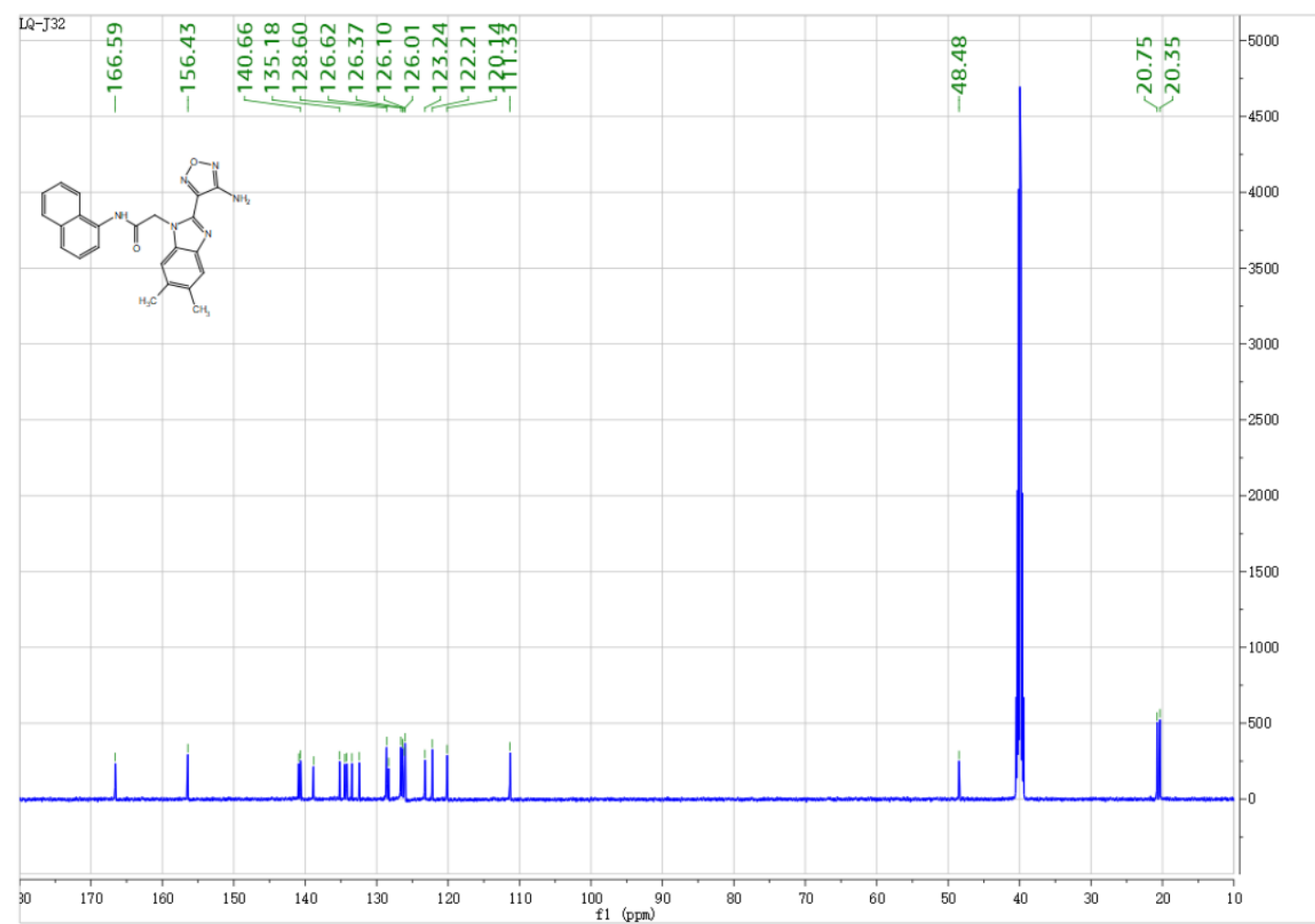

HRMS of compound S06-1045.

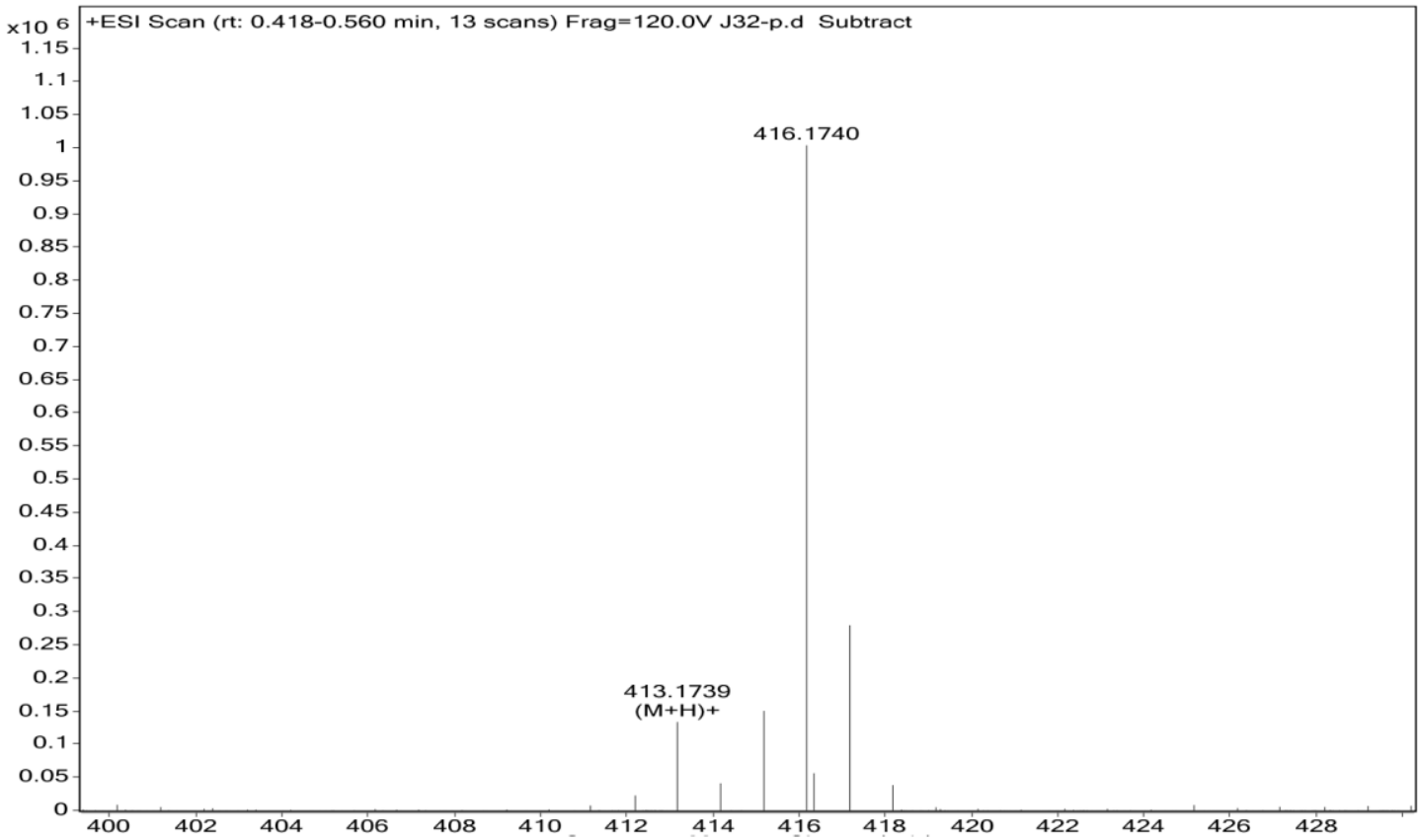

